
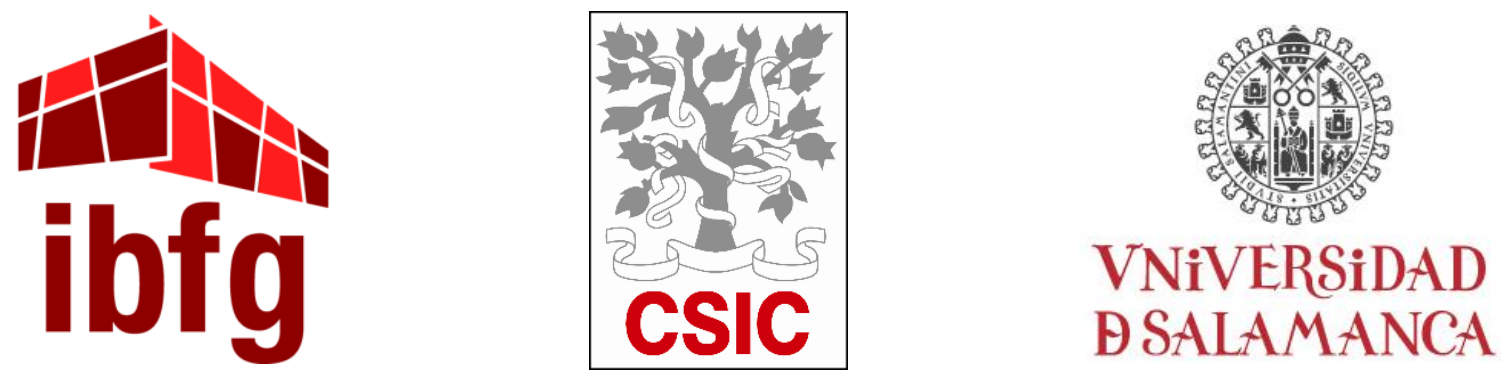

\title{
Función de la fosfatasa calcineurina en la citocinesis de
}

Schizosaccharomyces pombe

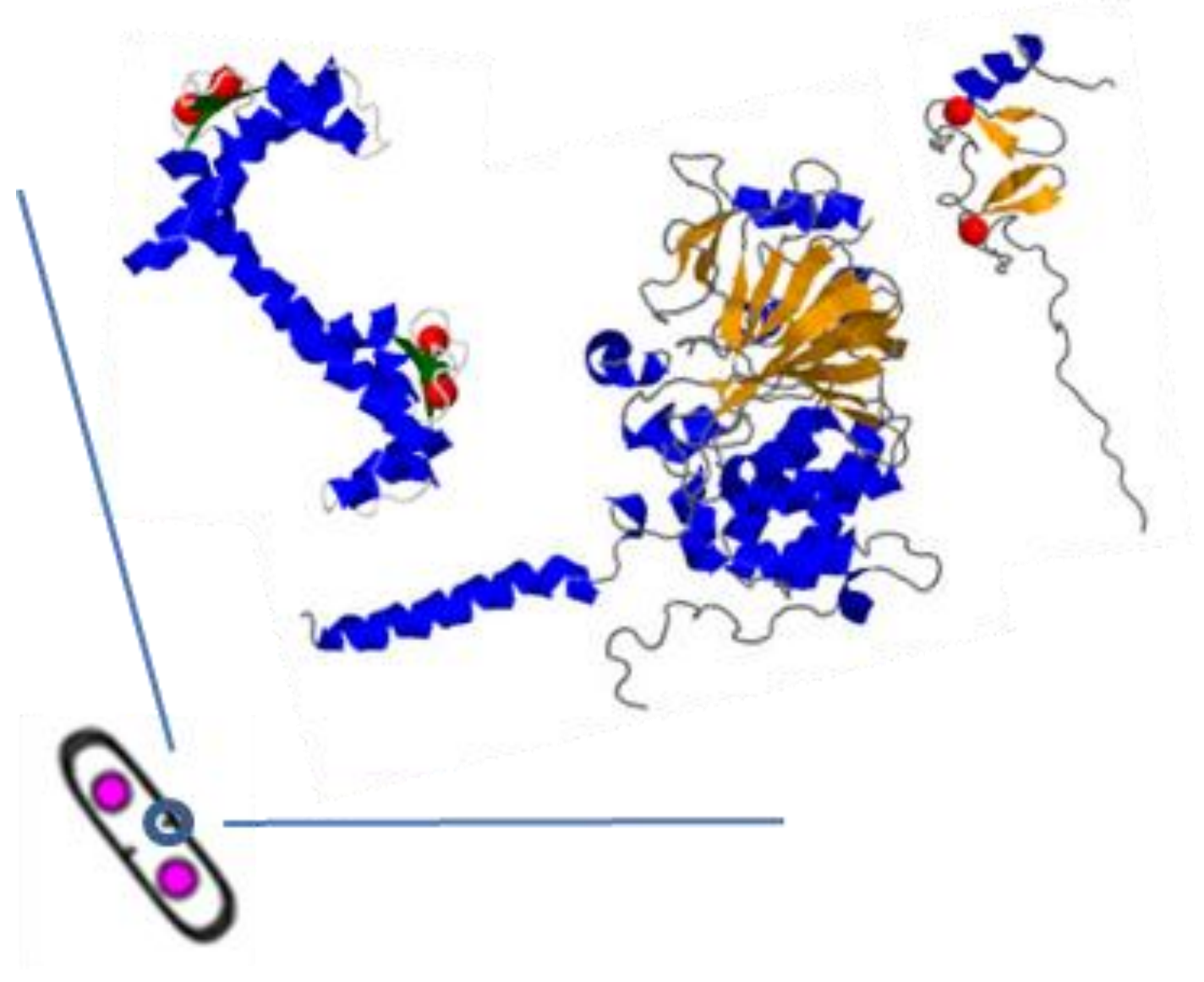

Víctor Arribas Antón Instituto de Biología Funcional y Genómica (CSIC/Universidad de Salamanca) 


\section{Departamento de Microbiología y Genética}

\section{Instituto de Biología Funcional y Genómica}

\section{(USAL / CSIC)}
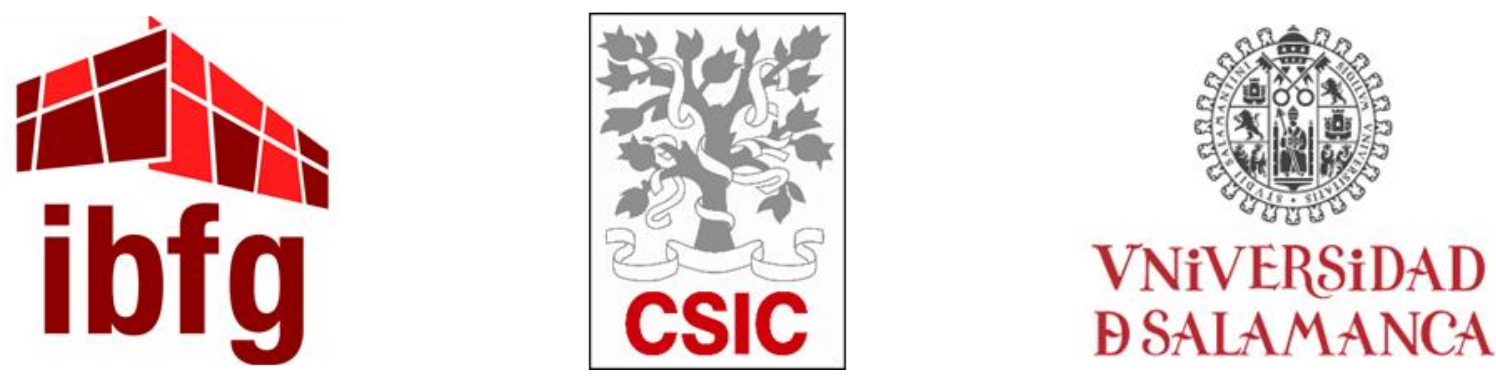

Función de la fosfatasa calcineurina en la citocinesis de Schizosaccharomyces pombe

Memoria presentada por Víctor Arribas Antón para optar al Grado de Doctor en Biología Funcional y Genómica

Salamanca, 2019 

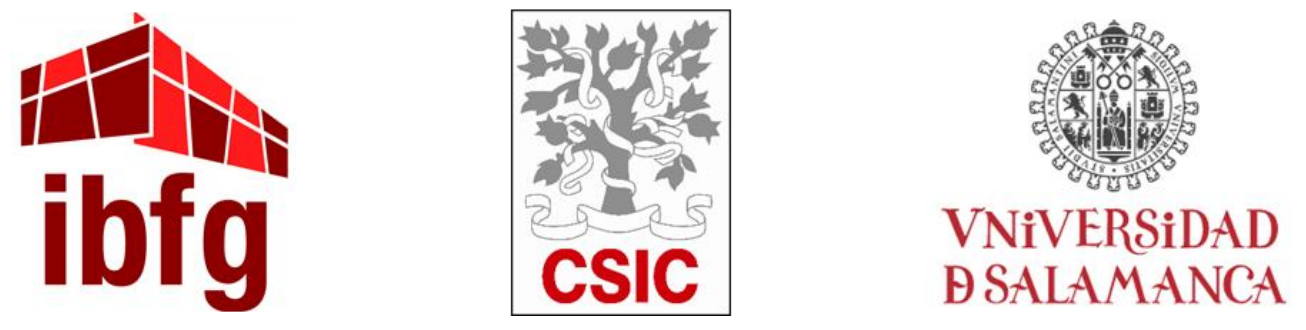

EL Dr. JOSÉ PÉREZ MARTíN, PROFESOR DE INVETIGACIÓN DEL CONSEJO SUPERIOR DE INVESTIGACIONES CIENTÍFICAS Y DIRECTOR DEL INSTITUTO DE BIOLOGÍA FUNCIONAL Y GENÓMICA DE LA UNIVERSIDAD DE SALAMANCA Y EL CONSEJO SUPERIOR DE INVESTIGACIONES CIENTÍFICAS

\section{CERTIFICA:}

Que la memoria titulada "Función de la fosfatasa calcineurina en la citocinesis de Schizosaccharomyces pombe", presentada por el graduado Víctor Arribas Antón para optar al grado de Doctor en Biología Funcional y Genómica por la Universidad de Salamanca, ha sido realizada bajo la dirección de los Dres. Ma del Pilar Pérez González y Pedro Miguel Coll Fresno, en el Instituto de Biología Funcional y Genómica, centro mixto de la Universidad de Salamanca (Departamento de Microbiología y Genética) y el Consejo Superior de Investigaciones Científicas.

Y para autorizar su presentación y evaluación por el tribunal correspondiente, firma el presente certificado

Salamanca, a de de

Fdo. Dr. José Pérez Martín 

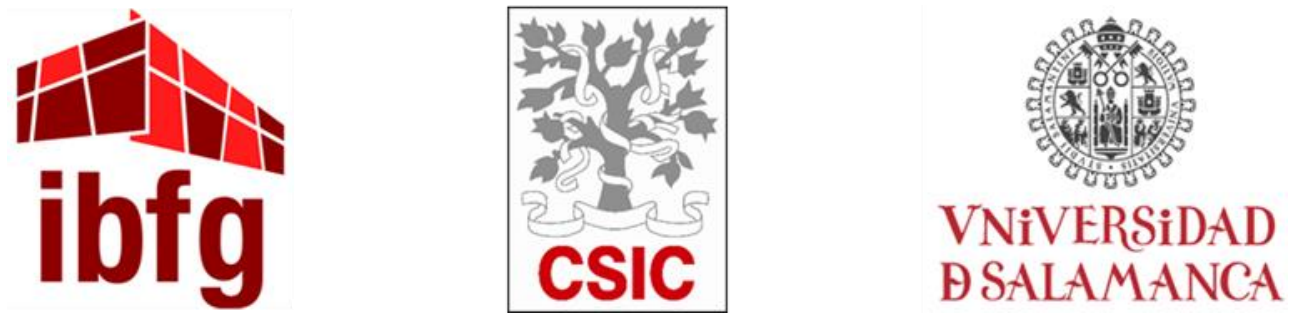

LA Dra. Mạ del PILAR PÉREZ GONZÁLEZ, PROFESORA DE INVETIGACIÓN DEL CONSEJO SUPERIOR DE INVESTIGACIONES CIENTÍFICAS Y EL Dr. PEDRO MIGUEL COLL FRESNO PROFESOR CONTRATADO DOCTOR PERMANENTE DEL DEPARTAMENTO DE MICROBIOLOGÍA Y GENÉTICA DE LA UNIVERSIDAD DE SALAMANCA

\section{CERTIFICAN:}

Que la memoria titulada "Función de la fosfatasa calcineurina en la citocinesis de Schizosaccharomyces pombe", presentada por el graduado Víctor Arribas Antón para optar al grado de Doctor en Biología Funcional y Genómica por la Universidad de Salamanca, bajo su dirección, en el centro mixto Instituto de Biología Funcional y Genómica (CSIC) / Departamento de Microbiología y Genética (USAL).

Y para autorizar su presentación y evaluación por el tribunal correspondiente, firma el presente certificado

Salamanca, a de de

Fdo. Dra. Ma del Pilar Pérez González Fdo. Dr. Pedro Miguel Coll Fresno 
Esta tesis doctoral ha sido financiada por una beca para la contratación predoctoral de personal investigador de la Junta de Castilla y León, cofinanciada por el Fondo Social Europeo mediante el CONSEJO SUPERIOR DE INVESTIGACIONES CIENTIFICAS (CSIC). 


\section{Agradecimientos}

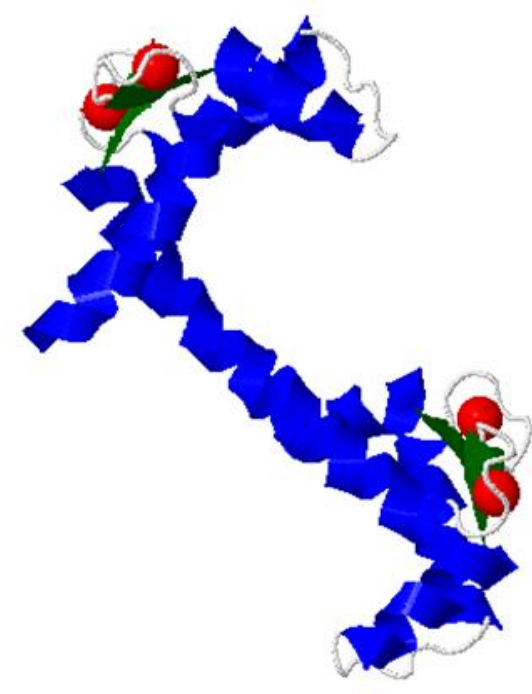




\section{Agradecimientos}

\section{AGRADECIMIENTOS}

Cuando estás acabando con las últimas correcciones de la tesis crees que la parte más difícil de la escritura ya ha terminado. Sin embargo, luego cuando empiezas a escribir los agradecimientos te das cuenta lo difícil que es acordarse y agradecer a toda persona que te ha ayudado, escuchado o dado unas palabras de ánimo durante estos 5 años.

Primero quiero agradecer a la Dra. Pilar Pérez González por permitirme realizar la tesis en su laboratorio, además de dirigirme y supervisarme durante los primeros pasos de mi carrera científica, ayudándome tanto en el lado profesional como personal. En segundo lugar, quiero darle las gracias al Dr. Pedro Miguel Coll Fresno por la codirección de la tesis, por enseñarme a desenvolverme en el laboratorio y realizar todas las técnicas empleadas en la tesis, además de por su enorme esmero y paciencia a la hora de enseñar a sus alumnos. Estoy seguro de que sin alguno de los dos no podría haber llevado a cabo este proyecto.

Además, este trabajo tampoco hubiera sido posible sin el apoyo del resto de los miembros que han formado en algún momento parte del grupo PPG. En este punto no puedo olvidarme de Rebeca, con la que he colaborado en varios experimentos iniciales de esta tesis, que se ha preocupado de mi formación científica tanto como mis directores, compaginando su vida laboral y familiar (eres una autentica luchadora), por lo que la considero como un referente para mi carrera. También quiero darle las gracias a Elvira que siempre está ahí para echarme una mano cuando lo necesitas (lo que hemos sufrido cuando había que producir paxilina). Además, también quiero agradecerle a Sergi todos los buenos consejos que me ha dado, aunque técnicamente no sea un PPG siempre hace sus experimentos con nosotros, espero que te vaya muy bien y formes un gran grupo de investigación. A María, nuestra nueva incorporación, que la veo y me recuerda a mis comienzos, espero que consigas la beca para hacer la tesis. No me quiero olvidar de darle las gracias a otras personas que durante estos años han formado parte de los PPGs pero que ya finalizaron su etapa como yo lo hago ahora. Empezaré por Maite, mi veterana de doctorado, que me ayudó a integrarme rápidamente con el resto de estudiantes de doctorado y siempre tenía buenos consejos e intentaba ayudarme. $A$ Pepiyo, que revolucionó todo el laboratorio cuando llegó dándole mucha vida, pasamos muy buenos momentos juntos y siempre que pudo me echo una mano. A Bea, que a pesar de estar liada con las clases siempre que pasaba por el laboratorio se interesaba y me preguntaba cómo iba con mis experimentos.

Agradecer también a todas las personas que forman la unidad 1 de investigación o "grupo de pared" todos los consejos que me han dado y el ambiente de trabajo, colaboración y ayuda que existe incentivado por los propios investigadores principales, no había visto algo así en ninguno de los otros centros en los que he trabajado. Este mismo agradecimiento es extensible al resto de personal investigador, técnico o de administración del IBFG que siempre están dispuestos a ayudarte con cualquier 


\section{Agradecimientos}

problema científico o burocrático que tengas. Igualmente, también tengo que agradecer a todo el personal del Wolfson Wohl Cancer Research Center y más concretamente a los integrantes de Glasgow Polyomics por el increíble trato que me dieron y enseñarme todo lo que pudieron de proteómica y metabolómica durante mis meses de estancia en Glasgow. También quiero darle las gracias a Eduardo y la delegación de la red SRUK/CERU de Escocia por echarme una mano en todo lo que necesité cuando estuve allí y ayudarme a integrarme. Gracias a ambos tuve una gran experiencia en Escocia y siempre la recordaré con cariño.

Por supuesto no me quiero olvidar de darles las gracias a todos aquellos que me han ayudado a desconectar y descansar de la vida científica en algún momento. Quiero agradecerle a María todos los buenos momentos que hemos pasado juntos además de los mensajes de ánimo, cariño y apoyo que me manda cuando más los necesito. A mis compañeros de piso Borja y David que me han escuchado y aguantado durante 4 años mis frustraciones cuando algún experimento no salía, despotricar contra todo mientras vemos First Dates ha sido la mejor terapia que hemos tenido nunca. A los que han sido mi grupo de amigos aquí en Salamanca (Fran, Sofía, Tomás, Luisa, Carlos, Elisa, Carol, Rubén y David) que me han ayudado a desconectar muchos fines de semana y tan bien lo hemos pasado en los viajes o en trivial. A mis amigos de toda la vida de Soria por estar siempre ahí y ayudarme a recargar las pilas cada vez que volvía a casa. A mis amigos de la carrera, que a pesar de todo todavía mantenemos el contacto y nos reunimos 2 veces al año, parece mentira que haga 10 años desde que la comenzamos. A todas las personas del antiguo "café de pared", a todo el grupo actual del café y a cualquiera con el que haya compartido un tiempo en la sala de descanso por esas risas a mitad de mañana que hacen que el día sea más ameno.

He querido dejar para el final a toda mi familia que me han apoyado durante toda esta etapa, aunque para ellos la levadura solo sirva para hacer tartas y pasteles. A mi madre que siempre ha creído en mí, lo ha dado todo por mí y me apoyó económicamente durante mi primer año. Al "pelao" de mi hermano Raúl que siempre me hace hacer el tonto cuando estoy con él y se ofrece el primero para ayudarme con todo lo que puede y acompañarme. A Fer, que siempre ha sido como un hermano para mí, le cuento todo lo que pasa en mi vida y está siempre ahí en mis peores momentos. Y finalmente a mis tíos y mis primos que siempre se preocupan por mí y tanto nos han ayudado a mi madre, a mi hermano y a mí con todo en estos dos últimos años.

\section{GRACIAS A TODOS POR HABERME AYUDADO A LLEGAR HASTA AQUÍ}




\section{Abreviaturas}

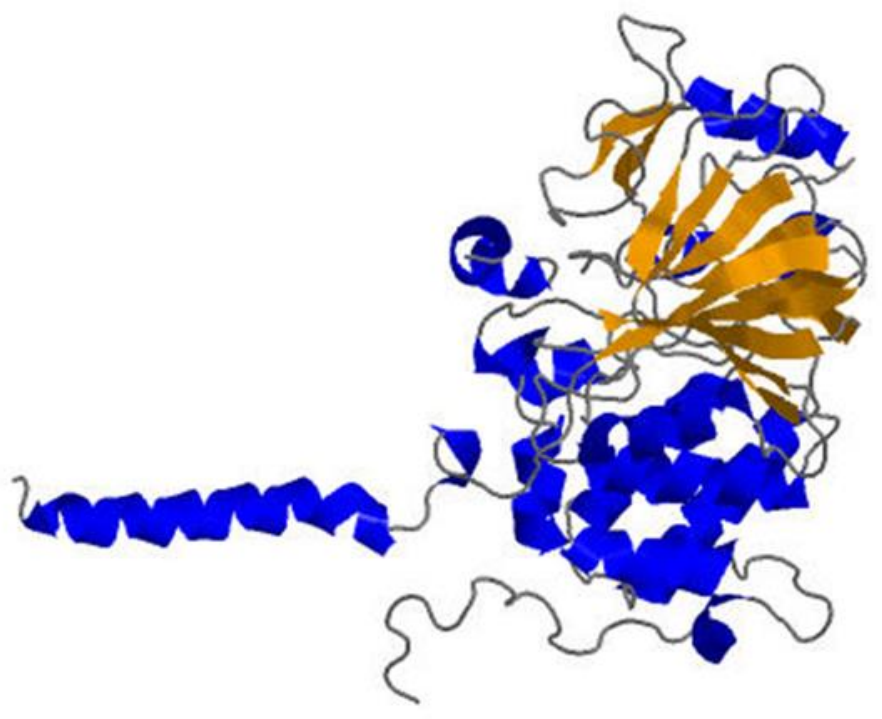




\section{Abreviaturas}

\section{ABREVIATURAS}

aa: Aminoácido

ADN: Ácido desoxirribonnucleico

BAR: Proteina de la familia $\underline{B} i n-\underline{A} m p h i p h y s i n-\underline{R} v s$

BGS: $\underline{\beta}$-glucán sintasa

BSA: Albumina sérica bovina ( $\underline{B} o v i n e \underline{S e r i c}$ Albumin)

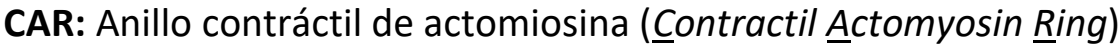

CDRE: Elementos de respuesta a calcineurina (ㅁalcineurin-Dependent $\underline{\text { Response }}$ Element)

CDK: quinasa dependiente de ciclina

DIC: Contraste interdiferencial (Differential Interphase $\underline{\text { Contrast) }}$

dNTPs: Desoxirribonucleotido trifosfato

D.O.: Densidad óptica

DTT: Ditiotreitol

EDTA: Ácido êtilén diamino tetra-accético

EGTA: Ácido êtilén glicol bis tetra-ạcético

EMM: Medio mínimo para S. pombe (Édimburgh Minimal Media)

FK506: Tacrólimus

FASP: Preparación de la muestra mediante filtro (Filter-aided sample preparation)

F-BAR: Fes/CIP4 homology-BAR

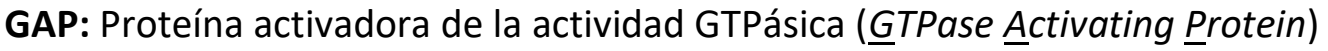

GBP: Proteína de union a GFP ( $\underline{G} F P$ Binding Protein)

GDP: Guanosina 5'-difostato

GEF: Factor intercambiador de nucleótidos de guanina (Guanine Nucleotide Exchange Factor)

GFP: Proteína verde fluorescente (Green Fluorescent $\underline{\text { Protein) }}$

GST: $\underline{\text { Glutation }} \underline{\mathrm{S}} \underline{\mathrm{t}}$ ransferasa 


\section{Abreviaturas}

GTP: Guanosina 5'-trifosfato

h: Horas

HA: Epítopo procedente de la hemaglutinina del virus humano de la gripe (Hemagglutinin Antigen)

HRP: Peroxidasa de rábano (븡seradish Peroxidase)

iMTOC: Centro organizador de microtúbulos de interfase (Interphase Microtubule Organizer $\underline{\text { Centre) }}$

IP: Inmunoprecipitado

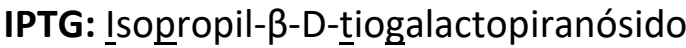

KDa: Kilodalton

kb: Kilobase

LB: Medio Luria-Bertani para E. coli

LC-MS/MS: Cromatografía líquida-espectrometría de masas/espectrometría de masas

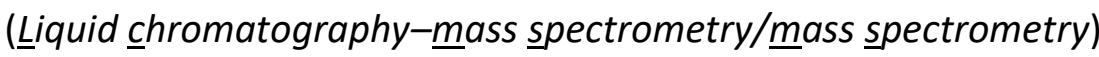

LIM: Dominio proteico cuyas iniciales proceden de las proteinas Lin11, Isl-1 y $\underline{\text { Mec-3 }}$

MBC: Metil 2-Benzimidazol Carbamato

MEA: Medio agar extracto de malta (Malt Extract $\underline{\text { Agar }})$

min: Minutos

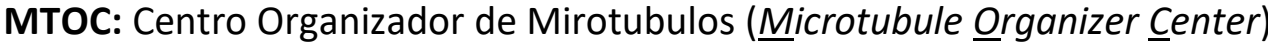

NETO: Comienzo del crecimiento por el polo celular nuevo (New End Take Off)

nmt: Promotor inhibido por tiamina (№ Messenger with Thiamine)

NP-40: Nonidet P-40

OE: Sobreexpresion de un gen (ㅁverExpression)

OETO: Comienzo del crecimiento por el polo celular antiguo (이를ㅁ Take Off)

ORF: Fase de lectura abierta (Open Reading Frame)

pb: $\underline{\text { Pares de } \underline{b} a s e s}$

PBS: Tampón fosfato salino (ㅁhosphate-ㅁuffered Saline) 


\section{Abreviaturas}

PCR: Reacción en cadena de la polimerasa ( Polymerase $\underline{\text { Chain }}$ Reaction)

PMSF: Fluoruro de ortometil fenil sulfonilo

PVDF: Fluoruro de polivinilideno

RBD: Dominio de unión a RhoA ( $\underline{R} h o A$ Binding Domain)

RFP: Proteína roja fluorescente (Red Fluorescent $\underline{\text { Protein) }}$

Rho: $\underline{\text { Ras Homology }}$

rpm: $\underline{\text { Revoluciones por minuto }}$

SDS: Dodecil sulfato sódico

SDS-PAGE: Electroforesis en gel de poliacrilamida en condiciones desnaturalizantes (PolyAcrilamide Gel Electrophoresis)

SH3: Dominio con homologia a Src3 ( $\underline{\operatorname{Src}} \underline{3}$ Homology)

SIN: Complejo de inicio de la septacion (Septation Initiation Network)

SPA: Medio agar de esporulación (ㅁporulation $\underline{A g a r}$ )

SPB: Cuerpo polar del huso (Spindle $\underline{P} o l e \underline{B} o d y$ )

TAE: Tampón Iris-Ácético EDDTA

TBST: Tampón Tris salino con Tween-20 (Tris-B Buffered Saline Iween-20)

TCA: Ácido Iricloroacético

TRIS: Tris-(hidroximetilamino)-metano

u.a.: $\underline{\text { Unidades arbitrarias }}$

UV: Ultravioleta

v/v: volumen-volumen

wt: Estirpe silvestre (Wild Type)

YES: Medio rico para S. pombe ( $\underline{\text { eeast }}$ Extract + Suplements)

2XYT: Medio rico para E. coli (Yeast Extract Tryptone) 


\section{Índice}

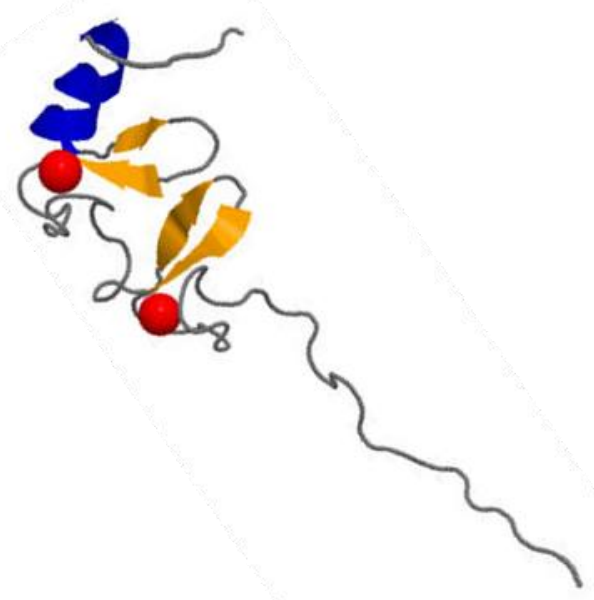




\section{Índice}

INTRODUCCIÓN

1. Schizosaccharomyces pombe: un modelo eucariota para el estudio de la morfogénesis celular................................................................................................. 3

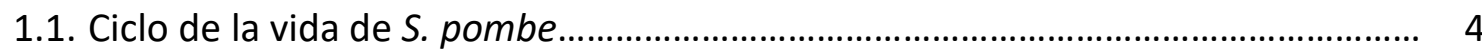

1.2. Ciclo celular y morfogénético de $S$. pombe ................................................................ 5

1.3. El citoesqueleto de actina en S. pombe .................................................................... 6

1.4. El citoesqueleto de microtúbulos......................................................................... 8

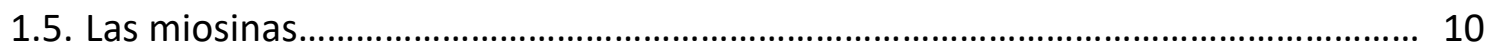

1.5.1. Miosinas de clase I................................................................................ 10

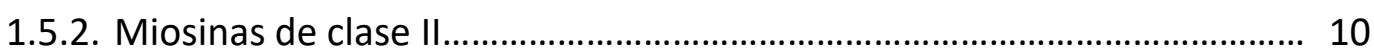

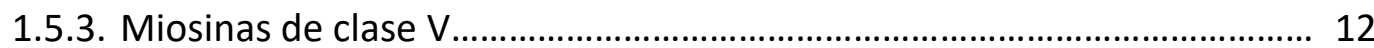

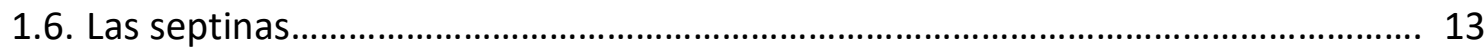

2. La pared celular de S. pombe

2.1. Composición de la pared celular.......................................................................... 14

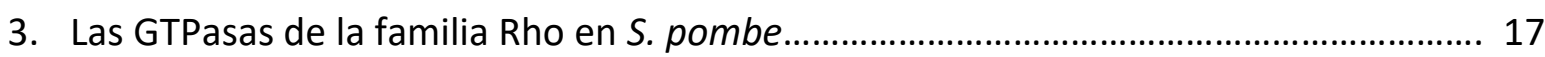

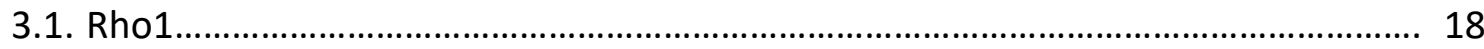

3.2. Cdc42

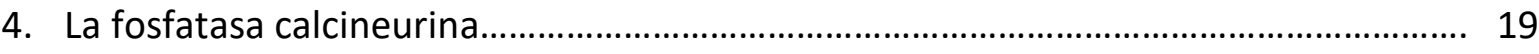

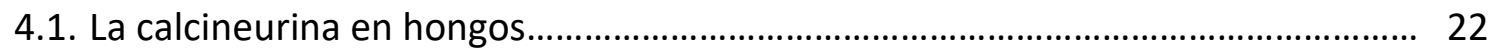

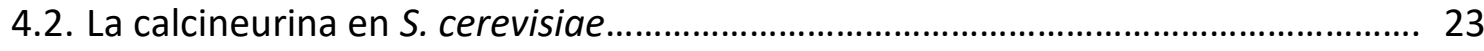

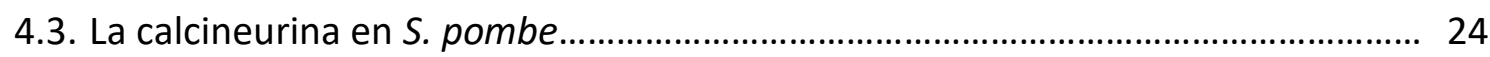

5. La calmodulina como proteína adaptadora y reguladora............................................. 25

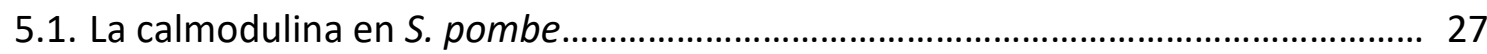

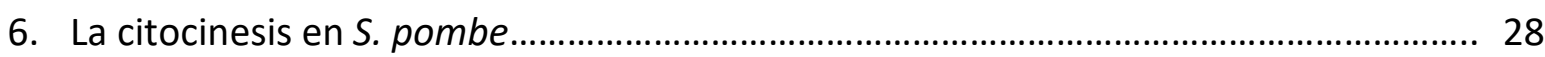

6.1. Selección del sitio de división y formación de nodos.......................................... 29

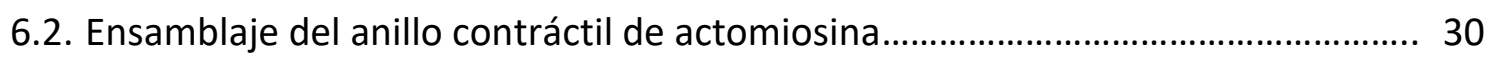

6.3. Maduración del anillo de actomiosina ...................................................................... 31

6.4. Componentes del anillo contráctil de actomiosina............................................... 32

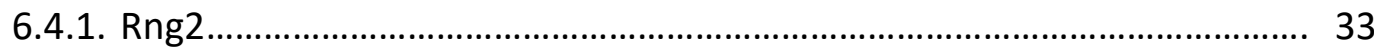

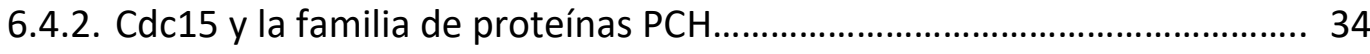

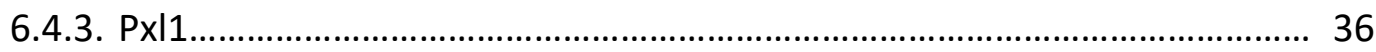

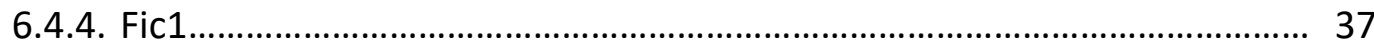

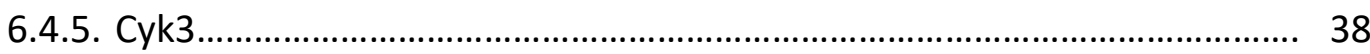

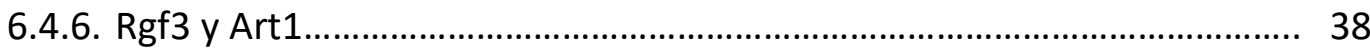

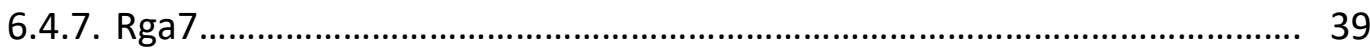

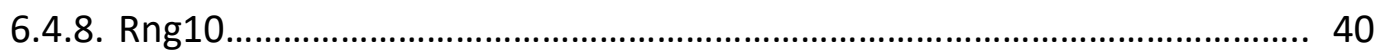




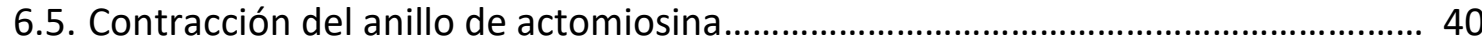

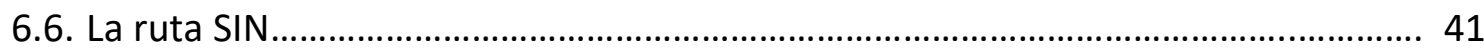

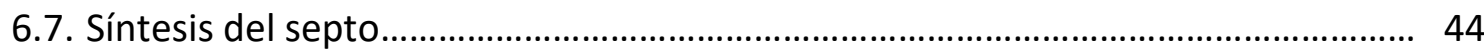

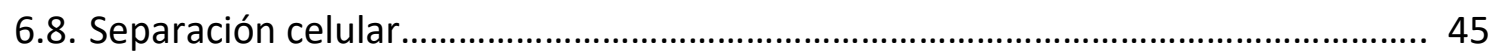

OBJETIVOS

RESULTADOS

CAPÍTULO 1: LA FOSFATASA CALCINEURINA SE INCORPORA AL ANILLO DE ACTOMIOSINA MEDIANTE SU UNIÓN A LA PAXILINA

1. La paxilina posee un sitio de interacción con calcineurina y es necesaria para su localización en el anillo contráctil de actomiosina........................................................... 53

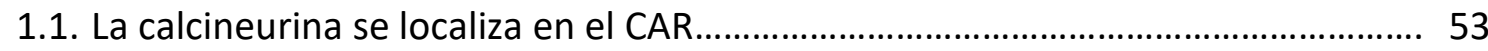

1.2. La calcineurina debe de estar activa para su localización en el CAR....................... 54

1.3. La ausencia de calcineurina provoca defectos similares a los causados por la

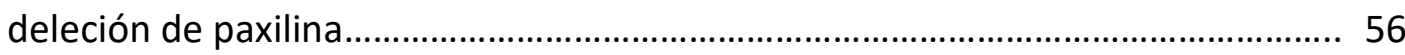

1.4. Paxilina y calcineurina colocalizan en el CAR ........................................................ 58

1.5. La subunidad catalítica de la calcineurina Ppb1 interacciona con la paxilina........ 59

1.6. La paxilina interacciona directamente con la subunidad catalítica de la

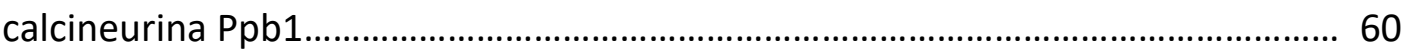

1.7. La paxilina es necesaria para la localización de la calcineurina en el anillo........... 61

1.8. Ppb1 interacciona con ambas regiones de la paxilina.............................................. 62

1.9. La paxilina tiene un motivo de unión a Ppb1 en su dominio LIM C-terminal que es necesario para la interacción con Ppb1 y su localización en el CAR........... 64

1.10. La función principal de la paxilina es la localización de la calcineurina en el CAR.

1.11. La localización de la calcineurina en el CAR no depende de los dominios LIM de otras proteínas.

1.12. Caracterización de un posible motivo de unión a paxilina en la subunidad catalítica de la calcineurina

2. La calcineurina es necesaria para la localización de la paxilina en el anillo y para la desfosforilación de Cdc15.

2.1. La localización de la calcineurina en el anillo provoca la llegada de más paxilina al anillo creándose un feedback loop positivo.

2.2. La paxilina no parece ser desfosforilada por la calcineurina para localizarse en el CAR.

2.3. La calcineurina afecta a la fosforilación de Cdc15 in vivo.

2.4. La localización de Fic1, otro componente del anillo reclutado por Cdc15, también se encuentra disminuida en ausencia de calcineurina. 


\section{Índice}

3. Otros posibles sustratos de la calcineurina en el CAR ................................................. 80

3.1. Identificación de posibles sustratos de la calcineurina en el CAR .......................... 80

3.2. Pom1 podría ser un sustrato de la calcineurina .................................................... 82

3.3. Rga7 se encuentra más fosforilada en ausencia de Ppb1...................................... 83

3.4. La $\alpha$-glucán sintasa Ags1 no presenta cambios en su estado de fosforilación en ausencia de Ppb1.............................................................................................. 86

3.5. Las miosinas no parecen ser un sustrato de la calcineurina y su interacción con la paxilina no es dependiente de esta fosfatasa............................................... 88

3.6. Rng2 no parece ser un sustrato de la calcineurina............................................... 91

3.7. Cdc12 no parece ser un sustrato de la calcineurina ................................................ 92

3.8. Los componentes de la ruta SIN Spg1, Cdc7 y Sid2 no parecen ser un sustrato de la calcineurina.

\section{CAPÍTULO 2: LA CALMODULINA SE LOCALIZA EN EL ANILLO Y EN LA MEMBRANA} PLASMÁTICA DE LA ZONA DE DIVISIÓN E INTERACCIONA CON RHO1

1. La calmodulina mantiene su localización en la membrana de la zona de división en ausencia de la paxilina o la calcineurina....

2. La calmodulina interacciona con la GTPasa Rho1

2.1 La sobreexpresión de Cam1 suprime parcialmente el fenotipo de

termosensibilidad del mutante rho1-596.

2.2 La calmodulina interacciona con la GTPasa Rho1 de forma independiente de la calcineurina y esta interacción se ve aumentada en presencia de calcio.......... 100

2.3 Identificación de un sitio putativo de unión a calmodulina en la GTPasa Rho1.

102

2.4 Los mutantes de unión a calmodulina presentan algunos defectos similares al mutante rho1-596 donde la funcionalidad de Rho1 se encuentra comprometida. 104

2.5 Los mutantes rho1-CM1 y rho1-CM3 poseen menos cantidad de Rho1 total y mantienen su interacción con Cam1. 108

DISCUSIÓN. 111

1. La calcineurina se localiza en el anillo de actomiosina a través de su interacción con los dominios LIM de la paxilina

2. La calcineurina desfosforila a Cdc15 provocando la llegada de más paxilina al anillo contráctil de actomiosina.

3. Otros sustratos de la calcineurina en el CAR................................................................. 118

4. La calmodulina como proteína adaptadora entre la GTPasa Rho1 y otras proteínas como la calcineurina. 
CONCLUSIONES

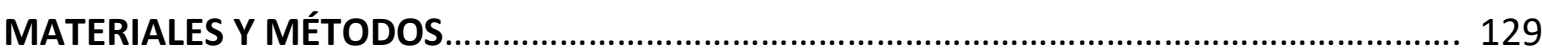

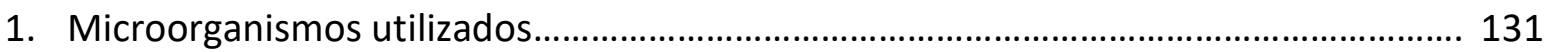

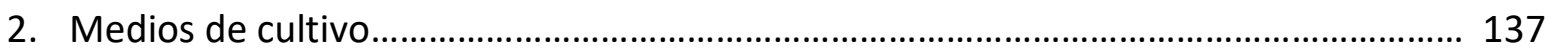

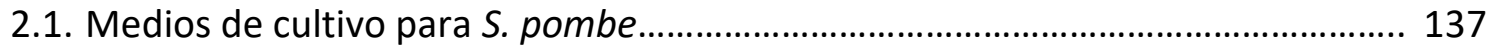

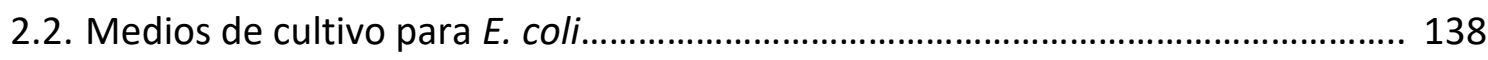

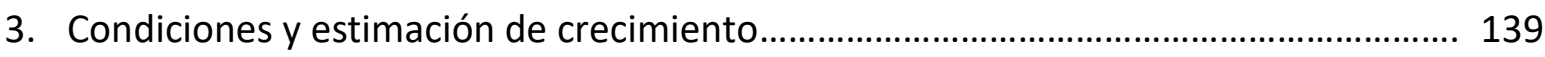

3.1. Condiciones de crecimiento para S. pombe ...................................................... 139

3.2. Sincronización de cultivos celulares de S. pombe mediante uso de cepas mutantes termosensibles............................................................................. 139

3.3. Ensayos de crecimiento en gota............................................................................. 139

3.4. Condiciones de crecimiento para E. coli........................................................... 140

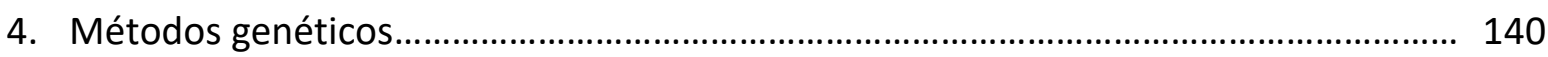

4.1. Conjugación y obtención de diploides................................................................... 140

4.2. Aislamiento y selección de ascosporas................................................................ 140

5. Procedimientos generales de biología molecular..................................................... 141

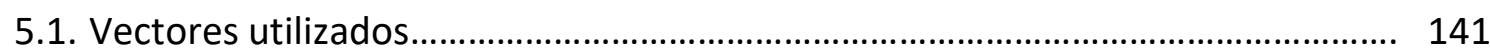

5.1.1. Vectores de E. coli ................................................................................... 141

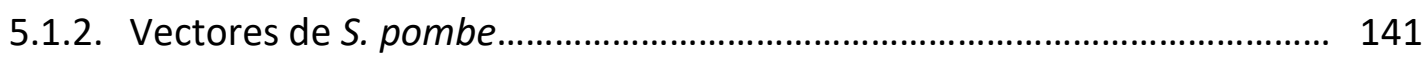

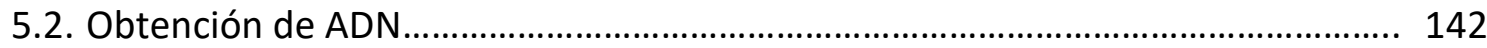

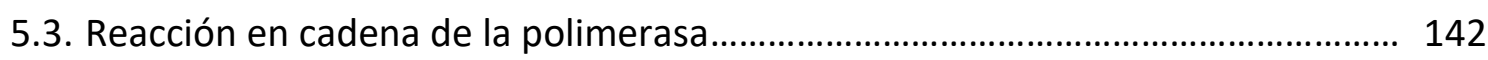

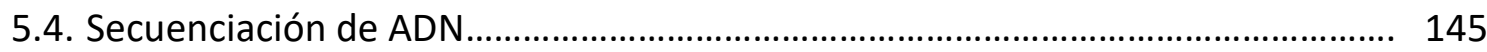

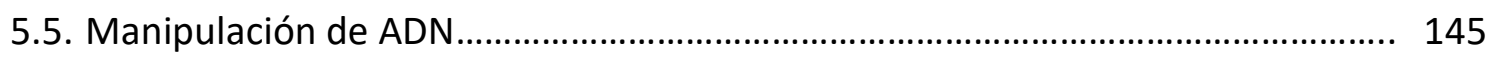

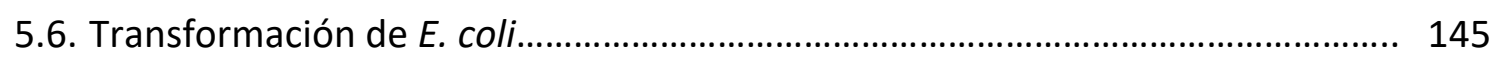

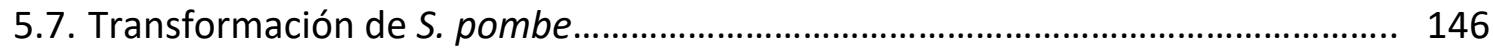

5.8. Vectores de integración........................................................................................ 146

5.8.1. Construcción del módulo de integración de los alelos mutantes de $p \times 11^{+}$del sitio de unión a calcineurina.................................................. 146

5.8.2. Construcción del módulo de integración de los alelos mutantes de $r h o 1^{+}$del sitio de unión a calmodulina.............................................. 147

5.9. Vectores de expresión..................................................................................... 148

5.9.1. Construcción del vector de sobreexpresión de los alelos mutantes de $p p b 1^{+}$del sitio de unión a sustrato..................................... 148

5.9.2. Construcción del vector de expresión de $p x / 1^{+}$, sus truncamientos y sus alelos mutantes del sitio de unión a calcineurina............................ 148 


\section{Índice}

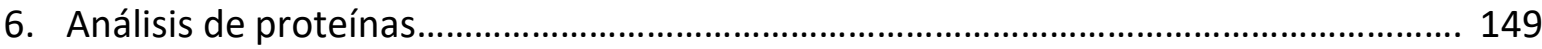

6.1. Obtención de extractos celulares con TCA.......................................................... 149

6.2. Obtención de extractos celulares.......................................................................... 149

6.3. Ensayos de inmunoprecipitación........................................................................... 150

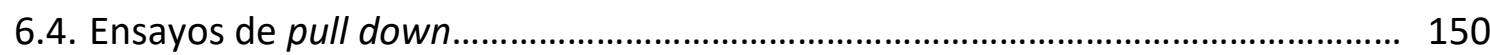

6.4.1. Producción de proteína recombinante (GST-Pxl1/Cam1)....................... 150

6.4.2. Ensayo de unión.................................................................................... 151

6.5. Análisis de Rho1 activo (GTP-Rho1) ............................................................... 151

6.5.1. Producción de GST-RBD recombinante................................................. 152

6.5.2. Ensayo de unión...................................................................................... 152

6.6. Electroforesis y electrotransferencia de proteínas............................................ 152

6.7. Inmunodetección de proteínas........................................................................... 153

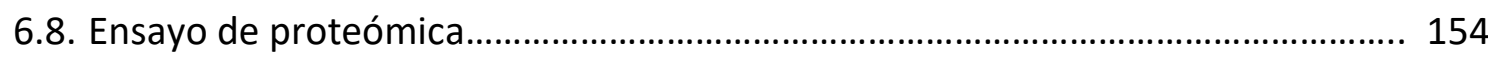

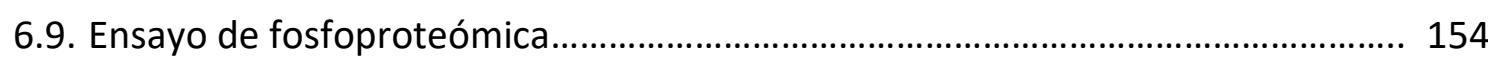

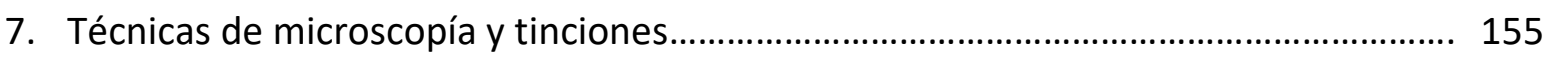

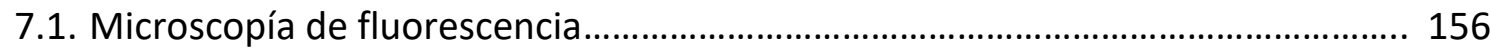

7.1.1. Fluorescencia directa con GFP............................................................. 156

7.1.2. Tinción con calcofluor.............................................................................. 157

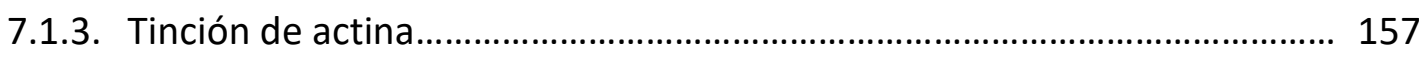

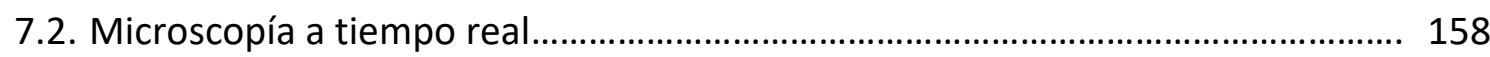

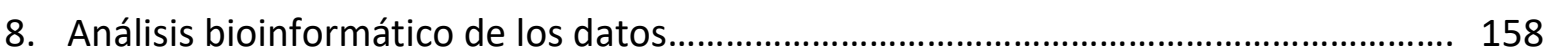

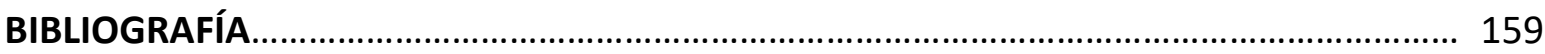


Introducción

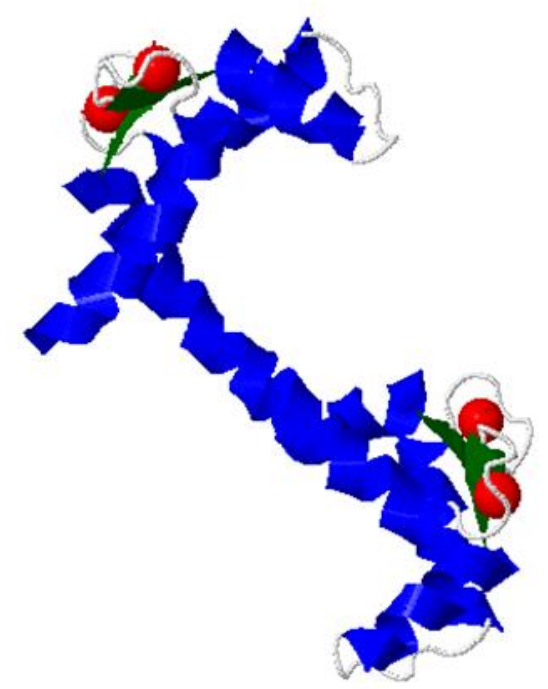





\section{Schizosaccharomyces pombe: UN MODELO EUCARIOTA PARA EL ESTUDIO DE LA MORFOGÉNESIS CELULAR}

La levadura Schizosaccharomyces pombe fue descrita por primera vez en el año 1.893 por P. Lindner, quien la aisló de una cerveza de mijo del este de África. Su epítopo específico "pombe" significa cerveza en Swahili y posteriormente se denominó "levadura de fisión" debido a que su división sucede por fisión transversal. La mayoría de cepas usadas hoy en día en el laboratorio derivan de una estirpe homotálica $\mathrm{h}^{90}$ aislada por Ostewalder en Francia en 1921 a partir de jugo de uva, de la que se obtuvieron cepas heterotálicas con los dos tipos sexuales opuestos, h+ y h- (Leupold, 1949). Posteriormente, Mitchison en Edimburgo entre los años 50 y 60 comenzó el estudio de su patrón de crecimiento celular y no fue hasta 1971 cuando se inició el estudio del control de su división celular (Fantes and Hoffman, 2016). S. pombe es un organismo eucariota unicelular clasificado dentro del filo Ascomycota, al igual que Saccharomyces cerevisiae. Sin embargo, se estima que la separación evolutiva entre estas dos levaduras tuvo lugar hace 1.144 millones de años mientras que la división entre $S$. pombe y las plantas o los metazoos se produjo hace 1.600 millones de años (Heckman et al., 2001) (Figura1).

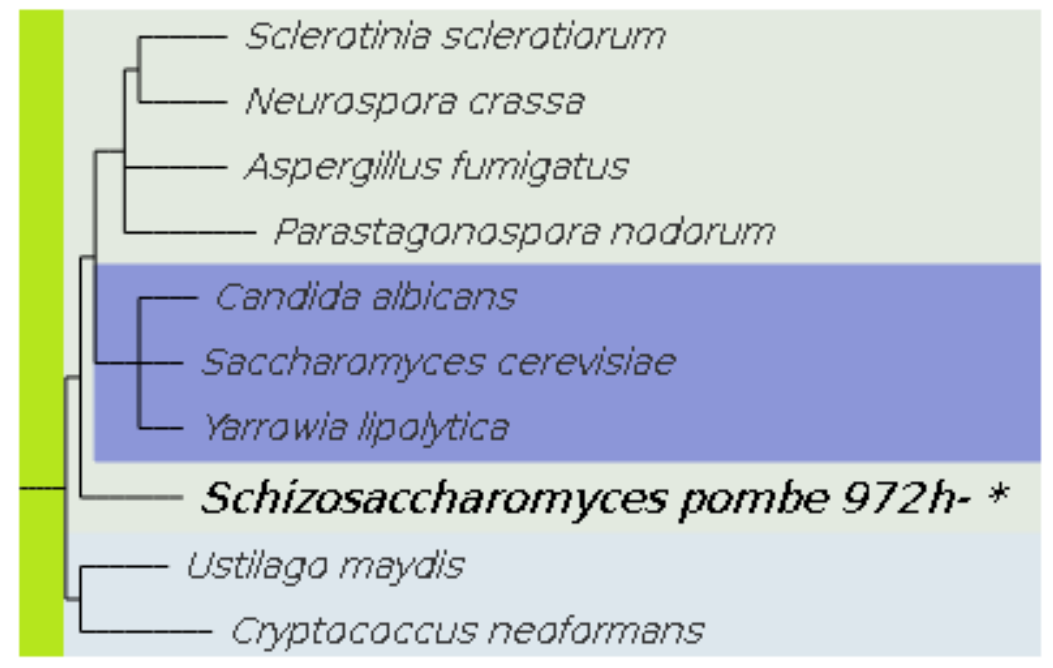

Fungi Ascomycota

Saccharomycotina

Figura 1.- Árbol filogenético de S. pombe. Obtenido y adaptado a partir de la base de datos http://phylomedb.org/ utilizando datos de NCBI.

S. pombe es considerado un excelente modelo de estudio en muchos campos de la biología celular debido a su fácil manejo en condiciones de laboratorio, a su falta de patogenicidad, a su ciclo de vida rápido y fundamentalmente haploide, así como a su ciclo sexual de corta duración. S. pombe es, además, muy similar a las células eucariotas superiores en su modo de división celular mediante fisión transversal formando un anillo contráctil de actomiosina (CAR) en el plano medio de la célula. Por estas razones $S$. pombe es un sistema modelo ideal para el estudio de procesos biológicos como la división celular, el ciclo celular y la morfogénesis (Yanagida, 2002). 
Además la secuenciación de su genoma fue completada en el año 2002 lo que convierte a esta levadura en un organismo modelo susceptible de análisis genético clásico y molecular (Wood et al., 2002). Esta levadura posee, como los demás hongos, una pared celular que le confiere protección mecánica, forma y estabilidad osmótica lo que hace que sea un buen modelo para el análisis de la biosíntesis y degradación de esta estructura fúngica.

\subsection{Ciclo de vida de S. pombe}

S. pombe es un organismo con un ciclo de vida haplodiplonte, con una fase haploide y una diploide, siendo la primera la fase predominante. Durante la fase haploide las células tienen forma cilíndrica con un tamaño aproximado de 3-4 $\mu \mathrm{m}$ de diámetro y 7-8 $\mu \mathrm{m}$ de longitud, llegando a medir hasta 12-15 $\mu \mathrm{m}$ mediante el crecimiento de forma polarizada por sus extremos. En ese momento se produce la división celular por fisión transversal mediante la formación de un septo en la zona central de la célula que, tras la citocinesis, se digiere parcialmente dando lugar a dos células hijas de idéntico tamaño (Figura 2).

Si dos células de diferente tipo sexual se encuentran en un medio pobre en nutrientes las células $\mathrm{h}^{-}$comienzan a secretar factor $\mathrm{M}$ y producen receptores para el factor $\mathrm{P}$ mientras que las células $\mathrm{h}^{+}$liberan factor $\mathrm{P}$ y sintetizan receptores para el factor $\mathrm{M}$. La unión de los factores a sus receptores desencadena el proceso de conjugación con la formación de una proyección denominada shmoo en un extremo de cada célula, hasta que ambas células se ponen en contacto y se fusionan, formando un zigoto diploide (Kelly et al., 1988). A continuación, el zigoto sufre meiosis y esporulación formándose un asca zigótica con cuatro esporas haploides que se liberan tras la rotura del asca. Estas esporas permanecerán latentes hasta que las condiciones del medio sean favorables germinando y reiniciando el ciclo (Klar et al., 2014) (Figura 2). Por otro lado, existen colonias homotálicas $\mathrm{h}^{90}$ que esporulan con mucha más eficacia al existir células $P$ y células $M$ en la misma proporción, por lo que la conjugación se produce entre células que vienen de la misma colonia (Maki et al., 2018). En condiciones de laboratorio es posible mantener células diploides en cultivo a partir de un zigoto mediante la utilización de un medio de crecimiento rico inmediatamente después de la conjugación y antes de la meiosis (Egel y Egel-Mitani, 1974). Las células diploides de $S$. pombe se diferencian fácilmente de las haploides puesto que tanto su tamaño al comienzo del ciclo de vida, entre 11-14 $\mu \mathrm{m}$ de longitud, como antes de la división, entre 20-25 $\mu \mathrm{m}$, es mayor. Estas células diploides son muy inestables y esporulan rápidamente al entrar en fase estacionaria o en situaciones de escasez de nutrientes en el medio, formándose un asca zigótica con cuatro ascosporas haploides. Este ciclo sexual, que comienza con la conjugación, permite combinar mutaciones, crear estirpes 
con proteínas marcadas con distintos epítopos o condicionar la expresión de genes de una manera sencilla (Figura 2).

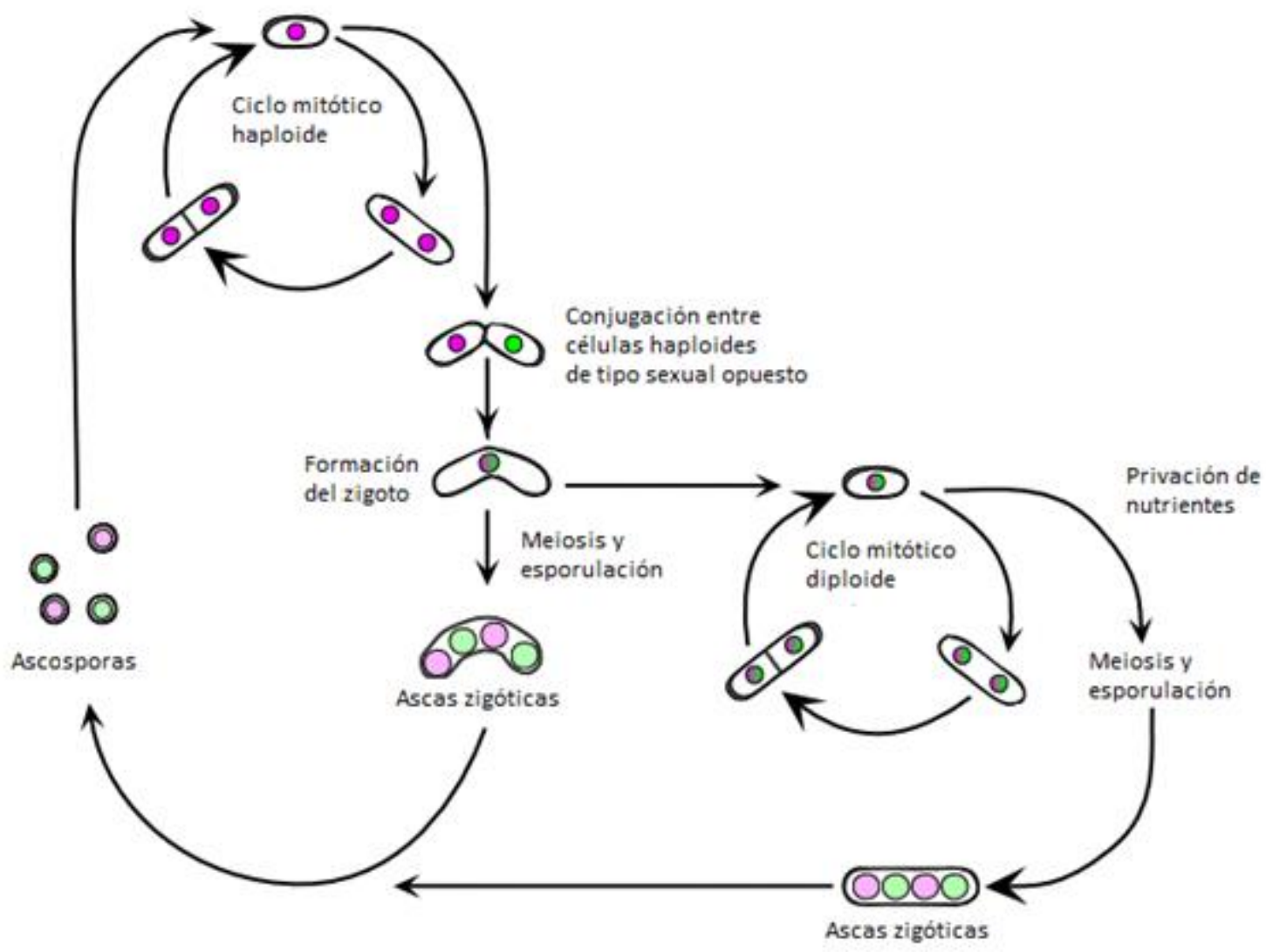

Figura 2.- Ciclo de vida de $\boldsymbol{S}$. pombe. Los colores verde y magenta muestran dos tipos sexuales diferentes $\left(\mathrm{h}^{+} \mathrm{y} \mathrm{h}^{-}\right)$. Ciclo de vida haploide (izquierda) y ciclo de vida diploide (derecha) de S. pombe. Adaptado de Stuart A. Macneill, 1997.

\subsection{Ciclo celular y morfogenético de S. pombe}

La generación de polaridad celular en cada uno de los diferentes momentos del ciclo celular (división, diferenciación, señalización molecular etc.) es esencial en todos los tipos de células y organismos. S. pombe se ha utilizado como organismo modelo para el estudio de la polaridad celular debido a su forma cilíndrica regular. Al igual que el resto de células eucariotas, presenta cuatro fases durante su ciclo celular: G1, S, G2 y M (Mitchison y Creanor, 1971). En la fase G1 las células crecen únicamente por el polo heredado de la célula madre llamado polo antiguo. Este crecimiento monopolar continúa durante toda la fase $S$, en la que se produce la duplicación del $A D N$, y se mantiene durante parte de la fase G2. Tras alcanzar un tamaño determinado, durante la fase G2, las células comienzan un patrón de crecimiento bipolar activándose el crecimiento del otro polo surgido de la división celular anterior en un proceso denominado NETO (New End Take Off), aunque el crecimiento es siempre más rápido 
en el polo antiguo (Cerone et al., 2012; Martin and Chang, 2005; Mitchison and Nurse, 1985a). Cuando el tamaño celular es el adecuado, el crecimiento celular en los polos cesa y la célula entra en mitosis (fase M). Al inicio de esta fase es cuando se produce el ensamblaje del anillo de actomiosina, produciéndose su contracción y la formación del septo simultáneamente tanto al final de la fase $\mathrm{M}$ como en el principio de una nueva fase G1. Antes de la finalización de la separación celular, ya iniciada la fase G1, comienza el crecimiento celular por el polo heredado. Este proceso se denomina OETO (Old End Take Off) (Stuart A. Macneill, 1997) (Figura 3).

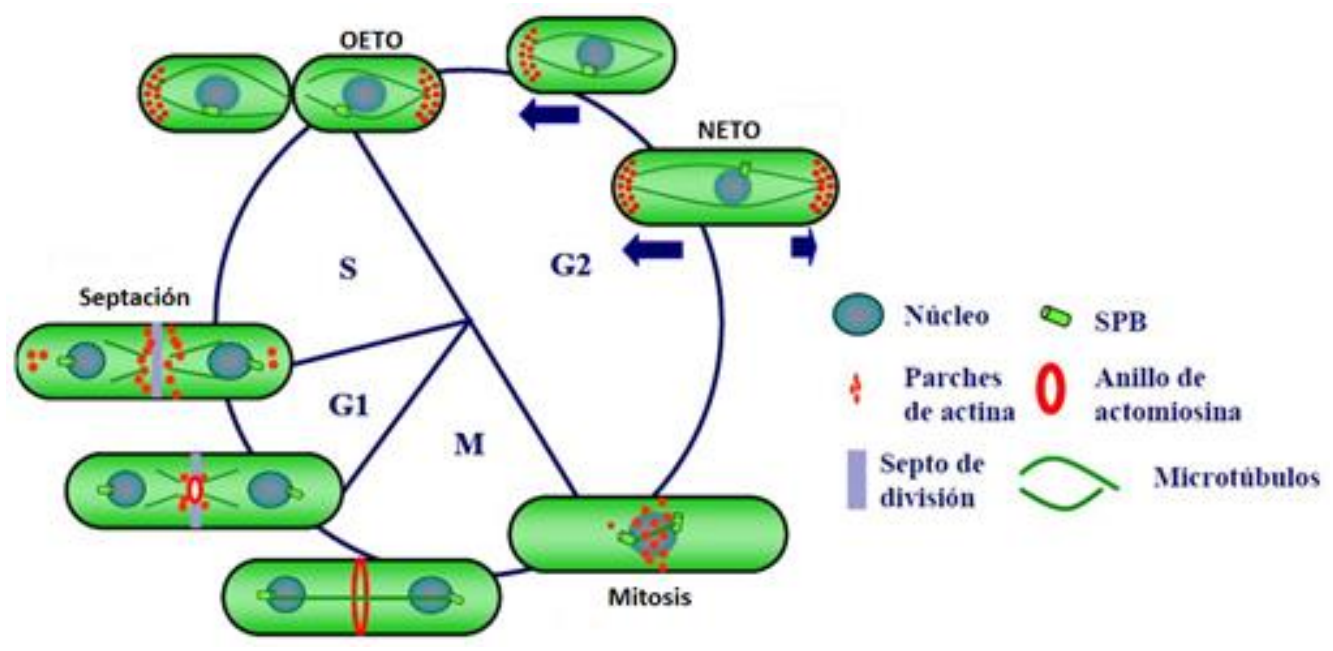

Figura 3.- Ciclo morfogenético y ciclo celular de S. pombe. La fase G1 del ciclo celular es la más corta y sucede cuando ambas células todavía no se han separado. El final de la fase $\mathrm{S}$ coincide con la separación celular y los parches de actina pasan a localizarse en un uno de los polos (OETO). Durante la fase G2 estos parches ya se localizan en ambos polos (NETO) y, al final de esta fase, pasan a localizarse en la región central donde se producirá la división celular. Por último, durante la fase $\mathrm{M}$ se completa el anillo de actomiosina y se produce la separación de los núcleos. Adaptado de Cruz Quintana et al., 2014.

\subsection{El citoesqueleto de actina de S. pombe}

La actina es una proteína pequeña (42 kDa) muy conservada en eucariotas que puede encontrarse tanto en forma monomérica globular (G-actina) como en forma polimerizada (F-actina) formando filamentos polarizados. El citoesqueleto de actina es esencial para la progresión correcta del ciclo celular, colaborando con los microtúbulos interfásicos en la generación de polaridad y en el proceso de citocinesis, estableciendo el sitio de división y la formación del anillo de actomiosina (Chiou et al., 2017; Minc et al., 2009; Tay et al., 2018). En S. pombe podemos encontrar la actina polimerizada en 3 diferentes estructuras: parches, cables y el anillo contráctil de actomiosina (CAR) (Chhabra and Higgs, 2007; Subramanian et al., 2013). Los parches se encuentran en los polos y participan en la endocitosis, los cables se localizan desde los polos a lo largo del citoplasma y se encargan del transporte de vesículas hasta las zonas de crecimiento. 
Por último, el anillo contráctil de actomiosina se localiza en la zona de división y es necesario para la citocinesis y separación celular (Mishra et al., 2014) (Figura 4).

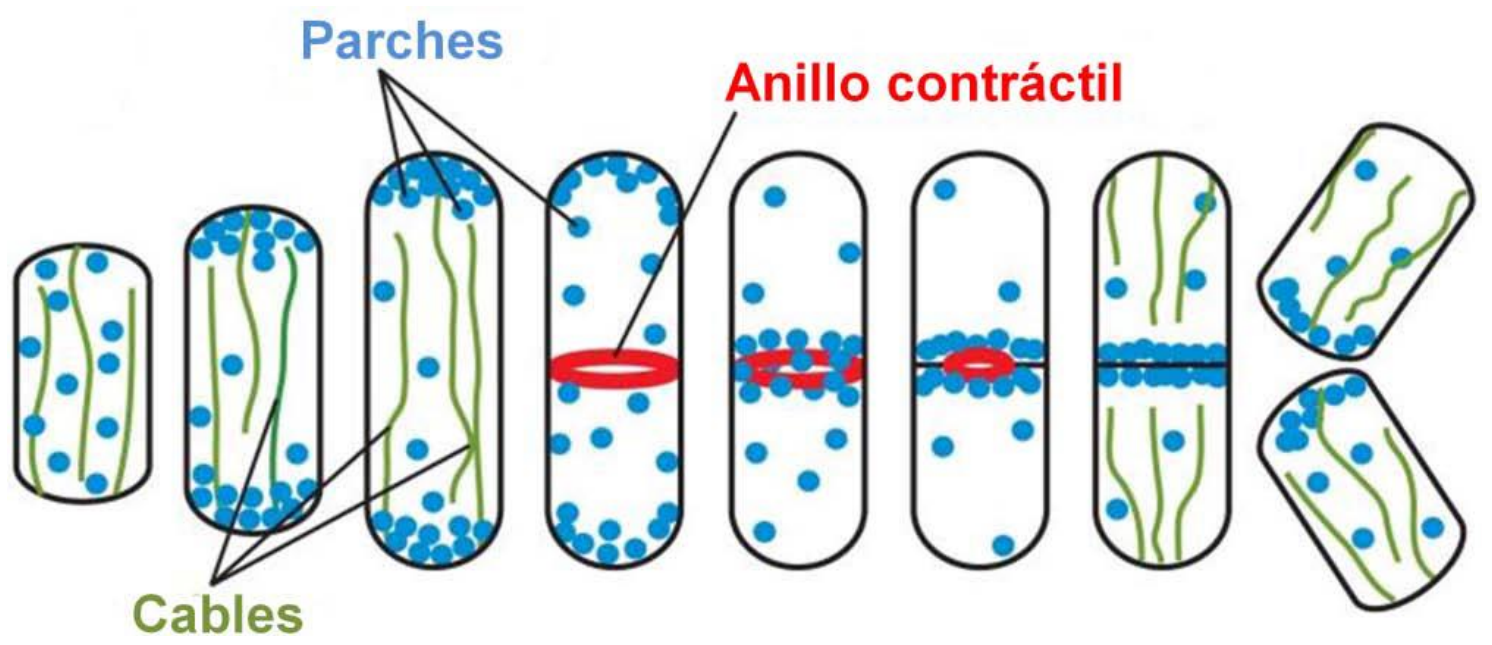

Figura 4. - Citoesqueleto de actina de S. pombe. En la levadura de fisión, el citoesqueleto está formado por parches que se localizan en los polos de crecimiento, los cables que van desde los polos a la zona central y el anillo contráctil que se forma en la zona central durante la división. Adaptado de Kovar et al., 2011.

Los parches de actina son filamentos de actina polimerizada cortos y ramificados de entre 100 y $200 \mathrm{~nm}$ de longitud (Berro et al., 2010; Sirotkin et al., 2010). Se forman a partir del complejo Arp2/3 que posee la propiedad de polimerizar monómeros de actina (McCollum et al., 1996; Morrell et al., 1999). La activación de este complejo viene dada por tres factores promotores de nucleación: Pan1, Wsp1 y Myo1 con funciones distintas pero solapantes. Aunque todos ellos llegan al polo, solo Wsp1 y Myo1 son capaces de iniciar la formación del parche de actina. Wsp1 es el activador más fuerte mientras que Myo1 necesita la llegada de la verprolina Vrp1 para la activación del complejo Arp2/3 (Kovar et al., 2011; Lee et al., 2000; Sirotkin et al., 2005, 2010). Este complejo se halla normalmente inactivo pues Arp2 y Arp3 se encuentran separados entre sí y del propio filamento de actina. La llegada de los factores de nucleación provoca un cambio conformacional en el complejo Arp2/3 acercando Arp2 a Arp3, esto favorece la unión al filamento de actina que permite una reorganización del resto de subunidades del complejo y el inicio de la nucleación (Espinoza-Sanchez et al., 2018). En S. pombe la función principal de los parches de actina se ejerce en el proceso de endocitosis. Se han identificado varios mutantes puntuales del complejo Arp2/3 con defectos en el proceso de endocitosis (Gachet and Hyams, 2005; Kovar et al., 2011). Los parches de actina también participan en la división celular y están implicados en la formación del septo. Sin embargo, no participan en el ensamblaje del CAR, aunque se localizan muy próximos a este pero nunca formando parte de él (Carnahan and Gould, 2003; Wu et al., 2006). 
Los cables de actina están compuestos de haces paralelos de filamentos cortos de actina sin ramificar. La selección del sitio de ensamblaje de los cables de actina es compleja. Se sabe que existen vías paralelas y superpuestas, como la mediada por la GTPasa Cdc42 junto con la proteína adaptadora Pob1 (Martin, 2009). Los microtúbulos también pueden inducir el ensamblaje de los cables en sitios específicos de la corteza celular mediante el complejo Tea1-Tea4 (Minc et al., 2009; Tay et al., 2018). Tras la selección del sitio de ensamblaje la formina For3 es reclutada y activada iniciando rápidamente la polimerización de los filamentos de actina (Feierbach and Chang, 2001; Martin and Chang, 2006). La GTPasa de la familia Rho Cdc42 y Bud6 son las encargadas de la activación y localización de esta formina liberándola de su autoinhibición (Martin et al., 2007). Otras proteínas que forman parte de los cables iniciados por For3 son la tropomiosina Cdc8 y la coronina Crn1, que participan en su ensamblaje estabilizándolos y facilitando su interacción con las miosinas (Balasubramanian et al., 1992; Pelham and Chang, 2001). Una de las principales funciones de los cables de actina es la regulación del crecimiento polarizado ya que participan en el transporte de vesículas mediado por la miosina de tipo $\mathrm{V}$ Myo52 que transporta los componentes necesarios para la síntesis de la pared celular (Motegi et al., 2001; Mulvihill et al., 2006).

El anillo contráctil de actomiosina (CAR) se forma en la zona media de la célula y está compuesto principalmente por actina y miosinas de clase II (Marks and Hyams, 1985). La formación de este anillo contráctil se produce al final de la mitosis, determinando el lugar donde se va a producir la formación del septo y la división celular (Chang et al., 1996; Pollard and Wu, 2010). El proceso de formación del CAR y sus componentes se describirá más adelante en los apartados $4.2,4.3$ y 4.4 .

\subsection{El citoesqueleto de microtúbulos}

Los microtúbulos, están formados por dímeros de $\alpha / \beta$ tubulina de unos $25 \mathrm{~nm}$ de diámetro y están presentes a lo largo de todo el ciclo celular, tanto en interfase formando haces paralelos al eje de la célula, como en mitosis formando el huso mitótico (Marks et al., 1986). En S. pombe los microtúbulos interfásicos se polimerizan desde el centro organizador de microtúbulos (iMTOC) y están formados por entre 3 y 5 haces de filamentos antiparalelos, presentando un extremo positivo orientado al polo celular y uno negativo anclado al centro organizador de los microtúbulos. Los microtúbulos van creciendo por su extremo positivo hasta alcanzar el polo, iniciándose rápidamente el desensamblaje para volver a comenzar su crecimiento (Drummond and Cross, 2000; Hagan, 1998). Las fuerzas ejercidas por el crecimiento de los extremos positivos en contacto con ambos polos ayudan a mantener al núcleo en el centro celular. Durante la mitosis, los microtúbulos se desensamblan y a partir del cuerpo polar del huso o spindle pole body (SPB) comienza la formación del huso mitótico, 
necesario para la separación de los cromosomas. Tras la separación de los núcleos, el huso se desensambla y se forma de nuevo el citoesqueleto de microtúbulos desde el MTOC (Heitz et al., 2001; Tran et al., 2001).

Los microtúbulos desempeñan un papel esencial en la selección del sitio de crecimiento polarizado ya que transportan al marcador inicial de dichos sitios Tea1 (Mata and Nurse, 1997). Tea1 es una proteína con repeticiones Kelch que se localiza en los polos gracias a la quinesina Tea2 y la mantiene unida a los extremos positivos de los microtúbulos para transportarla. Este transporte también está regulado por Tip1, un miembro de la familia de proteínas CLIP-170, necesaria para regular la dinámica de los microtúbulos. Una vez en los polos, Tea1 es anclada a la membrana y las proteínas Mod5 y Tea3 participan en dicho anclaje aunque este proceso no se conoce con exactitud (Snaith and Sawin, 2003, 2005). La proteína Tea4 también es transportada por los microtúbulos y forma un complejo con Tea1 en los polos. Tea4 gracias a su dominio SH3 se une a For3 y sirve de anclaje entre Tea1 y esta formina en el polo de crecimiento. Se ha descrito que el complejo Tea1-Tea4 participa en la formación de los dominios de membrana ricos en esterol que definen los sitios de crecimiento de $S$. pombe (Makushok et al., 2016).

La quinasa Pom1 también se localiza en los polos de forma dependiente de Tea4 y se ha sugerido que puede actuar por debajo de Tea1 conectando la señalización de microtúbulos y actina para asegurar la posición del crecimiento. Tea4 actúa como subunidad reguladora de la fosfatasa PP1, reclutando a su subunidad catalítica, Dis2, a los polos de la célula (Alvarez-Tabares et al., 2007). Dis2 es capaz de desfosforilar a Pom1 favoreciendo su asociación con la membrana plasmática mediante la unión a fosfolípidos cargados negativamente a través de un dominio con carga positiva. Al finalizar la señalización, Pom1 se autofosforila en este dominio y esto inhibe su localización en la membrana (Hachet et al., 2011).

Además de la regulación de la polaridad celular, los microtúbulos tienen un papel importante en la citocinesis puesto que están implicados en el posicionamiento del núcleo en la zona central de la célula. Las proteínas motoras asociadas al SPB responden a las señales que indican la posición del núcleo en el centro de la célula durante la mitosis y la posición de los núcleos postmitóticos en las dos regiones que serán el centro de las células hijas (Hagan, 1998; Hagan and Yanagida, 1997). El SPB también es el encargado de la formación del huso mitótico y de los microtúbulos astrales que comienzan a formarse en prometafase y son más abundantes en anafase B (Hagan and Hyams, 1996). 


\subsection{Las miosinas}

Las miosinas son proteínas motoras que se desplazan a lo largo de la actina de forma dependiente de la hidrólisis de ATP. Las cadenas pesadas de las miosinas incluyen una región $\mathrm{N}$-terminal altamente conservada que contienen el dominio motor, capaz de producir fuerza, y una región C-terminal o cola muy divergente entre las distintas miosinas. El dominio motor incluye el motivo de unión a actina y de hidrolisis de ATP mientras que el dominio C-terminal determina la localización de la miosina y le otorga sus funciones específicas, como la movilidad celular o la citocinesis (Berg et al., 2001). Entre los dominios motor y C-terminal de las cadena pesadas hay un número variable (entre uno a seis) de dominios de unión a las cadenas ligeras en una región denominada "cuello" (Baker and Titus, 1998; Mooseker and Cheney, 1995). En S. pombe existen cinco cadenas pesadas diferentes que se dividen en tres clases diferentes: I (Myo1), II (Myo2 y Myp2/Myo3) y V (Myo51 y Myo56) (Clayton et al., 2010; Gachet et al., 2004).

\subsubsection{Miosinas de clase I}

En S. pombe solo existe una miosina de clase I, Myo1, cuya deleción no es letal pero causa retraso en el crecimiento a bajas o elevadas temperaturas y una morfología aberrante (Toya et al., 2001). Como se ha descrito anteriormente, Myo1 está implicada en la activación del complejo Arp2/3 para la formación y localización de los parches de actina que participan en la endocitosis y el proceso de conjugación (Lee et al., 2000; Sirotkin et al., 2005). La localización de Myo1 depende de su fosforilación por la quinasas de la familia de Ste20, como Pak1, aunque su actividad motora es independiente de esta fosforilación (Attanapola et al., 2009). La tropomiosina Cdc8 inhibe a Myo1 impidiendo su capacidad de asociarse a la actina, mientras que la proteína entrecruzadora de filamentos de actina, la fimbrina Fim1, recupera su actividad motora quitando a Cdc8 de los filamentos de actina (Clayton et al., 2010). Además de los parches, también se ha observado la localización de Myo1 en la zona del septo y en el CAR, probablemente como activador del complejo Arp2/3 (Takeda and Chang, 2005; Wu et al., 2006) (Figura 5).

\subsubsection{Miosinas de clase II}

Las miosinas de clase II se encuentran formando hexámeros compuestos por dos cadenas pesadas, dos cadenas ligeras esenciales y dos reguladoras. En S. pombe hay dos formas de cadenas pesadas, Myo2 y Myo3/Myp2 (Bezanilla et al., 1997; Kitayama et al., 1997; Motegi et al., 1997, 2000), una cadena ligera esencial denominada Cdc4 (McCollum et al., 1995) y una cadena ligera reguladora denominada Rlc1 (Le Goff et al., 2000). 
Myo2 y Myp2 se localizan en la zona de división y su función principal es en citocinesis (Bezanilla et al., 1997; Kitayama et al., 1997; May et al., 1997; Motegi et al., 1997). Myo2 es uno de los principales componentes del CAR y es de las primeras moléculas en localizarse en la zona de división mientras que Myp2 llega 30 minutos más tarde (Wu et al., 2003). Myo2 forma un dímero de 2 cabezas con 9 dominios ricos en prolina en su cola, mientras que Myp2 es monomérica y contiene 25 dominios ricos en prolina de los cuales 19 se concentran en la zona central de la cola dividiéndola en dos subdominios que se pliegan de forma antiparalela (Bezanilla and Pollard, 2000).

La contribución de Myo2 y Myp2 a la citocinesis es diferente. Myo2 es esencial y su deleción da lugar a células capaces de germinar pero que mueren debido a los defectos en citocinesis (Kitayama et al., 1997; May et al., 1997). La deleción de Myp2 presenta un fenotipo más leve, las células muestran un leve defecto en citocinesis pero son capaces de crecer (Fujita et al., 2002; Mulvihill et al., 2000). El defecto en la cepa mutante myp2 $\Delta$ se agudiza cuando crece en condiciones de estrés. Se ha observado que esta proteína es esencial para la regulación del ion cloruro y presenta interacción génica con la deleción de la calcineurina en citocinesis (Bezanilla et al., 1997; Fujita et al., 2002; Motegi et al., 1997). La cepa mutante doble myo2-E1 myp2 $\Delta$ presenta defectos aditivos en citocinesis respecto a los mutantes sencillos. Por tanto, ambas proteínas actúan en distintas vías de señalización y regulan procesos diferentes dentro de la citocinesis (Bezanilla and Pollard, 2000; Motegi et al., 2000). Myo2 está implicada en el ensamblaje del anillo de actomiosina y en la contracción del mismo debido a su actividad motora, como se explicará en el apartado 4.5. Myp2 tiene un papel secundario en la contracción del CAR que se manifiesta cuando la actividad de Myo2 se encuentra comprometida (Palani et al., 2017; Zambon et al., 2017). A pesar de tener funciones distintas, recientemente se ha descrito que ambas proteínas también pueden colaborar en algunos procesos como en la activación de la glucán-sintasa Bgs1. Además, en situaciones de estrés osmótico, Myp2 regula a Myo2 colaborando así ambas en la contracción del CAR (Okada et al., 2019). En células animales se ha visto cómo la actividad motora de las miosinas de clase Il es necesaria junto con las septinas para generar la fuerza necesaria en el sitio de constricción de la célula que formará el futuro sitio de abscisión (Wang et al., 2019). Myo2 posee dos sitios putativos de fosforilación y, aunque la fosforilación de la serina 1.444 no influye en la actividad motora de esta proteína, sí promueve el inicio de la constricción del CAR (Sladewski et al., 2009) (Figura 5).

Las cadenas ligeras Cdc4 y Rlc1 se unen a las cadenas pesadas por sus dominios IQ presentes en la zona del cuello. Cdc4 es una proteína con un dominio EF-hand compuesto por un dominio $\mathrm{N}$-terminal y otro $\mathrm{C}$-terminal unidos por un linker muy flexible. Cada uno de estos dominios se une a proteínas diferentes de la maquinaria de citocinesis (Escobar-Cabrera et al., 2005). Cdc4 mantiene su localización en el CAR durante la mitosis a pesar de la eliminación de los dominios de unión IQ de ambas 
cadenas pesadas Myo2 y Myp2, por lo que su localización es independiente de estas. Esto se debe a que Cdc4 se une a otras proteínas del CAR con dominio IQ como Rng2 o Myo51, provocando un aumento de la interacción de Myo2 con Rlc1 (D'souza et al., 2001a). Cdc4 es fosforilado durante citocinesis, aunque su estado de fosforilación no afecta a su capacidad de unión a Myo2. Los mutantes fosfonulos y fosfomiméticos de Cdc4 presentan un crecimiento normal y sin defectos en citocinesis, por lo que su estado de fosforilación no parece afectar a la función de la proteína (McCollum et al., 1999).

El papel de Rlc1 es liberar a Myo2 de su estado de autoinhibición mediante la interacción con sus dominios IQ (Naqvi et al., 2000). Rlc1 posee dos sitios de fosforilación en las posiciones 35 y 36 (S35 y S36) fosforilados por la quinasa Pak1/Shk1/Orb2. En S. pombe, al contrario que en células animales, la fosforilación de Rlc1 parece reducir la afinidad de Myo2 por la actina, aunque todavía no está claro cómo el estado de fosforilación de Rlc1 es capaz de regular este proceso (Pollard et al., 2017). De esta forma, la fosforilación de estos aminoácidos produce retrasos en la citocinesis, mientras que en los mutantes fosfonulos se produce una constricción del CAR prematura (Loo and Balasubramanian, 2008a). Tampoco está claro como la fosforilación o desfosforilación de estas serinas de Rlc1 afecta a la actividad ATPasa o a la movilidad de Myo2 (Pollard et al., 2017; Sladewski et al., 2009).

\subsubsection{Miosinas de clase V}

Existen dos tipos de miosinas de clase V, Myo51 y Myo52. Myo52 se localiza en los polos de crecimiento y en la zona media durante la división y Myo51 solo se localiza en el CAR durante citocinesis (Motegi et al., 2001; Win et al., 2001). Ambas miosinas necesitan un citoesqueleto de actina intacto para su correcta localización. El papel principal de ambas miosinas es el transporte de vesículas secretoras a lo largo de los cables de actina (Lo Presti et al., 2012). La cepa mutante Myo51 crecimiento y una morfología normales mientras que en la deleción de Myo52 se puede observar una pérdida parcial de la polaridad, un retraso en el crecimiento y defectos en citocinesis. La combinación de ambas deleciones no produce un fenotipo aditivo (Motegi et al., 2001; Win et al., 2001). En las células con la deleción de myo52 ${ }^{+}$ y/o myo51 $1^{+}$los cables de actina están enroscados y fallan al extenderse hacia el interior del citoplasma. Myo52 contribuye a la formación de los cables de actina mediante el transporte de los reguladores de las forminas a los polos celulares (Lo Presti et al., 2012). Myo52 es también responsable de llevar las vesículas con Bgs1, y probablemente, con las otras glucán-sintasas, a los polos de crecimiento y al ecuador de la célula para la formación del septo. Por otro lado, Myo51 tiene un papel no esencial en la citocinesis como componente del CAR (Mulvihill et al., 2006; Win et al., 2001) (Figura 5). 


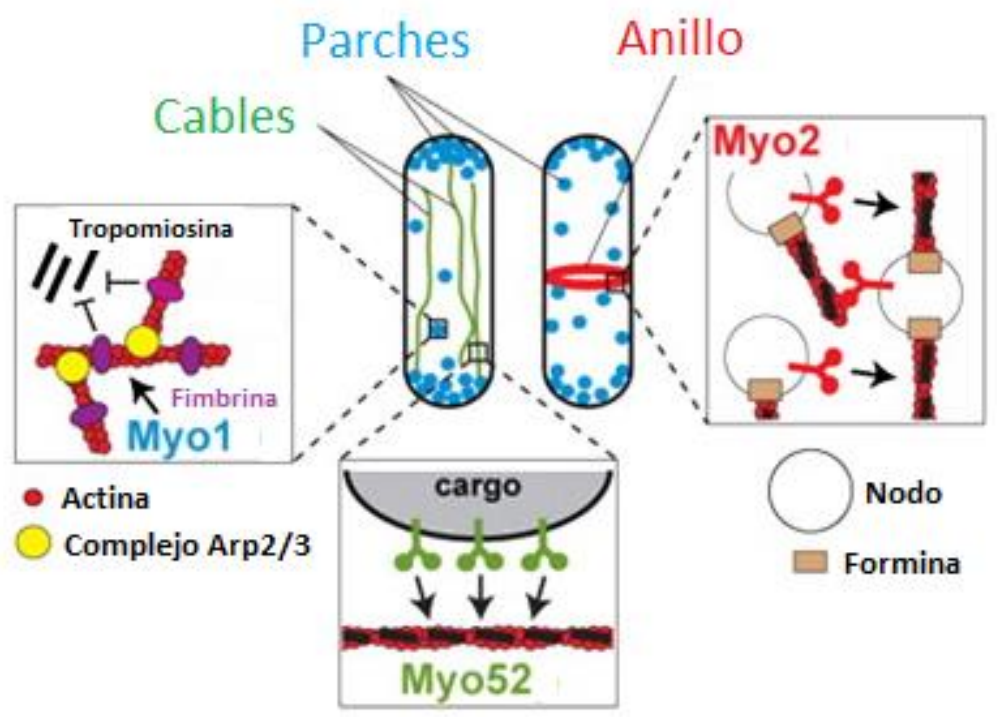

Figura 5.- Localización de las miosinas en la célula. En la levadura de fisión existen 3 clases de miosinas, la de clase I está implicada en la formación de los parches mientras que las de clase $\mathrm{V}$ transportan los cargos a través de los cables. Finalmente, las de clase II participan en la formación del anillo de actomiosina durante la división celular. Adaptado de Clayton et al., 2010.

\subsection{Las septinas}

Las septinas son proteínas de unión a GTP que forman filamentos de unos $10 \mathrm{~nm}$ que fueron identificadas inicialmente en S. cerevisiae (Hartwell, 1971) y, posteriormente, descritas en la mayoría de los organismos eucariotas (Faty et al., 2002; Macara et al., 2002). Estas proteínas poseen una estructura muy conservada con un dominio central de unión a GTP flanqueado por una región básica en el extremo $\mathrm{N}$-terminal y un dominio coiled-coil en su región C-terminal (An et al., 2004).

En S. pombe se han encontrado 7 septinas (Spn1-7) de las cuales Spn5, Spn6 y Spn7 están implicadas en esporulación (Onishi et al., 2010). Al contrario que en la levadura de gemación, las septinas no son esenciales, pero la deleción de alguna de las 4 primeras, Spn1-4, provoca defectos en la división celular observándose un fenotipo de células encadenadas (Berlin et al., 2003; Tasto et al., 2003). Spn1 y Spn3 son las primeras en localizarse en el sitio de división al final de la mitosis formando un anillo al que luego llegan el resto. Estas septinas forman un octámero, siendo Spn1 y Spn4 el núcleo de esta estructura. El anillo de septinas no se contrae con el CAR y desaparece tras la división celular (An et al., 2004; Berlin et al., 2003; Tasto et al., 2003). El anillo de septinas sirve de anclaje a otras proteínas como por ejemplo la GTPasa Rho4, su activador Gef3, o las glucanasas Eng1 o Agn1 que tienen un papel importante en la separación celular tras la constricción del CAR (Martín-Cuadrado et al., 2005; Muñoz et al., 2014; Santos et al., 2015; Wang et al., 2015). En los mutantes carentes de Spn1 se puede observar más adelantada la formación del anillo de septinas, mientras que su contracción está ligeramente disminuida (Zheng et al., 2018). Además, en estos 
mutantes, la quinasa de la ruta SIN, Sid2, y las glucán-sintasas, Bgs1 y Ags1, se localizan en la zona media de forma prematura y se mantienen menos tiempo en ella (Zheng et al., 2018).

Para la formación correcta del anillo de septinas es necesaria la localización de la anillina Mid2 en el sitio de división (Berlin et al., 2003; Tasto et al., 2003). Mid2 se expresa únicamente durante anafase y la sobreexpresión de una forma más estable de esta proteína lleva a la persistencia del anillo de septinas a lo largo de múltiples divisiones celulares (An et al., 2004; Berlin et al., 2003; Tasto et al., 2003). Spt20 es una unidad estructural de un complejo de activación transcripcional que regula la expresión de Mid2 e interacciona con esta y con Spn2, colocalizando, por tanto, con el anillo de septinas. La deleción de Spt20 provoca defectos en la separación celular debidos a la falta del anillo de septinas o a un fallo en su ensamblaje causado por la falta de transcripción de Mid2 (Lei et al., 2014).

\section{LA PARED CELULAR DE S. pombe}

Las células fúngicas, al igual que las bacterias y las células vegetales poseen una pared celular hecha de polisacáridos que puede considerarse equivalente a la matriz extracelular de las células animales, pero es más resistente y rígida y es esencial para su supervivencia. Esta pared es externa a la célula y por tanto debe crecer con ella y soportar todos los cambios que esta experimenta durante el ciclo de división (Durán and Pérez, 2004).

\subsection{Composición de la pared celular}

Estudios mediante microscopía electrónica de la pared celular de $S$. pombe muestran una estructura de tres capas (Osumi, 2012). Dos capas densas a los electrones en los lados externo e interno formadas por galactomanano que constituye la parte sacarídica de las glicoproteínas de la pared (9-14\% del total pared), y una capa central transparente a los electrones compuesta de $\beta$-glucanos y $\alpha$-glucanos $(54-60 \%$ y $28-32 \%$ de la pared respectivamente). Esta capa contiene fibras cristalinas de $\beta$-(1,3)-glucano que proporcionan rigidez a la pared celular, ramas de glucano $\beta-(1,6)$ que aumentan la resistencia de la pared y $\alpha$-(1,3)-glucano que funciona como un factor de agregación esencial para la integridad celular (Bush et al., 1974; García Cortés et al., 2016; Grun et al., 2004; Humbel et al., 2001; Kopecká et al., 1995; Manners and Meyer, 1977) (Figura $6)$. 
Cuando las células de S. pombe forman un septo de división, en el microscopio electrónico se observa una estructura de tres capas con un septo primario central principalmente hecho de $\beta$-(1,3)-glucano lineal que desaparece tras la separación celular y dos septos secundarios externos que son similares a la pared celular pero inicialmente no tienen una capa externa de galactomanano (G. Cortés et al., 2018).

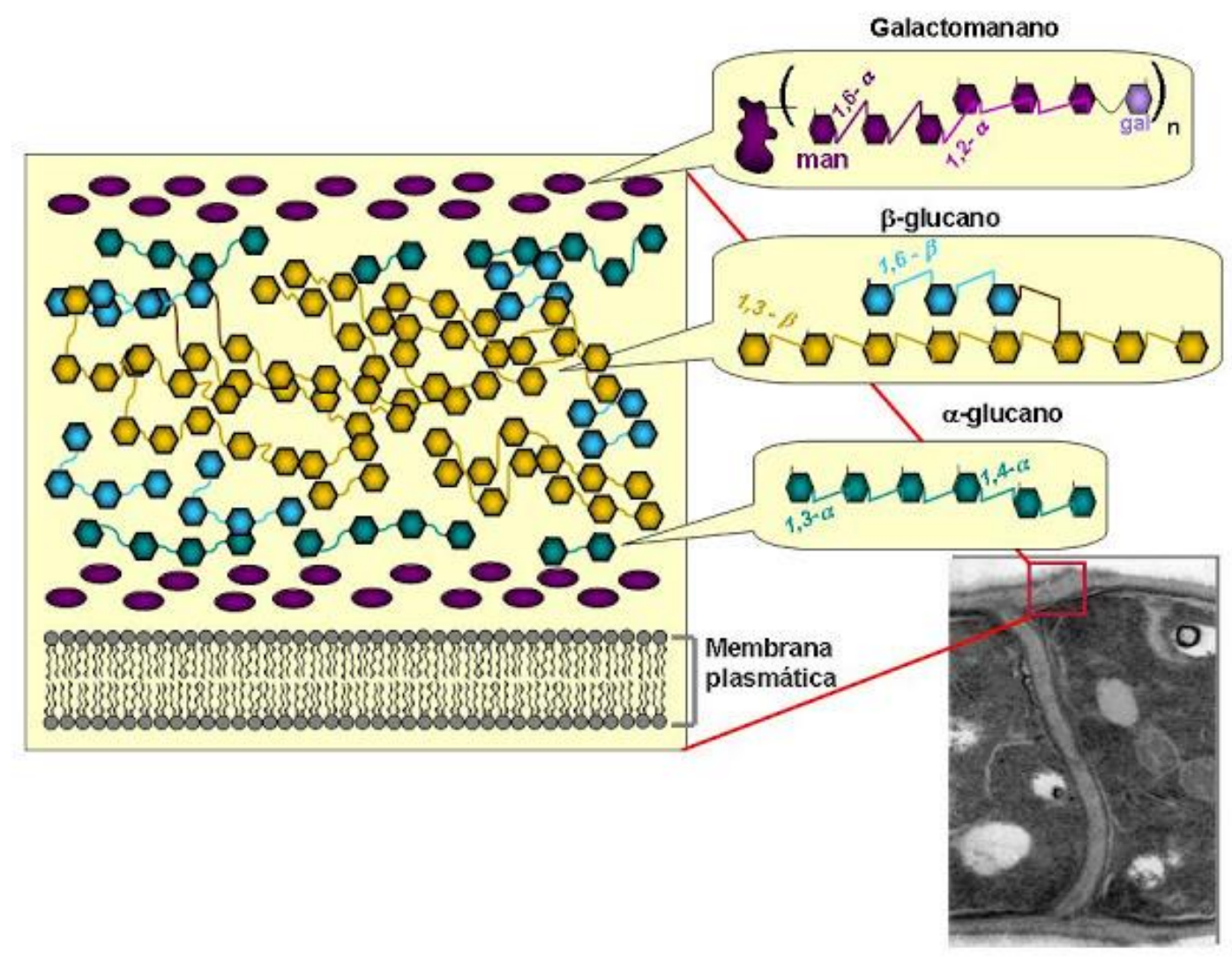

Figura 6.- Pared celular de S. Pombe. La pared celular de la levadura de fisión consta de 3 capas, la central está formada por $\beta$-(1-3)-D-glucano con ramificaciones de $\beta$-(1-6)-D-glucano y por $\alpha$-(1-3)-Dglucano con ramificaciones de $\alpha-(1-4)-D-g l u c a n o$. Esta se encuentra flanqueada por dos capas de galactomanano. Adaptado de de Medina-Redondo et al., 2010.

Las enzimas encargadas de la síntesis del $\beta$ glucano son las $\beta$-(1-3)-glucán-sintasas, unas proteínas transmembranales de alto peso molecular formadas por una subunidad catalítica y una subunidad reguladora (Arellano et al., 1996; Drgonová et al., 1996; Kang and Cabib, 1986). Se han identificado 4 genes codificantes para las subunidades catalíticas de las $\beta$-glucán-sintasas $b g s 1^{+}, b g s 2^{+}, b g s 3^{+}$y $b g s 4^{+}$, todas ellas esenciales. Bgs1, Bgs3 y Bgs4 están implicadas en la síntesis de pared celular durante el crecimiento vegetativo y Bgs2 participa en esporulación (García Cortés et al., 2016). Estas proteínas presentan una gran similitud con las $\beta$-glucán-sintasas de $S$. cerevisiae Fks1 y Fks2. Sin embargo, estas últimas tienen un papel redundante mientras que en la levadura de fisión cada glucán-sintasa tiene un papel distinto y no solapante (García Cortés et al., 2016; Mazur et al., 1995). Bgs1, Bgs3 y Bgs4 se localizan en la zona de división, en los polos celulares y en zonas de crecimiento de pared celular durante la 
diferenciación sexual (Cortés et al., 2016). Bgs1 es la enzima responsable de la síntesis del $\beta$-glucano lineal (Cortés et al., 2007). Además, se ha identificado una proteína de membrana, Sbg1, que interacciona con Bgs1 y cuya pérdida de función lleva a una reducción del $\beta$-glucano lineal. Esta proteína es parecida a Kre6 en S. cerevisiae y podría participar en el transporte de Bgs1 a la zona de división (Sethi et al., 2016).

Bgs4 es la responsable de la síntesis del $\beta$-glucano ramificado mayoritario en la pared celular y es necesaria para la formación del septo secundario durante la citocinesis (Cortés et al., 2005). La deleción de Bgs4 o el tratamiento específico con ciertos inhibidores de las glucán-sintasas provocan la lisis celular, fundamentalmente durante la septación (Cortés et al., 2005; Martins et al., 2011). El papel de Bgs3 en la biosíntesis de pared es aún desconocido (Martín et al., 2003).

Aunque existen 4 subunidades catalíticas distintas de las glucán-sintasas, únicamente se ha descrito una subunidad reguladora de todas ellas que es la GTPasa Rho1. Para activar la síntesis de $\beta$-glucano, Rho1 debe anclarse a la membrana plasmática y estar unida a GTP (Arellano et al., 1999). La GTPasa Rho1 es capaz también de unirse a las protein-quinasas de la familia PKC, Pck1 y Pck2, en su extremo N-terminal y actúa protegiéndolas de su degradación y permitiendo que sean activadas por la quinasa dependiente de fosfolípidos denominada Ksg1 (Madrid et al., 2015, 2017). Por su parte, Pck1 y Pck2 también son capaces de aumentar la actividad de las $\beta$-glucánsintasas (Arellano et al., 1999) (Figura 7).

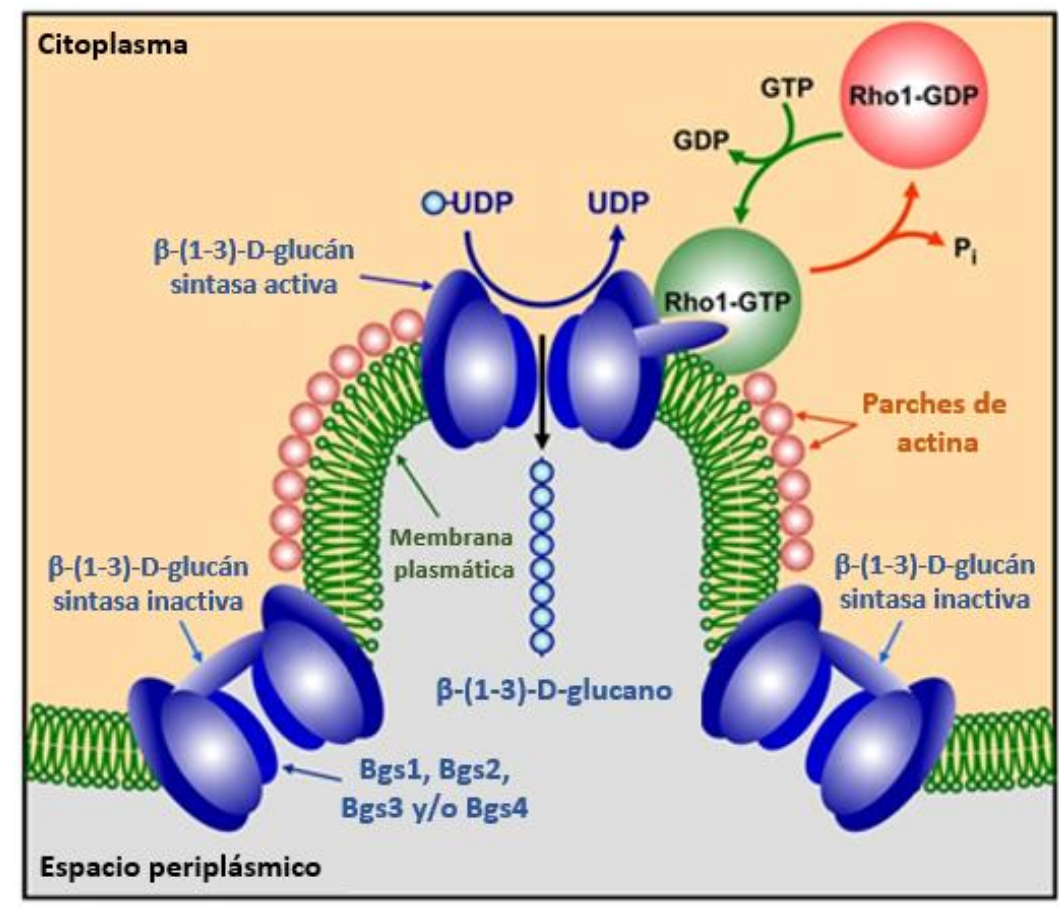

Figura 7.- Formación de $\boldsymbol{\beta}$-glucano por la $\boldsymbol{\beta}$-glucán-sintasa. La GTPasa Rho1 es el principal regulador de las $\beta$-glucán-sintasas. La hidrólisis de GTP en la isoforma activa de Rho1 confiere la energía necesaria a la glucán-sintasa para polimerizar el $\beta$-glucano. Adaptado de Cortés et al., 2016. 
La biosíntesis del $\alpha$-glucano depende de la enzima Ags1/mok1 (Garcia et al., 2006; Hochstenbach et al., 1998; Katayama et al., 1999). Es una proteína esencial de 272 $\mathrm{KDa}$, con múltiples dominios transmembrana, un dominio sintasa citoplasmático encargado de añadir los residuos de glucosa y un dominio transglicosidasa extracelular implicado probablemente en el entrecruzamiento del $\alpha$-glucano con otros componentes de la pared celular (Vos et al., 2007). Ags1, al igual que las $\beta$-glucánsintasas, se localiza en el septo, en los polos de crecimiento y en los lugares de crecimiento durante la fase sexual (Cortés et al., 2012; Konomi et al., 2003). La quinasa Pck2 es necesaria para la localización de Ags1 (Calonge et al., 2000).

\section{LAS GTPasas DE LA FAMILIA RHO EN S. pombe}

Las GTPasas de la familia Rho (Ras Homology) forman parte de la superfamilia de las proteínas Ras que se han conservado en todas las células eucariotas desde levaduras hasta mamíferos (Madaule and Axel, 1985). Estas GTPasas son moléculas pequeñas de entre 20-40 KDa que ciclan entre su estado activo unidas a GTP y su estado inactivo unidas a GDP. Las GTPasas Rho están implicadas en diversas funciones celulares como la morfogénesis y la polaridad, la migración celular o la citocinesis mediante la regulación de la formación y contracción del CAR (Hodge and Ridley, 2016). Para ejercer su función las proteínas Rho requieren anclarse a la membrana, para ello sufren cambios postraduccionales en su extremo carboxilo que consisten en la incorporación de grupos isoprenoides seguida de una proteólisis y metilación (Bustelo et al., 2007). Algunas GTPasas también son modificadas mediante palmitoilación (Sanchez-Mir et al., 2014).

Los factores intercambiadores de nucleótidos de guanina o GEF (Guanine nucleotide Exchange Factor) promueven el cambio de unión de GDP a GTP activando así a estas GTPasas (Rossman et al., 2005). Por otra parte, las proteínas denominadas GAPs (GTPase Activating Protein) incrementan la actividad intrínseca de hidrólisis de GTP de las GTPasas y así las inactivan (Moon and Zheng, 2003). Existen más GEFs y GAPs que proteínas Rho, por lo que una misma GTPasa puede ser regulada por más de un GEF o GAP, lo que permite el control y especificidad de las distintas vías de señalización en las que intervienen las GTPasas (Bos et al., 2007). Otros reguladores de las GTPasas son los denominados inhibidores de la disociación de guanina o GDI (Guanine Disociation Inhibitor) que secuestran a las GTPasas unidas a GDP en el citoplasma previniendo que se localicen en las membranas y sean activadas por los GEF o que sean degradadas (Cherfils and Zeghouf, 2013; DerMardirossian and Bokoch, 2005; Olofsson, 1999). Además, las GTPasas pueden ser reguladas mediante fosforilación, ubiquitinación y otras modificaciones postraduccionales (Hodge and Ridley, 2016; Lang et al., 1996). En S. pombe existen 6 miembros de esta familia: Rho1-5 y Cdc42, de las cuales solo Rho1 y Cdc42 son esenciales para la viabilidad celular (Arellano et al., 1999). 


\subsection{Rho1}

Rho1 es, como hemos mencionado, la principal GTPasa que interviene en la formación de la pared celular y es esencial para la viabilidad celular. Presenta $73 \%$ y $67 \%$ de similitud frente a sus homólogos Rho1 de S. cerevisiae y RhoA de Homo sapiens respectivamente (Nakano and Mabuchi, 1995). Cuando se reprime la expresión de Rho1, se sobreexpresa el alelo constitutivamente inactivo rho1T20N o se expresa un alelo en el que la función de Rho1 se encuentra comprometida, como rho1-596, las células presentan una reducción del glucano en la pared celular debido a una reducción de las actividades $\beta$-(1-3) glucán-sintasa y $\alpha$-glucán-sintasa. Además se observan defectos en el citoesqueleto, fundamentalmente la disminución de los cables de actina y microtúbulos aberrantes (Arellano et al., 1997). Por otro lado, en las células que sobreexpresan Rho1 o el alelo constitutivamente activo rho1G15V aparecen cúmulos de actina y una pared celular mucho más gruesa con células encadenadas incapaces de dividirse, indicando un papel de Rho1 en la división celular (Arellano et al., 1997).

Rho1 se localiza en las zonas de crecimiento, polos celulares, y en la zona de división (Arellano et al., 1997). Se han identificado tres GEFs de Rho1: Rgf1, Rgf2 y Rgf3. Rgf1 es el principal activador de Rho1 a lo largo del ciclo vegetativo, es necesario para la transición a NETO y para mantener la integridad celular (García et al., 2006). Además este GEF es también responsable de la activación de Rho1 en el núcleo de la célula que es necesaria para la reparación del daño al ADN (Manjón et al., 2017; Muñoz et al., 2014). Rgf2 está implicado en el proceso de esporulación y colabora con Rgf1 durante el ciclo vegetativo (García et al., 2009). Rgf3 es esencial y activa a Rho1 durante la citocinesis (Mutoh et al., 2005; Tajadura et al., 2004). Hasta la fecha se han descrito tres GAP de Rho1: Rga1, su principal regulador negativo (Nakano et al., 2001a); Rga5, implicado en la regulación de la citocinesis (Calonge et al., 2003) y Rga8 cuya función se desconoce (Yang et al., 2003).

Las principales proteínas activadas por Rho1 son las quinasas Pck1 y Pck2 cuya deleción simultánea es letal puesto que estas proteínas regulan conjuntamente la activación de las $\beta$-glucán-sintasas (Arellano et al., 1999). Pck2 es también activada por Rho2 y participa en la localización de la $\alpha$-glucán-sintasa, aunque el mecanismo se desconoce (Calonge et al., 2000) y además, juega un papel principal junto con esta GTPasa en la activación de la ruta de la MAP quinasa de integridad, Pmk1 (Ma et al., 2006). Rho1 y Pck1 también participan en la respuesta de activación de Pmk1 a ciertos estímulos como el daño en la pared celular (García et al., 2009; Sanchez-Mir et al., 2014). 


\section{$3.2 \operatorname{Cdc} 42$}

Cdc42 es esencial y está implicada el crecimiento polarizado y en el mantenimiento de la morfología cilíndrica de $S$. pombe, presentando una identidad del $85 \%$ respecto a su homólogo de S. cerevisiae (Miller and Johnson, 1994). Su deleción provoca un cambio en la morfología de las células que pierden la polaridad y se redondean (Miller and Johnson, 1994). Cdc42 se localiza en todas las membranas celulares, pero cuando se activa se concentra en la membrana plasmática de las áreas de crecimiento (Bendezú et al., 2015; Estravís et al., 2011, 2017). El control espacial de la activación de Cdc42 determina la morfología de S. pombe y se realiza mediante los GEFs y GAPs de Cdc42. Dos GEFs, Scd1 y Gef1, regulan su activación y la eliminación de ambos es letal (Coll et al., 2003). Scd1 parece jugar un papel prominente en el control de la morfología celular y Gef1 en la citocinesis (Coll et al., 2003). Recientemente se ha propuesto que Scd1 actúa como el principal activador de Cdc42 en las áreas de crecimiento, mientras que Gef1 es una proteína citosólica y se asocia con la membrana plasmática en situaciones de estrés actuando como un activador global de Cdc42 (Tay et al., 2018). Se han descrito tres GAPs que inactivan a Cdc42: Rga3, Rga4 y Rga6, de las cuales las dos últimas proteínas se localizan en los lados de la célula (Gallo Castro and Martin, 2018; Revilla-Guarinos et al., 2016; Tatebe et al., 2008) y contribuyen a restringir la actividad de Cdc42 en los polos celulares (Revilla-Guarinos et al., 2016). Rga3 se localiza en los sitios de crecimiento y también en las zonas de la membrana plasmática con Cdc42 activa durante la conjugación y actúa inestabilizando a Cdc42-GTP y su complejo señalizador. En consecuencia, las células que carecen de Rga3 se hiperpolarizan y tienen defectos en la conjugación (Gallo Castro and Martin, 2018).

Se han descrito dos tipos de proteínas transmisoras de la señal de Cdc42 que son: la formina For3, responsable de la formación de los cables de actina de interfase, y las quinasas de la familia PAK, Pak1/Shk1 y Pak2/Shk2 (Perez and Rincón, 2010). La quinasa Pak1/Shk1 participa en la citocinesis y es esencial el crecimiento polarizado puesto que las células que llevan el alelo mutante hipomorfo de esta quinasa orb2-34 presentan morfología redondeada (Polverino et al., 1995). Las dianas de Pak1 descritas hasta la fecha incluyen Tea1 (Kim et al., 2003), Rga8 (Yang et al., 2003), la miosina de tipo I Myo1 asociada con los parches de actina (Attanapola et al., 2009) y la cadena ligera reguladora de las miosinas Rlc1, que forma parte del anillo contráctil (Loo and Balasubramanian, 2008).

\section{LA FOSFATASA CALCINEURINA}

La calcineurina es una fosfatasa de tipo 2B dependiente de $\mathrm{Ca}_{2}^{+} /$calmodulina y uno de los cuatro tipos principales de fosfatasas específicas de serina o treonina presentes en las células eucariotas (Cohen, 1989). Aunque fue descubierta en el tejido neuronal, está distribuida por todas las células y muy conservada desde las levaduras al hombre 
(Klee and Krinks, 1978; Wang and Desai, 1977). Esta fosfatasa es un heterodímero formado por una subunidad catalítica (Calcineurina A) de unos $60 \mathrm{KDa}$ y una subunidad reguladora (Calcineurina $B$ ) de 19 KDa (Klee et al., 1979; Lu et al., 2002a). La subunidad catalítica posee una región $\mathrm{N}$-terminal catalítica y una región reguladora formada por un dominio helicoidal de unión a la subunidad reguladora, calcineurina $B$ (Watanabe et al., 1995), un dominio de unión a calmodulina (Kincaid et al., 1988) y un dominio autoinhibidor (Hashimoto et al., 1990) (Figura 8).

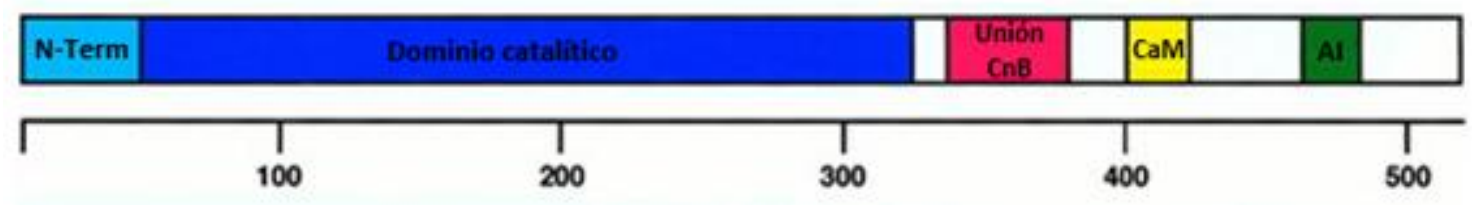

Figura 8.- Estructura de los dominios de la Calcineurina A. La calcineurina posee un dominio catalítico en su región $\mathrm{N}$-terminal mientras que en su extremo C-terminal posee una región reguladora formada por un dominio de unión a la calcineurina $\mathrm{B}(\mathrm{CaB})$, un dominio de unión a calmodulina (CaM) y un dominio autoinhibidor (Al). Adaptado de Rusnak and Mertz, 2000.

Para la activación de la subunidad catalítica se requiere la unión tanto de la calcineurina B como de la calmodulina. Sin embargo, mientras la calcineurina B está fuertemente asociada, la calmodulina se une de forma transitoria. La calcineurina desfosforila a los aminoácidos serina o treonina de forma poco selectiva, por lo que es necesario un fuerte control de su activación e inhibición para dar especificidad a su señalización. Este control está mediado por picos transitorios de calcio que se unen a los dominios EF-hand de la calcineurina B y de la calmodulina (Mehta et al., 2014). La calcineurina B posee 4 dominios EF-hand, de estos, los sitios 3 y el 4 presentan una mayor afinidad por la calmodulina, mientras que la de los sitios 1 y 2 es inferior (Gallagher et al., 2001; Kakalis et al., 1995). Los sitios de mayor afinidad siempre tienen una molécula de calcio unida y su función es estabilizar el heterodímero con la subunidad catalítica. Los sitios de baja afinidad sirven como sensor de calcio para regular a la subunidad A permitiendo la unión de calmodulina. Para su total activación, a la calcineurina $A$ (forma I) se le une la subunidad reguladora activada por la unión a calcio (forma II), esto libera al dominio de unión de la calmodulina. Cuando los niveles de calcio aumentan se produce la activación de la calmodulina que provoca un cambio en su estructura y le permite unirse a una hélice alfa de la subunidad A (forma III). Esta interacción desplaza al dominio autoinhibidor de la fosfatasa dejando libre el sitio activo (forma IV) (Li et al., 2011; Stemmer and Klee, 1994; Yang and Klee, 2000) (Figura 9). En S. cerevisiae se ha descrito que esta fosfatasa también puede ser activada por el ion $\mathrm{Mn2}^{+}$aunque de forma menos eficiente (Ren et al., 2009). 


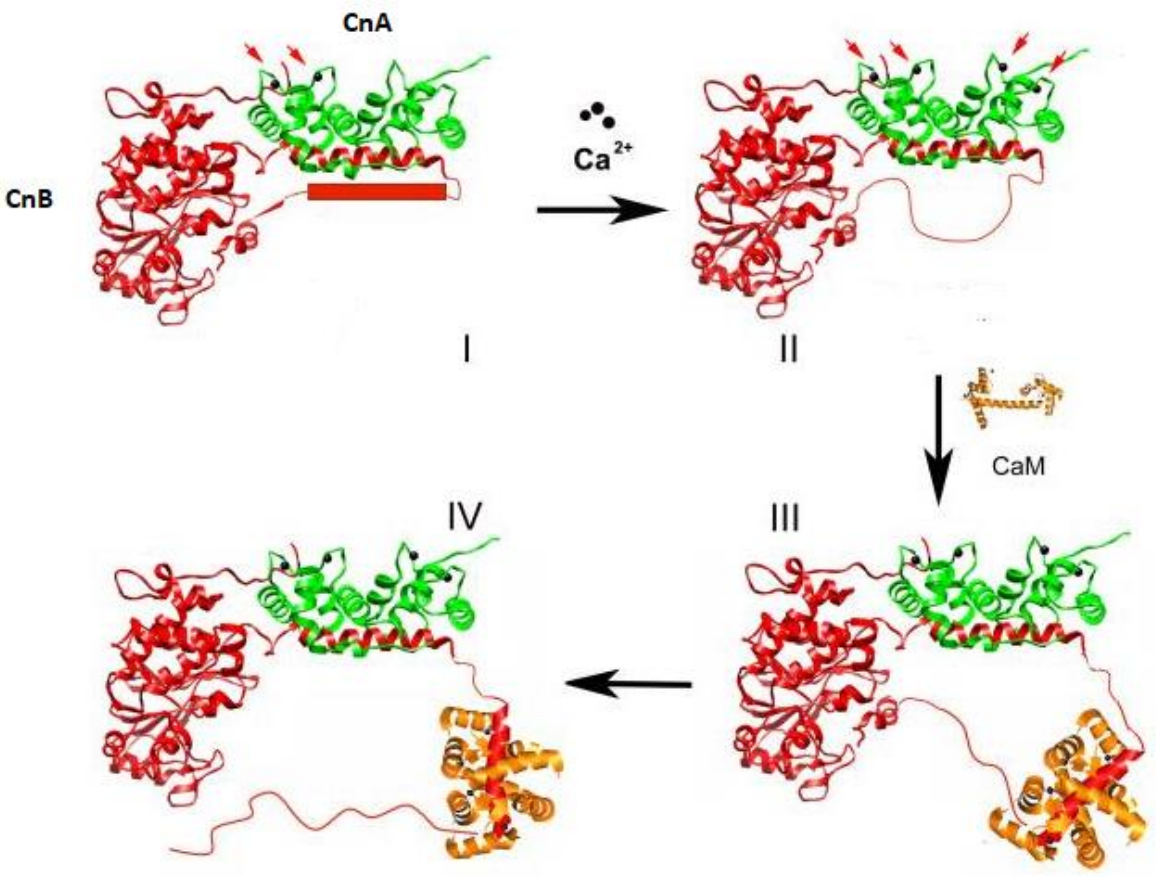

Figura 9.- Estados de activación de la calcineurina. La unión de calcio libera el dominio de unión de la calmodulina (forma II), la unión de esta (forma III) desplaza el dominio autoinhibidor obteniendo la forma completamente activa (forma IV). Adaptación de Li et al., 2011.

El sitio catalítico de la subunidad $A$ está formado por láminas $\beta$ que interaccionan con dominios PxIxIT presentes en otras proteínas que también forman estas estructuras (Li et al., 2007). Este motivo se encuentra muy degenerado lo que hace que existan distintas variantes con diferente afinidad por la calcineurina. Además esta fosfatasa también reconoce el motivo LxVP cuya función es orientar el sustrato para su correcta desfosforilación (Roy and Cyert, 2009). La calcineurina es potencialmente inhibida por los compuestos inmunosupresores FK506 y ciclosporina A. Se ha visto que el lugar de unión de estos compuestos solapa con el sitio de unión LxVP, por lo que estos compuestos impedirían la correcta orientación del sustrato (Roy and Cyert, 2009). La elevada variabilidad del motivo PxIxIT hace que la calcineurina tenga numerosos sustratos potenciales por lo que la interacción por el dominio LxVP le confiere especificidad a la unión (Nygren and Scott, 2016). Se han identificado alrededor de 75 sustratos directos de la calcineurina, aunque la reciente utilización de inhibidores de esta fosfatasa como FK506 o ciclosporina A están siendo de utilidad para la identificación de nuevos sustratos (Roy and Cyert, 2019).

En células animales existen tres isoformas de la subunidad catalítica $A(\alpha, \beta \circ \gamma)$ junto con dos isoformas de la subunidad reguladora B (tipo 1 y tipo 2) (Kuno et al., 1989; Nygren and Scott, 2016). Esta fosfatasa está implicada en numerosos procesos, en linfocitos $\mathrm{T}$ el principal papel de la calcineurina es la activación del factor de transcripción NFAT. Su desfosforilación provoca un cambio conformacional que expone 
una señal de localización nuclear y permite que NFAT se transloque al núcleo, activando la expresión de varios genes (Li et al., 2011). En las neuronas el canal de potasio TRESK que tiene un bucle entre los dominios transmembrana 2 y 3 con un motivo PxIxIT es sustrato de la calcineurina (Li et al., 2007). También se ha propuesto que la calcineurina podría regular el estado de fosforilación de los receptores AMPA en el hipocampo del cerebro implicados en la plasticidad sináptica, limitando la incorporación de calcio mediante vesículas (Sanderson et al., 2012). Además, la calcineurina es reclutada por diferentes proteínas adaptadoras de la vía de señalización de la insulina (Hinke et al., 2012) y participa en la función cardiaca (Li et al., 2010; Santana et al., 2002).

\subsection{La calcineurina en hongos}

En hongos se ha descrito ampliamente el papel de la calcineurina en la respuesta a estrés, en virulencia, en integridad celular, en morfogénesis, en la progresión del ciclo celular y en la homeostasis de iones (Fox and Heitman, 2002; Kraus and Heitman, 2003). En Aspergillus fumigatus la subunidad catalítica de la calcineurina CnaA, al igual que en mamíferos, mantiene el dominio de unión a calmodulina necesario para su activación y el dominio autoinhibidor, mientras que la subunidad reguladora $\mathrm{CnaB}$ conserva los dominios de unión a calcio (Juvvadi et al., 2011). Ambas subunidades se localizan en pequeñas estructuras móviles que van de los polos al septo y en las zonas de crecimiento, es decir, en la membrana de los polos y del septo de las hifas. La localización de la subunidad catalítica $\mathrm{CnaA}$ en el septo es independiente de la subunidad reguladora $\mathrm{CnaB}$, aunque esta última si necesita de la primera para localizarse. Todavía se desconoce la proteína encargada de la localización de la subunidad catalítica CnaA en el septo (Juvvadi et al., 2011). La calcineurina interacciona con sus sustratos a través de los dominios PxIxIT y LxVP presentes en ellos mediante la secuencia FMDVF de la subunidad catalítica. Las mutaciones en los aminoácidos F368 y F372 de esta secuencia producen la deslocalización de la subunidad catalítica de la calcineurina de la zona de división. Aún no se ha estudiado la funcionalidad de este dominio en otros hongos (Juvvadi et al., 2011).

La deleción de los genes codificantes de ambas subunidades produce células con ramificaciones irregulares y septos aberrantes (Juvvadi et al., 2011). Estos defectos en la formación del septo son muy similares a los observados en la deleción de los genes codificantes para quitin-sintasa. Se ha propuesto que la calcineurina podría estar implicada en la activación de estas sintasas para la formación del septo (Juvvadi et al., 2014). La deleción de la calcineurina también produce defectos en la pared celular, probablemente debidos a la inactivación de la vía de la señalización de la proteinquinasa C (PKC) mediada por el factor de transcripción Crz1, como ocurre en la levadura de gemación S. cerevisiae (Juvvadi and Steinbach, 2015). 
En A. fumigatus la calcineurina puede ser fosforilada en una secuencia rica en serina y prolina (SPRR). Los mutantes fosfonulos de esta región poseen ramificaciones irregulares y un crecimiento disminuido. Tanto la quinasa dependiente de ciclina CDK1 como la MAP quinasa Pmk1 han demostrado tener la capacidad de fosforilar a la calcineurina in vitro en esta región. El tratamiento con el inhibidor FK506 produce una disminución del estado de fosforilación de CnaA, por lo que este compuesto, además de actuar sobre la propia calcineurina, podría inhibir a las quinasas encargadas de activarla (Juvvadi and Steinbach, 2015; Juvvadi et al., 2013).

En los hongos patógenos como Candida albicans o Cryptococcus neoformans la calcineurina está implicada en la vía de señalización de respuesta a estrés regulando genes como RCN1, al igual que en S. cerevisiae (Reedy et al., 2010). Además, en $C$. albicans la subunidad catalítica está implicada en el crecimiento de las hifas y, por ello, esta fosfatasa es considerada esencial en el proceso de virulencia de este hongo (Bader et al., 2003). De igual forma, la subunidad catalítica de la calcineurina de $C$. neoformans regula la expresión de ciertas proteínas necesarias para la patogénesis y su eliminación impide el crecimiento de este hongo, disminuyendo su virulencia (Odom et al., 1997). Se ha descrito que esta fosfatasa posee un papel similar en la respuesta a estrés o la regulación del ciclo celular y crecimiento de las hifas, y por tanto, en la virulencia de otros hongos como Aspergillus oryzae, Aspergillus nidulans o Neurospora crassa (Juvvadi et al., 2011).

\subsection{La calcineurina en S. cerevisiae}

En la levadura de gemación la calcineurina está formada por dos isoformas de la subunidad catalítica, Cna1 o Cmp2 (Cna2), y una subunidad reguladora Cnb1 que no son esenciales para la viabilidad celular (Cyert and Thorner, 1992; Cyert et al., 1991; Liu et al., 1991). No obstante, si son esenciales en condiciones de estrés como temperaturas elevadas, estrés de retículo, $\mathrm{pH}$ alcalino o problemas en la pared celular (Bonilla et al., 2002; Lagorce et al., 2003; Serrano et al., 2004). Esta fosfatasa participa, junto con la ruta MAPK de integridad celular, en la respuesta a daños en la pared y en la activación del factor de transcripción Crz1. Este factor de transcripción, como NFAT, migra al núcleo cuando se activa por desfosforilación e induce la expresión de varios genes, entre ellos el de la glucán-sintasa FKS2. De esta forma la ruta de integridad mantiene altos los niveles de expresión de este gen mientras dure el estrés de pared (Matheos et al., 1997; Stathopoulos and Cyert, 1997; Zhao et al., 1998). La calcineurina también modula la respuesta a estrés por sales mediante la regulación de la bomba de sodio Pmr2 de forma indirecta a través de Crz1 y directamente mediante modificaciones postraduccionales en los canales de potasio Trk1 (Mendoza et al., 1994, 1996; Nakamura et al., 1993). Además la calcineurina regula el calcio intracelular inhibiendo el canal vacuolar Vcx1, implicado en el secuestro de calcio (Garrett-Engele 
et al., 1995; Tanida et al., 1995) y la expresión de las bombas de calcio Pmc1 y Pmr1 mediante Crz1 (Cunningham and Fink, 1994). La calcineurina también está implicada en la parada de las células en G1 que se genera tras la producción de un pico de calcio que produce la activación de la fosfatasa durante el proceso de conjugación (Heitman et al., 1993). Además, en la levadura de gemación la calcineurina también desfosforila y activa a Rga2, un GAP de la GTPasa Cdc42, para inhibir la vía de señalización de respuesta a feromonas (Ly and Cyert, 2017). El análisis de todos estos sustratos de la calcineurina en la levadura de gemación se utilizó para identificar los motivos de interacción con la fosfatasa, PxIxIT y LxVP (Roy and Cyert, 2009).

\subsection{La calcineurina en S. pombe}

En la levadura de fisión existe una subunidad catalítica y una subunidad reguladora que están codificadas por los genes $p p b 1^{+}$y $c n b 1^{+}$respectivamente, ninguno de ellos esencial (Sio et al., 2005; Yoshida et al., 1994). La deleción de $p p b 1^{+}$produce un defecto en el crecimiento a temperaturas bajas, sensibilidad al ion cloruro, defectos en citocinesis, polaridad celular, integridad celular, conjugación, esporulación y posicionamiento del SPB (Plochocka-Zulinska et al., 1995; Yoshida et al., 1994; Sugiura et al., 1998; Sugiura et al., 1999; Kume et al., 2011). La deleción de Ppb1 provoca hipersensibilidad a $\mathrm{Cl}_{2} \mathrm{Mg}$ y se ha visto que la vía de señalización de la MAPK Pmk1 es necesaria para dicha hipersensibilidad (Sugiura et al., 1998). Además, la deleción presenta interacción génica con la de otras fosfatasas como Dis2 o Ppa2. La deleción de $c n b 1^{+}$produce un fenotipo similar a la deleción de la subunidad catalítica con un aumento de células en septación, la formación de células encadenadas y un retraso en la citocinesis (Fan et al., 2013). Los niveles de expresión de calcineurina no sufren grandes cambios a lo largo del ciclo celular salvo en condiciones de estrés como la carencia de nitrógeno donde se produce un aumento de expresión mediado por el factor de transcripción Ste11 (Plochocka-Zulinska et al., 1995). La activación de la calcineurina mediante la entrada de calcio en la levadura de fisión viene determinada por los canales Prm1, Pmc1 (Cortés et al., 2004) y el canal Cch1-Yam8 (Ma et al., 2011).

En este organismo la calcineurina activa al menos dos rutas de señalización distintas, una dependiente del factor de transcripción Prz1 (homólogo de Crz1) y otra independiente de Prz1, siendo esta última antagónica a la ruta de la MAPK Pmk1 (Hirayama et al., 2003). Prz1 es capaz de reconocer secuencias nucleotídicas denominadas "elementos de respuesta dependiente de calcineurina" (CDRE) en los promotores de los genes diana, induciendo su expresión (Chatfield-Reed et al., 2016). Ante situaciones de estrés se promueve la activación de la calcineurina que induce la desfosforilación y traslocación de Prz1 al núcleo, activando la expresión de varios genes de forma dependiente de los CDRE (Higa et al., 2015). Entre los genes con estos elementos en el promotor se encuentra el propio $p r z 1^{+}$, generándose un feedback loop 
positivo (Deng et al., 2006). Además, los genes que codifican los canales Prm1 y Pmc1 que permiten la entrada de más calcio también poseen CDRE en sus promotores formándose otros feedback loop positivos, de esta forma, la calcineurina amplifica su propia activación (Maeda et al., 2004). Los elementos CDRE se utilizan para medir la actividad de la calcineurina mediante la fusión al gen de la luciferasa o a una proteína fluorescente. Así, cuando la calcineurina esté activa, se produce la activación del factor de transcripción Prz1 que reconoce los CDRE e inicia la expresión de la proteína reportera, que será proporcional a la activación de la calcineurina en la célula (Deng et al., 2006).

En S. pombe existe un homólogo de los sensores neuronales de calcio (NCS) que está codificado por $n c s 1^{+}$. La transcripción de este sensor es dependiente de Prz1 (Hamasaki-Katagiri and Ames, 2010). El fenotipo de la deleción de $n c s 1^{+}$se suprime mediante la eliminación del canal de calcio Cch1-Yam8. Además, la entrada de calcio y la unión de Ncs1 a la membrana están disminuidas en la deleción de Yam8, lo que sugiere que esta proteína se une al canal de calcio para cerrarlo. De esta forma, ante una elevada concentración de calcio, Prz1 activa la transcripción de Ncs1 que se une al canal y lo cierra para que se finalice la señalización (Hamasaki-Katagiri and Ames, 2010). Además, la entrada de calcio activa a la quinasa $C k k 2$, que a su vez activa a la quinasa Cmk1 y esta fosforila a Prz1, regulando negativamente su actividad. La propia expresión de Cmk1 también está regulada por Prz1 formándose un feedback loop negativo que finaliza la señalización mediante Prz1 (Cisneros-Barroso et al., 2014).

Prz1 no participa en la función que ejerce la calcineurina en el retraso de la transición a NETO hasta que la replicación del DNA este completa (Kume et al., 2011). La quinasa Cds1 fosforila a la calcineurina, que es capaz de desfosforilar a Tip1, una proteína que se asocia a los extremos positivos de los microtúbulos y modula su dinámica en ambos polos de manera asimétrica para el retraso en la transición a NETO (Kume et al., 2011). La quinasa Cki3 actúa en paralelo a Tip1 en el retraso en la transición a NETO y es activada también mediante su desfosforilación por la calcineurina (Koyano et al., 2015). Prz1 tampoco participa en la función de la calcineurina en la homeostasis de cloro, en la citocinesis y en la viabilidad celular (Sugiura et al., 1998).

\section{LA CALMODULINA COMO PROTEÍNA REGULADORA Y ADAPTADORA}

La calmodulina es una proteína conservada en organismos eucariotas que está formada por dos dominios terminales, cada uno de ellos con dos motivos EF-Hand capaces de unir una molécula de calcio, conectados por un linker muy flexible. Estos dominios presentan distinta afinidad por el calcio, siendo mayor en el dominio $\mathrm{N}$ terminal. La unión de calcio produce un cambio conformacional que expone los sitios hidrofóbicos y le permiten la interacción con otras proteínas como la calcineurina. Por este motivo la calmodulina es considerada como una de las principales proteínas en 
cargadas de regular la señalización mediada por calcio en eucariotas (Villalobo et al., 2018). Además, la calmodulina es una proteína adaptadora que permite la unión de dos proteínas con las que es capaz de interaccionar de forma simultánea. Esto se debe a que, al estar formada por dos extremos que unen calcio de forma independiente, la calmodulina puede ejercer de nexo entre dos proteínas iguales o diferentes favoreciendo la interacción entre ellas (Villalobo et al., 2018).

En mamíferos esta proteína está implicada en la interacción y activación de varias fosfatasas como la MAPK fosfatasa I (Ishida et al., 2009) o la calcineurina (Chyan et al., 2017; Klee et al., 1979) y de varias quinasas como la quinasa dependiente de calcio/calmodulina II (CaMKII), implicada en plasticidad sináptica junto con la calcineurina (Heidarinejad et al., 2018). La calmodulina también regula la actividad de otras proteínas señalizadoras como los receptores de estrógenos, la glutamato descarboxilasa o diversos canales de $\mathrm{Ca}^{++}$o $\mathrm{K}^{+}$en las neuronas (Villalobo et al., 2018). También se ha descrito que la calmodulina, mediante su dominio C-terminal, interacciona con RalA y RalB, dos GTPasas que pertenecen a la familia de las GTPasas Rho y esta interacción necesaria para la activación de la GTPasas mencionadas (Clough et al., 2002). En la GTPasa Rac1 se ha identificado una secuencia entre los aminoácidos 151 y 164 que está implicada en su interacción con la calmodulina y es esencial para su activación (Xu et al., 2012).

El compuesto inhibidor W7 ha sido caracterizado como el principal antagonista de la calmodulina actuando sobre varias bombas como la de $\mathrm{Na}^{+} / \mathrm{H}^{+}$sin alterar la endocitosis (Hunziker, 1994), aunque también se han identificado otros inhibidores como el tamoxifeno (Lam, 1984). Actualmente el tamoxifeno es el tratamiento antitumoral de referencia frente a muchos tipos de cáncer de mama debido a su gran afinidad por los receptores de estrógenos impidiendo su dimerización y activación mediada por la calmodulina (de Médina et al., 2004).

En S. cerevisiae la calmodulina es una proteína esencial codificada por el gen CMD1 (Davis et al., 1986) que interacciona con diferentes sustratos de forma dependiente e independiente de calcio (Cyert, 2001). De esta forma interacciona con Spc110 para regular su localización en el SPB (Stirling et al., 1994) y con las miosinas de clase $V$ Myo2 y Myo4 en ambos casos de forma independiente de calcio (Cyert, 2001). Además la calmodulina posee un papel muy importante en la endocitosis y el tráfico de vesículas también de forma independiente de calcio (Geli et al., 1998; Grötsch et al., 2010; Kübler et al., 1994). Por otro lado, la calmodulina también regula a algunas quinasas como $\mathrm{Cmk1}$ o $\mathrm{Cmk} 2$ y algunas fosfatasas como la calcineurina o el complejo PP2B de manera dependiente de calcio (Cyert, 2001). 


\subsection{La calmodulina en S. pombe}

En la levadura de fisión la calmodulina esta codificada por el gen $\operatorname{cam}^{+}$y se localiza en las zonas de crecimiento polarizado y en el SPB (Moser et al., 1997). La calmodulina de S. pombe presenta más homología con la de vertebrados que con la de $S$. cerevisiae (Takeda and Yamamoto, 1987). Esta proteína es esencial para el crecimiento vegetativo, puesto que las esporas carentes de este gen no superan la primera división celular durante la germinación (Takeda and Yamamoto, 1987). La cepa mutante termosensible cam1-E14 no tiene defectos en la síntesis y duplicación del DNA, pero deja de ser viable durante la mitosis porque presenta problemas en la segregación de los cromosomas debido a los defectos en el SPB (Moser et al., 1997). Por otra parte, la cepa mutante cam1-F116 posee defectos en la encapsulación de los 4 núcleos formados tras la conjugación, por lo que Cam1 está implicada en el proceso de formación de esporas (Takeda et al., 1989). Este último mutante presenta unos niveles de Cam1 total inferiores a los de la cepa silvestre y las diferencias se agudizan en ausencia de compuestos nitrogenados en el medio, por lo que estos son esenciales para la estabilidad de la proteína (Takeda et al., 1989). Se han caracterizado también otras cepas mutantes de Cam1 que han servido para estudiar el papel de esta proteína en la segregación cromosómica y en la esporulación (Itadani et al., 2010; Moser et al., 1995). La capacidad de la calmodulina de unir calcio es necesaria para la viabilidad celular, pues solo el $25 \%$ de las células que poseen 3 de los sitios de unión a calcio mutados y un único sitio funcional eran viables (Moser et al., 1995). Al igual que en mamíferos, se ha observado que cada uno de los sitios presenta distinta afinidad por el calcio. El sitio 3 presenta más afinidad por calcio que el resto, aunque esta mayor afinidad no influye en su importancia funcional, siendo el sitio 2 el más necesario seguido del sitio 1, el sitio 4 y el sitio 3 (Moser et al., 1995) (Figura 10).

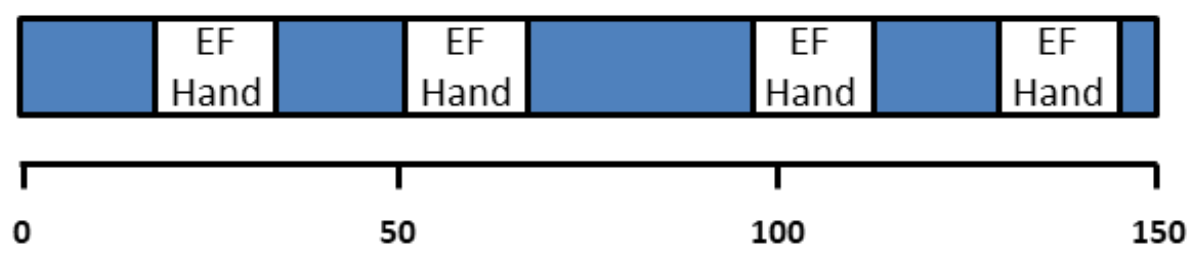

Figura 10.- Estructura de los dominios de la Calcineurina A. La calcineurina posee 4 dominios EF-hand mediante los que une calcio para activarse.

La calmodulina posee diversas funciones durante el crecimiento vegetativo que ejerce mediante su interacción con distintas proteínas. Así, Myo51 necesita asociarse con la calmodulina para interaccionar con Rng8 y Rng9 (Tang et al., 2016). Además la calmodulina interacciona con Myo1 también mediante el dominio IQ de la miosina (Toya et al., 2001), por lo que tiene una función en endocitosis. La calmodulina es también capaz de interaccionar con Rng2, un componente esencial del CAR, por lo que 
Cam1 podría estar implicada en la citocinesis (Eng et al., 1998). Además, Cam1 es necesaria para el reclutamiento de 3 proteínas: Spo2, Spo13 y Spo15 al SPB que participan en la formación de la membrana de las esporas (Itadani et al., 2010). Se han descrito muchas otras interacciones de la calmodulina con otras proteínas en el SPB como Pcp1 o Sha1 (Craig and Norbury, 1998; Flory et al., 2002) o con algunas quinasas como Cmk1 (Rasmussen, 2000), sin embargo, no se ha estudiado su posible papel en la regulación de las GTPasas de la familia Rho a pesar de que el sitio de interacción con la calmodulina está conservado en estas proteínas.

\section{LA CITOCINESIS EN S. pombe}

El ciclo celular de S. pombe comienza con un crecimiento monopolar en el polo antiguo de la célula, seguido de un crecimiento bipolar. Cuando el tamaño celular es el apropiado comienza la fase final conocida como citocinesis en la cual se produce la segregación de los componentes celulares para dar lugar a dos células hijas. En la levadura de fisión, al igual que en las células animales, la citocinesis comienza cuando se marca la localización del futuro surco de división. Esta viene determinada por la posición del núcleo y la localización de Mid1, una proteína similar a la anilina de mamíferos, en la región central de la célula. La colocación precisa del sitio de división es muy importante para la formación de dos células hijas iguales, cada una con su propio núcleo. El proceso continúa, igual que en las células animales, con el ensamblaje de un anillo contráctil (CAR) que incluye miosinas de tipo II, filamentos de actina y otras proteínas que también proporcionan el anclaje del CAR a la membrana. Tras la formación del CAR, en los hongos comienza la formación del septo de división que es simultánea a la contracción del CAR (Perez et al., 2016; Pollard y Wu, 2010).

El mecanismo de citocinesis mediante la formación del CAR apareció hace millones de años en un ancestro común entre las células animales, las amebas y los hongos. Por ello, estos organismos comparten la mayoría de los genes implicados en citocinesis y esto permite aplicar muchos de los conocimientos adquiridos en $S$. pombe a las células animales. Hasta hoy se han identificado más de 100 genes implicados en la citocinesis de la levadura de fisión y se han obtenido mutantes condicionales de casi todos ellos. El estudio de estos mutantes junto con el marcaje de las proteínas con epítopos fluorescentes para poder observarlas mediante microscopía ha permitido establecer una línea temporal de todos los eventos de la citocinesis (Pollard, 2008; Pollard and $\mathrm{Wu}, 2010)$. 


\subsection{Selección del sitio de división y formación de nodos}

A pesar de que la citocinesis es un proceso muy conservado, la selección del sitio de división varía de unos organismos a otros. En células animales la localización del surco de división viene determinada por la posición del huso mitótico (Glotzer, 2004). En S. cerevisiae las septinas determinarán el plano de división y reclutan a otros factores al lugar de división, que se producirá en una zona adyacente o enfrentada a la división anterior (Carroll et al., 1998; Marston et al., 2001). En S. pombe, a diferencia de la levadura de gemación y de los mamíferos, el sitio de división viene determinado por la posición del núcleo en la zona media, que a su vez depende de los microtúbulos interfásicos y por la presencia en la membrana de la proteína Mid1 (Daga et al., 2006; Pollard y Wu, 2010).

El inicio de la citocinesis viene definido por la duplicación del SPB. Durante la interfase, Mid1 se localiza mayoritariamente en el núcleo y en la región perinuclear, hasta una hora antes del inicio de la citocinesis, en que pasa a localizarse en nodos corticales de la zona central (Bähler et al., 1998a; Padte et al., 2006; Paoletti and Chang, 2000). La polo quinasa Plo1 es la encargada de liberar a Mid1 del núcleo antes de la mitosis (Bähler et al., 1998a; Paoletti and Chang, 2000). La cepa mutante mid1 1 presenta un fenotipo con anillos de actomiosina aberrantes y septos deslocalizados debido a que la selección del sitio de división no se produce correctamente y por tanto el ensamblaje del CAR no se produce en la región central (Wu et al., 2003). La interacción entre Mid1 y la quinasa $\mathrm{Cdr} 2$ es esencial para la formación de los denominados nodos citocinéticos en la zona media de la célula durante interfase (Almonacid et al., 2009; Moseley et al., 2009). Cdr1 y Cdr2 son dos quinasas que fosforilan e inhiben a Wee1, que es la quinasa que se encarga de mantener a la célula en G2 al inhibir a la quinasa Cdk1/Cdc2 (Martin and Berthelot-Grosjean, 2009; Moseley et al., 2009).

La quinasa Pom1 establece un punto adicional de regulación del sitio de división puesto que en la cepa mutante pom1 $1 \Delta$, Mid1 se extiende hacia el polo, esto provoca que el anillo contráctil no se ensamble en la zona central de la célula (Celton-Morizur et al., 2006; Padte et al., 2006). Por tanto, la localización de la quinasa Pom1 en ambos polos delimita la localización de los nodos a la zona media de la célula. Esto permite a Mid1 y Cdr2 interaccionar para que esta última, junto a Cdr1, fosforile a Wee1 y la inhiba. La inhibición de Wee1 aumenta la actividad de la quinasa Cdc2 y se inicia la mitosis (Martin and Berthelot-Grosjean, 2009; Rincon et al., 2014). Las primeras proteínas comienzan a localizarse en los nodos unos diez minutos antes de la duplicación del SPB. Estas son: la cadena pesada de las miosinas Myo2; la proteína de ensamblaje del anillo de actomiosina Rng2, ortóloga de lqg1 en S. cerevisiae; la proteína adaptadora con dominio F-BAR Cdc15 que participa en el anclaje del CAR a la membrana y la formina Cdc12 (Wu and Pollard, 2005). Algunas de las proteínas mencionadas anteriormente como Cdr2 solo se mantienen en los nodos hasta el comienzo del ensamblaje del CAR y luego desaparecen (Moseley et al., 2009). En el 
caso de Cdr2, esta proteína es fosforilada por la quinasa de la ruta de inicio de la septación (SIN), lo cual favorece su interacción con la proteína Rad24 que la lleva al citoplasma al final de la división celular (Rincon et al., 2017) (Figura 11).

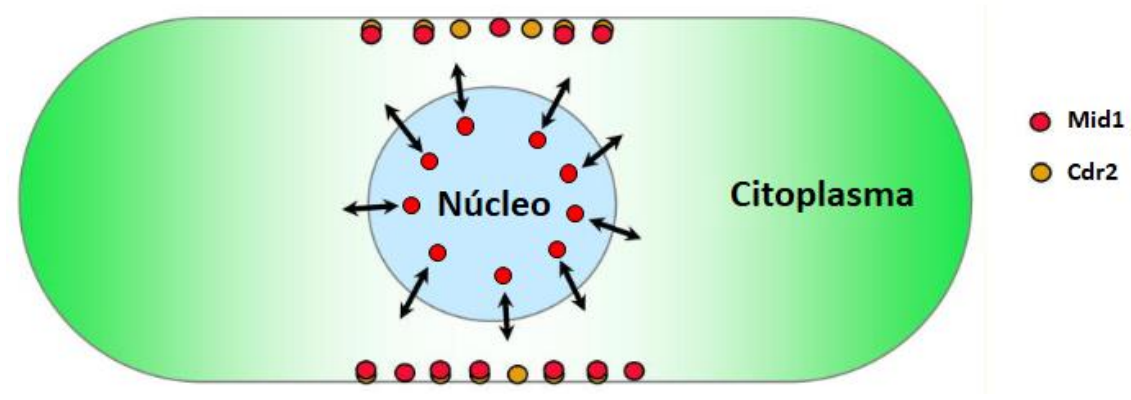

Figura 11.- Selección del sitio de división. La posición del núcleo en la zona central determina el lugar de división. Mid1 sale del núcleo e interacciona con Cdr2 para formar los nodos. Adaptado de Bathe and Chang, 2010.

\subsection{Ensamblaje del anillo contráctil de actomiosina}

El ensamblaje de los filamentos de actina para la formación del CAR no sucede hasta 2 minutos después de la duplicación del SPB y son sintetizados por la formina Cdc12 (Kovar et al., 2003; Yonetani et al., 2008). La profilina Cdc3 es una proteína que puede interaccionar con los monómeros de actina y con secuencias ricas en prolina, y junto con Cdc12, está implicada en el ensamblaje de los filamentos de actina del CAR. Cdc12 produce la nucleación de los monómeros de actina para la formación de los filamentos, mientras que la profilina se une a los dominios ricos en prolina de Cdc12 (FH1/2) colaborando en la elongación de estos filamentos. Cdc12 junto con Cdc3 son capaces de anclar los filamentos de actina a los nodos (Chang et al., 1997; Lu and Pollard, 2001; Paul et al., 2008). La tropomiosina Cdc8 también se puede unir a los filamentos de actina y regular a Cdc12 en la elongación de los filamentos de actina (Skau et al., 2009) (Figura 12).

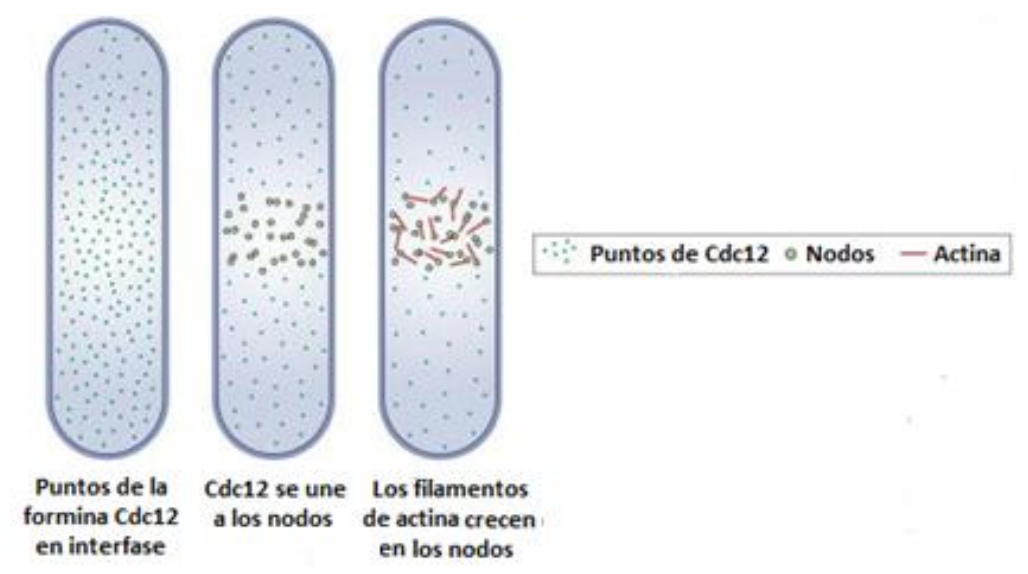

Figura 12. - Nucleación de los filamentos de actina en los nodos. La formina Cdc12 pasa a localizarse en los nodos y comienza a producir los filamentos de actina. Adaptado de Pollard y Wu, 2010. 
Una vez se ha iniciado la nucleación de los filamentos de actina en los nodos, éstos comienzan a moverse de forma estocástica. A partir de este punto existen dos modelos que explican el ensamblaje del CAR. El modelo de múltiples nodos, más aceptado, propone que durante los siguientes 8 minutos Myo2 va capturando los filamentos de actina que surgen de los diferentes nodos haciendo finalmente que estos se condensen en la zona media (Pollard y Wu, 2010; Vavylonis et al., 2008). El segundo modelo propone que los filamentos de actina se polimerizan a partir de un solo nodo en el que estaría el complejo Cdc12-Cdc15. A partir de ese punto se extienden los filamentos de actina formando el CAR (Arai and Mabuchi, 2002; Carnahan and Gould, 2003; Kamasaki et al., 2007; Willet et al., 2015). La proteína entrecruzadora de filamentos de actina Ain1 sería la encargada unir los filamentos formando un anillo, aunque su deleción no provoca defectos en el CAR (Coffman et al., 2009). Por tanto, todavía se desconoce la mecanística concreta de la formación del anillo de actomiosina en S. pombe (Pollard y Wu, 2010) (Figura 13).
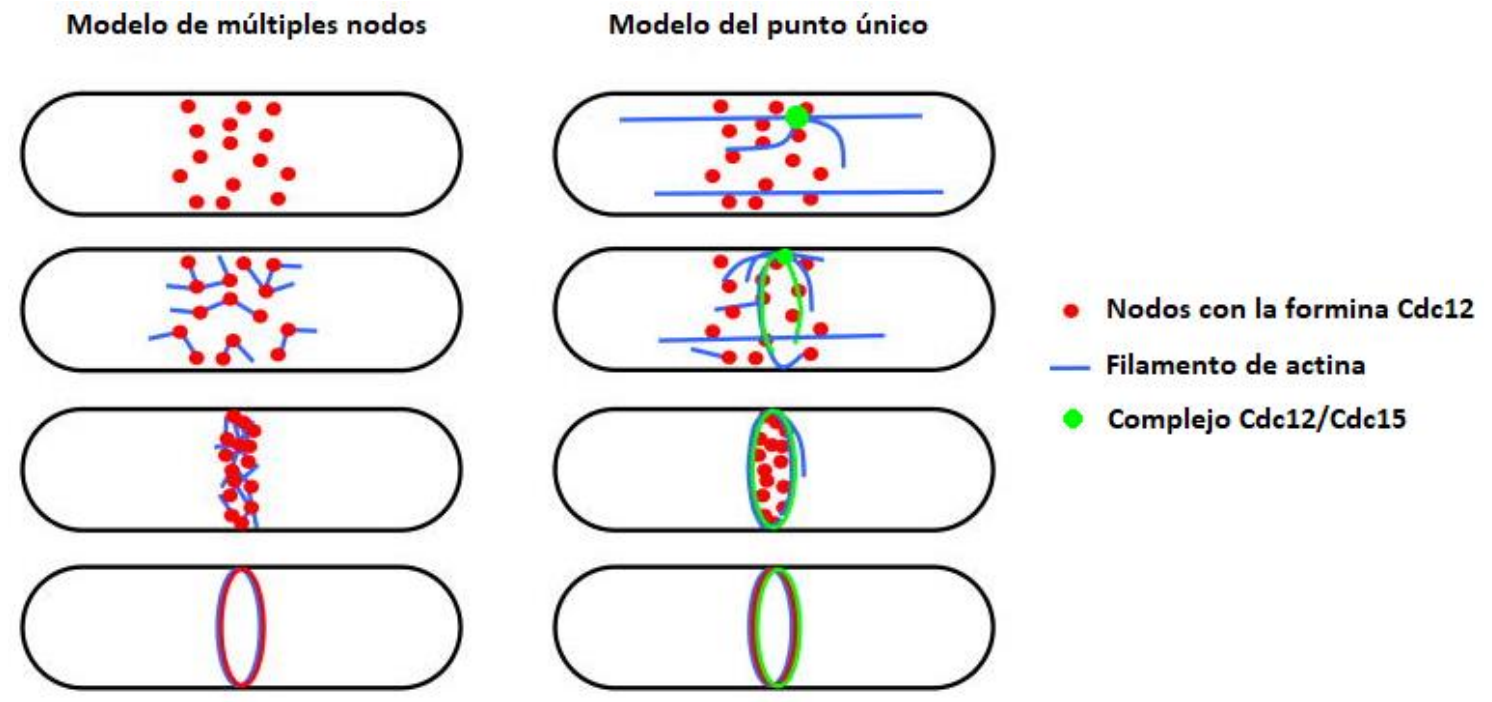

Figura 13.- Modelos de ensamblaje del anillo de actomiosina. El modelo de múltiples nodos establece que Myo2 acaba agrupando los diferentes nodos hasta formar el CAR. El modelo del punto único propone que los filamentos de actina se producen a partir de un único punto formado por el complejo Cdc12/Cdc15. Adaptado de Bathe and Chang, 2010.

\subsection{Maduración del anillo de actomiosina}

Una vez ensamblado el CAR, entre 11 y 35 minutos después de la duplicación del SPB, se produce el denominado proceso de maduración del anillo de actomiosina (Pelham and Chang, 2002). En esta fase el CAR está formado aproximadamente por unos 150 dímeros de Cdc12, 2.900 de Myo2 y entre 1.000 y 2.000 filamentos de actina (Kamasaki et al., 2007; Wu and Pollard, 2005). En esta etapa, las dimensiones del CAR se mantienen más o menos constantes y sus componentes se van renovando continuamente (Clifford et al., 2008a; Pelham and Chang, 2002). Así, durante la 
maduración del CAR se produce un recambio de los filamentos de actina debido a la pérdida de los ya existentes y a la formación de nuevos filamentos. Los mutantes de Cdc12 que tienen reducida su eficacia de polimerización de actina también tienen un recambio disminuido tanto de filamentos de actina como de la propia Cdc12 (Yonetani et al., 2008). La dinámica del CAR también está regulada por la fosfatasa Clp1, que es reclutada al CAR por Mid1 (Clifford et al., 2008a). Durante la etapa de maduración llegan al CAR otras proteínas como Myp2 o Imp2 y poco a poco va desapareciendo Mid1. También llegan al CAR y se unen, mediante los dominios SH3 de las proteínas Cdc15 o Imp2, otra serie de proteínas como la paxilina Pxl1 o la proteína con dominio C2 Fic1 (Roberts-Galbraith et al., 2009). Se ha sugerido que la actividad motora de Myo2 puede estar inhibida durante la maduración mediante la fosforilación de Rlc1 por la quinasa Pak1, activándose nuevamente durante la constricción del CAR (Loo and Balasubramanian, 2008a; Naqvi et al., 2000). De esta forma, la actividad motora de Myo2 podría regular el momento de formación y constricción del CAR. No obstante, durante la maduración del CAR se produce un recambio de sus componentes por lo que Myo2 debe de estar parcialmente activa. Por tanto, la constricción del CAR debe estar inhibida también por otras vías de señalización (Lee et al., 2012). Estudios recientes han demostrado que la formación del septo y el surco de división se inicia antes de lo que se había descrito, durante la anafase temprana, independientemente de la finalización de la mitosis y, por tanto, durante la etapa descrita como maduración del CAR (G. Cortés et al., 2018). En esa fase se produce también un septo incipiente que apenas se contrae y por eso no se había detectado anteriormente (G. Cortés et al., 2018).

\subsection{Componentes del anillo contráctil de actomiosina}

Además de actina y miosina, el CAR está formado por un total de más de 100 proteínas, de las cuales algunas son esenciales, que llegan y se van conforme el CAR se ensambla y se contrae. Algunas de estas proteínas poseen funciones específicas conocidas en el CAR como servir de anclaje a la membrana plasmática, mientras que de otras proteínas su función concreta todavía es desconocida (Ren et al., 2015).

Cuando el CAR se observa mediante microscopía de alta resolución se ve que sus componentes están dispuestos en diferentes capas respecto a la membrana celular

(Figura 14). La actina, al igual que las cadenas de la miosina II, se localiza de forma homogénea en la capa más distal de la membrana (McDonald et al., 2017). Algunas quinasas como Pak1, Sid2 o Pck1 se disponen en las capas más próximas a la membrana, mientras que otras como Pom1 se localizan en una zona intermedia a pesar de sus motivos de unión a membrana (Hachet et al., 2011; McDonald et al., 2017). Se ha sugerido que Pom1 podría localizarse en el CAR mediante la unión de su región rica en prolinas a los dominios $\mathrm{SH} 3$ de Cdc15 o Imp2. Las diferentes proteínas F- 
BAR Cdc15, Imp2 y Rga7 se encuentran en distintas capas, Cdc15 forma grupos en la capa más proximal. Sin embargo, el dominio C-terminal de Myo2 o el dominio SH3 de Cdc15 se encuentran en la capa intermedia junto con Imp2 y Rga7. Así, las 3 proteínas con dominio F-BAR se encuentran próximas entre sí formando complejos gracias a su capacidad de oligomerizar y de reclutar proteínas como Rgf3, Cyk3, Pxl1 o Fic1 (McDonald et al., 2017; Roberts-Galbraith et al., 2009). En la capa intermedia también se encuentran fosfatasas como la calcineurina o Clp1 o el GEF de la familia Rho denominado Gef2. Rng2 y Mid1 se encuentran en la capa más próxima a la membrana formando también complejos (McDonald et al., 2017). La estructura y función de estos componentes del CAR se desarrollarán en los siguientes apartados.

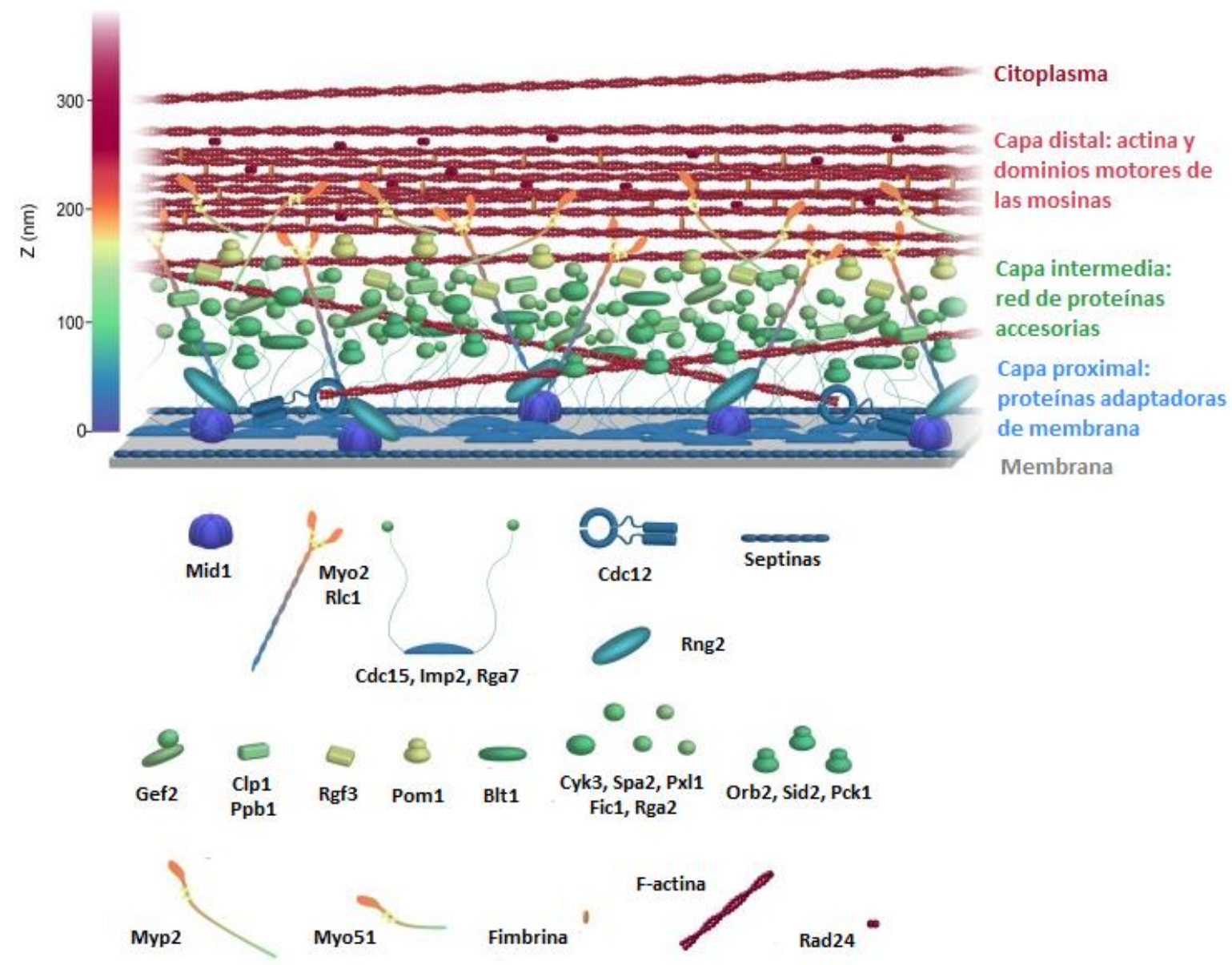

Figura 14.- Estructura y componentes del anillo de actomiosina. Los componentes del CAR se distribuyen en diferentes capas respecto a la membrana plasmática. Adaptado de McDonald et al., 2017.

\subsubsection{Rng2}

Rng2 es una proteína esencial similar a la proteína IQGAP1 de células humanas y a lqg1 de $S$. cerevisiae. Es una de las primeras proteínas en llegar al anillo de actomiosina, localizándose en éste y en el SPB. (Eng et al., 1998; Epp and Chant, 1997). La localización de esta proteína en la zona de división depende de Mid1. Por tanto, se 
concentra en los nodos junto con los filamentos de actina unos 10 minutos antes de la división del SPB y se mantiene en el CAR durante su formación hasta su constricción (Pollard y Wu, 2010; Wu et al., 2003). La incorporación de Rng2 al anillo de actomiosina establece un ciclo de retroalimentación o feedback loop por el cual se produce más llegada de Mid1 a la zona de división (Laporte et al., 2011; Padmanabhan et al., 2011). Al contrario, una menor localización de Rng2 provoca menor concentración de Mid1 en la zona de división lo que hace que otras proteínas reclutadas por Mid1 como Cdc15 también disminuyan su presencia (Tebbs and Pollard, 2013).

Rng2 se caracteriza por ser una proteína adaptadora con un dominio calponina en su extremo N-terminal capaz de unir actina (Takaine et al., 2009). Este dominio es seguido por una serie de dominios IQ que a su vez contiene secuencias EF-hand mediante las cuales Rng2 es capaz de interaccionar físicamente con la calmodulina Cam1 y con Cdc4 (D’souza et al., 2001a; Dixon et al., 2012). La deleción de los dominios IQ provoca defectos en la localización de las glucán-sintasas como Bgs1 y en la activación de la ruta de inicio de la septación (SIN) que coordina el inicio de la formación del septo (Johnson et al., 2012). En su extremo C-terminal posee un dominio GRD (GAP-related domain) aunque no se ha demostrado interacción con ninguna GTPasas (Tebbs and Pollard, 2013). Rng2 además recluta al CAR a otras proteínas como Myo2 o Rlc1 (Laporte et al., 2011; Tebbs and Pollard, 2013). Las células que expresan el alelo mutante termosensible $r n g 2-D 5$ crecidas a la temperatura restrictiva de $36^{\circ} \mathrm{C}$ no forman correctamente los filamentos de actina y no se produce la formación del anillo contráctil.

\subsubsection{Cdc15 y la familia de proteínas PCH}

La familia de proteínas PCH (Pombe Cdc15 Homology), de la que Cdc15 es el miembro fundador, son proteínas con un dominio F-BAR en su extremo $\mathrm{N}$-terminal y uno o varios dominios SH3 en su extremo C-terminal (Fankhauser et al., 1995; Lippincott and $\mathrm{Li}, \mathbf{2 0 0 0 )}$. Dentro de esta familia de proteínas existen 3 miembros en $S$. pombe: Cdc15, Imp2 y Bzz1 (Lippincott and Li, 2000). Todas ellas están implicadas en la organización del citoesqueleto de actina, aunque solo en el caso de las dos primeras se ha demostrado una función en la citocinesis (Arasada and Pollard, 2011; RobertsGalbraith et al., 2009) (Figura 15).

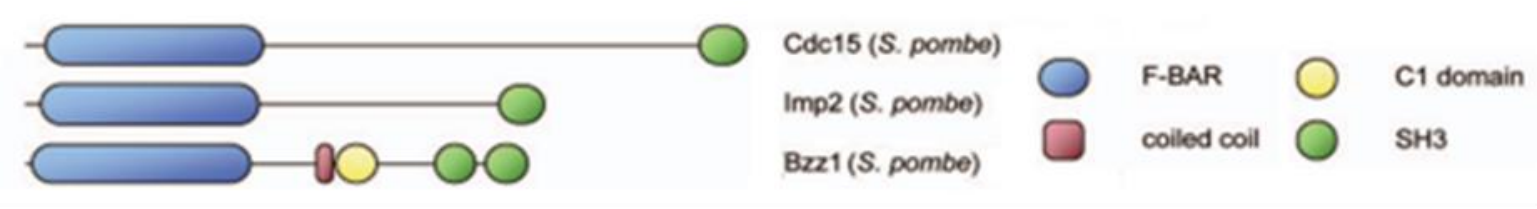

Figura 15.- Proteínas de la familia PCH en S. pombe. Adaptado de Roberts-Galbraith and Gould, 2010. 
Cdc15 es esencial para la viabilidad celular y las células en las que la funcionalidad de la proteína se encuentra reducida forman anillos aberrantes (Fankhauser et al., 1995). Su expresión está regulada por el factor de transcripción Sep1 y aumenta durante la citocinesis (Zilahi et al., 2000). Cdc15 se localiza en los nodos citocinéticos unos diez minutos antes de la división del SPB y colocaliza con el CAR en la zona media (Fankhauser et al., 1995). Durante la citocinesis une y recluta a Cdc12, al complejo Arp2/3 y a sus activadores Wsp1 y Myo1 a través del dominio F-BAR (Carnahan and Gould, 2003). Sin embargo, se ha visto que el complejo Arp2/3 no está implicado en la formación del CAR sino en la formación del septo (Wu et al., 2006). En la membrana plasmática del sitio de división celular se forman unas regiones denominadas lipids rafts ricas en esteroles (Takeda et al., 2004). Cdc15 se asocia a estas regiones formando dímeros mediante sus dominios F-BAR y proporciona el anclaje del CAR a la membrana plasmática a la vez que permite el reclutamiento de muchas proteínas al CAR mediante su dominio SH3 (McDonald et al., 2015).

Cdc15 es una fosfoproteína que se encuentra muy regulada, su fosforilación provoca un cambio conformacional con el cual se autoinhibe mientras que su desfosforilación durante la mitosis le confiere una conformación abierta que es capaz de oligomerizar, unirse a la membrana plasmática y al resto de componentes del CAR. Así en los mutantes fosfonulos esta proteína es reclutada de forma temprana al sitio de división y a las zonas de endocitosis (Roberts-Galbraith et al., 2010). Hasta hoy solamente se ha identificado a la fosfatasa Clp1 como reguladora parcial de la activación mediante desfosforilación de Cdc15 (Clifford et al., 2008; Wachtler et al., 2006). Por otro lado, se han idenficado diversas quinasas que fosforilan a Cdc15 en los polos como Kin1 o Pom1 (Lee et al., 2018). Esta última podría además fosforilar a Cdc15 en el CAR impidiendo su unión a Pxl1 o a Fic1, desestabilizando el CAR y disminuyendo su velocidad de constricción (Ullal et al., 2015) (Figura 16).

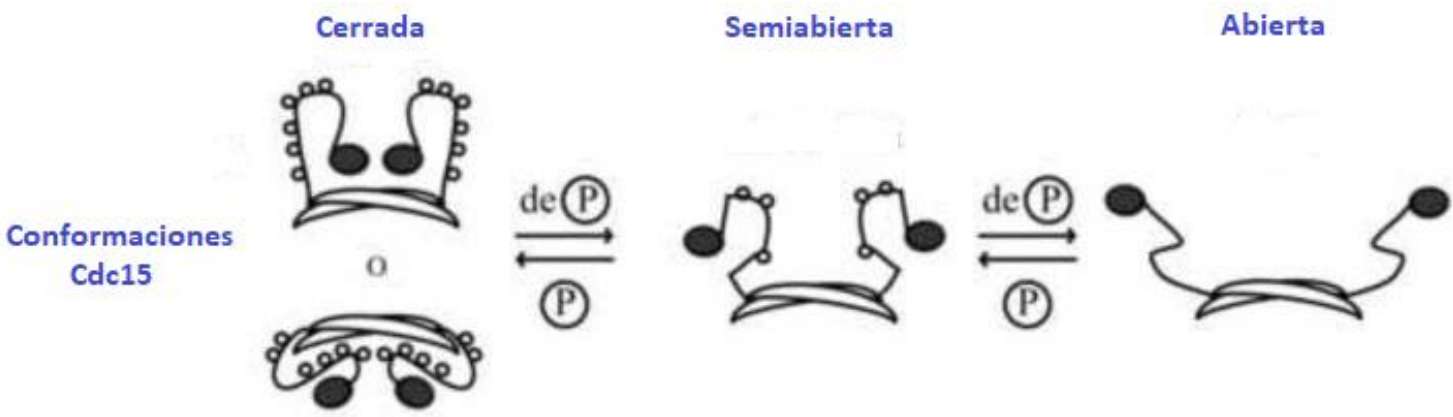

Figura 16.- Conformaciones de Cdc15. La desfosforilación de Cdc15 provoca un cambio en su conformación, favoreciendo la unión a otras proteínas. Adaptado de Roberts-Galbraith et al., 2010.

Imp2 es otra proteína de la familia PCH que se localiza en el CAR. No es esencial y aparece en el anillo más tarde que Cdc15, a los 20 minutos tras la división del SPB (Ren et al., 2015). Está implicada en la regulación del citoesqueleto de actina durante la 
citocinesis (Demeter and Sazer, 1998). Las cepas que carecen de esta proteína presentan defectos en el CAR y su sobreexpresión produce la desaparición del CAR. Además, se ha demostrado una fuerte interacción génica con otros genes que codifican proteínas del CAR como Cdc15 o Cdc4 (Demeter and Sazer, 1998). La cepa mutante imp2-c3 muestra un fenotipo de multiseptación con septos engrosados que se agrava con el tratamiento del inhibidor de la calcineurina FK506. Este mutante también presenta defectos en el aparato de Golgi y en las vesículas de secreción y tiene una pared celular más reducida, lo que implica que también tiene un papel importante en la integridad celular (Kita et al., 2015).

La deleción del dominio SH3 de Cdc15 no es esencial a menos que el dominio SH3 de Imp2 también sea eliminado. Además, ambas regiones son parcialmente redundantes ya que pueden sustituirse entre sí sin observarse defectos drásticos en la célula (Roberts-Galbraith et al., 2009). Los dominios SH3 de Cdc15 e Imp2 reclutan numerosas proteínas al CAR como la paxilina Pxl1, la proteína con dominio C2 Fic1, el GEF Rgf3 o la proteína de anclaje a actina Cyk3 (Ren et al., 2015; Roberts-Galbraith et al., 2009). Estas proteínas se unen a SH3 mediante una región rica en prolinas y colaboran en la integridad del anillo de actomiosina previniendo su fragmentación. En ausencia de ambos dominios SH3 el CAR se forma en metafase, pero se desensambla durante anafase. Por tanto Cdc15 e Imp2 contribuyen al mismo proceso pero con funciones distintas aunque parcialmente solapantes (Roberts-Galbraith et al., 2009). También se han identificado otras proteínas que llegan al CAR a través del dominio SH3 de Cdc15 e Imp2 como Art1 o Spa2 aunque su función específica en citocinesis no está clara (Davidson et al., 2015; Roberts-Galbraith et al., 2009).

\subsubsection{Pxl1}

En células animales la paxilina es una proteína adaptadora que se encuentra en las adhesiones focales de las células adherentes y está implicada en el control del citoesqueleto y en la movilidad celular. Esta proteína contiene cuatro dominios LIM en su extremo C-terminal y numerosas repeticiones de leucina en su extremo $\mathrm{N}$-terminal. La paxilina es capaz de unir y regular a diversas quinasas y fosfatasas y a la GTPasa RhoA (Brown and Turner, 2004; Carragher and Frame, 2004; Turner, 2000). En S. cerevisiae PxI1 posee dos dominios LIM y regula a Rho1, homólogo de RhoA, por ello afecta a la selección y mantenimiento del lugar de crecimiento de esta levadura (Gao et al., 2004; Mackin et al., 2004). En S. pombe Pxl1 contiene tres dominios LIM y también afecta a la función de Rho1. Sin embargo, no posee ningún papel en el crecimiento polarizado, sino que forma parte del CAR y participa en la citocinesis (Pinar et al., 2008; Ge and Balasubramanian 2008). px/1+ es un gen cuya expresión depende del factor de transcripción Ace2 que se expresa exclusivamente en citocinesis, alcanzando la máxima expresión al final de la mitosis (Alonso-Nuñez et al., 2005; 
Rustici et al., 2004). Pxl1 no es una proteína esencial y su deleción causa defectos durante la citocinesis con la aparición en cultivo de un elevado número de células septando y algunas multiseptadas y con septos deslocalizados. Además, aparecen anillos de actomiosina aberrantes y dobles producidos por un defecto de organización de la miosina. De igual forma, la constricción del CAR esta ralentizada en estas células, lo que indica que Pxl1 tiene un papel tanto en el mantenimiento como en la constricción del CAR. La cepa carente de paxilina presenta además unos niveles más elevados de Rho1 activa, indicando que Pxl1 podría ser un regulador negativo de Rho1 (Pinar et al., 2008). Existe interacción génica entre la deleción de $p x / 1^{+}$y mutaciones en los genes de la mayoría de los componentes del CAR, de las glucán-sintasas o de reguladores de la citocinesis como Mid1 (Pinar et al., 2008). Pxl1 interacciona con otros componentes del CAR como Myo2 o Cdc15. De hecho, esta última es responsable de la unión de Pxl1 al CAR mediante su dominio SH3 (Roberts-Galbraith et al., 2009). Además, se ha visto que Pxl1 coopera con la glucán-sintasa Bgs1 en la formación del surco de división y en el anclaje del anillo contráctil a la membrana al inicio de la septación (Cortés et al., 2015). Pxl1 tiene un dominio rico en prolinas en su región $\mathrm{N}$ terminal y tres dominios LIM en su región C-terminal. Estos últimos son los que dan la funcionalidad a la proteína mientras que su zona $\mathrm{N}$-terminal es necesaria para su localización, al contrario de lo que ocurre en S. cerevisiae donde los dominios LIM son los encargados de la localización (Gao et al., 2004; Mackin et al., 2004; Pinar et al., 2008).

\subsubsection{Fic1}

Fic1 es muy similar a la proteína Inn1 de $S$. cerevisiae implicada en la citocinesis (Bohnert and Gould, 2012). En S. pombe esta proteína posee un dominio C2 en su extremo $\mathrm{N}$-terminal y una zona rica en prolinas en su extremo $\mathrm{C}$-terminal con la que interacciona directamente con $\mathrm{Cdc} 15$ e Imp2 mediante los dominios SH3 de estas proteínas. Fic1 se sitúa en los polos y en el núcleo durante interfase mientras que en citocinesis se encuentra en el CAR, esta localización es dependiente de su dominio Cterminal rico en prolinas (Bohnert and Gould, 2012; Roberts-Galbraith et al., 2009). Además de Cdc15 e Imp2, Fic1 interacciona con otras proteínas del CAR como Rga7 (Martín-García et al., 2014) o Cyk3 (Bohnert and Gould, 2012; Devrekanli et al., 2012).

Fic1 no es esencial y su deleción no tiene defectos aparentes en la formación del anillo de actomiosina. No obstante, al final de la constricción en la cepa fic1 $\Delta$ algunos componentes del CAR como Rlc1 se mantienen en la zona de división, por lo que parece que Fic1 está implicada en el desensamblaje del anillo contráctil. Fic1 también podría estar implicada en la formación del septo primario y/o su degradación puesto que la glucanasa Eng1, responsable de la degradación del glucano lineal, se mantiene más tiempo en la zona de división de la cepa fic1 $($ Bohnert and Gould, 2012). En esta 
cepa también se ha observado un aumento del porcentaje de células con crecimiento monopolar. Esto indica que el desensamblaje del CAR y la maquinaria de división son necesarios para que se inicie el crecimiento en el polo nuevo. Así, otras cepas mutantes afectadas en los estadios finales de la citocinesis tienen defectos de polaridad similares a los de la cepa fic1 $\Delta$ (Bohnert and Gould, 2012). La deleción de fic $1^{+}$es sintética letal con la deleción de $p x / 1^{+}$y con la ausencia de dos reguladores de la citocinesis como la subunidad catalítica de la fosfatasa calcineurina o la quinasa de inicio de la septación Sid2 (Roberts-Galbraith et al., 2009).

\subsubsection{Cyk3}

Cyk3 fue descrita por primera vez en S. cerevisiae como una proteína involucrada la citocinesis (Korinek et al., 2000). En S. pombe esta proteína tiene un dominio SH3 en su extremo $\mathrm{N}$-terminal mientras que en su extremo C-terminal posee un dominio transglutaminasa (TGasa) muy conservado en hongos. Cyk3 se localiza en los polos y en el CAR. Esta proteína llega a la zona de división al final de la formación del anillo contráctil y se mantiene durante su constricción y la formación del septo (Pollard et al., 2012). Cyk3 se une al anillo mediante el dominio SH3 de Cdc15 y también interacciona con Fic1 (Bohnert and Gould, 2012; Ren et al., 2015). Cyk3 no es una proteína esencial, la cepa $c y k 3 \Delta$ presenta un ligero retraso en la formación del CAR, pero las células son viables sin defectos en su morfología o crecimiento a temperaturas entre $25^{\circ} \mathrm{C}$ y $32^{\circ} \mathrm{C}$. Sin embargo, a la temperatura de $36^{\circ} \mathrm{C}$ la cepa cyk3 3 muestra células alargadas, multiseptadas y multinucleadas y algunas células adquieren una forma redondeada, por lo que este gen está implicado en la citocinesis y también en la polaridad celular (Bohnert and Gould, 2012; Pollard et al., 2012). La deleción de $c y k 3^{+}$es sintética letal con mutantes termosensibles de otros componentes del CAR como Myo2, Cdc12 o

Cdc15 (Pollard et al., 2012). Sin embargo, cyk3 $\Delta$ no presenta letalidad sintética con myp $2 \Delta$ y en la cepa mutante doble $c y k 3 \Delta$ chs $2 \Delta$ se suprimen los defectos asociados a la pérdida de Cyk3 (Martín-García et al., 2003). Chs2 es una proteína similar a las quintin-sintasas de otros hongos que contribuyen a la formación del septo, aunque en S. pombe no tiene actividad enzimática. Por lo tanto, Cyk3 podría compartir una función con Myp2 y Chs2 uniendo la contracción del anillo de actomiosina con la formación del septo (Pollard et al., 2012).

\subsubsection{Rgf3 y Art1}

El GEF de Rho1 Rgf3 y la arrestina Art1 también se unen al dominio SH3 de Cdc15 y/o Imp2 (Ren et al., 2015). Rgf3 es una proteína esencial que activa a Rho1 y aumenta la cantidad de $\beta$-glucano (Tajadura et al., 2004; Mutoh et al., 2005). La deleción de Rgf3 causa defectos en los parches de actina, en el CAR y en la septación, dando lugar a la 
aparición de células ramificadas y a lisis celular que se produce cuando el septo primario empieza a ser degradado (Morrell-Falvey et al., 2005; Mutoh et al., 2005).

La arrestina Art1 forma un complejo con Rgf3 y su deleción provoca un fenotipo de lisis con septos defectuosos y más finos (Ren et al., 2015). Su localización depende de su extremo C-terminal mediante el cual también interacciona con Rgf3. Tanto los niveles de Rgf3 como su localización dependen a su vez de Art1 por lo que ambas proteínas son interdependientes (Davidson et al., 2015).

\subsubsection{Rga7}

Rga7 es, junto con Cdc15 e Imp2, una de las tres proteínas con dominio F-BAR que se han visto implicadas en citocinesis. Cdc15 llega al CAR antes que Rga7 e Imp2 mientras que estas llegan de forma simultánea. Además, se ha observado que Rga7 interacciona con Imp2 pero no se ha visto interacción con Cdc15 (Martín-García et al., 2014). Rga7 posee dominio GAP en su extremo C-terminal que le permite inactivar a Rho2 y, por tanto, a la ruta MAPK de integridad celular (Soto et al., 2010; Villar-Tajadura et al., 2008) pero no parece esencial para sus funciones durante la citocinesis, mientras que el dominio F-BAR es necesario para su localización y función (Martín-García et al., 2014).

Rga7 se localiza tanto en los polos como en el sitio de división (Arasada and Pollard, 2011) y depende de la proteína Rng10 para su localización ya que en la cepa mutante rng10 se deslocaliza completamente de los polos y forma un único punto en la zona de división en lugar de un anillo (Liu et al., 2016, 2019). Rga7 tiene un papel importante en la morfogénesis y en la citocinesis dando estabilidad al CAR y participando en su desensamblaje (Martín-García et al., 2014). La deleción de $r g a 7^{+}$ provoca un aumento de células en septación y de lisis celular debido a que aumenta el tiempo de contracción del CAR (Martín-García et al., 2014). Este retraso en la contracción provoca además varios defectos en la septación, observándose septos asimétricos, irregulares y con un engrosamiento en el área central (Martín-García et al., 2014). Además se produce una menor llegada y más tardía de Bgs4 a la zona de división, lo que provoca el fenotipo de lisis durante la citocinesis tardía (Arasada and Pollard, 2015). Rga7 interacciona con Fic1 y Pxl1, dos proteínas que se localizan en el CAR mediante del dominio SH3 Cdc15 e Imp2. Esto sugiere que Rga7 es capaz de cooperar con Cdc15 e Imp2 formando un complejo para unir el anillo de actomiosina a la membrana, asegurando una correcta citocinesis y el reclutamiento de otras proteínas al CAR (Liu et al., 2016; Martín-García et al., 2014). 


\subsubsection{Rng10}

rng $10^{+}$no es esencial, aunque su deleción produce un fenotipo de lisis con células ligeramente alargadas. Esta proteína se localiza en los polos durante interfase y en la membrana plasmática de la zona de división celular cuando los nodos ya se han condensado. Rng10 interacciona con Rga7 siendo ambas interdependientes en su localización (Liu et al., 2016, 2019). Sin embargo, la cepa mutante rng10 $\Delta$ rga7 $\Delta$ es letal mostrando que ambas también poseen funciones independientes (Liu et al., 2016). En la cepa mutante rng10 $\Delta$ hay un aumento en el porcentaje de células con crecimiento monopolar por lo que esta proteína regula parcialmente el crecimiento apical (Liu et al., 2016). Sin embargo, esta cepa no muestra defectos en el ensamblaje o en la constricción del CAR aunque el cultivo presenta un ligero aumento de células septando y un aumento de la lisis celular (Chen et al., 2016; Liu et al., 2016). Además, rng10 presenta letalidad sintética con mutaciones de las $\beta$-glucán-sintasas Bgs1 y Bgs4 y con alguno de sus reguladores como el GEF de Rho1 Rgf3 o la quinasa Sid2 de la ruta de inicio de la septación (Chen et al., 2016).

\subsection{Contracción del anillo de actomiosina}

En este proceso el CAR se va estrechando de forma circular y pierde los filamentos de actina y las proteínas que lo forman para ir reduciendo su diámetro (Wu et al., 2003). Se ha propuesto un modelo en el cual Myo2 se uniría a los filamentos de actina tirando de ellos, los entrecruza y hace que se deslicen entre sí contrayendo el CAR (Stachowiak et al., 2014). A medida que se contrae el CAR, se van cortando los filamentos de actina estocásticamente mediante la cofilina y así se disocian del anillo contráctil (Michelot et al., 2007; Stachowiak et al., 2014) (Figura 17). Como el CAR permanece unido a la membrana plasmática, la formación del surco de división en esta también contribuye a la contracción del CAR.

Unión de la miosina a la actina

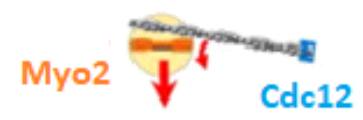

Las miosinas tiran de los filamentos de actina

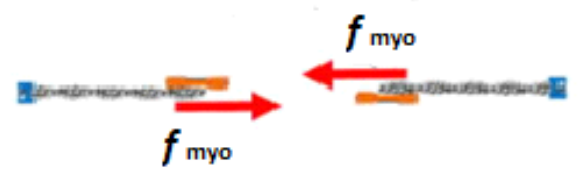

Entrecruzamiento de los filamentos de actina

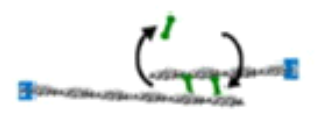

Figura 17.- Modelo de contracción del anillo de actomiosina. Myo2 se une a lo filamentos de actina nucleados por $\mathrm{Cdc} 12$, la actividad motora de $\mathrm{Myo} 2$ atrae estos filamentos que se entrecruzan deslizando entre sí. Adaptado de Stachowiak et al., 2014. 
La fuerza producida únicamente por la contracción del CAR es muy débil como para superar la presión de turgencia de la célula contra la membrana plasmática y formar el surco de división. Por tanto se ha propuesto que la formación del septo durante la contracción del CAR actúa como soporte y contribuye a la formación del surco de división (Proctor et al., 2012; Thiyagarajan et al., 2015). El inicio de la formación del septo durante la contracción del CAR viene determinado por la ruta de inicio de la septación SIN (Gerien and Wu, 2018).

\subsection{La ruta SIN}

Para que se produzca correctamente la división celular es necesario que a la vez que produce la contracción del CAR comience la formación del septo de división. Este proceso está regulado por una cascada de quinasas denominada ruta de inicio de la septación o SIN (Septation Initiation Network) (Gerien and Wu, 2018). La pérdida de funcionalidad de esta ruta provoca la aparición de células alargadas y multinucleadas debido a que el ciclo celular continúa sin iniciarse la formación del septo. De esta forma, en los mutantes de la ruta SIN, al acabar la mitosis se produce una nueva fase de crecimiento polarizado seguida por una nueva mitosis (Mitchison and Nurse, 1985). Por otro lado, un error en la finalización de esta ruta o la sobreexpresión de alguno de sus miembros, como la GTPasa Spg1, genera células multiseptadas (Minet et al., 1979). La activación ectópica de esta vía provoca en la célula la formación del CAR y del septo en cualquier momento del ciclo celular (Ohkura et al., 1995; Schmidt et al., 1997; Simanis, 2015).

Existen 13 componentes principales de la ruta SIN, todos ellos se encuentran en el SPB excepto Etd1 que es citoplásmica (Figura 15). Pcp89, Sid4 y Cdc11 forman un complejo adaptador para el resto de componentes (Simanis, 2015). Pcp89 y Sid4 se encuentran en la cara citoplasmática del SPB por lo que el inicio de la ruta SIN se produce en el citoplasma (Simanis, 2015).

La GTPasa Spg1 es la encargada de iniciar la activación de la SIN y se une al SPB por el complejo adaptador Pcp89/Sid4/Cdc11 (Schmidt et al., 1997). Su señalización está controlada por un complejo GAP en el que Cdc16 es la subunidad catalítica y Byr4 es su adaptadora que facilita la interacción con la GTPasa Spg1 (Krapp et al., 2008). No se ha descrito ningún GEF de Spg1 aunque la propia GTPasa posee actividad en ausencia de GEF (Simanis, 2015) y activa a la quinasa Cdc7 durante la mitosis mediante su interacción con ella (Fankhauser and Simanis, 1994; Mehta and Gould, 2006). Cdc7 activa a la siguiente quinasa, Sid1, que forma un complejo con su regulador Cdc14 (Guertin and McCollum, 2001; Guertin et al., 2000). Esta quinasa a su vez activará a la quinasa Sid2 con su regulador Mob1 (Hou et al., 2004, 2000; Salimova et al., 2000). La localización asimétrica de las quinasas de la ruta SIN ocurre tanto al inicio de la ruta SIN (Schmidt et al., 1997; Sohrmann et al., 1998) como al final (García-Cortés and 
McCollum, 2009). Los mutantes que fallan en la localización asimétrica de estas quinasas tienen defectos en la regulación de la citocinesis (Johnson et al., 2012). La GTPasa Spg1 se localiza en el SPB durante interfase, mientras que cada una de las quinasas de la cascada solo se localizan en el SPB cuando están activas durante la citocinesis (Simanis, 2015). La localización de Cdc7 de forma asimétrica viene determinada por la fosforilación de Byr4 que realizan las quinasas Cdk1 (complejo Cdc2-Cdc13) o Plo1 (Rachfall et al., 2014). La quinasa Sid2 regula la localización asimétrica de $\mathrm{Cdc7}$ mediante la fosforilación de $\mathrm{Cdc11}$, lo que sugiere que existe un feedback loop positivo entre los componentes de la ruta SIN para su localización (Feoktistova et al., 2012).

Etd1 se ha relacionado con la regulación tanto de Spg1 como de Rho1 y es necesaria para la localización asimétrica de las quinasas de la ruta en el SPB o en el CAR durante anafase, pudiendo ejercer de nexo entre el CAR y la ruta SIN (Alcaide-Gavilán et al., 2014; Daga et al., 2005; García-Cortés and McCollum, 2009; Lahoz et al., 2010). Recientemente se ha demostrado que el inicio de la septación en $S$. pombe ocurre durante anafase temprana y está regulado por los niveles de Etd1 y Rho1 (G. Cortés et al., 2018).

Se han descrito otros reguladores de la ruta SIN, entre ellos algunas fosfatasas como el complejo PP2A (Jiang and Hallberg, 2001; Lahoz et al., 2010), Clp1 (Trautmann et al., 2001) o la calcineurina (Lu et al., 2002). Estas fosfatasas pueden actuar en varios puntos de la ruta, por ejemplo, Cdc11 es fosforilada al inicio de la septación y desfosforilada al final de la mitosis y tanto la fosfatasa PP2A como Clp1 contribuyen a ello (Chen et al., 2013; Lahoz et al., 2010; Simanis, 2015; Singh et al., 2011). Por otro lado, la pérdida de la función de la calcineurina agrava el fenotipo de las células cuando la ruta se encuentra comprometida, por lo que esta fosfatasa promueve la activación de la ruta (Lu et al., 2002). También se han descrito diferentes quinasas que regulan la ruta SIN como el complejo Cdk1, que regula a Byr4 (Dischinger et al., 2008). La quinasa Plo1 se localiza en el SPB e interacciona con la proteína adaptadora de la ruta SIN, Sid4 (Krapp et al., 2003; Tanaka et al., 2001). Plo1 también coopera con Cdk1 en la eliminación de Byr4 del SPB (Rachfall et al., 2014). Por otro lado, la caseína quinasa, Ck1, se une y fosforila a Sid4 para que posteriormente sea ubiquitinada por Dma1 y degradada (Guertin et al., 2002; Johnson and Gould, 2011; Johnson et al., 2013). Esta fosforilación por Ck1 funciona como punto de control o check point, previniendo la activación de la ruta por Plo1 en el SPB en células paradas en mitosis.

La ruta SIN regula un gran número de procesos de la citocinesis a través del complejo Sid2/Mob1, la última quinasa de la vía de señalización, que se asocia con el CAR durante anafase (Hou et al., 2000; Simanis, 2015). Cdc12 necesita la fosforilación de Sid2 para formar los filamentos de actina del CAR (Bohnert et al., 2013). Cdc15 también necesita la activación de la ruta SIN para localizarse en el CAR, aunque no se sabe si Cdc15 es un sustrato directo de Sid2 (Hachet and Simanis, 2008). Durante la 
maduración del anillo de actomiosina existe un check point que se activa en mutantes de la glucán-sintasa Bgs1 o en algunos mutantes del CAR (Le Goff et al., 1999; Liu et al., 2000; Mishra et al., 2004). La ruta SIN es necesaria tanto para la activación de este check point (Le Goff et al., 1999; Liu et al., 1999, 2000) como para el mantenimiento del CAR mediante la fosforilación de sus componentes por Sid2 (Alcaide-Gavilán et al., 2014). Además, la fosforilación de la quinasa Cdr2 por Sid 2 promueve su interacción con Rad24 y su localización en el citoplasma tras la división celular, así la ruta SIN garantiza la formación de un nuevo sitio de división en la zona central de las células hijas (Rincon et al., 2017). Se desconoce con exactitud cómo se produce la finalización de la señalización de la ruta SIN. Sid2 es capaz también de fosforilar a la fosfatasa Clp1 para mantenerla en el citoplasma (Chen et al., 2008) y esta fosfatasa podría provocar, junto con la fosfatasa PP2A, la desfosforilación e inhibición de Cdc11, produciendo el final de la señalización (Chen et al., 2008). Además, la deslocalización de Etd1 de la zona de división provoca la inactivación de Spg1 y por tanto la finalización de la activación de la ruta SIN. Este suceso ocurre simultáneamente con el fin de la constricción del CAR, aunque el mecanismo que coordina ambos procesos todavía se desconoce (García-Cortés and McCollum, 2009) (Figura 18).

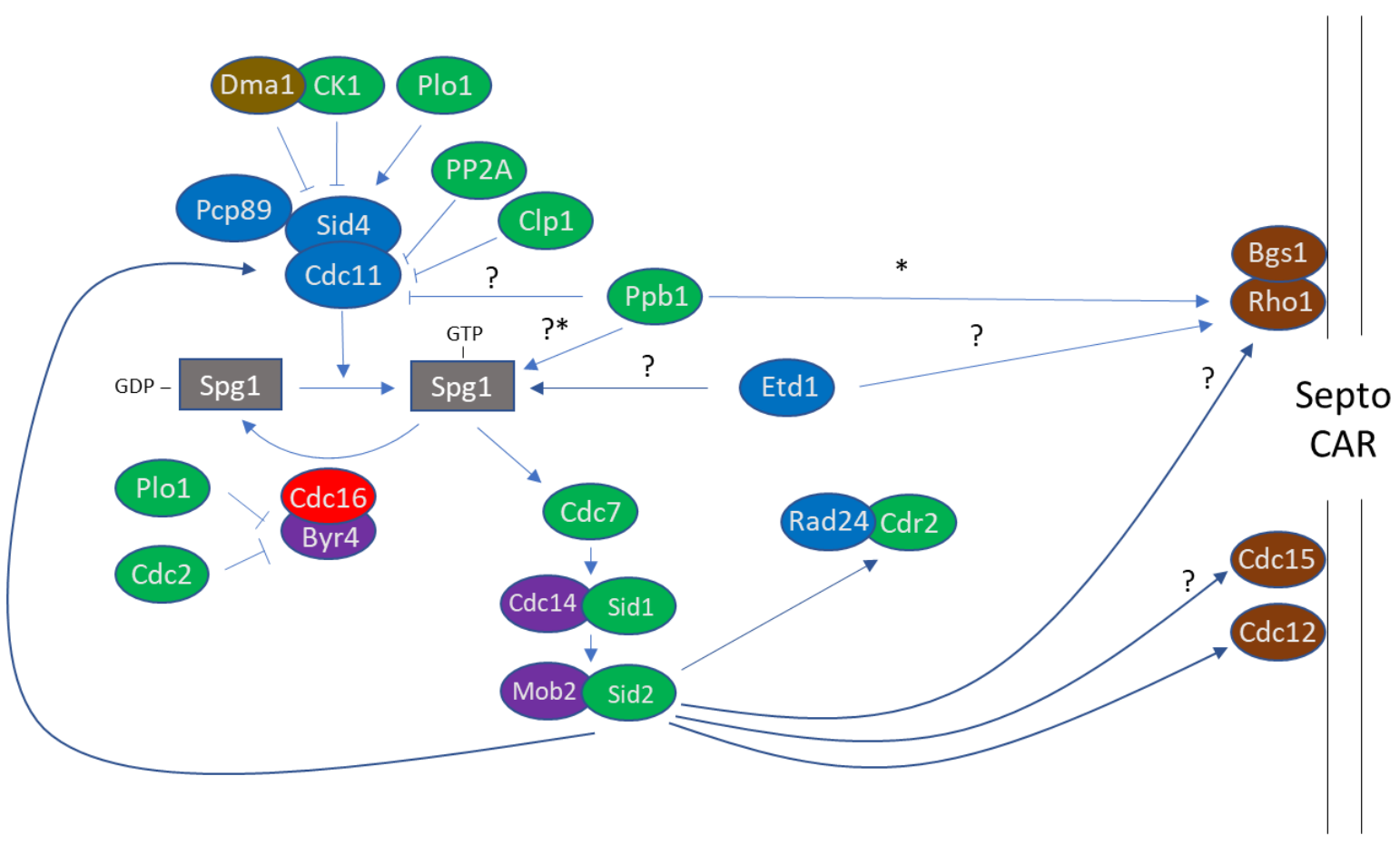

Figura 18.- Componentes de la ruta de inicio de la septación SIN, reguladores y efectores. En verde se representan las diferentes quinasas o fosfatasa, en azul las proteínas adaptadoras o reguladoras, en morado las subunidades reguladoras, en gris las GTPasas, en rojo los GAP, en dorado las ubiquitinasas y en marrón los componentes del CAR y el septo. Las posibles interacciones marcadas con asterisco indican que solo se producirían cuando la vía de señalización se encuentra comprometida. 


\subsection{Síntesis del septo}

El septo de división de S. pombe es una estructura de tres capas con un septo primario flanqueado por dos septos secundarios (García Cortés et al., 2016; Sipiczki, 2007). Bgs1 es la enzima encargada de la síntesis del B-glucano lineal, principal polímero del septo primario (Cortés et al., 2007), mientras que Ags1 y Bgs4 son las responsables del septo secundario (Cortés et al., 2005; Vos et al., 2007). La síntesis del septo está coordinada con la tensión producida por el CAR al contraerse, por lo que la actividad de Bgs1 podría estar regulada por algunos de los componentes del anillo de actomiosina (Thiyagarajan et al., 2015; Zhou et al., 2015). Por otra parte, en la cepa termosensible de Bgs1 cps1-191 el CAR resbala por la membrana y no se contrae, por lo que la funcionalidad de Bgs1 es también necesaria para la estabilidad y contracción del CAR (Arasada and Pollard, 2014; Cortés et al., 2015; Liu et al., 1999). Además, la constricción del CAR por sí sola no ejerce la fuerza suficiente como para oponerse a la fuerza de turgencia y producir la división celular, por lo que se ha propuesto que ambos, septo y anillo de actomiosina, conjuntamente aportan la fuerza necesaria para la formación del surco de división (Proctor et al., 2012). La paxilina es una de la proteínas del CAR que colaboran con Bgs1 en la formación del septo y en el anclaje a la membrana plasmática del CAR durante la constricción y la separación celular (Cortés et al., 2015, 2016). La GTPasa Rho1 es capaz de rescatar algunos mutantes de la ruta SIN (Jin et al., 2005). Por esto, un posible modelo sugiere que la ruta SIN facilitaría la activación en la zona de división de esta GTPasa, que a su vez activaría a las glucánsintasas conectando ambos procesos (Pérez et al., 2016). Por otra parte, algunas de las proteínas que anclan el CAR a la membrana podrían regular la síntesis del septo. Así, la proteína Cdc15 es capaz, mediante su dominio SH3, de reclutar a otras proteínas como Pxl1 o Rgf3 que colaboran con Bgs1 (Cortés et al., 2015; Ren et al., 2015; RobertsGalbraith et al., 2009). Otra proteína F-BAR, Rga7, se ha relacionado con la localización en el sitio de división de Bgs4 (Arasada and Pollard, 2015). Por tanto, la formación del septo y la constricción del CAR han demostrado ser interdependientes, aunque los mecanismos exactos por los cuales ambos procesos se relacionan aún se desconocen (Figura 19). 


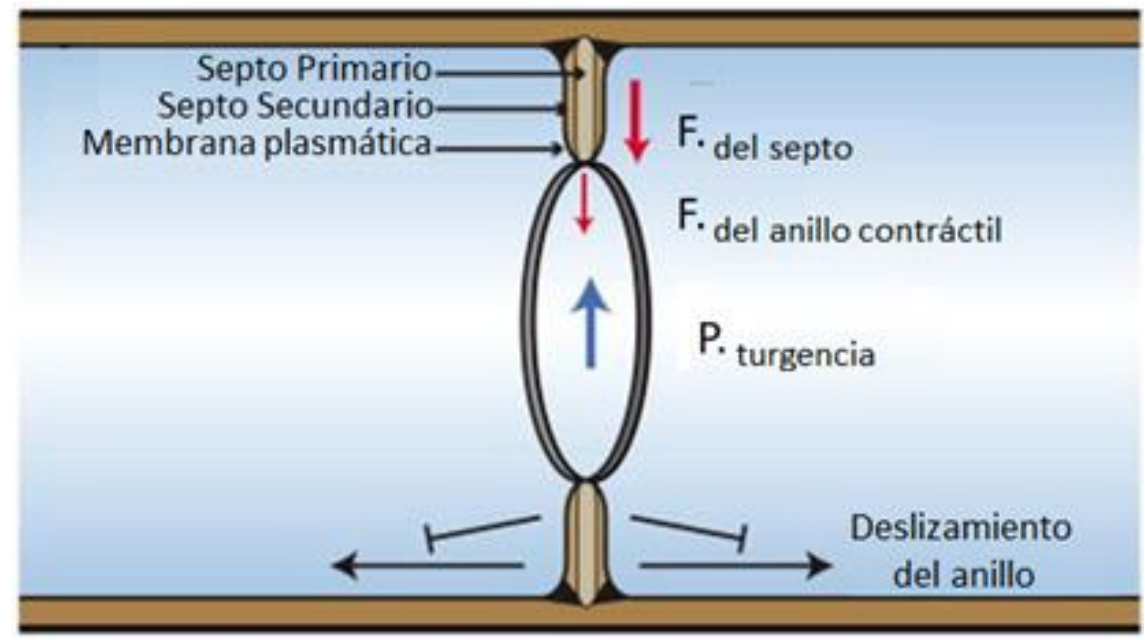

Figura 19.- Contracción del CAR. La contracción del CAR junto con la formación del septo ejerce la fuerza necesaria para superar la presión de turgencia y permitir que se produzca la división celular. Adaptado de Willet et al., 2015.

\subsection{Separación celular}

Una vez finalizada la septación, la separación celular requiere la disolución del septo primario. Este proceso no es esencial para la viabilidad celular puesto que las cepas mutantes sin este proceso forman cadenas de células que permanecen unidas entre sí por septos que no se han dividido pero son capaces de crecer (Sipiczki, 2007). Para la separación celular correcta, inicialmente se forma el anillo de septinas que se divide en dos a medida que el septo se va formando (Berlin et al., 2003; Tasto et al., 2003). Este anillo de septinas localiza al exocisto que a su vez permite la secreción localizada de las enzimas hidrolíticas que eliminan el septo primario (Dekker et al., 2004; MartínCuadrado et al., 2003) (Figura 20). El proceso de separación comienza con la secreción de la $\alpha$-glucanasa Agn1 que digiere la pared celular que hay entorno al septo primario (Dekker et al., 2004; García et al., 2005). Esta enzima se observa en el septo durante la septación y su sobreexpresión produce un elevado porcentaje de lisis (García et al., 2005). La enzima $\beta$-glucanasa Eng1 que degrada el $\beta$-glucano lineal actúa una vez digerida la pared lateral y elimina el septo primario. El septo secundario remanente se separa y se curva gradualmente debido a la presión de turgencia y forma el polo nuevo (Atilgan et al., 2015; Cortés et al., 2012; Sipiczki and Bozsik, 2000). En la cepa mutante agn1 $\Delta$ no se produce la degradación del septo primario (Dekker et al., 2004; García et al., 2005) y la sobreexpresión de Eng1 no produce una disolución del septo primario más rápida (Martín-Cuadrado et al., 2003). Esto podría deberse a que Eng1 no está activa mientras toda la pared celular que rodea al septo primario este intacta o no puede actuar por no entrar en contacto con el glucano lineal. La expresión de estas glucanasas está regulada por el factor de transcripción Ace2 (Alonso-Nuñez et al., 2005; Dekker et al., 2006). Por otro lado, las GTPasas Rho3 y Rho4 también están implicadas en la regulación de estas glucanasas mediando su transporte al septo y su 
secreción (Sipiczki, 2007). Rho3 participa en la secreción general de la célula (Perez and Rincón, 2010) y Rho4 participa en la secreción de las glucanasas Eng1 y Agn1 implicadas en la degradación del septo y la localización de estas enzimas es dependiente de ella (Pérez et al., 2015; Santos et al., 2005).

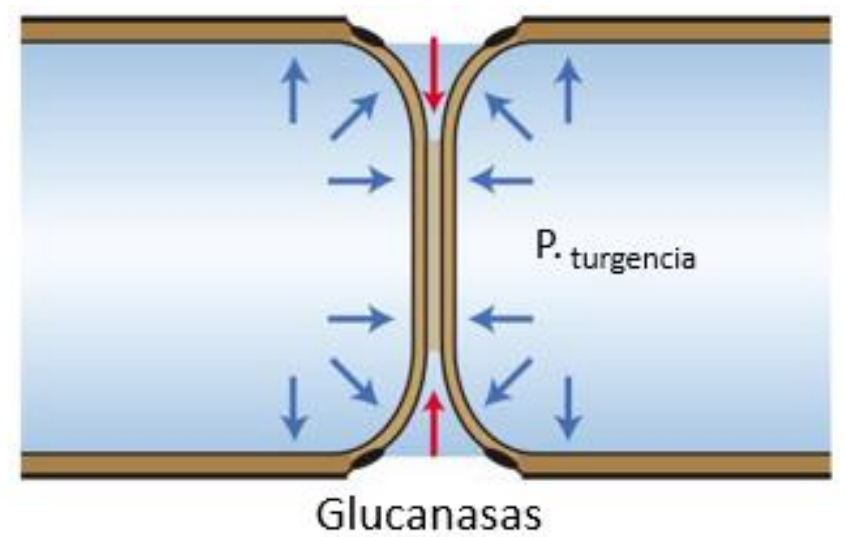

Figura 20.- Separación celular. Las glucanasas junto con la presión de turgencia ejerce la fuerza necesaria para terminar de romper el tabique primario. Adaptado de Willet et al., 2015. 


\section{Objetivos}

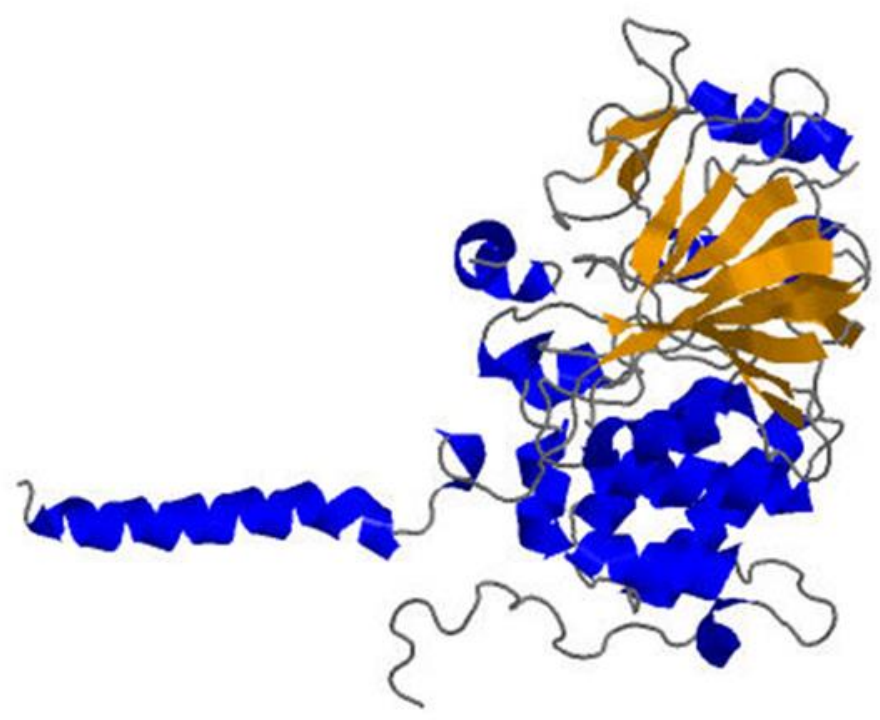





\section{Objetivos}

\section{OBJETIVOS}

El objetivo principal de este trabajo ha sido caracterizar la función de la calcineurina en la citocinesis de Schizosaccharomyces pombe y averiguar con qué elementos de la maquinaria de división celular colabora en este proceso. Además, puesto que la calmodulina es la principal reguladora de la calcineurina, hemos iniciado la caracterización de la función de la calmodulina en la regulación de la calcineurina y en la de la GTPasa Rho1 en la levadura de fisión. Para la consecución del objetivo nos propusimos:

1. Estudiar el papel de la paxilina en la localización de la calcineurina en el CAR.

2. Buscar los sustratos de la calcineurina en el CAR.

3. Caracterizar el papel de la calmodulina en la activación de la GTPasa Rho1 de forma dependiente e independiente de la calcineurina durante la citocinesis. 



\section{$\underline{\text { Resultados }}$}

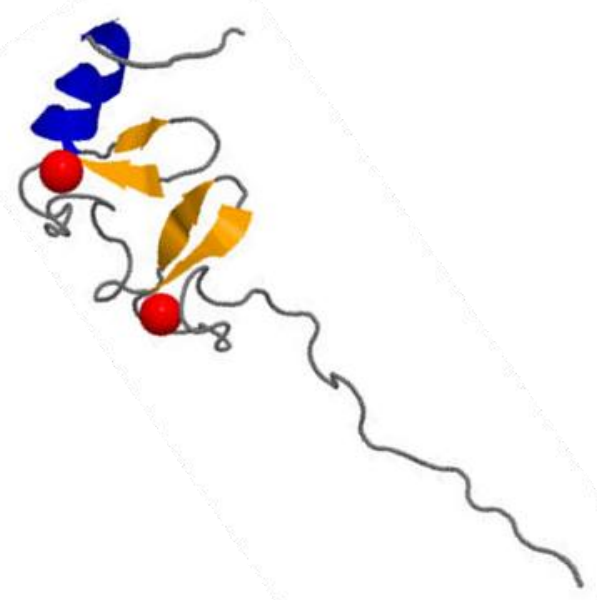





\section{Resultados}

\section{CAPÍTULO 1: LA FOSFATASA CALCINEURINA SE INCORPORA AL ANILLO DE ACTOMIOSINA MEDIANTE SU UNIÓN A LA PAXILINA.}

NOTA: Algunos de los resultados presentados en los apartados 1 y 2 corresponden a experimentos realizados conjuntamente con la Dra. Rebeca Martín García.

1. La paxilina posee un sitio de interacción con calcineurina y es necesaria para su localización en el anillo contráctil de actomiosina

\subsection{La calcineurina se localiza en el CAR}

La calcineurina es una fosfatasa conservada en todos los organismos eucariotas que participa en numerosos procesos. En S. pombe, la deleción de la calcineurina produce defectos en la separación celular y anillos de actomiosina aberrantes y presenta interacción génica negativa con las miosinas y la ruta SIN (Fujita et al., 2002; Lu et al., 2002; Yoshida et al., 1994). Para estudiar el papel que la calcineurina posee en la formación del anillo de actomiosina y del septo estudiamos la localización de esta fosfatasa a lo largo del ciclo celular. Para ello se construyó una cepa que poseía la subunidad catalítica de la calcineurina y la cadena ligera reguladora de las miosinas fusionadas con proteínas fluorescentes, Ppb1-GFP y Rlc1-tdTomato respectivamente, en su extremo C-terminal. Se observó la localización de ambas mediante microscopía de fluorescencia. Ppb1-GFP se encuentra en el citoplasma durante interfase pasando a localizarse en el CAR durante citocinesis, como se ha descrito previamente (McDonald et al., 2017), junto con Rlc1-tdTomato (Figura 21). La calcineurina es reclutada cuando el anillo está ya formado, aunque antes de su contracción, y se mantiene hasta que esta finaliza (Martín-García et al., 2018) lo que sugiere que Ppb1 realiza su función en el CAR durante la contracción y la formación simultánea del septo.

\section{A}

Ppb1-GFP RIc1-tdTomato
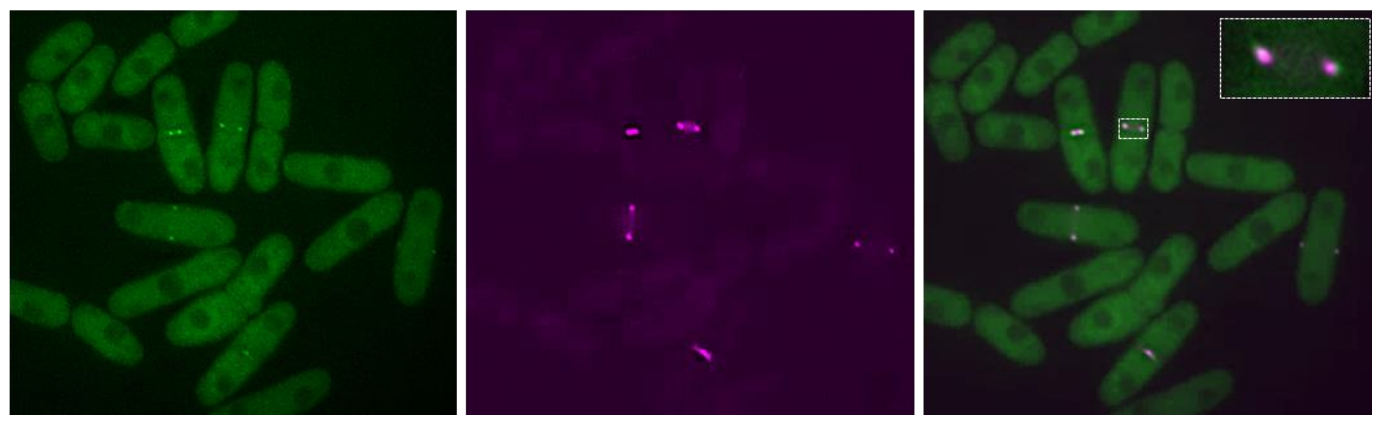


\section{Resultados}

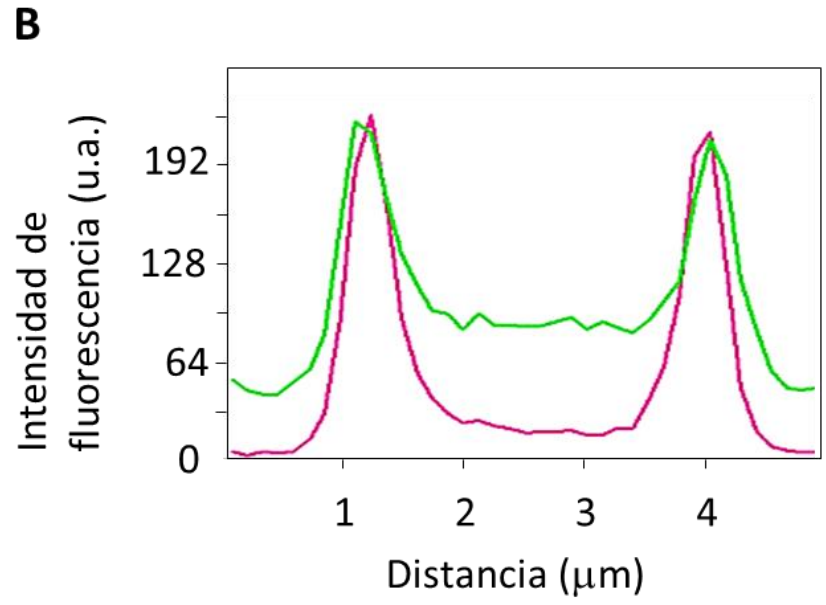

Figura 21.- La calcineurina se localiza en el anillo de actomiosina junto con la cadena ligera de las miosinas Rlc1. (A) Microscopía de fluorescencia de una cepa silvestre que expresa de forma endógena la calcineurina fusionada con la proteína fluorescente verde (Ppb1-GFP) y la cadena ligera reguladora de las miosinas fusionada con tdTomato (RIc1-tdTomato) incubadas a $28^{\circ} \mathrm{C}$ en medio YES (PPG12234). (B) Análisis mediante line scan de la fluorescencia de Ppb1-GFP y Rlc1-tdTomato para estudiar la colocalización de ambas proteínas. La línea para medir la intensidad de fluorescencia se trazó en la zona de formación del anillo de actomiosina dentro de la región encuadrada de la foto. Los valores obtenidos se miden en unidades arbitrarias (u.a.).

\subsection{La calcineurina debe de estar activa para su localización en el CAR}

En S. pombe, al igual que en otros organismos, la calcineurina es un heterodímero compuesto por una subunidad catalítica (Ppb1) y una subunidad reguladora (Cnb1) (Sio et al., 2005; Yoshida et al., 1994b). En algunos hongos como Aspergillus fumigatus la subunidad catalítica de la calcineurina se localiza en el septo de forma independiente de la subunidad reguladora (Juvvadi et al., 2011), por ello quisimos estudiar si esto sucedía de forma similar en la levadura de fisión. Se utilizaron cepas que poseían las subunidades catalítica o reguladora de la calcineurina fusionadas con (Ppb1-GFP). Además, las cepas tenían marcada la cadena ligera reguladora de la miosina Rlc1 con la proteína fluorescente roja tdTomato (RIc1-tdTomato) para comprobar la localización de ambas subunidades en el anillo mediante microscopía de fluorescencia. A diferencia de Aspergillus fumigatus, la localización de Ppb1 en S. pombe se pierde en ausencia de la subunidad reguladora Cnb1 (Figura 22). Lo mismo ocurría con Cnb1, su localización en el anillo de actomiosina se pierde en la deleción de $p p b 1^{+}$, por lo que la localización de ambas proteínas es interdependiente. 


\section{Resultados}

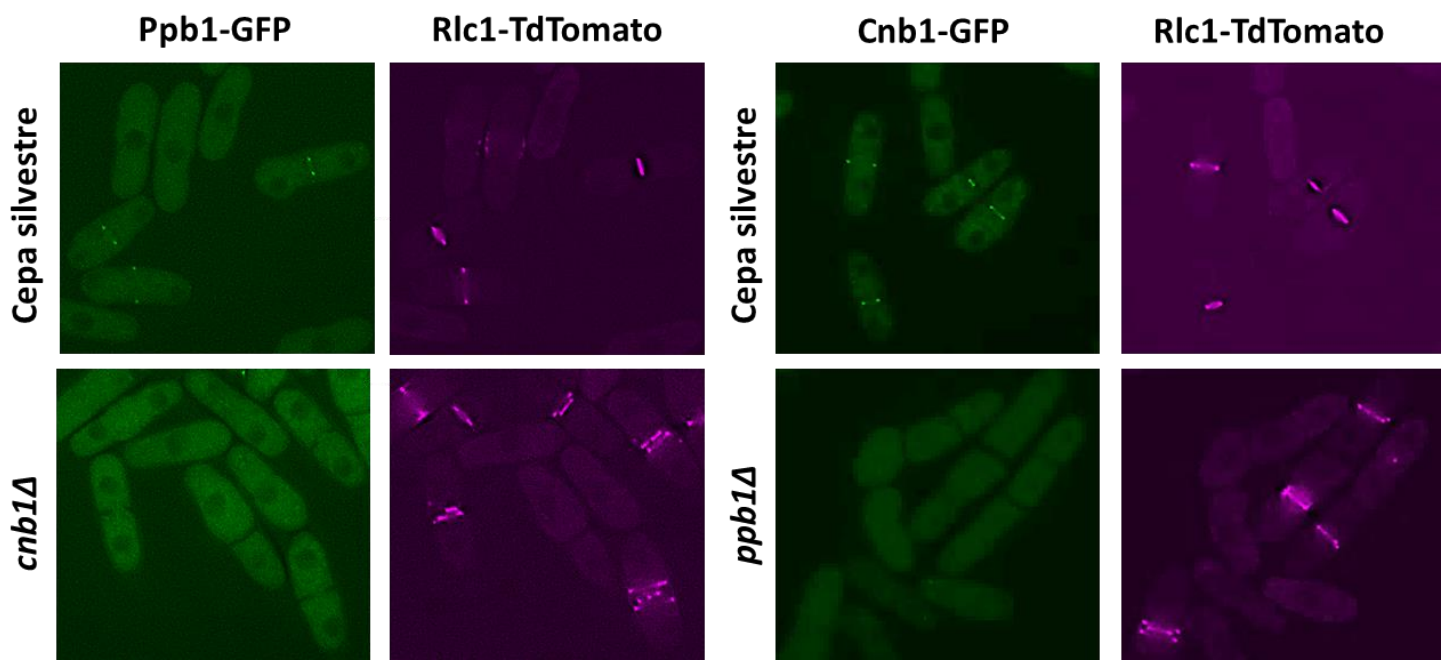

Figura 22.- Las subunidades de la calcineurina son interdependientes para su localización en el CAR. Microscopía de fluorescencia de una cepa silvestre y de las cepas cnb1 $\Delta$ y ppb1 $\Delta$ que expresan de forma endógena la otra subunidad de la calcineurina fusionada con la proteína fluorescente verde (Ppb1-GFP y Cnb1-GFP respectivamente) y RIc1-TdTomato (PPG12234, PPG15444, PPG15426, PPG15430). Las células se incubaron a $28^{\circ} \mathrm{C}$ en medio YES.

Estos resultados sugieren que en $S$. pombe, a diferencia de A. fumigatus, la calcineurina necesita estar activa para localizarse en el anillo y realizar su función. Para corroborar esto, se estudió la localización de la subunidad catalítica de la calcineurina (Ppb1-GFP) tras el tratamiento con FK506 durante seis horas (Figura 23). El FK506 es un inhibidor de la calcineurina cuyo sitio de interacción con la calcineurina solapa con la región de unión a los sitios LxVP, lo que impide la orientación correcta del sustrato e inhibe así la actividad de la calcineurina (Roy and Cyert, 2009). Al igual que ocurría en la cepa que carecía de la subunidad reguladora Cnb1, la fosfatasa no se localizaba en la zona de división tras el tratamiento con el inhibidor FK506. Este resultado confirmó que la calcineurina debe de estar activa para su correcta localización en el CAR. 


\section{Resultados}

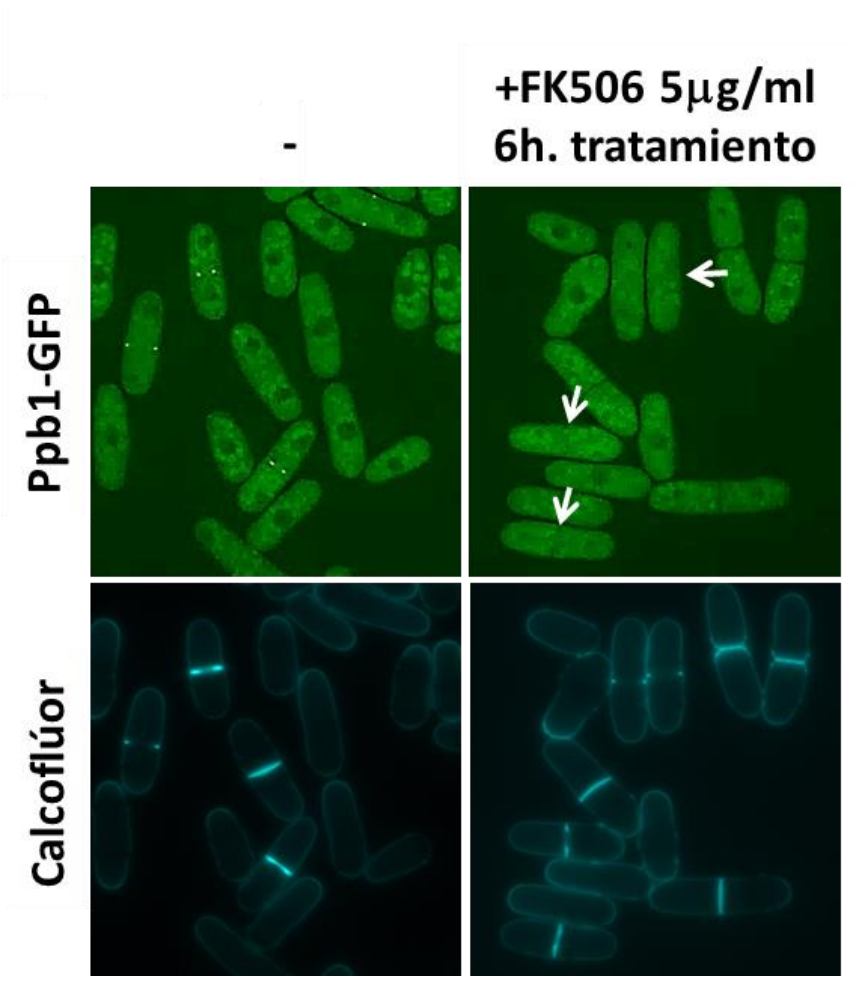

Figura 23.- La calcineurina debe estar activa para su localización en el CAR. (A) Microscopía de fluorescencia de una cepa silvestre incubada a $28^{\circ} \mathrm{C}$ en medio YES con y sin el tratamiento de FK506 para observar la localización de la subunidad catalítica de la calcineurina Ppb1-GFP (PPG11417). Se realizó una tinción con calcoflúor para ver la localización del septo. Las flechas blancas indican la pérdida de localización de Ppb1 en el anillo.

\subsection{La ausencia de calcineurina provoca defectos similares a los causados por la deleción de paxilina}

La deleción del gen que codifica la subunidad catalítica de la calcineurina causa un aumento de células en septación, la formación de células encadenadas y un retraso en la citocinesis (Fujita et al., 2002; Lu et al., 2002). Este fenotipo es muy similar al fenotipo de deleción del gen de la paxilina $p x / 1^{+}$(Pinar et al., 2008), lo que sugiere que ambas proteínas pueden estar en la misma vía de señalización. Para comprobar esto se analizó el porcentaje de células septadas y multiseptadas, así como el porcentaje de células con septos descentrados en las cepas silvestre, $p x \mid 1 \Delta, p p b 1 \Delta$ y la cepa mutante doble pxl1 $1 \Delta p b 1 \Delta$ (Figura 24). No se observaron diferencias significativas entre las respectivas cepas mutantes simples $p x / 1 \Delta$ y $p p b 1 \Delta$, y la cepa mutante doble $p x / 1 \Delta$ ppb1 $1 \Delta$ referidas al aumento de células septando, multiseptadas o al porcentaje de septos descentrados respecto a la cepa silvestre. 
A

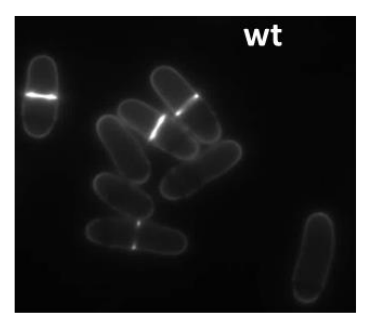

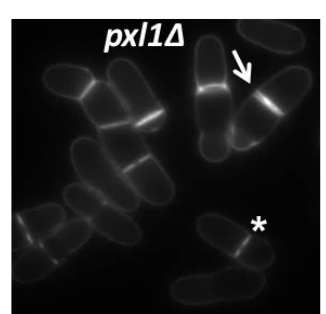
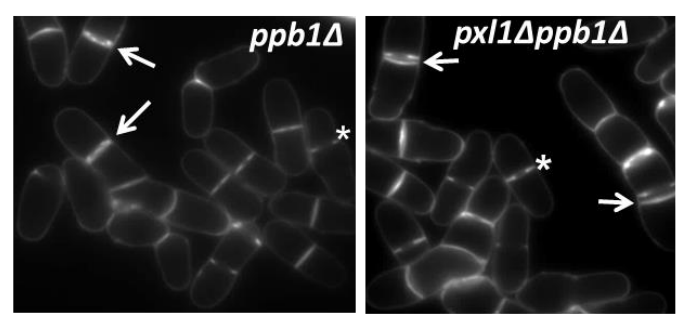

B

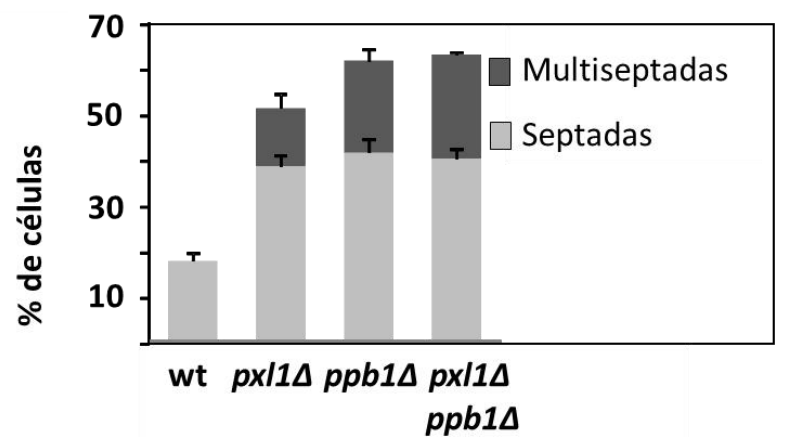

C

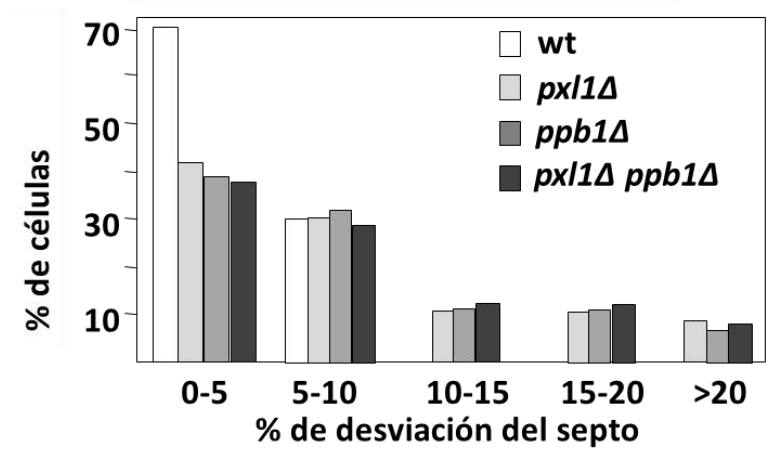

Figura 24.- La deleción de la calcineurina presenta un fenotipo muy similar al fenotipo de deleción de la paxilina y ambas deleciones simultáneamente causan un fenotipo aditivo. (A) Microscopía de

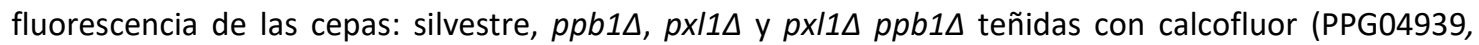
PPG10122, PPG09766 y PPG12272). Las células se incubaron a $28^{\circ} \mathrm{C}$ en medio YES. Las flechas indican los septos dobles y los asteriscos la presencia de septos descentrados. (B) Porcentaje de células septadas, multiseptadas o con el septo descentrado. (C) Porcentaje de células distribuidas en diferentes categorías según el porcentaje de desviación del septo.

La deleción de la paxilina provoca la aparición de anillos de actomiosina dobles y aberrantes (Pinar et al., 2008). Puesto que la deleción de la calcineurina poseía el mismo fenotipo de septación que el de la deleción de la paxilina quisimos ver si también producía defectos en el anillo de actomiosina. Para ello se utilizaron distintas cepas, silvestre y mutantes, que llevaban marcada la cadena ligera reguladora de las miosinas con la proteína fluorescente roja (Rlc1-tdTomato) (Figura 25). Se pudo observar que las células carentes de calcineurina presentaban anillos dobles o aberrantes en un porcentaje similar al de las células sin paxilina y al de la cepa mutante doble $p x \mid 1 \Delta p p b 1 \Delta$. El hecho de que estas mutaciones no presenten defectos aditivos sugiere que la calcineurina y la paxilina están implicadas en la misma vía de señalización. 


\section{Resultados}
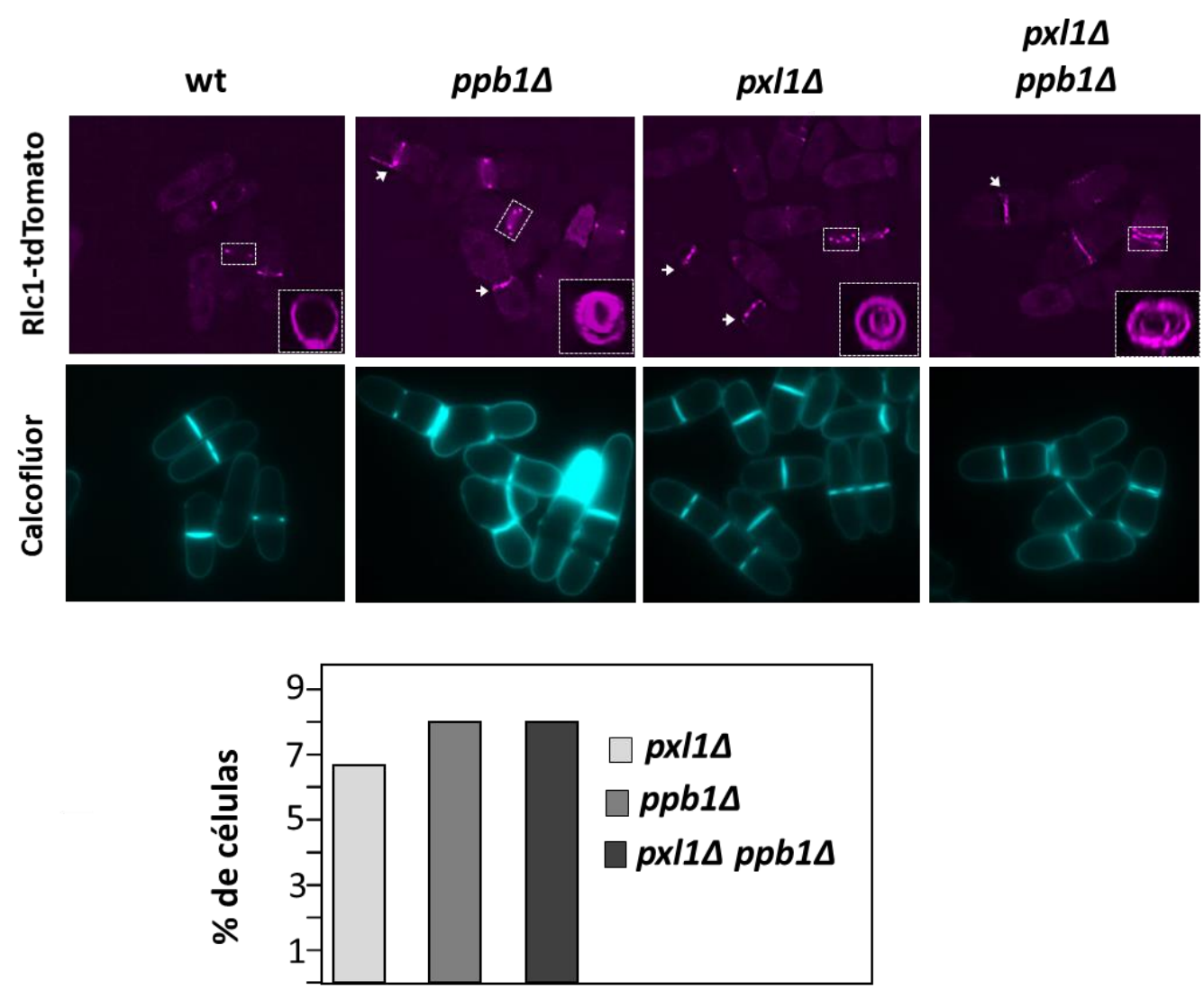

Anillos dobles

Figura 25.- La deleción de calcineurina provoca defectos en la formación del CAR similares a los observados con la deleción de paxilina y con la deleción conjunta de ambas proteínas. (A) Microscopía de fluorescencia de las cepas: silvestre, $p x \mid 1 \Delta, p p b 1 \Delta$, y $p x \mid 1 \Delta p p b 1 \Delta$ que poseen la cadena ligera reguladora de las miosinas fusionada con la proteína fluorescente roja (RIc1-tdTomato) incubadas en medio YES a $28^{\circ} \mathrm{C}$ y teñidas también con calcoflúor (PPG07036, PPG13238, PPG05748 y PPG14044). Las flechas indican los anillos dobles. Las zonas encuadradas presentan una reconstrucción tridimensional del anillo a partir de 28 imágenes adquiridas a intervalos de 0,3 $\mu \mathrm{m}$ entre cada una de ellas. (B) Porcentaje de células que presentan anillos dobles.

\subsection{Paxilina y calcineurina colocalizan en el CAR}

Los resultados anteriores sugieren que la paxilina y la calcineurina se encuentran en la misma vía de señalización y ambas se localizan en el CAR. Realizamos experimentos de video-microscopía de fluorescencia para observar la localización simultánea de ambas proteínas y establecer temporal y espacialmente la presencia de cada una de ellas en el CAR. Se utilizó una cepa que poseía la subunidad catalítica de la calcineurina fusionada con GFP (Ppb1-GFP) y la paxilina fusionada con la proteína fluorescente roja mCherry en su extremo N-terminal (mCherry-Pxl1). Se observó que tanto Pxl1 como Ppb1 se localizaban en el CAR, aunque la paxilina llegaba entre tres y seis minutos antes que la calcineurina (Figura 26A). El análisis mediante line scan de las señales verde y roja confirmó que ambas proteínas colocalizaban en el anillo (Figura 26B). 


\section{Resultados}

A

mCherry-Pxl1 Ppb1-GFP

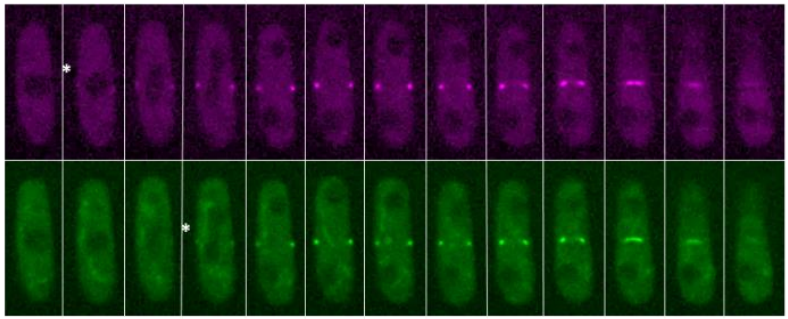

Intervalos de 3 minutos
B

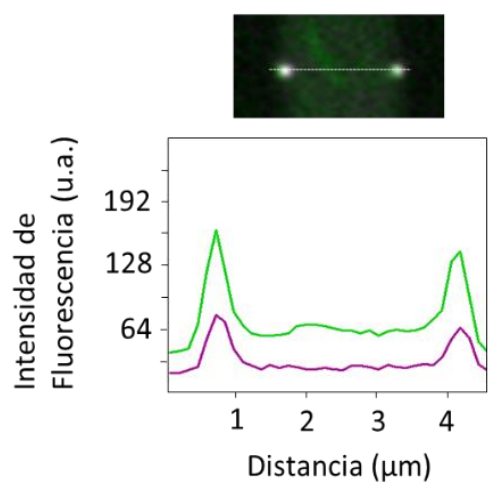

Figura 26.- Pxl1 y Ppb1 colocalizan en el CAR. (A) Video-microscopía de fluorescencia de una cepa silvestre que expresa de forma endógena la calcineurina fusionada con la proteína fluorescente verde (Ppb1-GFP) y la paxilina fusionada con mCherry (mCherry-Pxl1) (PPG12236). Las células se incubaron a $28^{\circ} \mathrm{C}$ en medio YES. Los asteriscos indican el momento en el que la paxilina y la calcineurina comienzan a localizarse en el CAR. (B) Análisis mediante line scan de la fluorescencia de Ppb1-GFP y mCherry-Pxl1. La línea para medir la intensidad de fluorescencia se trazó en la zona de formación del anillo de actomiosina

\subsection{La subunidad catalítica de la calcineurina Ppb1 interacciona con la paxilina}

Puesto que paxilina y calcineurina colocalizan en el CAR y parecen estar en la misma vía de señalización se decidió estudiar si también interaccionaban físicamente mediante un ensayo de coinmunoprecipitación. Se utilizó una cepa silvestre que expresaba de forma simultánea paxilina unida al epítopo HA en su extremo N-terminal (HA-Pxl1) y la subunidad catalítica de la calcineurina unida a GFP (Ppb1-GFP). Como control se utilizaron las cepas que expresaban únicamente una de estas proteínas marcadas. Los extractos celulares se incubaron con anticuerpos policlonales anti-HA unidos a proteína A-sefarosa para inmunoprecipitar la paxilina. Tras la incubación se realizó un Western blot empleando anticuerpos monoclonales anti-GFP y anti-HA para detectar Ppb1-GFP y HA-Pxl1 respectivamente. Tras el revelado pudimos detectar la banda correspondiente a Ppb1-GFP en el inmunoprecipitado, indicando la existencia de interacción de Pxl1 con Ppb1 (Figura 27). 


\section{Resultados}

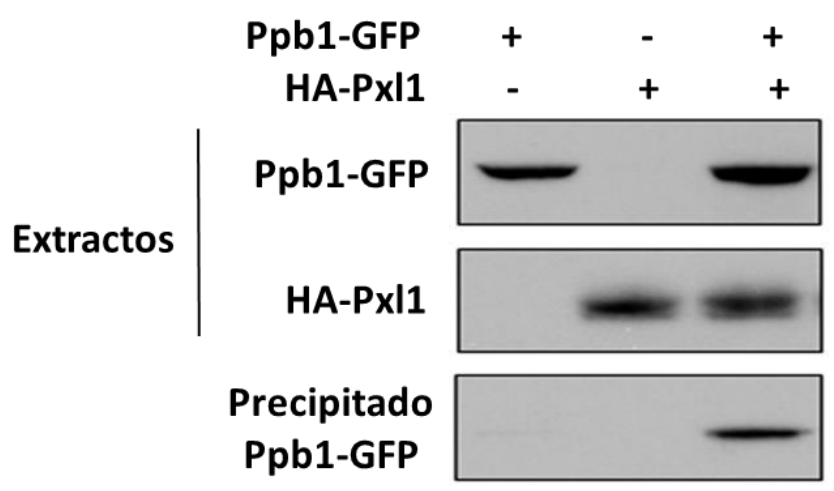

Figura 27. Ppb1 interacciona con Pxl1. Ensayo de coinmunoprecipitación de Pxl1 y Ppb1 en una cepa silvestre que expresa Ppb1-GFP y HA-Pxl1 (PPG13471). Como control se utilizaron las cepas que expresaban únicamente Ppb1-GFP o HA-Pxl1 (PPG11417 y PPG05110). Los extractos celulares de esta cepa se incubaron con anticuerpos policlonales anti-HA unidos a proteína A-sefarosa. Los extractos celulares y el inmunoprecipitado fueron analizados con anticuerpos anti-HA y anti-GFP.

\subsection{La paxilina interacciona con la subunidad catalítica de la calcineurina Ppb1}

La subunidad catalítica de la calcineurina Ppb1 necesita a la subunidad reguladora Cnb1 para localizarse en el anillo, por lo que estudiamos si la interacción de Ppb1 con la paxilina también era dependiente de la subunidad reguladora. Para ello se realizaron ensayos de pull down utilizando GST-PxI1 producida en bacterias y unida a bolas de glutatión-sefarosa. Estas bolas se incubaron con extractos celulares de cepas que poseían la subunidad catalítica de la calcineurina marcada con el epítopo HA (Ppb1-HA) y que tenían o carecían de la subunidad reguladora Cnb1. El resultado obtenido mostró que la interacción entre Pxl1 y Ppb1 es independiente de la subunidad reguladora Cnb1 (Figura 28A). De igual forma, nos preguntamos si la paxilina era también capaz de interaccionar con la subunidad reguladora de la calcineurina Cnb1 y si esta interacción era dependiente de la subunidad catalítica Ppb1. Por ello, se realizaron nuevos ensayos de pull down utilizando bolas con GST-Pxl1 recombinante que se incubaron con extractos celulares de cepas que poseían la subunidad reguladora marcada con el epítopo HA en su extremo C-terminal (Cnb1-HA) y que tenían o carecían de la subunidad catalítica Ppb1 (Figura 28B). El resultado obtenido demostró que Cnb1 interacciona con Pxl1. Sin embargo, esta interacción es dependiente de la subunidad catalítica Ppb1 y no se produce en su ausencia. Por tanto, concluimos que la paxilina interacciona con la calcineurina a través de la subunidad catalítica Ppb1. 
A
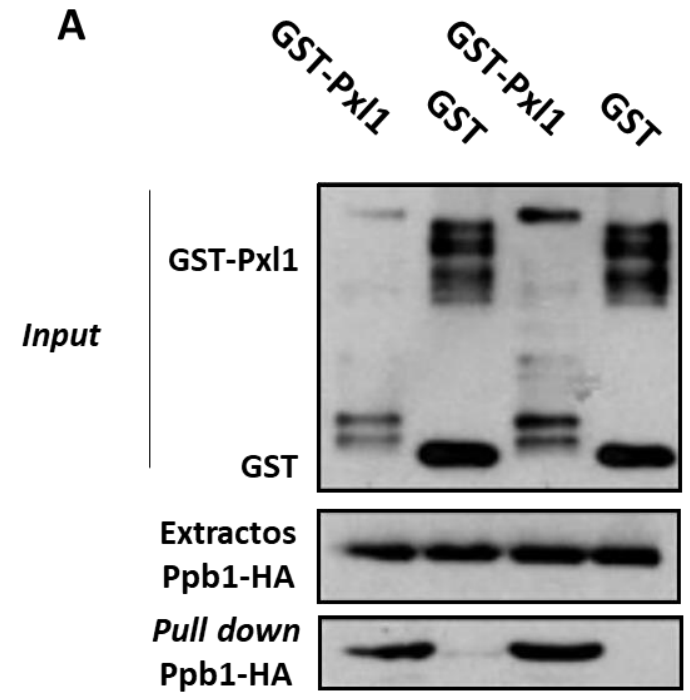

B
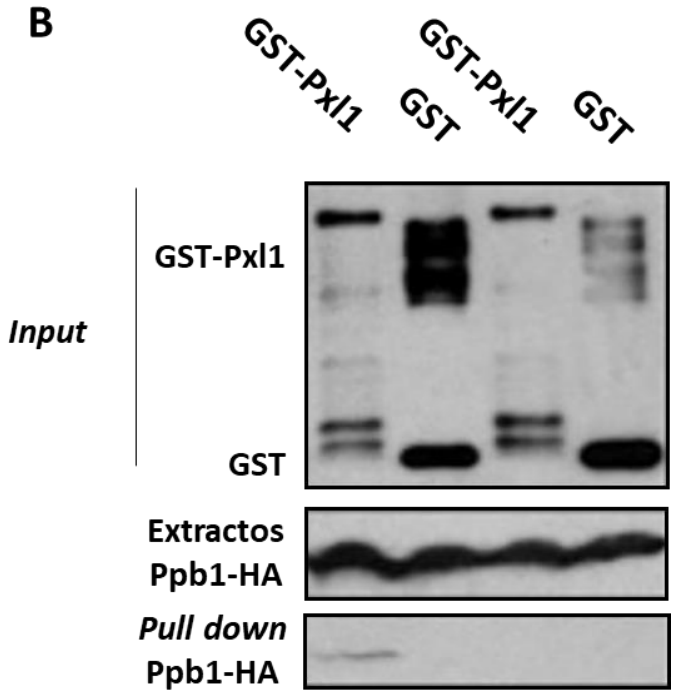

Figura 28. Pxl1 se une a la calcineurina por medio de la subunidad catalítica Ppb1. Ensayo de pull down con extractos de las cepas silvestre y cnb1 1 que expresan la proteína Ppb1-HA (PPG11414 y PPG14945) (A) y las cepas silvestre y ppb1 4 que llevan la proteína Cnb1-HA (PPG14674 y PPG14946) (B). Los extractos de las cepas se incubaron con bolas de glutatión-sefarosa que llevan unidas GST o GST-PxI1 producidas en bacterias. Los precipitados y los extractos celulares fueron analizados con anticuerpos anti-GST y anti-HA.

Puesto que la paxilina y la calcineurina parecen estar en la misma vía de señalización, colocalizan en el anillo de actomiosina e interaccionan físicamente, decidimos comprobar si la localización de Ppb1 era dependiente de Pxl1 ya que, como se mencionó anteriormente, esta llega unos minutos antes que la fosfatasa al CAR. Se utilizaron cepas con o sin paxilina que poseían la subunidad catalítica de la calcineurina fusionada con GFP (Ppb1-GFP) y la cadena ligera reguladora de la miosina marcada con tdTomato (Rlc1-tdTomato). Mediante microscopía de fluorescencia se observó que en la mayoría de las células la localización de la calcineurina en el CAR se perdía totalmente en ausencia de Pxl1, apreciándose una leve señal de Ppb1-GFP, con una intensidad unas diez veces inferior a la cepa silvestre, en un $7 \%$ de las células en las que el anillo se encontraba en la fase final de la contracción (Figura 29). Por tanto, la localización de la calcineurina en el anillo es debida principalmente a la paxilina, aunque otras proteínas podrían contribuir a su localización en el CAR al final de la septación. 


\section{Resultados}

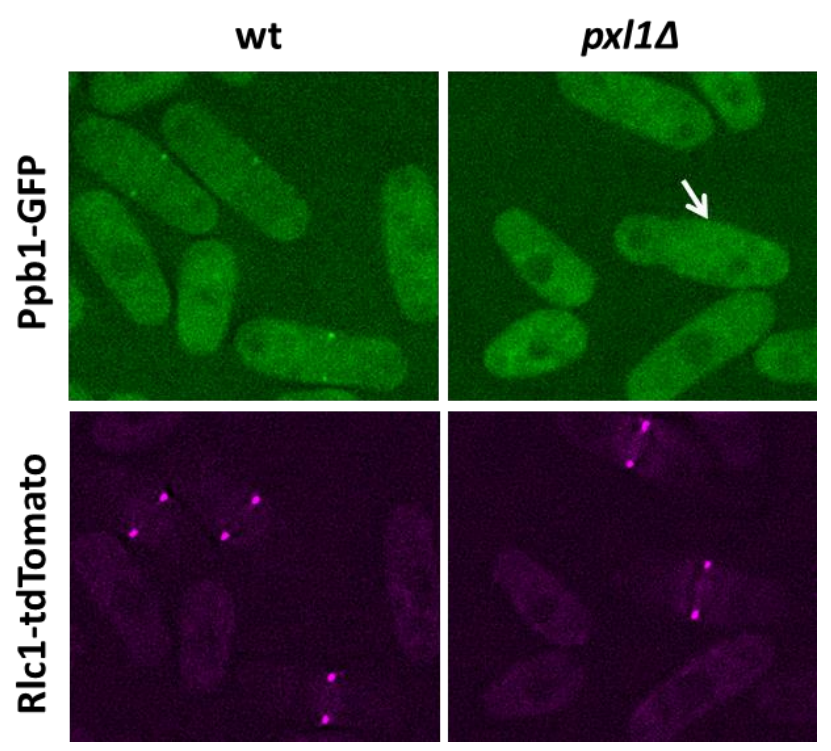

Figura 29.- La paxilina es necesaria para la localización de la calcineurina en el anillo. Microscopía de fluorescencia de las cepas silvestre y $p x / 1 \Delta$ que expresan de forma endógena la calcineurina fusionada con la proteína fluorescente verde (Ppb1-GFP) y la cadena ligera reguladora de las miosinas fusionada con tdTomato (RIc1-tdTomato) (PPG12234 y PPG12264). Las células se incubaron a $28^{\circ} \mathrm{C}$ en medio YES. Las flechas blancas indican la deslocalización de Ppb1 en el anillo.

\subsection{Ppb1 interacciona con diferentes regiones de la paxilina}

La paxilina es una proteína con una región rica en prolina en su mitad $\mathrm{N}$-terminal con y tres dominios LIM en su mitad C-terminal (Pinar et al., 2008) (Figura 30A). Esta proteína se localiza en el anillo mediante la interacción de su región $\mathrm{N}$-terminal con el dominio SH3 de Cdc15 o de Imp2 (Ren et al., 2015; Roberts-Galbraith et al., 2009) mientras que los dominios LIM le dan la funcionalidad a esta proteína (Pinar et al., 2008). Decidimos estudiar si la interacción de Pxl1 con Ppb1 se realizaba exclusivamente a través de estos tres dominios LIM o bien se producía también a través de su región $\mathrm{N}$-terminal.

Se analizó el efecto de los truncamientos de los dominios LIM de Pxl1 en la función de la localización de la calcineurina en el CAR. Las construcciones de pxl1 carentes de las regiones codificantes de los tres dominios LIM, pxIILLIM123, o sólo del último, pxI1LLIM3, se clonaron en el plásmido integrativo pJK148 bajo el control del promotor de paxilina y se integraron en el locus leu1 ${ }^{+}$de una cepa $p x / 1 \Delta$ que expresaba Ppb1-GFP para observar la localización de la calcineurina mediante microscopía de fluorescencia. Los resultados nos muestran cómo la localización en el CAR de la calcineurina se pierde casi totalmente con la eliminación del tercer dominio LIM y desaparece por completo con la deleción de todos los dominios LIM (Figura 30B). Esto confirma el papel esencial de estos dominios en la función de Pxl1 que es la localización de la calcineurina en el CAR. 
A

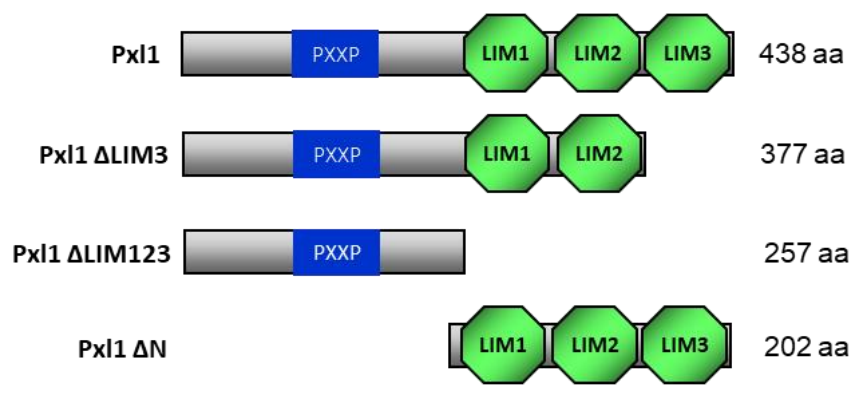

B

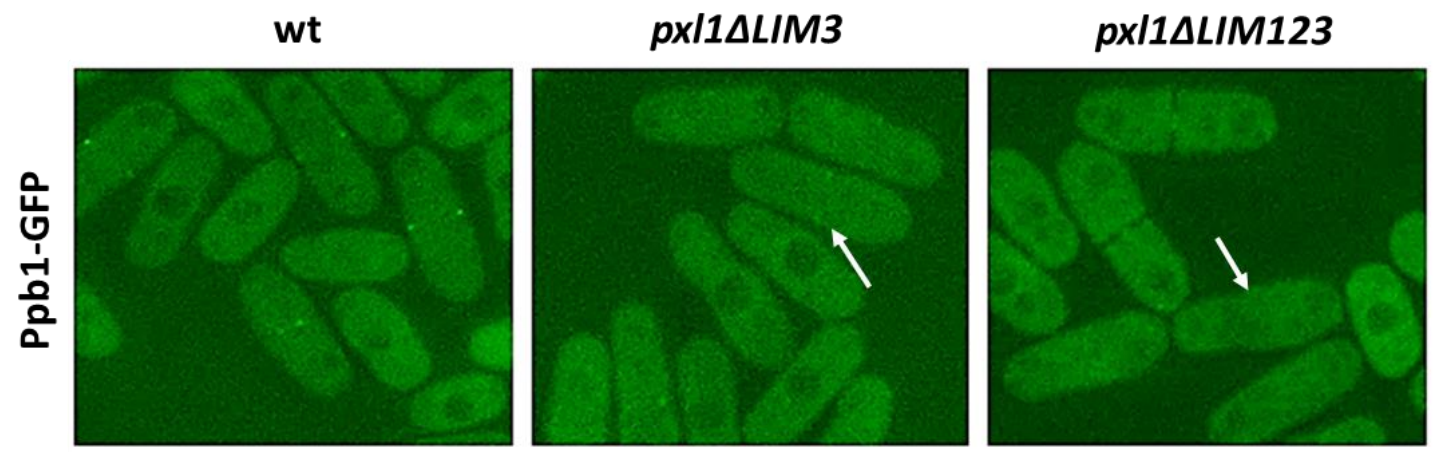

Figura 30.- Los dominios LIM de la paxilina son necesarios para la localización de la calcineurina en el anillo. (A) Esquema de paxilina donde se muestra la secuencia rica en prolinas en su región $\mathrm{N}$-terminal y tres dominios LIM en su parte C-terminal. (B) Microscopía de fluorescencia de una cepa silvestre y de cepas que carecen de uno o de los tres dominios LIM de la paxilina. Las cepas expresan de forma endógena la calcineurina fusionada con la proteína fluorescente verde (Ppb1-GFP) y se incubaron a $28^{\circ} \mathrm{C}$ en medio YES (PPG11417, PPG14632 y PPG13473). Las flechas blancas indican la pérdida de localización de Ppb1-GFP.

La mitad N-terminal de la paxilina es la encargada de la localización de esta en el anillo, por tanto, no se analizó el truncamiento de este extremo de la proteína en experimentos de localización de Ppb1-GFP ya que si no se localiza la paxilina tampoco se localizaría la calcineurina (Pinar et al., 2008). Se realizaron ensayos de pull down utilizando Pxl1 y diferentes truncamientos de la proteína carentes de sus regiones $\mathrm{N}$ terminal o C-terminal fusionados con GST, producidos en bacteria de forma recombinante y unidos a bolas de glutatión-sefarosa. Estas bolas se incubaron con extractos celulares de cepas que poseen la subunidad catalítica de la calcineurina marcada (Ppb1-HA). Los resultados muestran que tanto la deleción de la mitad $\mathrm{N}$ terminal como la de los tres dominios LIM del extremo C-terminal producen una pérdida de interacción de la paxilina con la subunidad catalítica de la calcineurina. Sin embargo, en ninguna de las deleciones se producía una pérdida total de la interacción, por lo que los dos extremos de la paxilina son capaces de interaccionar con Ppb1 (Figura 31B). 


\section{Resultados}

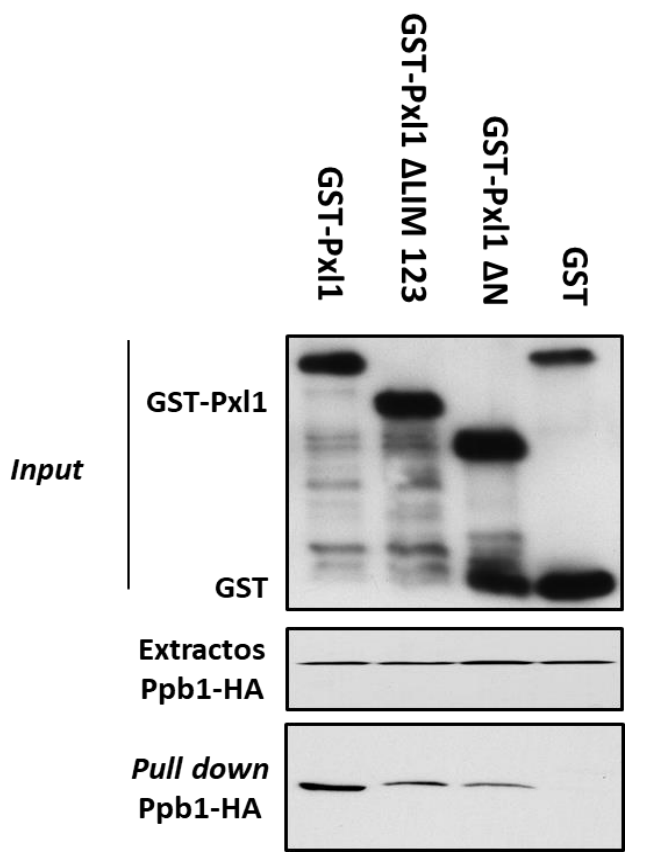

Figura 31.- Pxl1 interacciona con Ppb1. Ensayo de pull down con extractos de cepas que expresan la proteína Ppb1-HA (PPG11414). Los extractos de las cepas se incubaron con bolas de glutatión-sefarosa que llevan unidas GST, GST-PxI1 o los truncamientos de sus regiones N-terminal o C-terminal fusionados a GST y producidos en bacterias. Los precipitados y los extractos celulares fueron analizados con anticuerpos anti-GST y anti-HA.

\subsection{La paxilina tiene un motivo de unión a Ppb1 en su dominio LIM C-terminal que es necesario para la interacción con Ppb1 y su localización en el CAR.}

La paxilina interacciona con la calcineurina mediante distintos motivos presentes en sus regiones N- y C-terminal. En S. cerevisiae se han descrito dos motivos "consenso" diferentes de unión con calcineurina que están presentes en sus sustratos. El primer motivo, PxIxIT, se encuentra muy degenerado, pudiendo ser el residuo 3 y 5 cualquier aminoácido hidrofóbico mientras que el residuo 6 debe ser un aminoácido hidrofílico (Figura 32A). Esto hace que se puedan encontrar varios motivos de unión a calcineurina de mayor o menor afinidad dentro de la misma proteína (Roy and Cyert, 2009). El segundo motivo, LxVP, está implicado en la orientación del sustrato para su desfosforilación, incrementando la especificidad de unión de los motivos PxIxIT (Roy and Cyert, 2009). Se realizó una búsqueda in silico de motivos PxIxIT en la secuencia de aminoácidos de Pxl1, identificándose dos sitios putativos de unión a calcineurina que se ajustaban a la secuencia consenso descrita, aunque no en su totalidad: PTLPLQ en la mitad N-terminal (aminoácidos 181-186) y PILGIS en el extremo C-terminal (aminoácidos 384-389) (Figura 32B). Este último se encontraba en el tercer dominio LIM y sabíamos que la eliminación de ese dominio ya producía una pérdida casi completa de localización de la calcineurina. Para estudiar si los sitios identificados eran necesarios para la interacción realizamos una mutagénesis dirigida de ambos, cambiando todos sus aminoácidos por alaninas. Así obtuvimos las cepas mutantes 


\section{Resultados}

px/1-M3 y px/1-M4 con las secuencias PTLPLQ y PILGIS mutadas, respectivamente. Posteriormente realizamos ensayos de pull down para estudiar la interacción de los productos de los alelos mutantes de la paxilina, Pxl1-M3 y Pxl1-M4 con Ppb1 y los comparamos con la interacción de los truncamientos Pxl1 $\Delta$ LIM123 y PxI $1 \Delta N$. Se obtuvieron las diferentes versiones de Pxl1 fusionadas a GST, producidas de forma recombinante en bacterias y unidas a bolas de glutatión-sefarosa. Las bolas se incubaron con extractos de células que expresaban Ppb1-HA (Figura 32C). La proteína mutante Pxl1-M4 perdía parte de la interacción con Ppb1-HA, aunque no era una pérdida total como la del truncamiento que carece de los 3 dominios LIM, lo que indica que estos dominios poseen otros sitios de interacción con la calcineurina. Por otro lado, la proteína mutante Pxl1-M3 mantenía su interacción con la calcineurina, a diferencia de lo que pasaba en el truncamiento de su región $\mathrm{N}$-terminal. Esto nos indica que en esta región el sitio M3 no es responsable de la unión a la calcineurina y existen otros motivos de unión a Ppb1 con mayor afinidad.

A

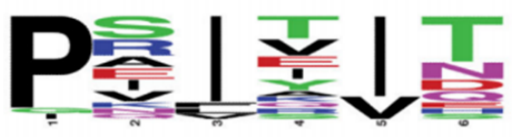

P\{PG\}[IVLF]\{PG\}[IVLF][TSHEDQNKR]

B

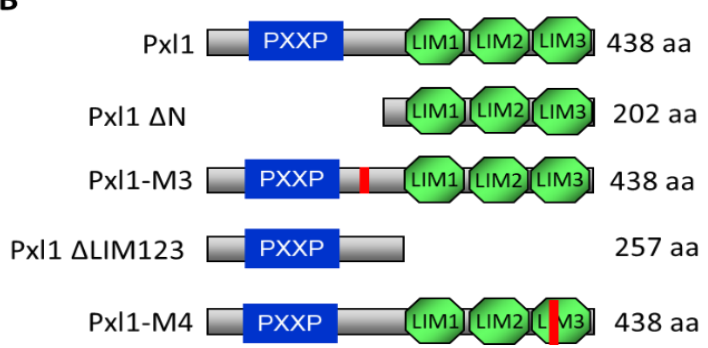

PxI1-M3: PTLPLQ $\rightarrow$ AAAAAA in 181-186 aa PxI1-M4: PILGIS $\rightarrow$ AAAAAA in 384-389 aa
C

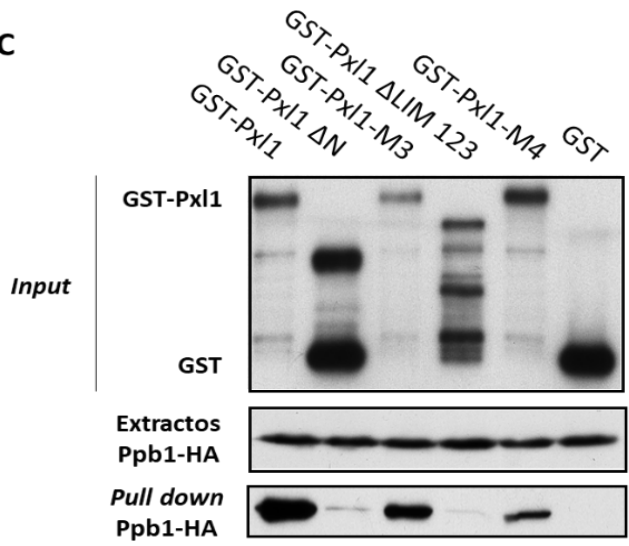

Figura 32.- Interacción de Pxl1 con la subunidad catalítica de la calcineurina. (A) Secuencia consenso del dominio de unión a sustrato de la calcineurina. El tamaño de cada letra es proporcional a su frecuencia en el dominio, los corchetes indican los aminoácidos que deben ocupar esa posición mientras que las llaves indican los aminoácidos que no pueden ocuparlas. Adaptado de Roy and Cyert, 2009. (B) Representación esquemática de los dominios de la paxilina, sus truncamientos y las mutaciones en los sitios putativos de interacción con la calcineurina. (C) Ensayo de pull down con extractos de células que expresan la proteína Ppb1-HA bajo su propio promotor (PPG11414). Los extractos de las cepas se incubaron con las bolas de glutatión-sefarosa que llevan unidas GST-PxI1, o GST fusionada a las versiones de Pxl1 sin las regiones $\mathrm{N}$ - terminal y C-terminal o a las proteínas mutadas en los sitios consenso de interacción con la calcineurina, Px|1-M3 o Pxl1-M4, producidas en bacterias. Los precipitados $v$ los extractos celulares fueron analizados con anticuerpos anti-GST $v$ anti-HA. 


\section{Resultados}

Para comprobar si las disminuciones de interacción observadas en las versiones truncadas o mutadas de Pxl1 provocaban la pérdida de localización de Ppb1, se observó mediante microscopía de fluorescencia la localización de esta fosfatasa en las cepas mutantes con las diferentes versiones de la paxilina y se analizaron los fenotipos de septación. Para ello se clonaron en el plásmido pJK148 las secuencias codificantes de la paxilina entera, las deleciones de la región $\mathrm{N}$-terminal y del tercer dominio LIM y los alelos mutantes en los sitios putativos de interacción con calcineurina. Todas las construcciones se clonaron bajo el control del promotor de $p x / 1^{+}$y se integraron en el locus leu1 ${ }^{+}$de una cepa que expresaba Ppb1-GFP y carecía de paxilina (Figura 33). En la cepa con el alelo mutante $p x / 1-M 3$ se observó que la calcineurina seguía localizándose en el CAR de igual forma que la cepa silvestre, al contrario de lo que ocurría en la cepa sin la región $\mathrm{N}$-terminal de la paxilina (pvalue=0,0012). Esta cepa se utilizó como control negativo ya que la paxilina pierde su localización en el anillo en ausencia de esta región, por lo que la calcineurina también la pierde. Se observó que la localización de la calcineurina disminuía parcialmente en la cepa mutante pxl1-M4 al igual que ocurría en la cepa que tenía la paxilina carente del tercer dominio LIM (pvalue=0,001). Además, el mutante pxl1-M4 presentaba los mismos defectos en citocinesis que la cepa sin el tercer dominio LIM, con la aparición de un elevado porcentaje de células septadas y multiseptadas que es ligeramente inferior al porcentaje de la cepa que no expresa paxilina. Por otra parte, en el mutante $p x / 1-M 3$ no disminuía significativamente la localización de Ppb1 presentando un porcentaje de septación muy similar al de la cepa silvestre. Por tanto, se confirmó que la calcineurina interacciona con la paxilina a través del motivo PxIxIT presente en su tercer dominio LIM y que la falta de interacción con Ppb1 de Pxl1LLIM3 y Pxl1-M4 provoca la deslocalización de la calcineurina en el CAR.

A

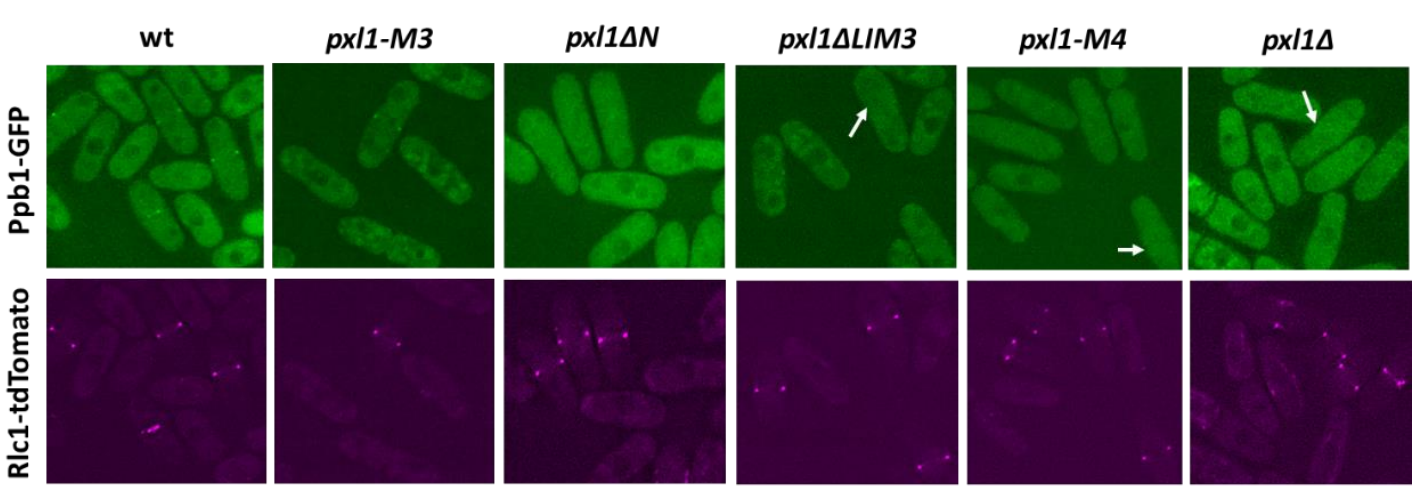


B

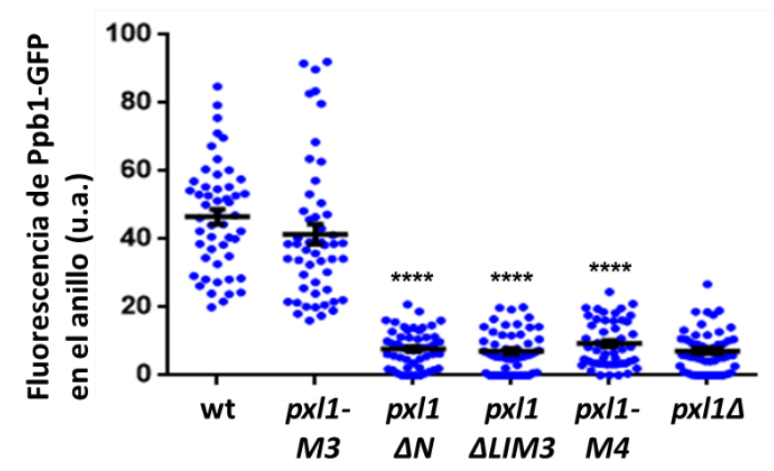

C

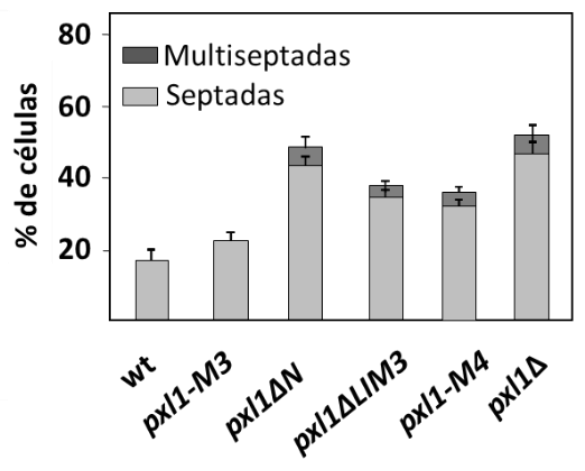

Figura 33.- La calcineurina se localiza en el CAR de la cepa mutante pxl1-M3 y su localización se pierde en la cepa pxI1-M4. (A) Microscopía de fluorescencia de las cepas: silvestre, carente del tercer dominio LIM o carente de la región $\mathrm{N}$-terminal de la Pxl1 y de las cepas que expresan los alelos mutantes de px/1 en los posibles sitios de unión a calcineurina (px/1-M3 y px/1-M4) (PPG13807, PPG14310, PPG14362, PPG14366, PPG14313 y PPG12264). Las células se incubaron a $28^{\circ} \mathrm{C}$ en medio YES. Todas las cepas expresan además de forma endógena Ppb1-GFP y RIc1-tdTomato. Las flechas blancas indican la pérdida de localización de Ppb1-GFP (B) Cuantificación de la intensidad de fluorescencia en el anillo de Ppb1GFP en las cepas anteriores. Solo se cuantificó la señal en las células en las que en el anillo se encontraba completamente formado y abierto. Los valores obtenidos se miden en unidades arbitrarias (u.a.). (C) Porcentaje de células septadas y multiseptadas en las cepas estudiadas.

\subsection{La función principal de la paxilina es la localización de la calcineurina en el} CAR

Los resultados obtenidos indican que la localización de la calcineurina en el anillo contráctil de actomiosina es dependiente de su interacción con la paxilina, identificándose un sitio de unión a la calcineurina en el tercer dominio LIM que la localiza en el CAR. Para comprobar que esta es la función principal de la paxilina y, por tanto, que la ausencia de la fosfatasa es la causa del fenotipo observado en la cepa $p x / 1 \Delta$, se dirigió de forma artificial la calcineurina al CAR en una cepa carente de paxilina. Para esto se utilizó una estrategia que permite anclar una proteína marcada con GFP a una segunda proteína fusionada con GBP (GFP B Binding Protein). La GBP posee una elevada afinidad de unión a GFP, de esta manera, nos permite localizar a una proteína marcada con la proteína fluorescente hacia un lugar concreto de la célula (Chen et al., 2017). Fusionamos la cadena ligera reguladora de las miosinas Rlc1 con GBP o GBP-mCherry en una cepa que expresa Ppb1-GFP y que carece de paxilina. En esta cepa se observó que la calcineurina volvía a localizarse en el anillo junto a Rlc1 dirigida por el dominio GBP, por tanto, la estrategia para localizar a la fosfatasa en el CAR funcionaba correctamente (Figura 34A). Además, la localización de la calcineurina en el anillo disminuyó los defectos en citocinesis de la cepa pxl1 $1 \Delta$ pb1-GFP, observándose una reducción en el porcentaje de células en septación (Figura 34B). Esto sugiere que la función principal de la paxilina es la localización de la calcineurina en el CAR. 


\section{Resultados}

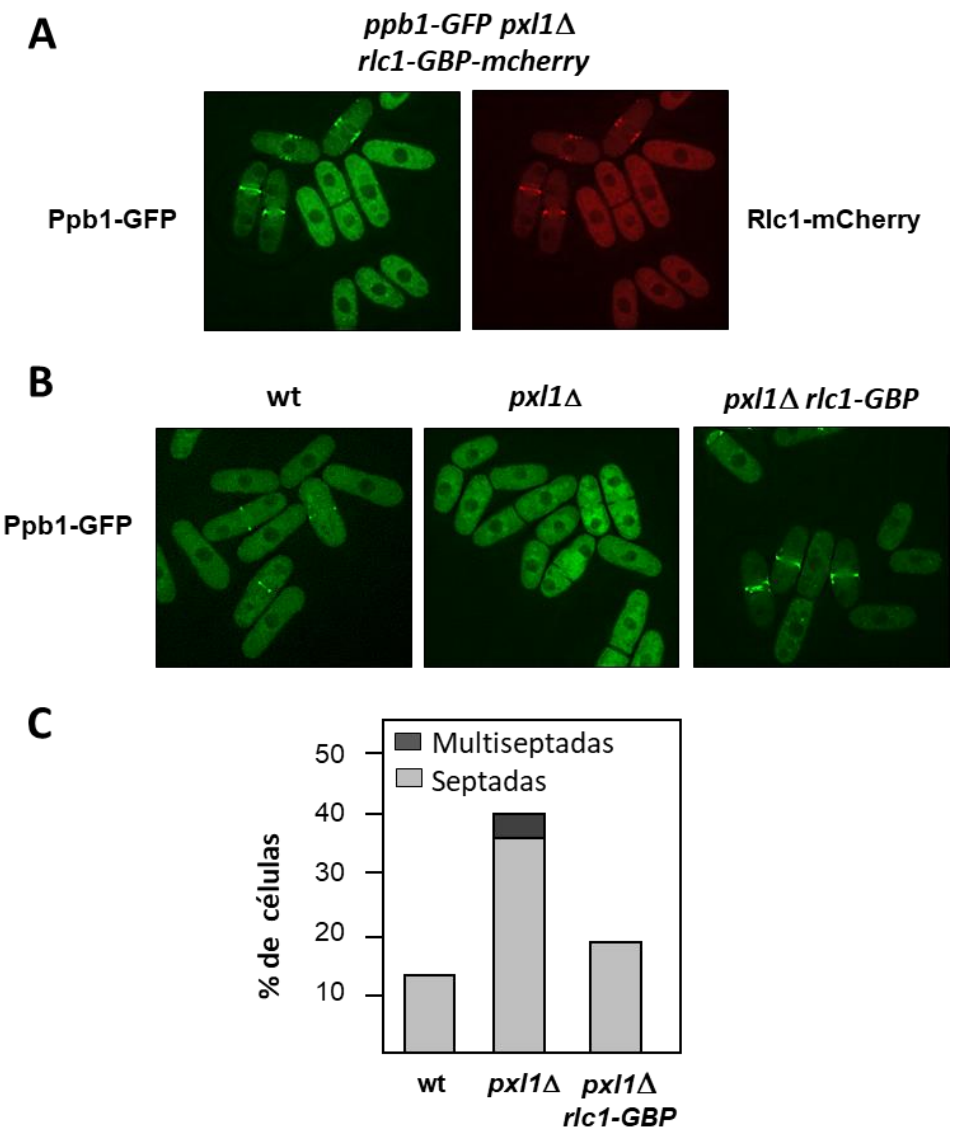

Figura 34. La localización de Ppb1 en el anillo suprime los defectos de la cepa px/14. (A) Microscopía de fluorescencia de la cepa que expresa de forma endógena la calcineurina fusionada con la proteína fluorescente verde (Ppb1-GFP) y la cadena ligera reguladora de las miosinas fusionada con la proteína de unión a GFP y mCherry (RIc1-GBP-mCherry) incubadas a $28^{\circ} \mathrm{C}$ en medio YES (PPG15528). (B) Microscopía de fluorescencia de las cepas silvestre y pxl1 $\Delta$ que expresan de forma endógena la calcineurina fusionada con la proteína fluorescente verde (Ppb1-GFP) y poseen o no la cadena ligera reguladora de las miosinas fusionada con la proteína de unión a GFP (Rlc1-GBP). Células incubadas a $28^{\circ} \mathrm{C}$ en medio YES (PPG11417, PPG15525 y PPG15526). (C) Porcentaje de células septadas y multiseptadas en las cepas estudiadas.

\subsection{La localización de la calcineurina en el CAR no depende de los dominios LIM de otras proteínas}

Nos preguntamos si otras proteínas con dominios LIM podrían intervenir también en la localización de la calcineurina en el CAR. En S. pombe existen otras 3 proteínas con dominios LIM: Rga1, Rga3 y Rga4, todas ellas presentan dominios RhoGAP y se han descrito como reguladoras negativas (GAPs) de las GTPasas Rho1 y Cdc42 (Nakano et al., 2001). Primero se realizó un análisis comparativo para estudiar el porcentaje de identidad de estas proteínas con la secuencia del tercer dominio LIM de la paxilina, en el que previamente se había identificado un dominio de unión a Ppb1, mediante el uso de BLAST (Figura 35A). Además de la identidad total con la secuencia del dominio LIM3 de la paxilina, el análisis detectó una identidad parcial con los dominios LIM de Rga1 y Rga3 y no identificó identidad significativa con la secuencia de Rga4. Por otro lado, el 


\section{Resultados}

análisis in silico de las secuencias de los dominios LIM de estas proteínas determinó que todas ellas presentan sitios putativos de unión a calcineurina PxIxIT (Figura 35B).

A

\begin{tabular}{|c|c|c|c|c|c|}
\hline Descripción & $\begin{array}{l}\text { Punt. } \\
\text { Max }\end{array}$ & $\begin{array}{l}\text { Punt. } \\
\text { Total }\end{array}$ & $\begin{array}{l}\text { Cober. } \\
\text { Sec }\end{array}$ & \begin{tabular}{c|}
$E$ \\
Value
\end{tabular} & $\begin{array}{l}\text { Porcentaje } \\
\text { Identidad }\end{array}$ \\
\hline paxillin-like protein Pxl11 [Schizosaccharomyces pombe] & 135 & 135 & $98 \%$ & $6 e-41$ & $100.00 \%$ \\
\hline Rho-ty.pe GTPase-activating.protein Rga 3 [Schizosaccharomyces pombe] & 32.0 & 32.0 & $85 \%$ & 0.003 & $25.93 \%$ \\
\hline Rho-type GTPase-activating.protein Rga1 1 Schizc & 31.6 & 31.6 & $76 \%$ & 0.004 & $29.63 \%$ \\
\hline
\end{tabular}

B

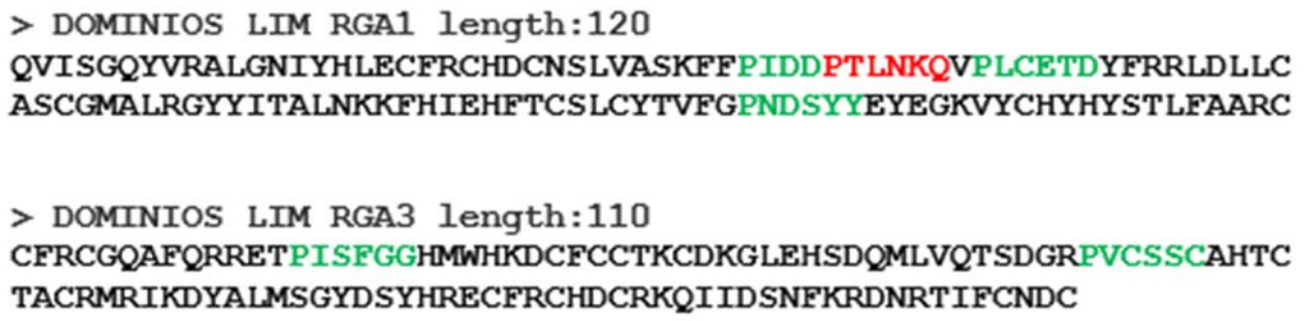

Figura 35.- Los dominios LIM de Rga3 y Rga1 presentan una ligera identidad con el tercer dominio LIM de paxilina. (A) BLAST del tercer dominio LIM de la paxilina para la estudiar el porcentaje de identidad con los dominios LIM de Rga1, Rga3 y Rga4. (B) Análisis in silico de los motivos PxIxIT en las secuencias de Rga1, Rga3 y Rga4. Los motivos en rojo presentan alta identidad, mientras que las secuencias en verde presentan baja identidad con la secuencia consenso.

Visto que Rga1 y Rga3 poseían una identidad parcial con la secuencia del tercer dominio LIM de la paxilina y que las tres proteínas poseían dominios PxIxIT, aunque la mayoría degenerados, se estudió la localización de Ppb1-GFP en las cepas que carecían de estos GAPs. La cepa mutante rga1 1 muestra defectos en la morfogénesis con la aparición de células redondeadas e hinchadas, con un aumento de células en septación y la aparición de células multiseptadas o ramificadas durante la citocinesis (Nakano et al., 2001). En esta cepa Ppb1-GFP se localizaba correctamente en el CAR sin diferencias apreciables en su intensidad (pvalue $=0,101$ ) (Figura 36A). La cepa mutante rga3 $\Delta$ no presenta defectos morfológicos aparentes (Nakano et al., 2001) y Ppb1-GFP es capaz de localizarse normalmente en el CAR durante la citocinesis (pvalue $=0,299$ ) (Figura 36B). Por último, la cepa mutante rga4 4 posee defectos en su morfología celular con células ligeramente más redondeadas y un leve defecto en citocinesis (Nakano et al., 2001) pero Ppb1-GFP es capaz de localizarse en el CAR como en la cepa silvestre (pvalue $=0,206$ ) (Figura 36C). Por tanto, los dominios LIM de la paxilina son los únicos necesarios para localizar a la calcineurina en el CAR cuando el anillo se encuentra formado y abierto. No excluimos la posibilidad de que las otras proteínas con dominios LIM tengan una función accesoria a la de la paxilina, estas podrían ser necesarias para 


\section{Resultados}

localizar a la calcineurina en el CAR al final de la contracción en ausencia de la paxilina. Para comprobarlo sería necesario estudiar la localización de la calcineurina en ausencia de paxilina y de cada una de estas proteínas. No obstante, dichos experimentos son difíciles de interpretar y/o cuantificar ya que en muy pocas células (7\%) en el anillo se observa al final de la contracción una mínima cantidad de calcineurina.

A
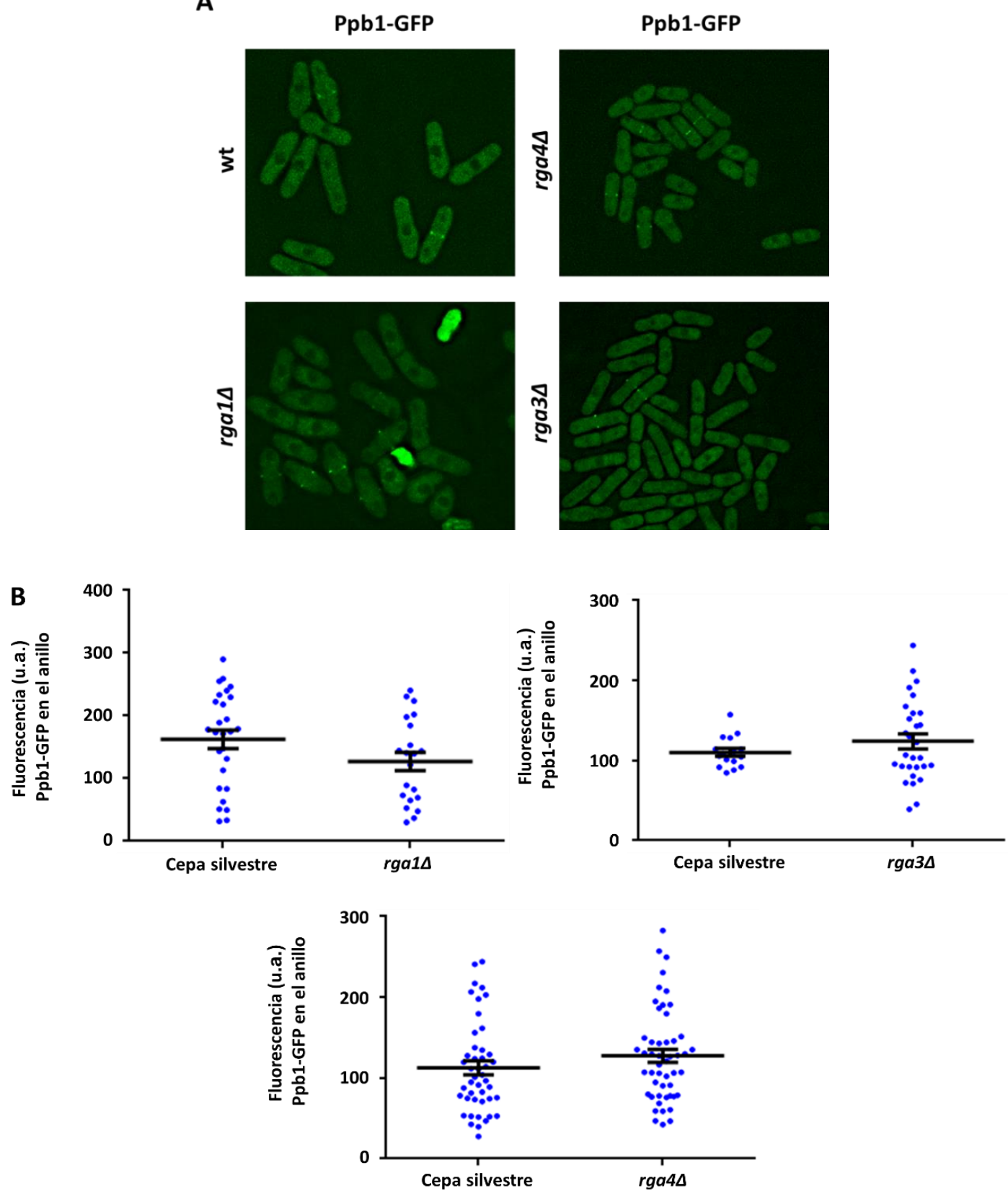

Figura 36.- Las proteínas GAP Rga1, Rga3 y Rga4 no parecen tener un papel en la localización de la calcineurina en el anillo. (A) Microscopía de fluorescencia de una cepa silvestre y las cepas

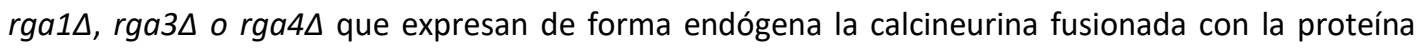
fluorescente verde (Ppb1-GFP) incubadas a $28^{\circ} \mathrm{C}$ en medio YES (PPG11417, PPG15501, PPG15540 y PPG15570). (B) Cuantificación de la intensidad de fluorescencia en el anillo de Ppb1-GFP en las cepas anteriores. 


\section{Resultados}

1.12 Caracterización de un posible motivo de unión a la paxilina en la subunidad catalítica de la calcineurina

Se han descrito dos motivos diferentes de unión a la calcineurina en sus proteínas diana (PxIxIT y LxVP), estos sitios son necesarios para la unión del sustrato y para su correcta orientación respectivamente. De igual forma se ha descrito un motivo (FMDVF) presente en la subunidad catalítica de la calcineurina de Aspergillus fumigatus que está muy conservado en hongos y que es necesario para su localización en el anillo de actomiosina. En Aspergillus, las mutaciones en los residuos F368 y F372 de este sitio de unión provocan la pérdida de localización de la subunidad catalítica de la calcineurina por la falta de unión a los motivos PxIxIT y LxVP de sus sustratos (Juvvadi et al., 2011). Para analizar la función del motivo FMDVF presente en Ppb1, la subunidad catalítica de la calcineurina de $S$. pombe, realizamos una mutagénesis dirigida de los aminoácidos terminales cambiándolos por alanina, por separado (FMDVF $\rightarrow$ AMDVF o FMDVF $\rightarrow$ FMDVA) y ambos a la vez (FMDVF $\rightarrow$ AMDVA). Se expresó el alelo mutante que codifica la proteína con ambos aminoácidos mutados, Ppb1-AA, en el plásmido pREP41 bajo el control del promotor nmt41 reprimible por tiamina en una cepa que poseía la deleción de $p p b 1^{+}$. En las células que expresaban este alelo de la calcineurina no se observó localización en la zona de división, lo que sugiere que este sitio de unión podría ser esencial para la interacción con los dominios PxIxIT y LxVP de los sustratos (Figura 37A). En S. pombe, al igual que en Aspergillus, este motivo solapa con el sitio de unión de la subunidad reguladora, la ciclosporina A y FK506. Por tanto, la falta de localización de Ppb1 podría deberse tanto a la pérdida de interacción con la paxilina como a una posible ausencia de activación de la calcineurina. Se realizó un ensayo para medir el nivel de activación de la calcineurina analizando la expresión de la proteína fluorescente verde (GFP) bajo el control de un promotor con tres elementos de respuesta a calcineurina (CDRE), así, cuanto más activa se encuentre la calcineurina más se expresará la GFP (Figura 37B). En los mutantes simples F368A y F372A del dominio de unión de Ppb1 se pierde casi completamente la actividad de la calcineurina y en el mutante doble la actividad desaparece por completo. Esto indica que la falta de localización de la calcineurina mutada se debe a una disminución de su funcionalidad de la calcineurina producida, probablemente, por la incapacidad de unirse a la subunidad reguladora Cnb1. 
A

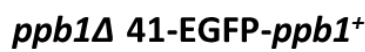

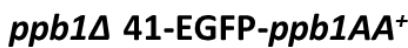
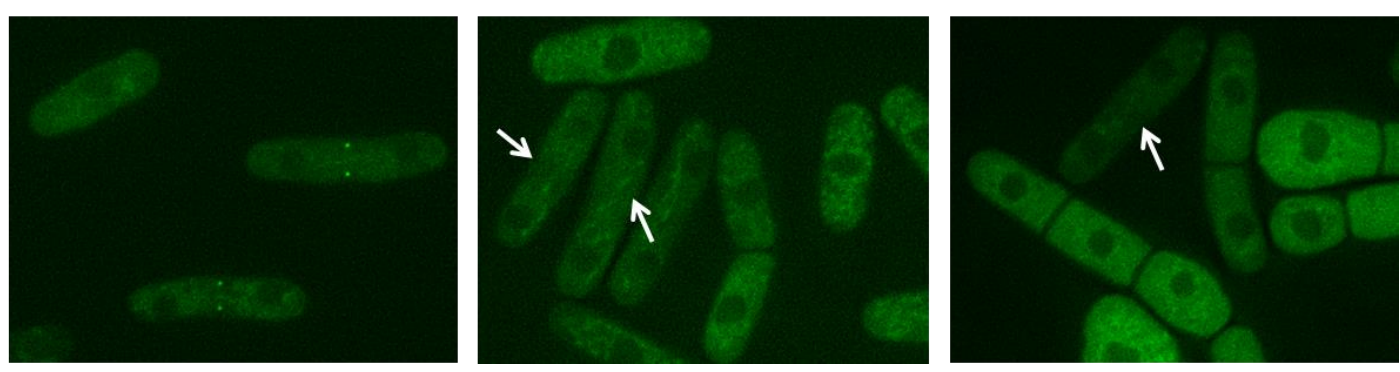

B

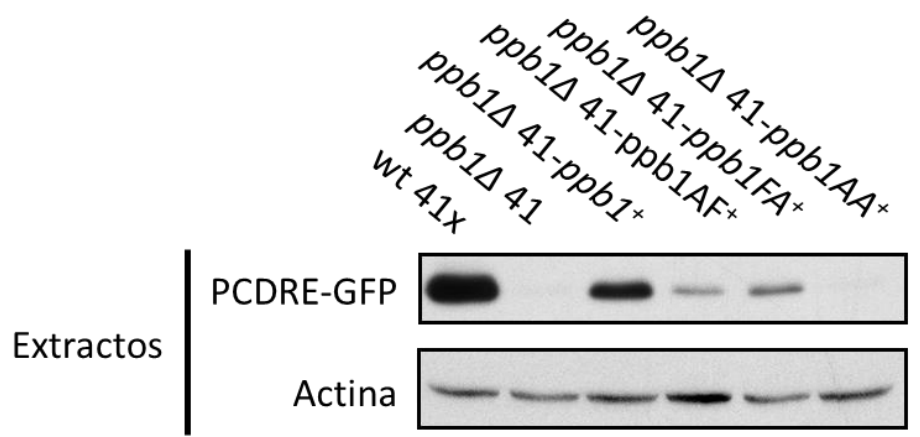

Figura 37.- Los mutantes de los sitios de unión a sustrato en la subunidad catalítica de la calcineurina codifican una proteína poco activa y por tanto no se localiza en el anillo contráctil. (A) Microscopía de fluorescencia de una cepa $p p b 1 \Delta$ que expresa la subunidad catalítica de la calcineurina o su versión mutada de los sitios de unión a sustrato en el plásmido pREP41. Células incubadas a $28^{\circ} \mathrm{C}$ en medio YES (PPG15273 y PPG15274). Las flechas blancas indican la pérdida de localización de Ppb1-GFP. (B) Ensayo de actividad de la calcineurina mediante análisis de la expresión de la proteína fluorescente verde controlada por tres elementos de respuesta a calcineurina CDRE en la cepa silvestre, en $p p b 1 \Delta$ y en las cepas $p p b 1 \Delta$ con la subunidad catalítica de la calcineurina o sus versiones mutadas en los sitios de unión a sustrato expresadas en el plásmido pREP41 (PPG15505, PPG15506, PPG15507, PPG15508, PPG15509 y PPG15510). Los extractos celulares se analizaron mediante Western blot utilizando anticuerpos anti-GFP y anti-actina. Se utilizó la cepa carente de la subunidad catalítica Ppb1 como control negativo y la actina como control de carga.

2. La calcineurina es necesaria para la localización de la paxilina en el anillo y para la desfosforilación de Cdc15

2.1 La localización de la calcineurina en el anillo provoca la llegada de más paxilina al anillo creándose un feedback loop positivo

Anteriormente se ha descrito que la localización de la calcineurina en el CAR al inicio de su contracción depende de la paxilina, que llega antes al CAR que la fosfatasa. Además, se ha observado que la concentración de paxilina va aumentando en el anillo de actomiosina hasta el final de su contracción (Cortés et al., 2015). Por tanto, consideramos que quizás la calcineurina fuese necesaria para la acumulación de la paxilina en el CAR. Para ver si este era el caso, se realizaron experimentos de video microscopía de fluorescencia con una cepa que expresaba la paxilina y la subunidad de la tubulina Atb2 fusionadas con las proteínas fluorescentes verde y roja respectivamente (GFP-Pxl1 y mCherry-Atb2). El marcaje de la tubulina posibilita 


\section{Resultados}

observar la formación del huso mitótico a partir del cuerpo polar del huso, permitiéndonos estudiar cómo avanza la citocinesis considerándose tiempo 0 la aparición de los microtúbulos del huso mitótico. Así se pudo observar la localización de la paxilina a lo largo de la citocinesis en células que expresaban o no la subunidad catalítica de la calcineurina. En ausencia de esta fosfatasa, se observó que la paxilina llegaba al anillo aproximadamente 6 minutos más tarde, cuando el núcleo ya ha comenzado a separase y el huso mitótico ya casi ha alcanzado los polos celulares (Figura 38A). El pico máximo de intensidad de paxilina en el CAR en la cepa ppb1 $\Delta$ se alcanzaba 30 minutos más tarde y era un $50 \%$ inferior al de la cepa silvestre (Figura 38B). Además, la velocidad de contracción del CAR disminuía al igual que pasaba en la cepa carente de paxilina (Pinar et al., 2008). Parece, por tanto, que existe una dependencia mutua de ambas proteínas formándose un bucle o feedback loop positivo por el cual se necesita Pxl1 para que Ppb1 se localice en el anillo y ésta a su vez es necesaria para que se acumule más Pxl1 en el anillo y así reclutar más calcineurina durante la contracción.

A

GFP-Pxl1 mCherry-Atb2

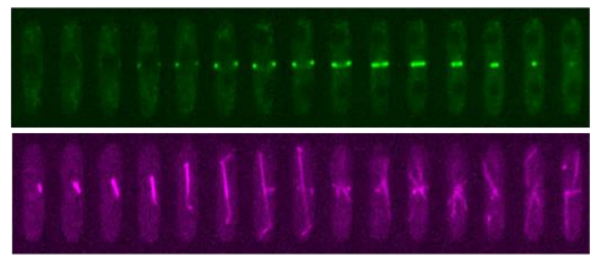

Intervalos de $3 \mathrm{~min}$

ppb1 1 GFP-Pxl1 mCherry-Atb2

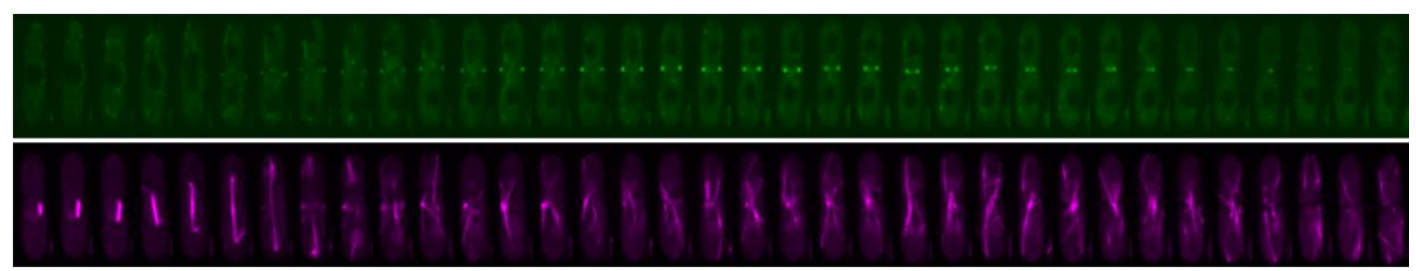

Intervalos de $3 \mathrm{~min}$ 


\section{Resultados}

B

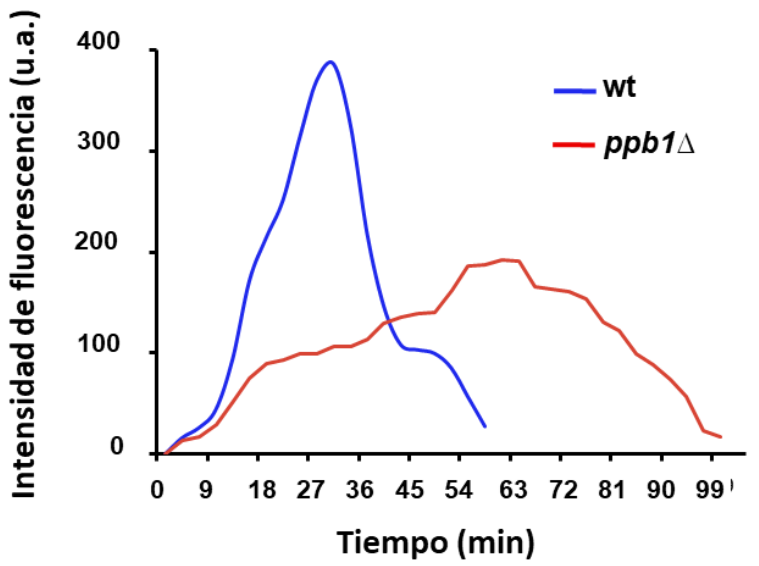

Figura 38.- En ausencia de calcineurina la paxilina se localiza en el anillo más tarde y no se acumula durante la citocinesis. (A) Video microscopía de una cepa silvestre y otra carente de calcineurina ( $p p b 1 \Delta)$ que expresan la paxilina fusionada con la proteína fluorescente verde (GFP-Pxl1) y la tubulina fusionada con mCherry (mCherry-Atb2) (PPG14879 y PPG14877). Las células se incubaron a $28^{\circ} \mathrm{C}$ en medio YES. (B) Cuantificación de la intensidad de fluorescencia en el anillo de GFP-Pxl1 en las cepas anteriores.

\subsection{La paxilina no parece ser desfosforilada por la calcineurina para localizarse en el CAR}

La paxilina es la proteína encargada de localizar a la calcineurina en el anillo de actomiosina que a su vez provoca la llegada de más paxilina al CAR. Por tanto, podría ser que la calcineurina desfosforilara a la paxilina, favoreciendo su localización o su interacción con otras proteínas del anillo. Así se analizó el estado de fosforilación de la paxilina en cepas que poseían esta proteína marcada con GFP y que a la vez poseían o no la subunidad catalítica Ppb1 en cultivos asincrónicos. Se realizaron ensayos de Western blot con phos-tag, que es un marcaje específico de los grupos fosfato. Este se incorpora al gel de acrilamida y permite aumentar el peso molecular de la proteína de estudio según su fosforilación, de esta forma se pueden analizar las proteínas fosforiladas con mayor facilidad (Figura 39). Se observaron diferentes bandas de Pxl1 en los extractos de las cepas analizadas, lo que nos indica la existencia de diferentes estados de fosforilación de Pxl1, por lo que podemos concluir que probablemente esta es una fosfoproteína. Sin embargo, no se observó ningún cambio en el patrón de bandas de esta proteína en la cepa que carecía de la subunidad catalítica Ppb1, por lo que no parece que la paxilina sea desfosforilada por esta fosfatasa. El único efecto observado fue una disminución de la cantidad de total de paxilina en las cepas carentes de calcineurina. Por tanto, esta fosfatasa no solo influye en su localización, sino que también afecta a los niveles de Pxl1 totales en la célula, pero no sabemos cómo lo hace. 


\section{Resultados}

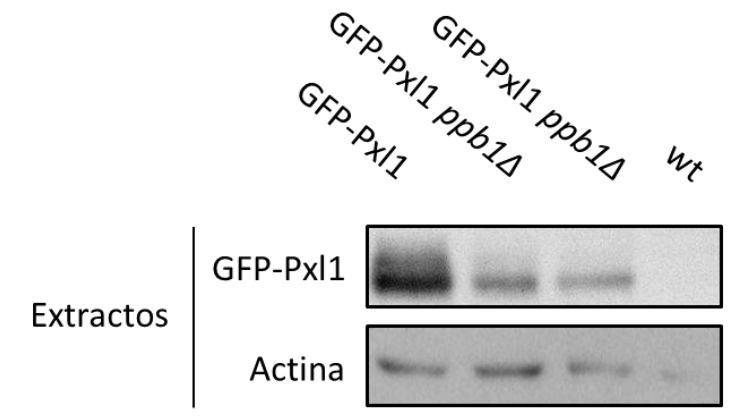

Figura 39.- Western blot de extractos de una cepa silvestre y cepas que expresan GFP-Pxl1 bajo el control de su propio promotor en un cultivo asincrónico y que poseen o no el gen de la subunidad catalítica de la calcineurina ppb1 ${ }^{+}$(PPG05060, PPG14825 y PPG04939). Los extractos celulares fueron analizados utilizando anticuerpos anti-GFP y la actina fue utilizada como control de carga.

\subsection{La calcineurina afecta a la fosforilación de Cdc15 in vivo}

Puesto que el fenotipo más obvio de la falta de calcineurina son los defectos de citocinesis y Cdc15 está implicada en este proceso sirviendo de anclaje del anillo a la membrana plasmática, quisimos ver si existía alguna relación entre la calcineurina, la paxilina y Cdc15. Se ha descrito que la localización de la paxilina en el anillo de actomiosina es dependiente de la unión a los dominios SH3 de Cdc15 e Imp2 que también funcionan como proteínas de anclaje de otros componentes del CAR (Ren et al., 2015; Roberts-Galbraith et al., 2009). En ausencia del dominio SH3 de Cdc15 la paxilina se localiza en el anillo pero lo hace en menor cantidad y no aumenta su nivel durante la citocinesis (Cortés et al., 2015).

También se ha descrito que la desfosforilación de Cdc15 provoca un cambio en su conformación que aumenta la capacidad de reclutar a los componentes del anillo como la paxilina (Roberts-Galbraith et al., 2010). Por ello se pensó en la posibilidad de que la calcineurina pudiera desfosforilar a Cdc15 para estimular el reclutamiento de más paxilina al CAR, formándose así el feedback loop positivo que hemos observado. En primer lugar, para comprobar si había interacción entre la calcineurina y Cdc15 se realizaron experimentos de coinmunoprecipitación entre ambas proteínas durante la citocinesis utilizando cultivos sincrónicos. Para ello se utilizó una cepa mutante termosensible de Cdc25, la fosfatasa inductora de la fase $\mathrm{M}$ del ciclo celular, cdc25-22. Este mutante detiene su ciclo en la fase G2 cuando es incubada a la temperatura restrictiva de $36^{\circ} \mathrm{C}$ y es capaz de continuarlo cuando se cambia a la temperatura permisiva de $25^{\circ} \mathrm{C}$. Se construyó una cepa cdc25-22 que además expresaba de forma simultánea la subunidad catalítica de la calcineurina fusionada con GFP (Ppb1-GFP) y Cdc15 con el epítopo HA (Cdc15-HA). Como control se utilizaron las cepas que expresaban únicamente una de estas dos proteínas marcadas también en la cepa mutante $c d c 25-22$. Las células se cultivaron a $25^{\circ} \mathrm{C}$ y posteriormente se incubaron 4 horas a $36^{\circ} \mathrm{C}$. Tras este bloqueo en $\mathrm{G} 2$, las células se pasaron a $25^{\circ} \mathrm{C}$ para que continuaran el ciclo y se obtuvieron muestras a los 30 minutos para realizar el ensayo 


\section{Resultados}

de coinmunoprecipitación. Los extractos celulares de los cultivos sincronizados se incubaron con anticuerpos policlonales anti-GFP y proteína A-sefarosa. Tras la incubación se realizó un Western blot empleando anticuerpos monoclonales anti-GFP o anti-HA para detectar Ppb1-GFP y Cdc15-HA respectivamente en los inmunoprecipitados y en los extractos celulares. Tras el revelado se pudo observar la banda correspondiente a Cdc15-HA en el inmunoprecipitado de la cepa que poseía ambas proteínas marcadas (Figura 40). Estos resultados sugieren la existencia de una interacción de Cdc15 con Ppb1 que podría ser directa o mediada por otra proteína. Una posibilidad es que esa unión fuera dependiente de la paxilina y esto se podría demostrar realizando la misma coinmnuprecipitación en una cepa $p x / 1 \Delta$. Se intentó obtener una cepa con Cdc15 marcada con el epítopo HA en su propio locus y carente de paxilina $p x / 1 \Delta$. Sin embargo, tal y como estaba descrito (Cortés et al., 2015), esta cepa resultó ser inviable, al igual que otras que intentamos construir utilizando otros marcadores en ambos extremos de la proteína Cdc15.

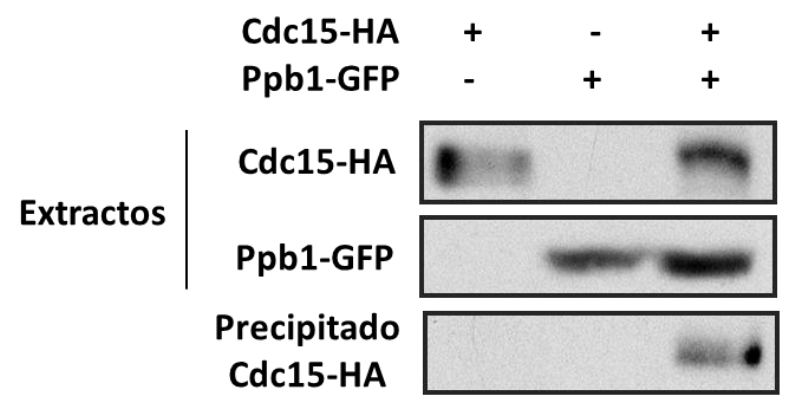

Figura 40.- Ppb1 interacciona con Cdc15. Ensayo de coinmunoprecipitación de Cdc15-HA y Ppb1-GFP expresadas bajo el control de sus propios promotores en la cepa mutante cdc25-22 (PPG15420). Como control se utilizaron las cepas que expresaban únicamente marcadas Ppb1-GFP o Cdc15-HA (PPG15403 y PPG14861). Se obtuvieron extractos celulares de las cepas sincronizadas mediante incubación a $36^{\circ} \mathrm{C}$ durante $4 \mathrm{~h}$ y posterior liberación a $25^{\circ} \mathrm{C}$ durante $30^{\prime}$. Se incubaron con anticuerpos policlonales anti-GFP unidos a proteína A-sefarosa para inmunoprecipitar Ppb1. Los extractos y los inmunoprecipitados fueron analizados con anticuperpos anti-HA y anti-GFP.

La interacción de Cdc15 y Ppb1 permitía pensar que Cdc15 fuera un sustrato de esta fosfatasa y ésta fuera capaz de regularla modificando su estado de fosforilación. Esta posibilidad se podría demostrar analizando el patrón de fosforilación de Cdc15 en ausencia de actividad calcineurina. Para ello, en primer lugar, se intentó obtener una cepa con Cdc15 marcada en su extremo N-terminal con GFP y carente de la subunidad catalítica $p p b 1 \Delta$. Sin embargo, al igual que pasaba en la cepa que carecía de paxilina, esta cepa resultó ser inviable. De esta forma se concluyó que el marcaje de Cdc15 en ambos extremos afecta a la funcionalidad de la proteína y parece que en ausencia de calcineurina es necesario que esta proteína sea completamente funcional. 


\section{Resultados}

Como estrategia alternativa para estudiar si Cdc15 era un sustrato de la calcineurina y poder observar un cambio en su estado de fosforilación en ausencia de la actividad de esta fosfatasa, se trató la cepa GFP-Cdc15 con FK506, un compuesto inhibidor de la calcineurina, a una concentración de $20 \mu \mathrm{g} / \mathrm{ml}$ durante 6 horas, lo que permite su completa inactivación. A continuación, se realizaron ensayos de Western blot para detectar Cdc15 en los extractos de un cultivo asincrónico de células sin tratar o tratadas con FK506. Los resultados obtenidos confirman que, en la muestra con la calcineurina inactivada por FK506, Cdc15 presenta distinta movilidad electroforética y por tanto podría encontrarse más fosforilada que en la cepa silvestre (Figura 41A). Esto sugiere que Cdc15 puede ser un sustrato de la calcineurina o que esta fosfatasa afecta a su fosforilación in vivo.

Para analizar en más detalle cuándo se producía esa desfosforilación, se realizaron experimentos con células sincronizadas. Para ello se utilizó nuevamente la cepa mutante termosensible de $\mathrm{Cdc25}$, cdc25-22, que además llevaba la proteína Cdc15 marcada con GFP. Las células se cultivaron en fase exponencial a $25^{\circ} \mathrm{C}$, posteriormente se añadió FK506 $(5 \mu \mathrm{g} / \mathrm{ml})$ y se incubaron 4 horas a $36^{\circ} \mathrm{C}$. Tras este bloqueo en $\mathrm{G} 2$, las células se incubaron de nuevo a $25^{\circ} \mathrm{C}$ y se obtuvieron muestras cada 30 minutos para comprobar el estado de fosforilación de GFP-Cdc15. En la cepa sin tratar con FK506, tal y como se ha descrito previamente (Roberts-Galbraith et al., 2010), Cdc15 se desfosforila pasando a la configuración abierta que favorece el reclutamiento de otras proteínas del anillo y posteriormente se fosforila de nuevo. Sin embargo, la cepa tratada con FK506 presentaba un estado de hiperfosforilación de GFP-Cdc15 respecto a la cepa sin tratar ya en el comienzo de la incubación a $25^{\circ} \mathrm{C}$. A los 60 minutos, $\mathrm{Cdc} 15$ se encontraba más desfosforilada que al tiempo inicial, pero a niveles menores que los de la cepa sin tratar (Figura 41B). Estos resultados sugieren que la desfosforilación de Cdc15 durante la citocinesis depende parcialmente de calcineurina y que otras fosfatasas podrían estar también participando en ella. A los 90 minutos después de pasar los cultivos a $25^{\circ} \mathrm{C}$, empieza a recuperarse la fosforilación en la cepa sin tratar, alcanzando el máximo a los 120 minutos, mientras que en la cepa con FK506 se producía también la refosforilación pero retrasada (Figura 41B). Este desfase en la refosforilación de la cepa con la calcineurina inactivada coincide con el retraso en la septación de estas células. No obstante, no podemos saber si el defecto en la refosforilación es la consecuencia o la causa del aumento en el tiempo de septación.

Estudiamos también si la hiperfosforilación de Cdc15 producía algún cambio en su localización en cultivos asincrónicos. Para ello, se observó GFP-Cdc15 en una cepa silvestre con y sin tratamiento con el inhibidor FK506 a una concentración de $20 \mu \mathrm{g} / \mathrm{ml}$ durante 6 horas (Figura 41C). No se observaron diferencias de localización en el anillo entre las cepas con y sin tratamiento con FK506. En conjunto, estos resultados sugieren que la ausencia de calcineurina cambia el estado de fosforilación de Cdc15, esto afectaría a su conformación y por tanto alteraría la localización de otros 


\section{Resultados}

componentes del anillo. Sin embargo, ni la localización de Cdc15 dentro de la célula ni su concentración en el anillo son dependientes de calcineurina.

A
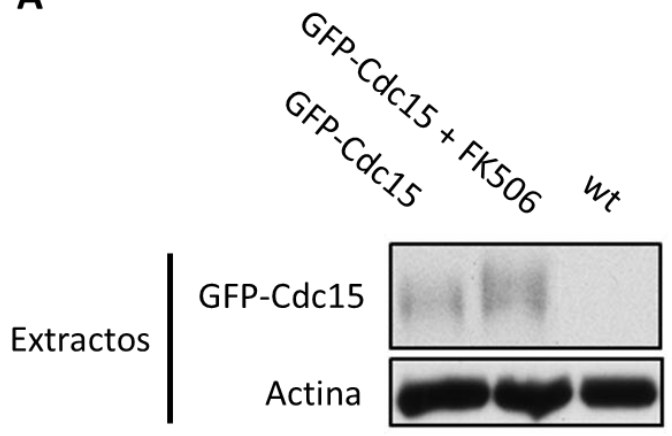

B

cdc25-22 GFP-Cdc15

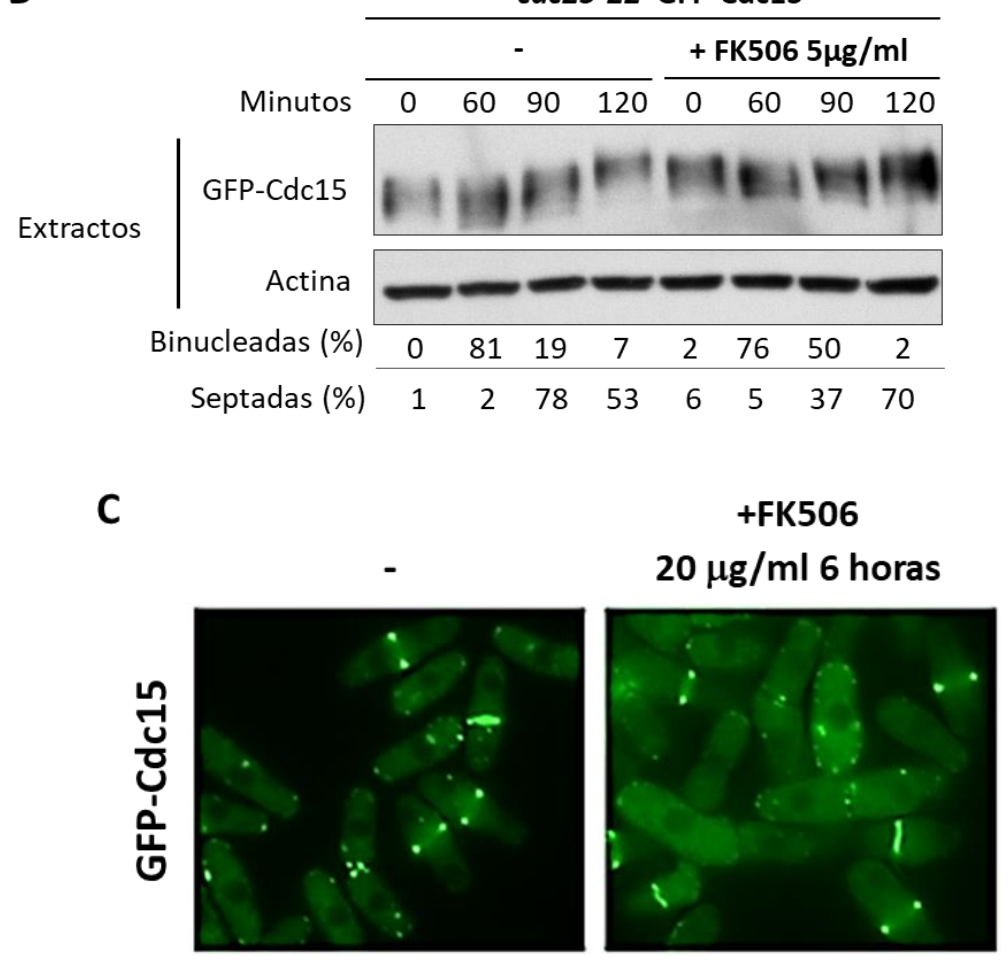

Figura 41.- Cd15 es un sustrato de la calcineurina. (A) Western blot de extractos de células que expresan GFP-Cdc15 bajo el control de su propio promotor en un cultivo asincrónico con y sin tratamiento con

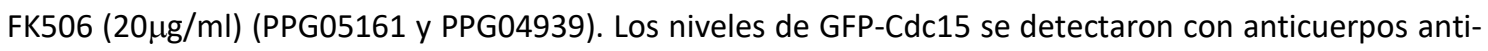
GFP. La actina fue utilizada como control de carga. (B) Western blot de extractos celulares obtenidos a diferentes tiempos de cultivos sincrónicos de la cepa mutante $c d c 25-22$ que expresa GFP-Cdc15 con y sin tratamiento con FK506 $(5 \mu \mathrm{g} / \mathrm{ml}$ ) (PPG14864). Los extractos se revelaron utilizando anticuerpos policlonales anti-GFP, mientras que la actina fue utilizada como control de carga. Se cuantificó el porcentaje de células binucleadas y en septación para observar el avance de la citocinesis en ambas cepas. (C) Microscopía de fluorescencia de una cepa silvestre que expresa GFP-Cdc15 incubada a $28^{\circ} \mathrm{C}$ en

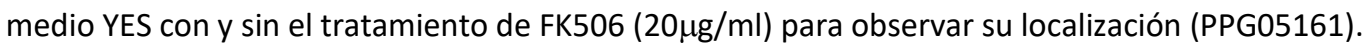




\section{Resultados}

2.4 La localización de Fic1, otro componente del anillo reclutado por Cdc15, también se encuentra disminuida en ausencia de calcineurina

Cdc15 se desfosforila durante la formación del anillo cambiando a su conformación abierta para reclutar otros componentes del anillo y posteriormente es refosforilada durante la septación volviendo a su configuración cerrada (Roberts-Galbraith et al., 2010). Según nuestra hipótesis la calcineurina contribuye en la desfosforilación de Cdc15 y en el cambio conformacional que permite la unión de paxilina y de otros componentes al anillo. Para corroborar esta hipótesis se analizó la localización de otras proteínas dependientes de la unión al dominio SH3 de Cdc15 como Fic1. Para comprobar el efecto de la deleción de la calcineurina sobre la localización de Fic1 se utilizaron las cepas silvestre y ppb1 $1 \Delta$ que poseían la proteína Fic1 marcada con GFP. Nuestros resultados mostraron que Fic1 mantenía su localización exclusiva en la zona de división en la cepa $p p b 1 \Delta$, aunque su intensidad disminuía significativamente (pvalue $<0,0001$ ) en comparación con una cepa silvestre (Figura 42A). Existe una interacción génica negativa entre fic1 $\Delta$ y px/1 (Roberts-Galbraith et al., 2009), por ello nos preguntamos si Ppb1 al localizarse en el anillo podría desfosforilar a Fic1, al igual que lo hace con la propia Cdc15. Se realizó un análisis del estado de fosforilación de esta proteína mediante Western blot utilizando las mismas cepas del experimento anterior (Figura 42B). No se observó diferencia en la movilidad electroforética de Fic1, por lo que el estado de fosforilación de esta proteína no parecería cambiar en estas condiciones de ensayo y no sería un sustrato de la calcineurina en el anillo.

A

wt

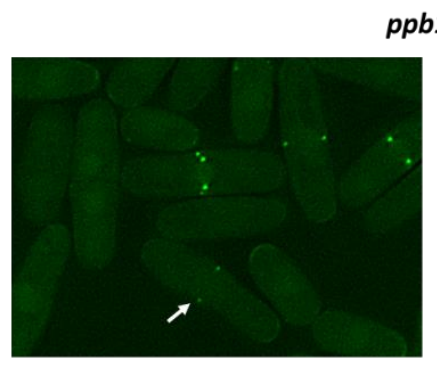

ppb1s
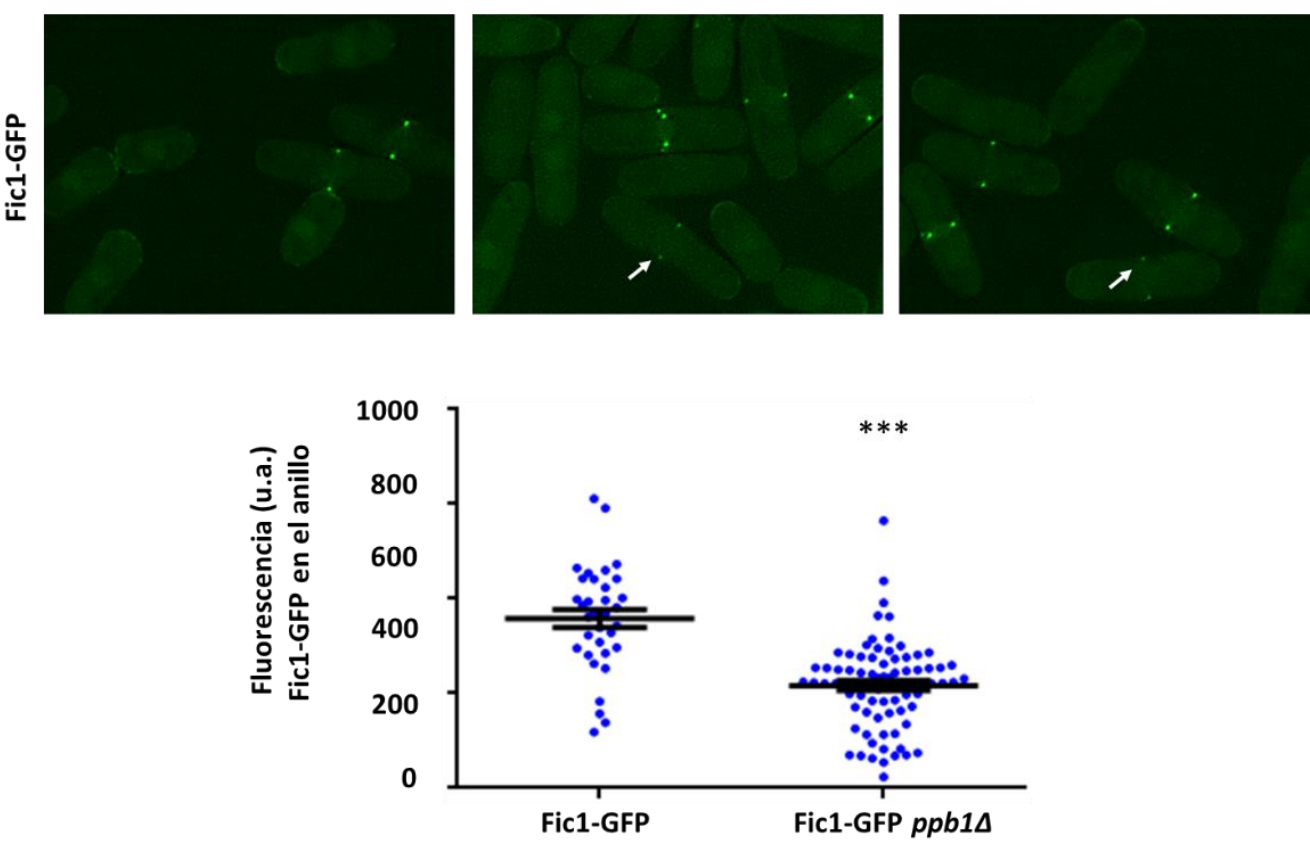


\section{Resultados}

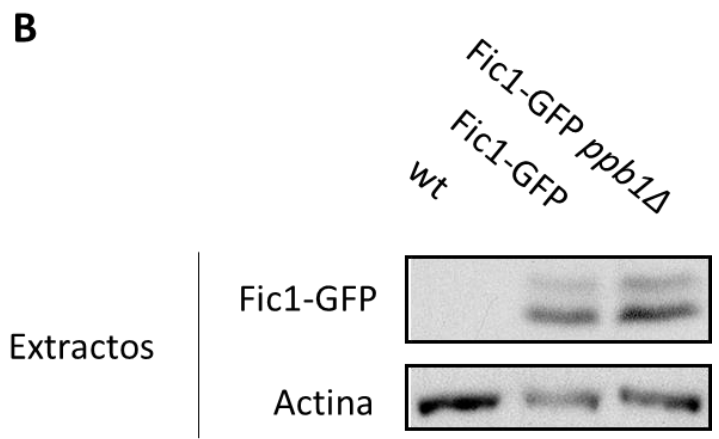

Figura 42. La localización de Fic1 en el CAR disminuye en ausencia de la calcineurina. (A) Microscopía de fluorescencia de una cepa silvestre y otra $p p b 1 \Delta$ que expresan de forma endógena Fic1 fusionada con la proteína fluorescente verde (Fic1-GFP). Células incubadas a $28^{\circ} \mathrm{C}$ en medio YES (PPG11624 y PPG15231). Las flechas blancas indican la disminución en la localización de Fic1-GFP (B) Western blot de extractos de una cepa silvestre y las cepas que expresan Fic1-GFP y que poseen o no el gen de la subunidad catalítica de la calcineurina $p p b 1^{+}$en un cultivo asincrónico (PPG04939, PPG11624 y PPG15231). Los extractos celulares fueron analizados utilizando anticuerpos anti-GFP y la actina fue utilizada como control de carga.

\section{Otros posibles sustratos de la calcineurina en el CAR}

\subsection{Identificación de posibles sustratos de la calcineurina en el CAR}

La llegada de la calcineurina al CAR y la consiguiente desfosforilación de algunos de sus componentes podría regular el inicio de la contracción del anillo. Se ha identificado a Cdc15 como un sustrato de esta fosfatasa que le permite el reclutamiento de otros componentes del anillo como Fic1 o Rgf3, un GEF activador de la GTPasa Rho1 (Ren et al., 2015). Por otra parte, se ha descrito que otros componentes del anillo, como la miosina Myo2 o Rlc1, necesitan ser desfosforilados para completar la contracción del anillo (Loo and Balasubramanian, 2008; Sladewski et al., 2009). Por ello, nos propusimos realizar una búsqueda de otros sustratos de la calcineurina. En primer lugar, se realizó un ensayo de proteómica para identificar las proteínas que interaccionan más con la fosfatasa cuando esta se localiza en el CAR. Para ello se utilizó

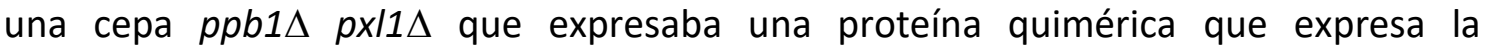
subunidad catalítica de la calcineurina fusionada con el dominio $\mathrm{N}$-terminal de la paxilina (aminoácidos 1-257) (N-pxl1-ppb1) que hace que la fosfatasa se localice en el CAR. Esta proteína quimérica está marcada con la proteína fluorescente verde (GFP) en su extremo $\mathrm{N}$-terminal y expresada bajo el control del promotor y el terminador de la paxilina que se hace que se expresa únicamente durante la citocinesis (Figura 43). Se obtuvieron extractos proteicos de las cepas que expresaban la proteína quimera en presencia y ausencia de Cnb1 y se inmunoprecipitó esta proteína junto con todas las proteínas que interaccionaban con ella. En la cepa cnb1 1 la proteína GFP-N-pxl1-ppb1 está en el CAR, pero no es activa porque carece de la subunidad reguladora Cnb1. Es, por tanto, un control negativo más específico que la cepa silvestre. Estos extractos se 


\section{Resultados}

enviaron al servicio de proteómica del Instituto Curie para su análisis mediante espectrometría de masas. Este ensayo de proteómica identificó diferentes proteínas: componentes del anillo, miosinas, reguladores de GTPasas, glucán-sintasas y quinasas que interaccionaban con la calcineurina activa y podrían ser sustratos de esta fosfatasa (Tabla 1).

\section{\begin{tabular}{l|llll} 
Prom $p x \mid 1$ & GFP & N-pxl1 & ppb1 & 3'UTR $p x / 1$
\end{tabular}}

Figura 43.- Esquema de la proteína quimera GFP-N-px|1-ppb1. Esta proteína posee fusionado el gen de la subunidad catalítica de la calcineurina fusionada con el dominio N-terminal de la paxilina y la proteína fluorescente verde GFP bajo el control del promotor de la paxilina (Martín-García et al., 2018).

\begin{tabular}{|c|c|}
\hline $\begin{array}{c}\text { Proteínas enriquecidas en el inmunoprecipitado de GFP-N- } \\
\text { Pxl1-Ppb1 en presencia de Cnb1 }\end{array}$ & Número de la proteína \\
\hline Cdc15 & Q09822 \\
Bgs4 & 074475 \\
Rng2 & 014188 \\
Pxl1 & 074398 \\
Kin1 & P22987 \\
Gef2 & Q09733 \\
Spa2 & 014248 \\
Rgf3 & Q9Y7U5 \\
Bgs3 & Q9P377 \\
Myo2 & Q9USI6 \\
Bgs1 & Q10287 \\
Ags1 & Q9USK8 \\
\hline
\end{tabular}

Tabla 1. Proteínas que aumentan su interacción con la calcineurina cuando esta se localiza en el anillo. Análisis de proteómica de las cepas silvestre y cnb1 $1 \Delta$ que expresan la proteína quimérica para identificar las proteínas que aumentan su interacción con la calcineurina cuando esta se encuentra en el CAR y se encuentra activa. En la columna de la derecha se muestra el número de entrada de UniProt.

Las proteínas identificadas en este ensayo son susceptibles de ser sustratos de la calcineurina en el anillo, por lo que se estudió el estado de fosforilación y la localización de algunas de ellas como Ags1, Myo2 o Rng2 (apartados 3.4, 3.5 y 3.6). Simultáneamente se realizaron ensayos similares con otras proteínas no detectadas mediante proteómica pero que por sus características $y / o$ función podrían ser desfosforiladas por la calcineurina (Pom1, Rga7, Cdc12 y diferentes componentes de la 


\section{Resultados}

ruta SIN). Para su estudio se realizaron ensayos de fosfoproteómica, Western blot y microscopía de fluorescencia tanto para la detección de cambios en su fosforilación como para observar su localización en células carentes de calcineurina. Todos estos estudios, que se presentan a continuación, son preliminares y se han realizado con el fin de profundizar en un futuro en la caracterización funcional de los posibles sustratos y su regulación por la calcineurina.

\subsection{Pom1 podría ser un sustrato de la calcineurina}

En las células tratadas con FK506, Cdc15 se encuentra hiperfosforilada durante la fase G2 y se ha descrito que la quinasa Pom1 es capaz de fosforilar a Cdc15 en varios sitios de su extremo C-terminal (Lee et al., 2018). Por ello, consideramos que esta quinasa también podría ser responsable del estado hiperfosforilado de Cdc15 en ausencia de la calcineurina y podría ser ella misma un sustrato de esta fosfatasa. Se analizó la movilidad electroforética de Pom1 mediante Western blot en la cepa silvestre y ppb1 $\Delta$ que expresaban Pom1 marcada con GFP (Pom1-GFP). Se observó en cultivos asincrónicos que en la cepa con la deleción del gen de la subunidad catalítica de la calcineurina la banda correspondiente a Pom1 migra a mayor altura (Figura 44A). Esto podría deberse a un aumento en la fosforilación de esta quinasa, que podría ser un posible sustrato de la calcineurina. Estudiamos también si la calcineurina tenía algún efecto en la localización celular de Pom1 en cultivos asincrónicos de una cepa silvestre y otra ppb1ム (Figura 44B y 44C). En la cepa silvestre Pom1 se localizó en los polos celulares y ligeramente en la zona de división cuando el septo se está formando, como ya se ha descrito (Bähler and Pringle, 1998). En la cepa mutante ppb1 $\Delta$ esta proteína seguía localizándose tanto en los polos como en la zona de división, aunque se produce un aumento significativo de la intensidad de fluorescencia en esta zona (pvalue $<0,0001)$.

A
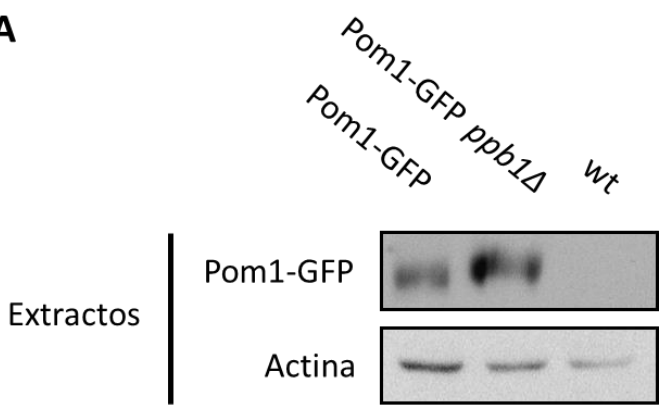


\section{Resultados}

B
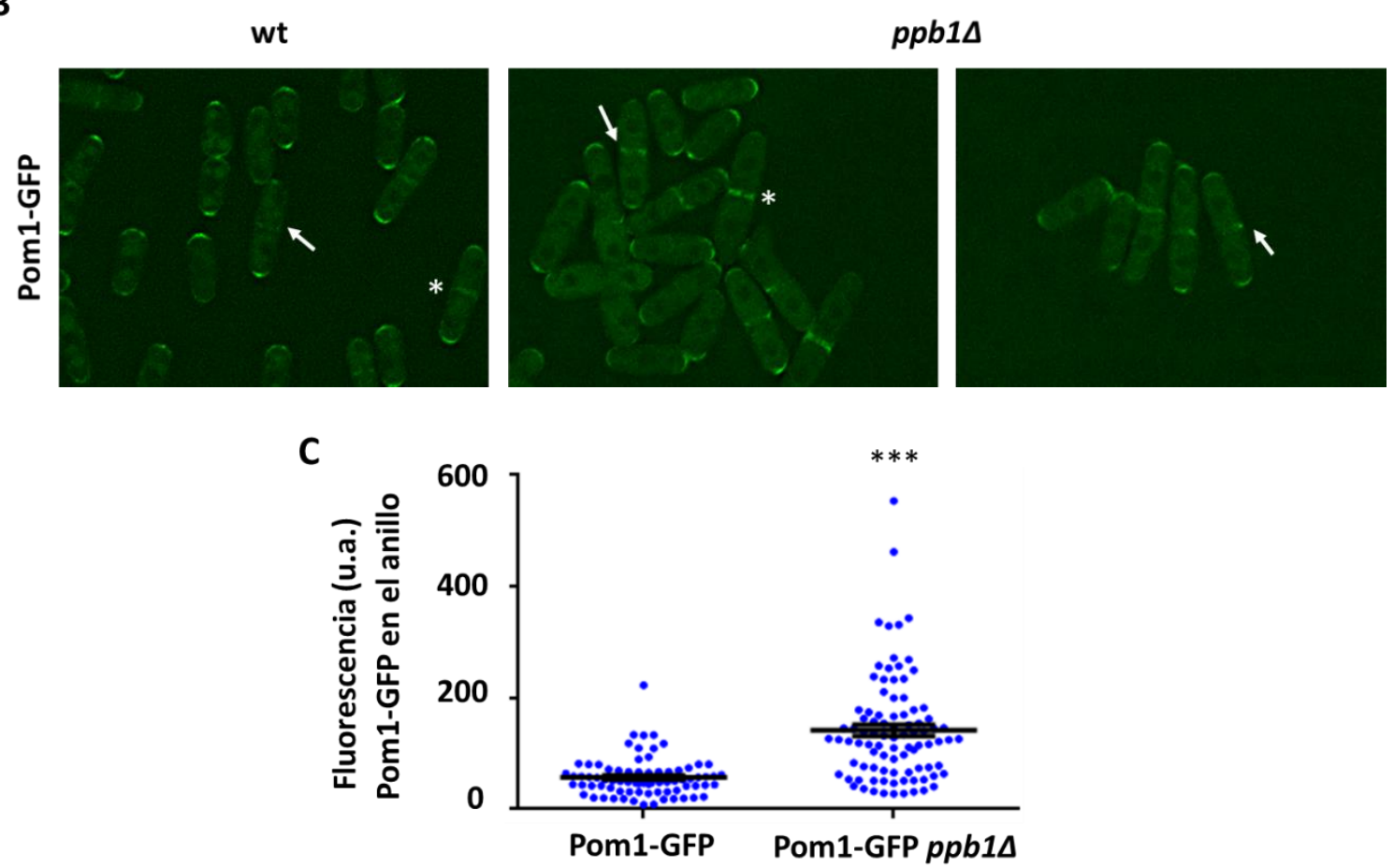

Figura 44.- Pom1 podría ser un sustrato de la calcineurina en el CAR. (A) Western blot de extractos celulares de las cepas silvestre y ppb1 1 que expresan Pom1-GFP (PPG02543, PPG15209 y PPG04939). Los extractos celulares se analizaron en geles de poliacrilamida al 6\%, fueron revelados con anticuerpos anti-GFP y la actina fue utilizada como control de carga. (B) Microscopía de fluorescencia de las cepas anteriores incubadas a $28^{\circ} \mathrm{C}$ en medio YES. Las flechas blancas y los asteriscos indican el aumento en la localización de Pom1-GFP en los diferentes estadios de la formación del septo. (C) Cuantificación de la intensidad de fluorescencia en el CAR.

\subsection{Rga7 se encuentra más fosforilada en ausencia de Ppb1}

Rga7 es una proteína con actividad GAP sobre la GTPasa Rho2, además, al igual que Cdc15 e Imp2, posee un dominio F-BAR. Rga7 se localiza en los polos y en la zona de división y es necesaria para prevenir la fragmentación del anillo de actomiosina y la formación incorrecta del septo de división (Martín-García et al., 2014). La deleción de Rga7 presenta letalidad sintética con $p x / 1^{+}$(Martín-García et al., 2014) y al igual que Cdc15, Rga7 es fosforilada por Pom1 (Kettenbach et al., 2015). Por estos motivos consideramos que Rga7 podría ser sustrato de la calcineurina. Primero comprobamos la movilidad electroforética de esta proteína en las cepas silvestre y ppb1 $\Delta$ que poseían Rga7 marcada con GFP (Rga7GFP). La proteína Rga7 de los extractos de la cepa ppb1 $\Delta$ migró en una zona más alta en el gel, lo que podría deberse a que está más fosforilada (Figura 45A) y por tanto podría ser un sustrato de la calcineurina en el CAR. En la cepa silvestre, Rga7 se localiza en los polos celulares y en la zona del anillo de división (Martín-García et al., 2014). Al analizar si la localización de Rga7 se modificaba en la cepa mutante ppb1 $\Delta$ respecto a la cepa silvestre se comprobó que esta proteína seguía localizándose correctamente en los polos y en el 


\section{Resultados}

CAR. Se observó también una ligera disminución en la intensidad de fluorescencia de Rga7, aunque no de forma significativa (pvalue=0,122) (Figura 45B y 45C).

A
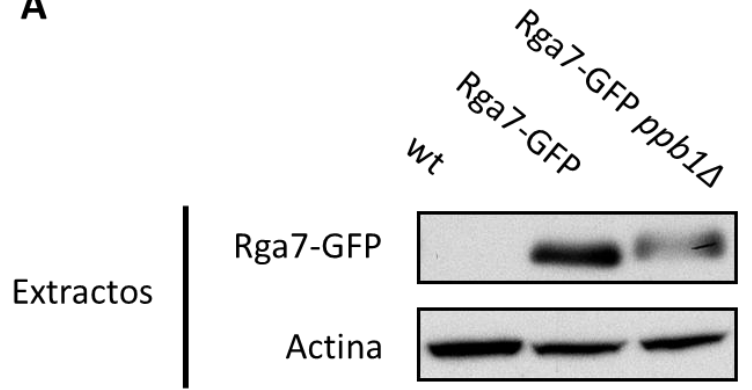

B
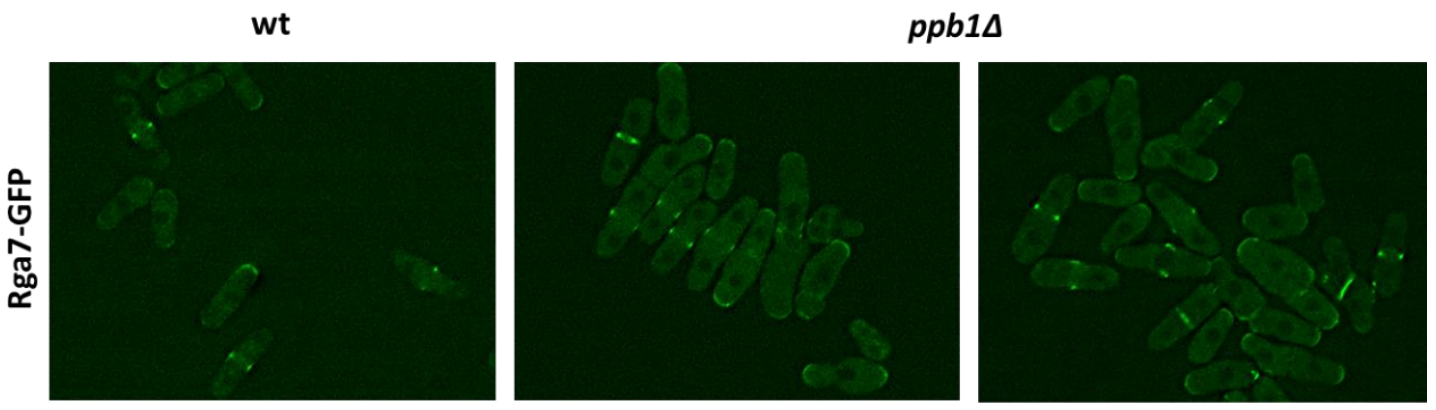

C

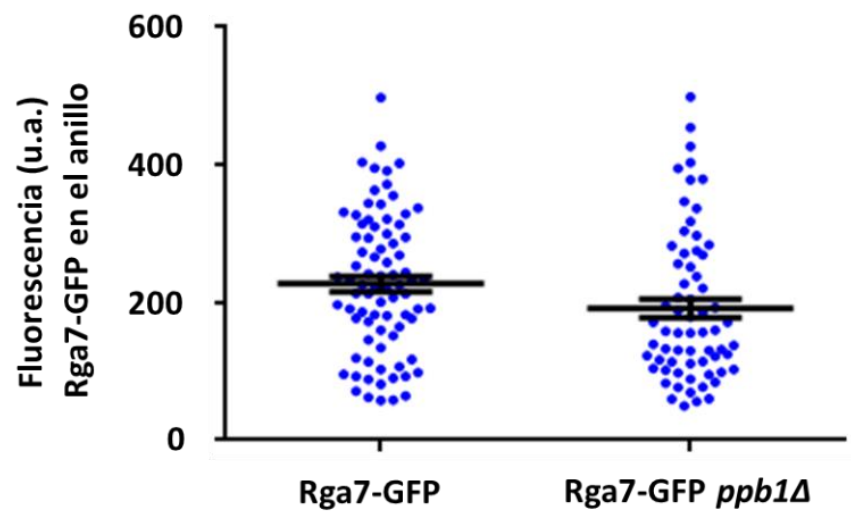

Figura 45. Rga7 podría ser un sustrato de la calcineurina en el CAR. (A) Western blot de extractos celulares de las cepas silvestre o ppb1 que expresan Rga7-GFP (PPG04939, PPG09936 y PPG15251). Los extractos celulares se analizaron en geles de poliacrilamida al $8 \%$ y fueron revelados con anticuerpos antiGFP y la actina fue utilizada como control de carga. (B) Microscopía de fluorescencia de las cepas anteriores incubadas a $28^{\circ} \mathrm{C}$ en medio YES. (C) Cuantificación de la intensidad de fluorescencia.

Puesto que Rga7 podría ser un sustrato de la calcineurina realizamos un análisis de fosfoproteómica con el fin de encontrar los sitios putativos de desfosforilación de Rga7 dependientes de calcineurina. Se obtuvieron extractos proteicos por triplicado de las cepas silvestre y ppb1 $\Delta$ que poseían Rga7 marcada en su extremo C-terminal con GFP (Rga7-GFP). A partir de estos extractos se inmunoprecipitó Rga7-GFP mediante el uso de un imán y bolas magnéticas que se unen a la proteína fluorescente verde. Las proteínas inmunoprecipitadas se analizaron mediante espectrometría de masas para 


\section{Resultados}

identificar las diferencias de fosforilación de Rga7 en ambas cepas. Este análisis se realizó durante la estancia predoctoral en el servicio de proteómica y metabolómica Glasgow Polyomics en el Centro Wolfson Wohl Cancer Research. Se han descrito previamente varios sitios de fosforilación en Rga7 mediados por Pom1 en una región próxima al dominio GAP comprendida entre los aminoácidos 482 y 500 de la proteína (Kettenbach et al., 2015).

Nuestro análisis de fosfoproteómica identificó dos secuencias peptídicas con sitios putativos de fosforilación en Rga7. Una de ellas incluía los sitios fosforilables por Pom1 previamente descritos, mientras que la segunda se encontraba precediendo a la anterior y presentaba 3 nuevos sitios de fosforilación (residuos S475, S478 y S479) que no habían sido identificados previamente (Figura 46). En este análisis también se cuantificó la abundancia relativa en la que estas secuencias peptídicas se encontraban fosforiladas en ambas cepas para comprobar si la diferencia de fosforilación entre ellas era significativa. Para ello los extractos se marcaron con tandem mass tag (TMT), unos marcadores isobáricos de masas que permiten la cuantificación de la abundancia de los péptidos fosforilados en diferentes muestras de forma simultánea utilizando espectrometría de masas. A partir de estos datos se calculó la proporción entre la abundancia de las secuencias fosforiladas de la cepa $p p b 1 \Delta$ y de la cepa silvestre. De esta forma, valores superiores a 1 indican que ese péptido se encuentra más fosforilado en la cepa que no posee la subunidad catalítica de la fosfatasa. Los resultados de los tres experimentos muestran para ambas secuencias peptídicas valores superiores a 1 , por lo que se confirma que, en ausencia de Ppb1, Rga7 se encuentra más fosforilada en esos aminoácidos y podría ser sustrato de la calcineurina.

\begin{tabular}{|c|c|c|c|c|}
\hline \multirow[b]{2}{*}{ Secuencia } & \multirow[b]{2}{*}{ Proteínas y residuos } & \multicolumn{3}{|c|}{$\begin{array}{l}\text { Ratio de abundancia } \\
\qquad(p p b 1 \Delta) /(w t)\end{array}$} \\
\hline & & Experimento 1 & Experimento 2 & Experimento 3 \\
\hline EVAPPPSSINSNR & $\begin{array}{l}\text { Rga7 [469-481] } \\
\text { 1xPhospho }[\mathrm{S}]\end{array}$ & 1,545 & 1,011 & 1,331 \\
\hline AASPFRPTSVSPQPSSPTK & $\begin{array}{l}\text { Rga7 [482-500] } \\
\text { 1xPhospho [S/T] }\end{array}$ & 1,539 & 1,196 & 2,004 \\
\hline
\end{tabular}

Figura 46.- Sitios de fosforilación de Rga7 y abundancia de la secuencia peptídica fosforilada. Los residuos marcados en rojo indican los sitios de desfosforilación afectados por la presencia o ausencia de calcineurina. La ratio indica la proporción entre la abundancia de la secuencia peptídica fosforilada en la cepa ppb1 1 y la cepa silvestre que expresan Rga7-GFP (PPG09936 y PPG15251). Valores superiores a 1 indican que el péptido fosforilado es más abundante en la cepa $p p b 1 \Delta$.

Rga7 forma un complejo con la proteína Rng10, siendo la localización de ambas interdependiente. Rng10 se localiza en la membrana plasmática tanto de los polos como de la zona de división celular provocando su deleción un ligero aumento de la 


\section{Resultados}

septación (Liu et al., 2016). Se ha propuesto que el complejo Rga7-Rng10 está implicado en la formación correcta del septo, regulando la dinámica y la localización de las glucán-sintasas en la pared celular (Liu et al., 2016). En el ensayo de fosfoproteómica realizado anteriormente Rng10 coinmunoprecipitó con Rga7-GFP, por lo que también se pudieron identificar sitios de fosforilación presentes en esta proteína además de cuantificar la abundancia de las secuencias fosforiladas y calcular la proporción entre la cepa silvestre y ppb1 $\Delta$ (Figura 47). El análisis únicamente identificó una secuencia con dos sitios de fosforilación (residuos S618 y S620) obteniendo una ratio superior a 1 en todos los experimentos, por lo que concluimos que Rng10 también se encuentra más fosforilada en ausencia de calcineurina y puede ser un sustrato de esta.

\begin{tabular}{c|c|ccc} 
& & \multicolumn{3}{|c}{$\begin{array}{c}\text { Ratio de abundancia } \\
(p p b 1 \Delta) /(w t)\end{array}$} \\
\hline Secuencia & Proteínas y residuos & Experimento 1 & Experimento 2 & Experimento 3 \\
\cline { 3 - 5 } & $\begin{array}{c}\text { Rng10 [616-629] } \\
\text { 1xPhospho }[\mathrm{S}]\end{array}$ & 1,269 & 1,028 & 1,779
\end{tabular}

Figura 47.- Sitios de fosforilación de Rng10. Los residuos marcados en rojo indican los sitos putativos de fosforilación. La ratio indica la proporción de la abundancia de la secuencia peptídica fosforilada en la cepa $p p b 1 \Delta$ respecto a la cepa silvestre. Valores superiores a 1 indican que el péptido fosforilado es más abundante en la cepa $p p b 1 \Delta$.

\subsection{La $\alpha$-glucán-sintasa Ags1 no presenta cambios en su estado de fosforilación en ausencia de Ppb1}

La eliminación de la glucán-sintasa Bgs1 en cepas que no expresan el gen $p x / 1^{+}$y por tanto no localizan la calcineurina en el anillo, provoca la deslocalización de la $\alpha$-glucánsintasa Ags1 de la zona de división (Cortés et al., 2015). Esto indica que Pxl1 coopera con Bgs1 para concentrar esta sintasa que participan en la elaboración del septo. Por ello nos planteamos ver si la calcineurina desfosforilaba a Ags1 colaborando así con Bgs1 en su localización. Se realizaron análisis de la proteína en cultivos asincrónicos mediante Western blot para detectar cambios en la movilidad electroforética de Ags1 que pudieran indicar que se encontraba más fosforilada en cepas que carecen de la proteína Ppb1. Se utilizaron cepas que expresaban el gen codificante de Ags1 fusionada con GFP (Ags1-GFP) y que poseían o no la deleción del gen $p p b 1^{+}$. En estas condiciones de ensayo no se apreciaron diferencias en el patrón de migración de Ags1 entre ambas cepas (Figura 48A). Sin embargo, dado que la proteína posee varios sitios putativos de unión a calcineurina PxIxIT y que su gran tamaño podría impedir apreciar las diferencias en su movilidad electroforética debidas a la fosforilación mediante Western blot, se decidió realizar un análisis de fosfoproteómica de esta proteína. Para ello, se obtuvieron extractos proteicos por triplicado de cultivos de las cepas silvestre control y 


\section{Resultados}

ppb1 $1 \Delta$ y se realizó una inmunoprecipitación de Ags1-GFP utilizando nuevamente un imán y bolas magnéticas que se unen a GFP. Posteriormente se analizaron los inmuprecipitados mediante espectrometría de masas en el servicio de proteómica y metabolómica Glasgow Polyomics para identificar sitios putativos de fosforilación en Ags1 e identificar diferencias en el estado de fosforilación de estos mediante tandem mass tag (TMT). El análisis identificó dos secuencias entre los aminoácidos 1.643-1.658 y 1.805-1.827 con varios residuos de serina o treonina susceptibles de fosforilación (Figura 48B). Sin embargo, la abundancia de estas secuencias fosforiladas en ambas cepas resultó ser muy baja, por lo que no se pudo cuantificar. Estos resultados indican que Ags1 se encuentra principalmente desfosforilada en citocinesis y su estado no varía en ausencia de la calcineurina. Por tanto, Ags1 no parece ser un sustrato de la calcineurina en el CAR.

A
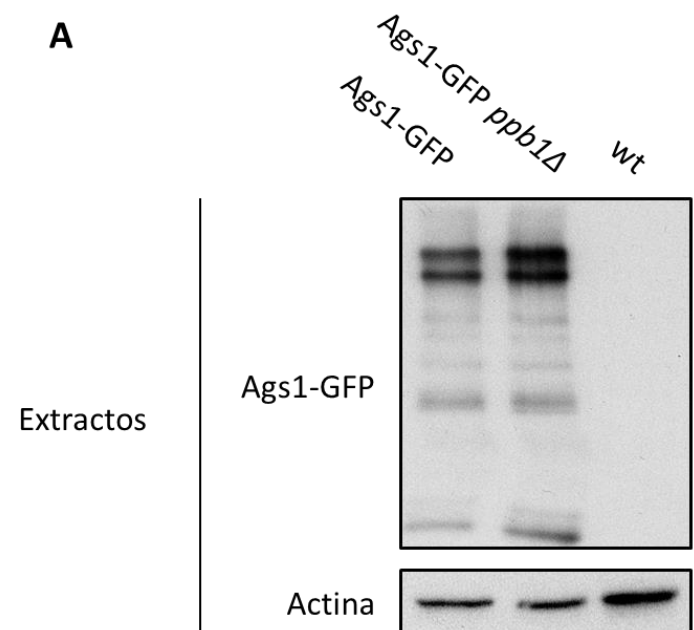

B

Figura 48.- Ags1 no es un sustrato de la calcineurina. (A) Western blot de extractos celulares de la cepa silvestre o ppb1 $\triangle$ que expresan Ags1-GFP en un cultivo asincrónico (PPG11363, PPG15517 y PPG04939). Los extractos celulares se corrieron en un gel de poliacrilamida al $6 \%$ y fueron analizados con anticuerpos anti-GFP. La actina fue utilizada como control de carga. (B) Secuencias peptídicas fosforilables de la proteína Ags1, los sitios putativos de fosforilación se encuentran marcados en rojo.

En la cepa $p x / 1 \Delta$ en la que expresión de la $\beta$-glucán-sintasa se encuentra reprimida, Ags1 se deslocaliza de la zona de división concentrándose en el citoplasma y a lo largo de la membrana (Cortés et al., 2015). Además, el tratamiento con el inhibidor de la calcineurina FK506 en células en las que la expresión de Bgs1 se encuentra disminuida Ags1 también se deslocaliza de la zona de división (Martín-García et al., 2018). Por tanto, la actividad de la calcineurina en el CAR podría favorecer de forma indirecta la localización de Ags1 en la zona de división. Por ello, estudiamos la localización de Ags1 en cultivos asincrónicos de una cepa silvestre y otra que carece del gen $p p b 1^{+}$. En una cepa silvestre Ags1 se localizó en las zonas de crecimiento de la pared celular como los polos celulares y el septo (Figura 49), tal y como se ha descrito previamente (Cortés et 


\section{Resultados}

al., 2012; Konomi et al., 2003). En la cepa ppb1 1 , Ags1 mantenía la misma localización y presentaba un leve aumento, no significativo, de intensidad en el CAR (pvalue=0,092), por lo que su localización en la zona de división no depende de la calcineurina.

A

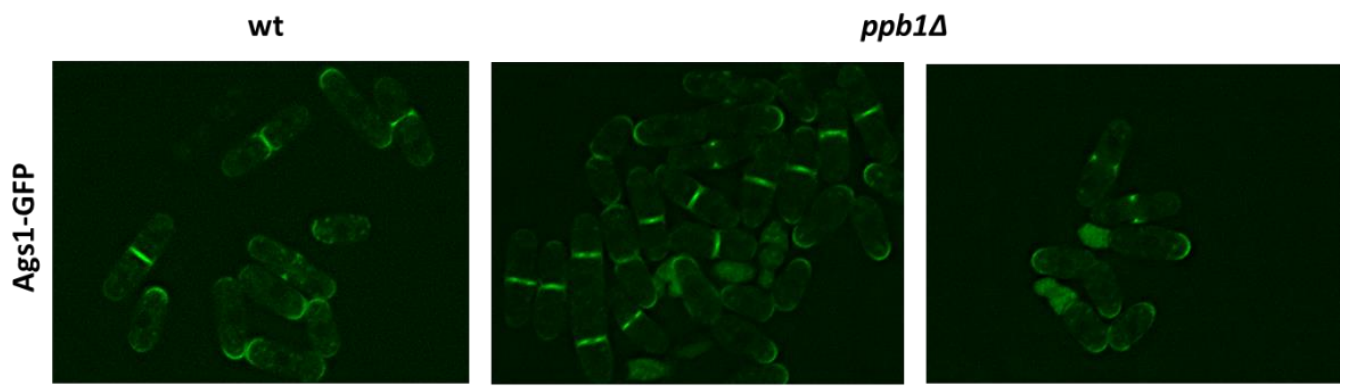

B

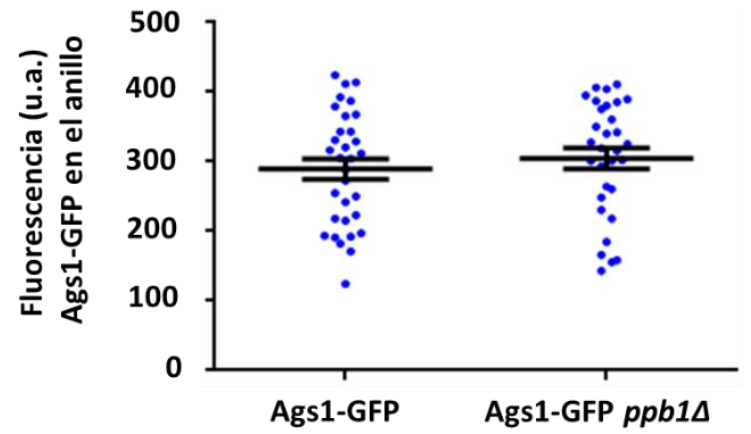

Figura 49.- Localización de Ags1 en el anillo de actomiosina. (A) Microscopía de fluorescencia de una cepa silvestre y otra $p p b 1 \triangle$ que expresan de forma endógena Ags1-GFP incubadas a $28^{\circ} \mathrm{C}$ en medio YES (PPG04363 y PPG15517). (B) Cuantificación de la intensidad de fluorescencia de las cepas anteriores.

\subsection{Las miosinas no parecen ser un sustrato de la calcineurina y su interacción con la paxilina no es dependiente de esta fosfatasa}

En S. pombe las miosinas de clase II se encuentran formando hexámeros compuestos por dos cadenas pesadas (Myo2 o Myp2) (Bezanilla et al., 1997; Kitayama et al., 1997) y cuatro cadenas ligeras: dos cadenas ligeras esenciales, Cdc4, y dos cadenas ligeras reguladoras, Rlc1 (Le Goff et al., 2000; McCollum et al., 1995). Se han propuesto diferentes sitios de fosforilación en las cadenas de las miosinas que podrían regular la actividad de la miosina II tanto en la formación del CAR como en su contracción. Uno de ellos se localiza en la serina 1.444 de la cadena pesada Myo2 y se ha implicado en el inicio de la contracción del anillo (Sladewski et al., 2009). También se ha observado que los residuos de serina en las posiciones 35 y 36 (S35 y S36) de la cadena ligera reguladora Rlc1 son fosforilados por la quinasa Pak1/Shk1/Orb2 de la familia Pak. La fosforilación de estos aminoácidos produce retrasos en la citocinesis mientras que en los mutantes no fosforilables en estos aminoácidos se produce una constricción del anillo prematura (Loo and Balasubramanian, 2008). Sin embargo, todavía no está claro 


\section{Resultados}

cómo la fosforilación o desfosforilación de estos aminoácidos afecta a la actividad ATPasa, a la movilidad de Myo2 y a su afinidad por la actina (Pollard et al., 2017; Sladewski et al., 2009). La cepa mutante pxl1 presenta anillos de actomiosina aberrantes y en ocasiones dobles. Además, hay un incremento en el porcentaje de células en septación debido a un aumento del tiempo de contracción del CAR, al igual que se observa en un mutante fosfomimético (S35D y S36D) de $r l c 1^{+}$(Pinar et al., 2008). Este fenotipo podría ser debido a la falta de desfosforilación de las miosinas durante la contracción del anillo provocada por la ausencia de calcineurina. Para comprobar esto se realizaron ensayos de Western blot en cepas con o sin calcineurina que llevaban las diferentes cadenas de las miosinas (Myo2, Myp2, Cdc4 y Rlc1) marcadas con GFP (Figura 50). Sin embargo, cuando se analizó su movilidad electroforética no se apreciaron cambios que pudieran indicar una hiperfosforilación dependiente de la ausencia de calcineurina, por lo que las cadenas de miosina II no parecen ser un sustrato de la calcineurina.

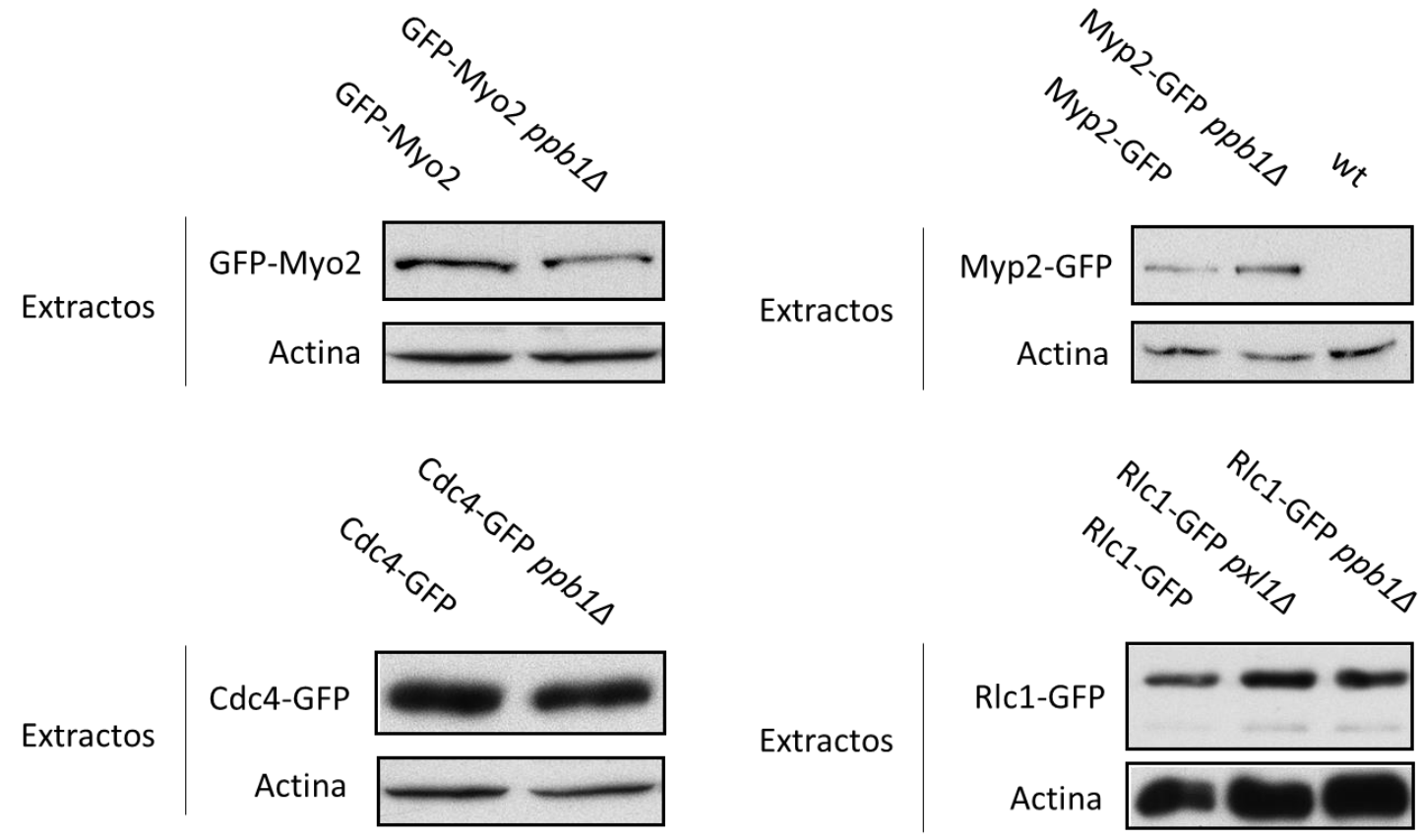

Figura 50.- La movilidad electroforética de las cadenas de las miosinas no cambia en ausencia de la subunidad catalítica calcineurina. Western blot de extractos celulares de las cepas silvestre o $p p b 1 \Delta$ que expresan las diferentes cadenas de las miosinas marcadas con GFP en un cultivo asincrónico (PPG06875, PPG15253, PPG09627, PPG15249, PPG04132, PPG15503, PPG02619, PPG15217 y PPG04939). Los extractos celulares se analizaron en un gel de poliacrilamida al 6\% para las cadenas pesadas Myo2 y Myp2 y al $10 \%$ en el caso de las cadenas ligeras Cdc4 y RIc1, y se revelaron con anticuerpos anti-GFP. La actina fue utilizada como control de carga.

Se ha descrito la interacción física entre la paxilina y las cadenas pesada y ligera reguladora de las miosinas de clase II, Myo2 y Rlc1 respectivamente, que forman el anillo de actomiosina (Pinar et al., 2008). Por ello, aunque no se apreciaron diferencias de movilidad 


\section{Resultados}

electroforética, consideramos la posibilidad de que la calcineurina pudiera desfosforilar a las miosinas en uno o dos residuos e influir en su interacción con el resto de los componentes del CAR como la paxilina o la actina. Esta pérdida de interacción podría provocar la formación de anillos aberrantes y anillos dobles observados en la cepa ppb1 $\Delta$. Realizamos ensayos de pull down utilizando GST-PxI1 y GST recombinante producidas en bacterias y unidas a bolas de glutatión-sefarosa. Estas bolas se incubaron con extractos de células de una cepa silvestre y otra $p p b 1 \Delta$ que expresaban Rlc1-GFP. El resultado obtenido nos demostró que la interacción entre Pxl1 y Rlc1 es independiente de la presencia o ausencia de la subunidad catalítica de la calcineurina Ppb1 en el CAR (Figura 51A). Además, tampoco se observó un aumento de la interacción entre Pxl1 y Rlc1 en ausencia de calcineurina, por lo que esta fosfatasa y Rlc1 no parecen competir por el sitio de unión a la Paxilina. Tampoco se observó un cambio en la localización de las miosinas en el CAR, aunque si se observaron unas ligeras diferencias, no significativas, en la intensidad de estas proteínas (Myo2 pvalue=0,159, Myp2 pvalue= 0,652) (Figura 51B y 52C). Estos resultados en conjunto nos indican que la calcineurina no afecta a la interacción de la miosina tipo II con Pxl1.

A
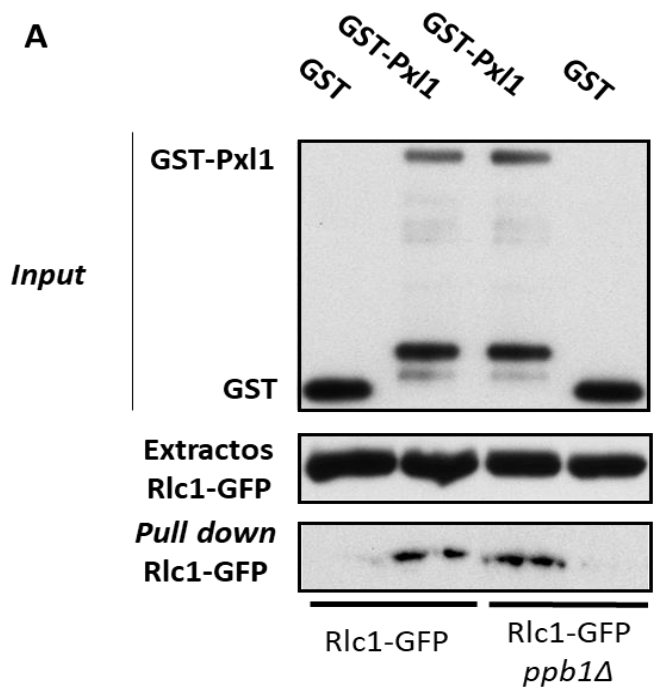

B

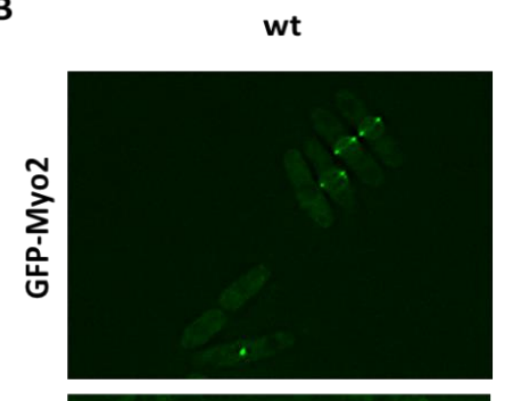

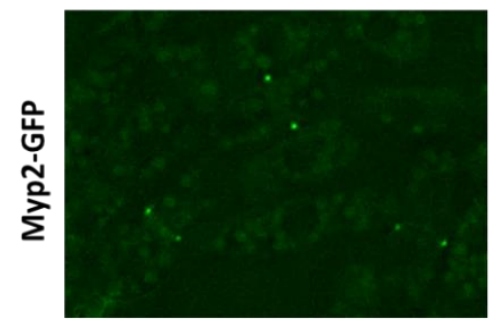
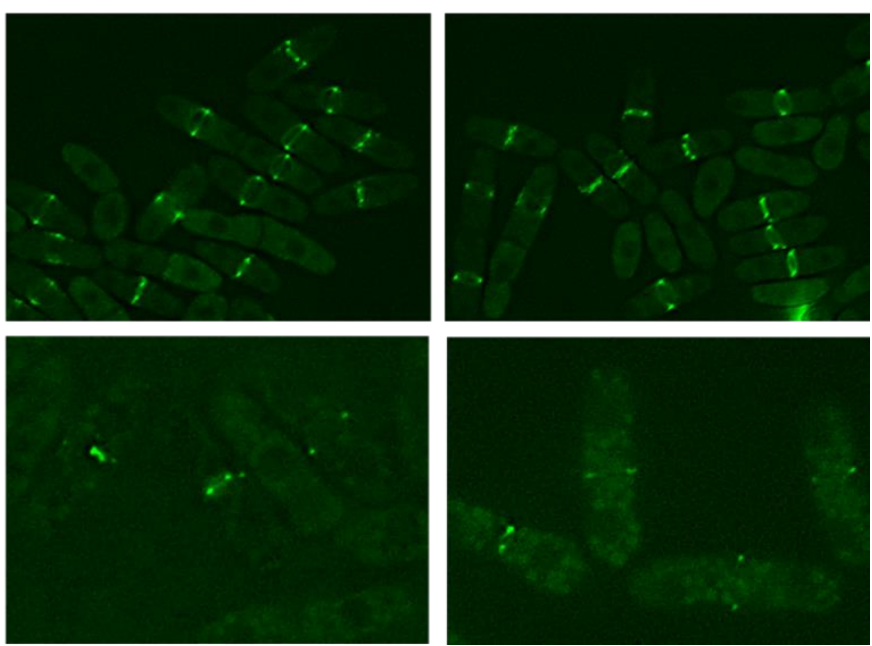


\section{Resultados}
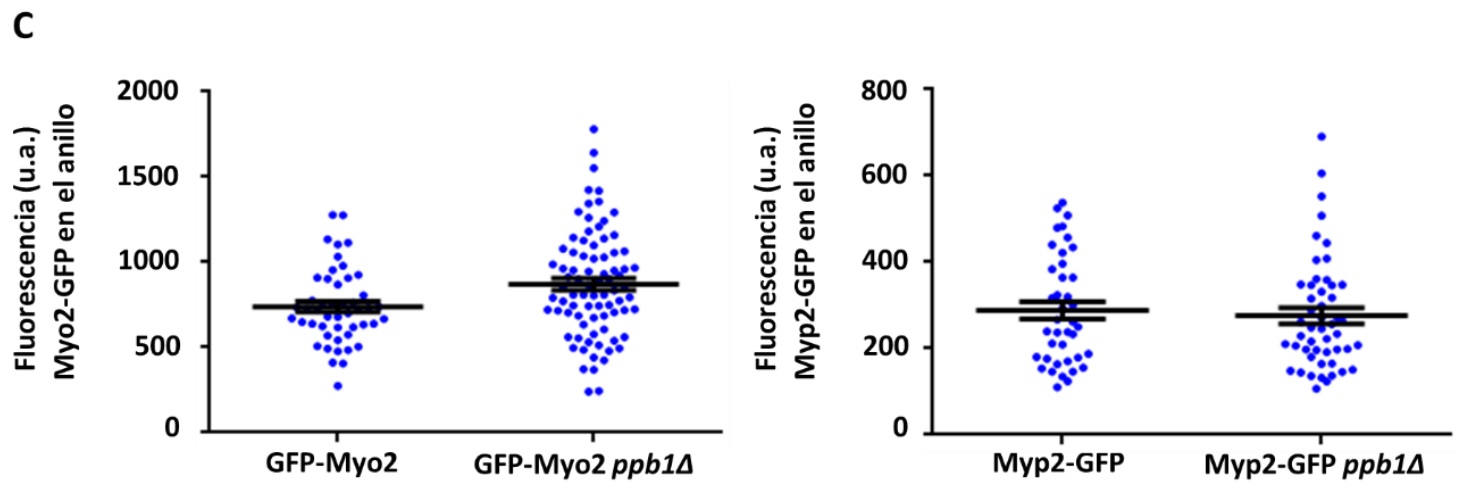

Figura 51.- Pxl1 interacciona con Rlc1 independientemente de la subunidad catalítica Ppb1 y no varía su localización en ausencia de calcineurina. (A) Ensayo de pull down con extractos de cepas que expresan la proteína RIc1-GFP bajo su propio promotor y que además poseen o carecen de la subunidad catalítica Ppb1 (PPG02619 y PPG15217). Los extractos de las cepas se incubaron con bolas de glutatión sefarosa que llevan unido GST-Px|1 o GST recombinante producido en bacterias. Los precipitados y los extractos celulares fueron analizados con anticuerpos anti-GST y anti-GFP. (B) Microscopía de fluorescencia de una cepa silvestre y otra $p p b 1 \Delta$ que expresan de forma endógena Myo2 o Myp2 fusionadas con la proteína fluorescente verde (GFP-Myo2 y Myp2-GFP) incubadas a $28^{\circ} \mathrm{C}$ en medio YES (PPG06875, PPG15253, PPG09627 y PPG15249). (C) Cuantificación de la intensidad de fluorescencia de las cepas anteriores.

\subsection{Rng2 no parece ser un sustrato de la calcineurina}

Rng2 es una de las primeras proteínas que se localiza en la zona de división y en el CAR actúa como adaptadora y favorece la localización de otras proteínas como Myo2 o Rlc1 (Laporte et al., 2011). Además, posee varios dominios IQ con los que es capaz de interaccionar con la cadena ligera de las miosinas Cdc4 (D'souza et al., 2001). La deleción de los dominios IQ de Rng2 provoca la deslocalización de Bgs1, lo que sugiere que también podría interaccionar con esta proteína para mantener su localización (Johnson et al., 2012). Por todo esto se analizó si el estado de fosforilación de Rng2 cambiaba en ausencia de la subunidad catalítica de la calcineurina Ppb1. Se realizaron ensayos de Western blot a partir de extractos de una cepa silvestre y otra cepa ppb1 $\triangle$ que expresaban YFP-Rng2. No se observaron diferencias de movilidad electroforética en esta proteína, por lo que Rng2 no parecería ser un sustrato de la calcineurina en el CAR (Figura 52A). Se estudió también la localización de Rng2 en estas mismas cepas y tampoco se observaron diferencias significativas en la intensidad de la señal en el CAR (pvalue= 0,616) (Figura 52B). 
A
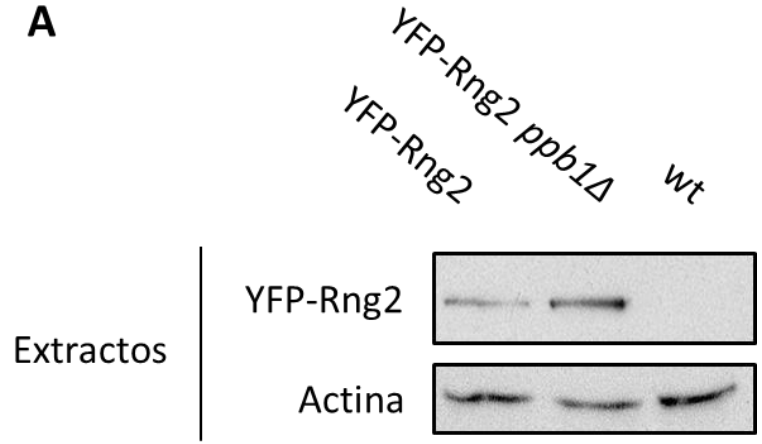

B
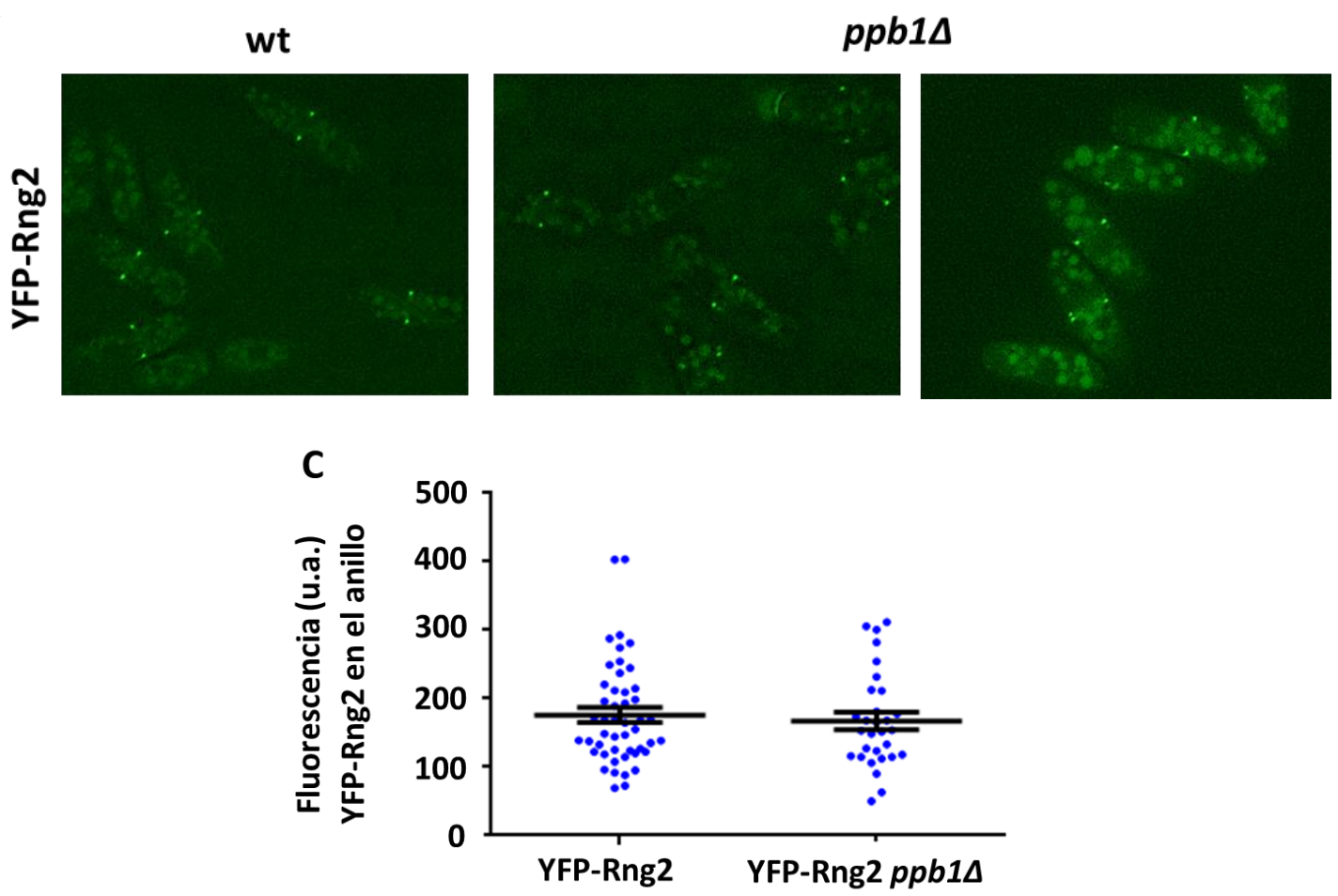

Figura 52.- Rng2 no cambia su movilidad electroforética ni su localización en ausencia de la subunidad catalítica de la calcineurina. (A) Western blot de extractos celulares de las cepas silvestre y ppb1 $\Delta$ que expresan YFP-Rng2 (PPG03753, PPG15247 y PPG04939). Los extractos celulares se analizaron en un gel de poliacrilamida al $6 \%$ y fueron revelados con anticuerpos anti-GFP. La actina fue utilizada como control de carga. (B) Microscopía de fluorescencia de las cepas anteriores incubadas a $28^{\circ} \mathrm{C}$ en medio YES. (C) Cuantificación de la intensidad de fluorescencia.

\subsection{Cdc12 no parece ser un sustrato de la calcineurina}

Cdc12 se localiza en la zona de división después de Rng2 o Myo2 y es la formina encargada de la nucleación de los filamentos de actina para la formación del anillo contráctil. Cdc12 es una fosfoproteína y su fosforilación por la quinasa de la ruta SIN, Sid2, afecta a su capacidad de multimerizar e impide su función de agrupar filamentos de actina durante la contracción del anillo (Bohnert et al., 2013). Cdc12 también es fosforilada por la quinasa Cdk1 en su extremo N-terminal y esto disminuye su localización en el anillo e inhibe su interacción con Cdc15 (Willet et al., 2018). Se ha 


\section{Resultados}

descrito que a lo largo de la citocinesis Cdc12 cambia su estado de fosforilación, estos cambios podrían regular tanto la formación del anillo como su contracción. La calcineurina podría ser una de las fosfatasas que desfosforila a $\mathrm{Cdc12}$, permitiéndole multimerizar y unirse a Cdc15 formando los filamentos de actina durante la contracción del anillo. Para comprobar si esto era así se analizó el estado de fosforilación de Cdc12 en una cepa silvestre, en ppb1 $1 \Delta$ y en $p x / 1 \Delta$ mediante Western blot. Estas cepas expresaban Cdc12 fusionada con GFP en su extremo N-terminal (GFP-Cdc12) (Figura 53A). No se observaron diferencias en la movilidad electroforética de esta proteína entre la cepa silvestre y $p p b 1 \Delta$. Sorprendentemente, Cdc12 migró en una posición más elevada en la cepa que no expresaba $p x / 1^{+}$, lo que podría indicar que se encontraba más fosforilada. Estos resultados sugieren que la paxilina podría estar reclutando al CAR a otra fosfatasa diferente de la calcineurina que estaría implicada en desfosforilar a Cdc12 para mantener la estructura correcta del anillo y regular su contracción. También se analizó la localización de Cdc12 en el anillo en las cepas anteriores (Figura 53B). En ninguna de las cepas se observó un cambio en la localización de Cdc12, aunque esta formina se localizaba con mayor intensidad en la cepa px/1 $\Delta$ (pvalue= $0,0034)$, al contrario de la cepa $p p b 1 \Delta$ donde la diferencia de intensidad respecto a la cepa silvestre no resultó significativa (pvalue=0,263) (Figura 53C).

A
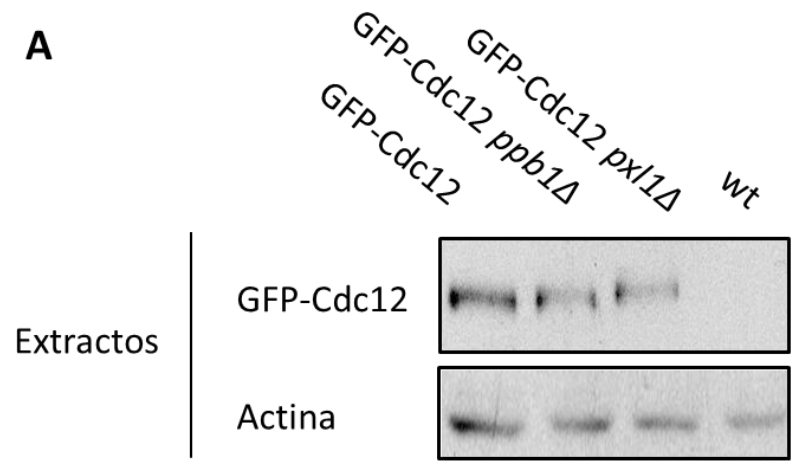

B

wt

ppb1ه

pxl10
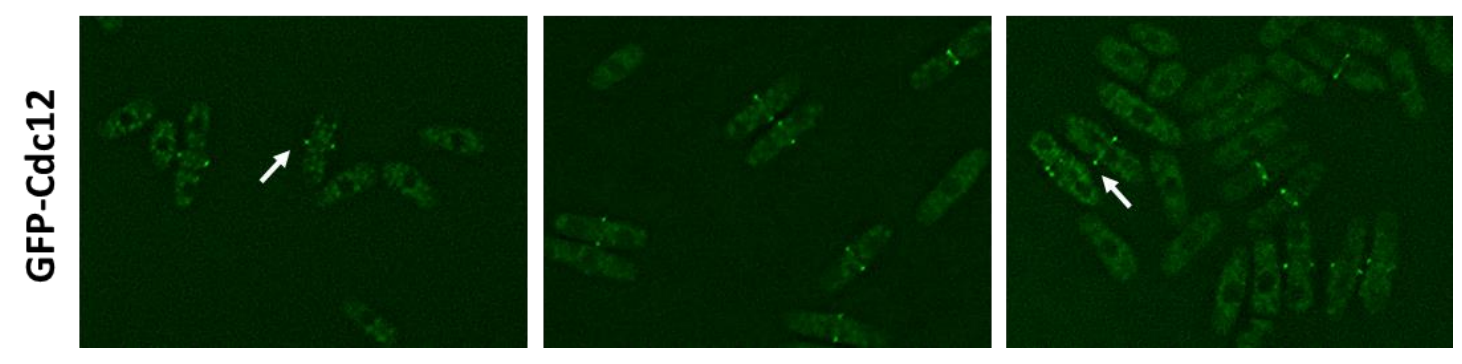


\section{Resultados}

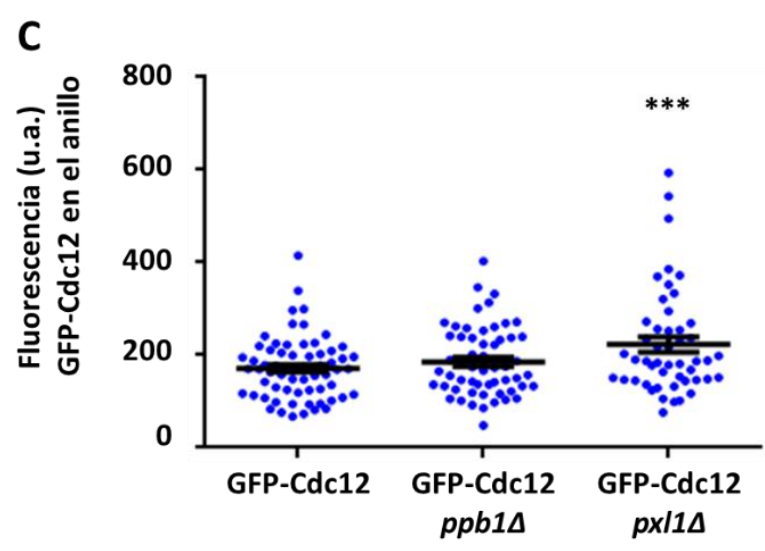

Figura 53.- Cdc12 cambia su movilidad electroforética y se localiza con mayor intensidad en la cepa

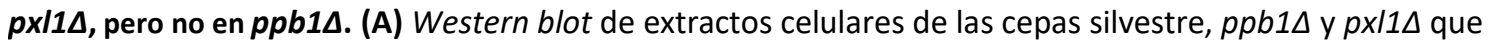
expresan GFP-Cdc12 (PPG02505, PPG15219, PPG15221 y PPG04939). Los extractos celulares se analizaron en geles de poliacrilamida al $6 \%$ y fueron revelados con anticuerpos anti-GFP. La actina fue utilizada como control de carga. Las flechas blancas indican un aumento de intensidad de Cdc12-GFP en ausencia de paxilina. (B) Microscopía de fluorescencia de las cepas anteriores incubadas a $28^{\circ} \mathrm{C}$ en medio YES. (C) Cuantificación de la intensidad de fluorescencia.

\subsection{Los componentes de la ruta SIN Spg1, Cdc7 y Sid2 no parecen ser un sustrato de la calcineurina}

La ruta SIN está regulada por varias fosfatasas como el complejo PP2A (Jiang and Hallberg, 2001; Lahoz et al., 2010), Clp1 (Trautmann et al., 2001) y, quizás, la calcineurina (Lu et al., 2002). La pérdida de función de la calcineurina agrava el fenotipo de las células en las que la ruta SIN se encuentra comprometida y la sobrexpresión de la calcineurina corrige el fenotipo de la deleción de algunos de sus componentes, como $\mathrm{Cdc} 7$, por lo que esta fosfatasa promueve la activación de la ruta SIN (Lu et al., 2002; Simanis, 2015). La GTPasa Spg1 es la encargada de iniciar esta ruta (Schmidt et al., 1997) y activa a Cdc7, la primera quinasa de la ruta (Fankhauser and Simanis, 1994; Mehta and Gould, 2006). Cdc7 continua la señalización que provoca finalmente la activación de la quinasa Sid2 que induce la formación del septo (Hou et al., 2004, 2000; Salimova et al., 2000). Se realizó un análisis del estado de fosforilación de Spg1, Cdc7 y Sid2 mediante Western blot de cepas que expresaban una de estas proteínas marcada con GFP (Spg1-GFP, Cdc7-GFP y Sid2-GFP). No se observaron diferencias en la movilidad electroforética de ninguno de estos componentes de la ruta SIN en presencia o ausencia de Ppb1, por lo que la calcineurina no parecería activar la ruta SIN a través de ellos (Figura 54A). La localización de Spg1, Cdc7 y Sid2 en el cuerpo polar del huso mitótico (spindle pole body, SPB) o en el CAR a lo largo de la citocinesis tampoco varió en las cepas que poseían la deleción del gen $p p b 1^{+}$(Figura 54B). Sin embargo, sí se pudo observar un aumento de la intensidad de la fluorescencia de Spg1 y Cdc7 (pvalue $=0,014$ y 0,016 respectivamente) en el SPB mientras que la intensidad de la señal de Sid2 en el CAR disminuía en ausencia de la fosfatasa (pvalue $<0,001$ ) (Figura 54C). 
A
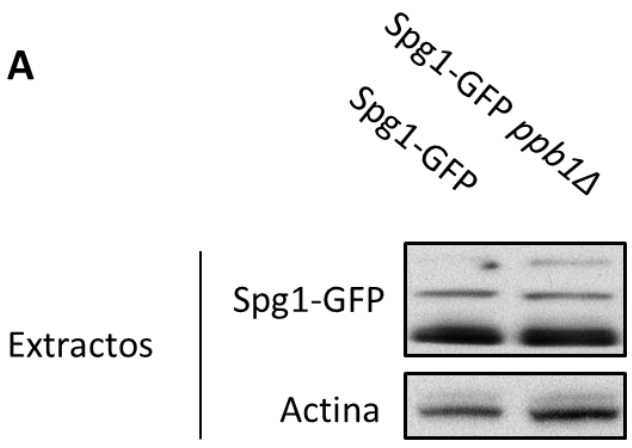

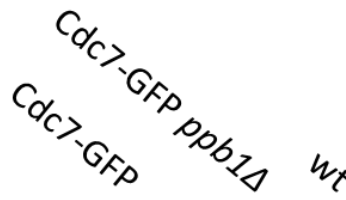

\begin{tabular}{l|r|} 
Extractos & $\begin{array}{r}\text { Cdc7-GFP } \\
\text { Actina }\end{array}$
\end{tabular}

B Spg1-GFP
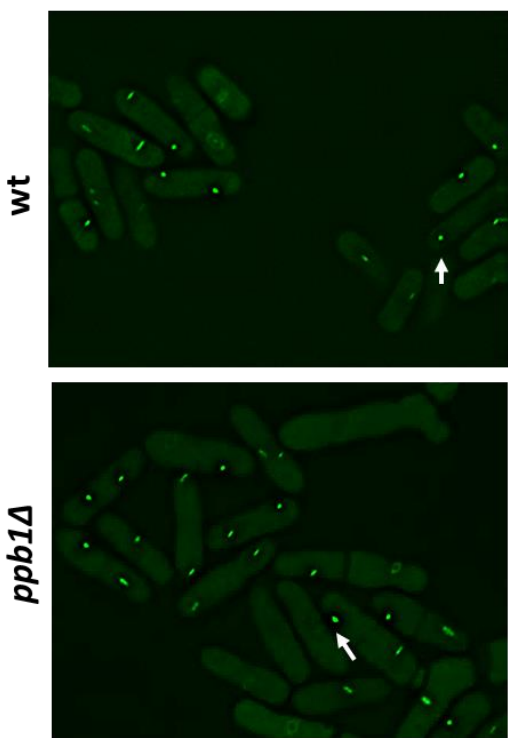

Cdc7-GFP
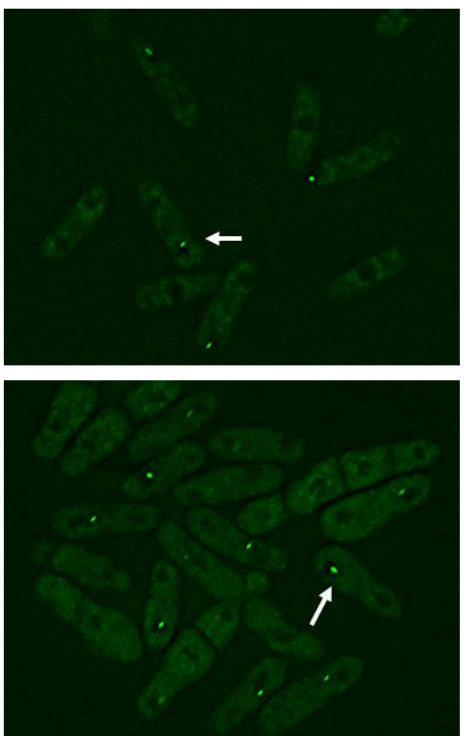

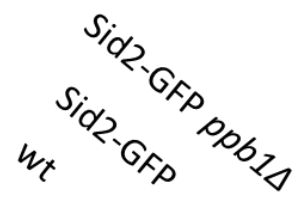

Sid2-GFP

Actina

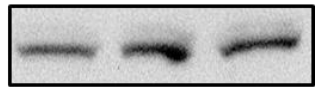

Sid2-GFP
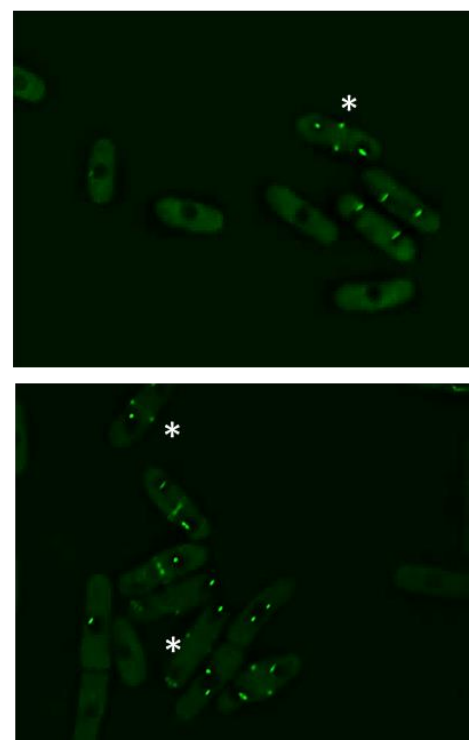


\section{Resultados}
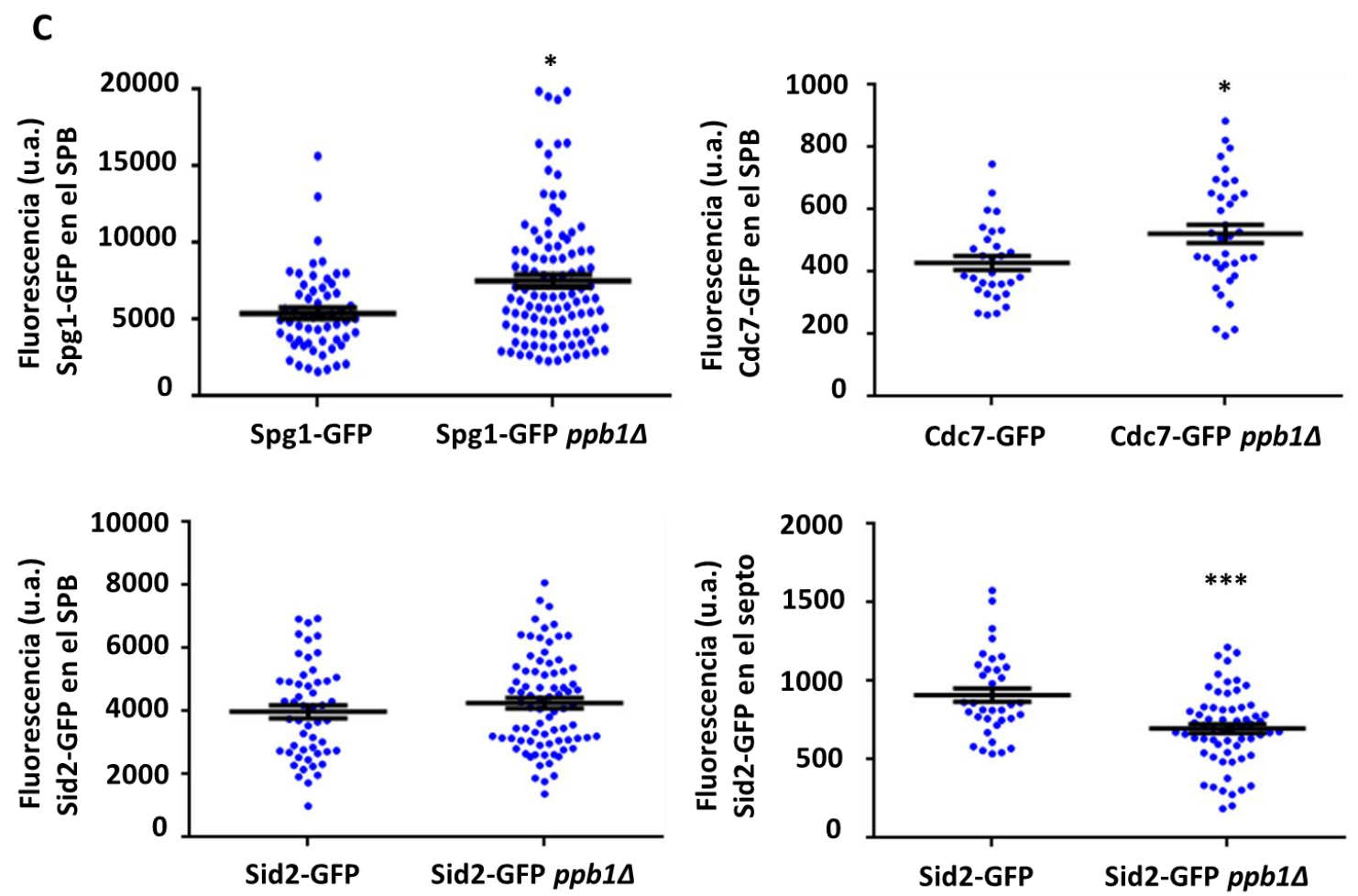

Figura 54.- Los componentes de la ruta SIN Spg1, Cdc7 y Sid2 no cambian su movilidad electroforética, aunque sí modifican su intensidad en la cepa ppb1s. (A) Western blot de extractos celulares de las cepas silvestre o ppb1 $1 \Delta$ que expresan distintos componentes de la ruta SIN marcados con GFP en su extremo C-terminal (PPG08815, PPG15758, PPG08814, PPG15279, PPG15754, PPG15755 y PPG04939). Los extractos celulares se analizaron en geles de poliacrilamida al 10\% para Spg1, al 8\% para Sid2 y al 6\% para $\mathrm{Cdc7}$, que fueron revelados con anticuerpos anti-GFP. La actina fue utilizada como control de carga. (B) Microscopía de fluorescencia de las cepas anteriores incubadas a $28^{\circ} \mathrm{C}$ en medio YES. Las flechas blancas indican un ligero aumento de intensidad de Spg1-GFP y Cdc7-GFP en el SPB. Los asteriscos blancos indican una disminución de Sid2-GFP en el CAR. (C) Cuantificación de la intensidad de fluorescencia. 


\section{CAPÍTULO 2: LA CALMODULINA SE LOCALIZA EN EL ANILLO Y EN LA MEMBRANA PLASMÁTICA DE LA ZONA DE DIVISIÓN E INTERACCIONA CON RHO1}

1. La calmodulina mantiene su localización en la membrana de la zona de división en ausencia de la paxilina o la calcineurina

La calcineurina necesita unirse a la calmodulina para estar activa (Li et al., 2011). Esta proteína se denomina Cam1 en S. pombe y se localiza en la membrana de las zonas de crecimiento celular (polos y zona de división) y en el cuerpo polar del huso mitótico (SPB) (Moser et al., 1997). Además, Cam1 forma parte del anillo de actomiosina interaccionando con alguno de sus componentes como Rng2 (Eng et al., 1998). En S. cerevisiae se ha descrito que la calmodulina participa en el proceso de endocitosis en los polos celulares (Myers et al., 2016), sin embargo, apenas se ha estudiado su papel en la citocinesis. La calmodulina se ha descrito como una proteína adaptadora capaz de unirse a dos proteínas de forma simultánea favoreciendo la interacción entre ellas, por lo que podría ejercer de enlance entre la calcineurina, a la cual activa, y sus sustratos en el anillo o el septo. Por ello se consideró interesante estudiar el papel que la calmodulina desempeña durante citocinesis regulando a la calcineurina. En primer lugar, se estudió la localización de Cam1 fusionada con GFP (Cam1-GFP) en células que carecían de Pxl1 o Ppb1 (Figura 55). La calmodulina mantuvo su localización y no se observaron diferencias significativas en la intensidad de fluorescencia en las cepas ppb1 $\Delta$ y pxl1 $\Delta$ respecto a la de células silvestres ( $p$ value $=0,233$ y pvalue $=0,156$ respectivamente). Esto nos indica que la localización de Cam1 en la zona de división no depende de la calcineurina.

A

wt

pxl14

ppb14
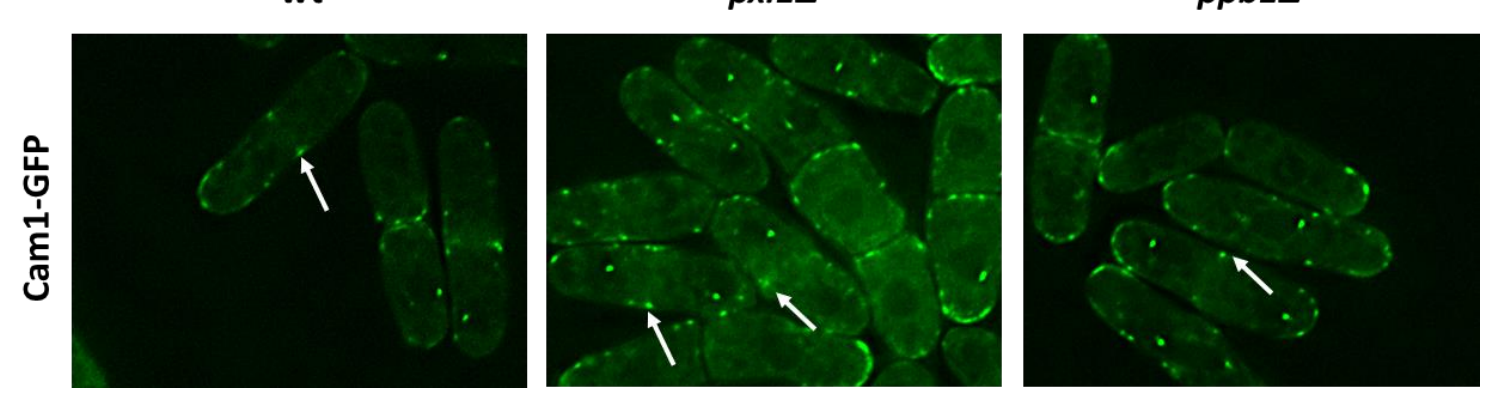


\section{Resultados}

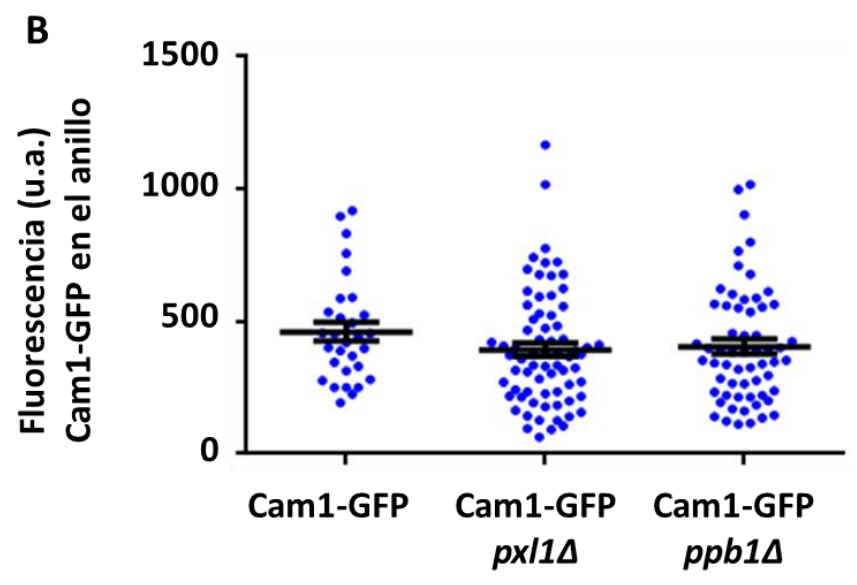

Figura 55.- Cam1 se localiza en la zona de división de forma independiente de paxilina o calcineurina. (A) Microscopía de fluorescencia de las cepas: silvestre, $p x \mid 1 \Delta$ y $p p b 1 \Delta$ que expresan Cam1-GFP.Células incubadas a $28^{\circ} \mathrm{C}$ en medio YES (PPG14653, PPG14913 y 14916). Las flechas blancas indican el mantenimiento de la localización de Cam1-GFP. (B) Cuantificación de la intensidad de fluorescencia de las cepas anteriores.

A continuación, se analizó si distintos niveles de calmodulina producían algún efecto sobre el CAR y/o en la citocinesis. En S. pombe el gen codificante para la calmodulina, cam1 $1^{+}$, es esencial para el crecimiento vegetativo (Takeda and Yamamoto, 1987). Por tanto, no es posible realizar su deleción para estudiar su papel durante la citocinesis así que recurrimos al uso del inhibidor específico de la calmodulina W7. Este compuesto se ha caracterizado como el principal antagonista de la calmodulina sin alterar la endocitosis en la célula (Hunziker, 1994; Jaumouillé et al., 2011). Se cultivaron células silvestres que expresaban la paxilina marcada en su extremo $\mathrm{N}$ terminal (GFP-Px|1) y se trataron con el inhibidor W7 a una concentración de $100 \mu \mathrm{M}$ durante 1 hora (Figura 56). La paxilina se localizaba en el CAR y este no presentaba defectos aparentes en su formación o en su contracción, aunque la intensidad de la señal de paxilina en el anillo estaba disminuida de manera similar a lo que ocurre cuando no hay calcineurina en la célula ( $p$ value $=0,007$ ). Esto se debe probablemente a que la calcineurina necesita calmodulina para estar activa y así localizarse en la zona de división y como se ha mencionado anteriormente, la calcineurina es necesaria para la acumulación de la paxilina en el anillo. Tampoco se observaron defectos dramáticos en la septación, sin embargo, se detectó que se producía lisis en algunas células cuando comenzaban a dividirse. 


\section{Resultados}

A

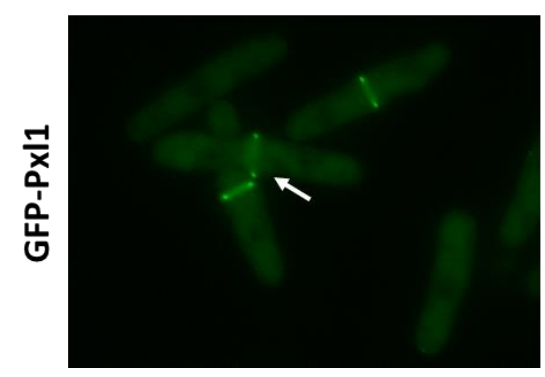

+W7 $100 \mu \mathrm{M} 1$ hora
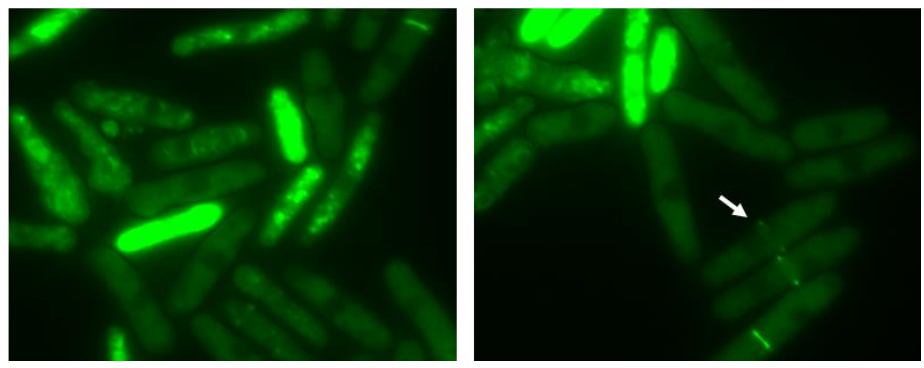

B

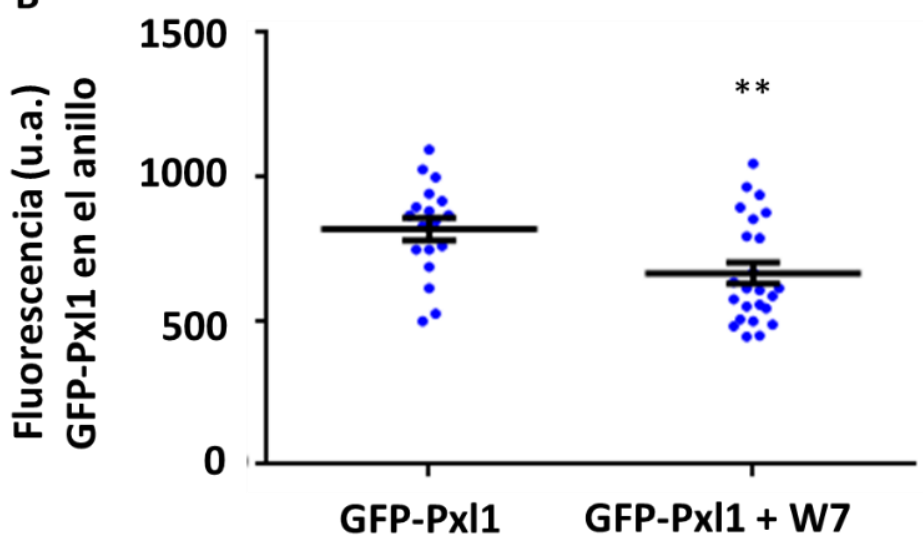

Figura 56.- (A) Microscopía de fluorescencia de una cepa GFP-Pxl1 tratada y sin tratar con el inhibidor W7 incubadas a $28^{\circ} \mathrm{C}$ en medio YES (PPG05060). Las flechas blancas indican la disminución en la intensidad de señal de GFP-PxI1. (B) Cuantificación de la intensidad de fluorescencia de las cepas anteriores.

\section{La calmodulina interacciona con la GTPasa Rho1}

2.1 La sobreexpresión de Cam1 suprime parcialmente el fenotipo de termosensibilidad del mutante rho1-596

El tratamiento con el inhibidor de la calmodulina W7 produce un fenotipo de lisis similar al que se observa en los mutantes de la GTPasa Rho1 en los que su funcionalidad se encuentra comprometida como en las cepas con el alelo rho1-596 o el alelo dominante negativo rho1T20N. En ambos casos la actividad $\beta$-glucán-sintasa disminuye y las células se lisan durante la separación celular, al finalizar el proceso de citocinesis (Arellano et al., 1997; Viana et al., 2013). Por tanto, se pensó que la calmodulina podría actuar como proteína adaptadora en la vía de señalización de la GTPasa Rho1 que activa a las $\beta$-glucán-sintasas Bgs1 y Bgs4. Para comprobar esta hipótesis se transformó la cepa mutante rho1-596 con el vector de sobreexpresión pREP1-cam $1^{+}$. Esta cepa se cultivó a la temperatura restrictiva de $34^{\circ} \mathrm{C}$ en la que la funcionalidad de Rho1-596 está comprometida y se vio que la sobreexpresión de Cam1 suprimía parcialmente el fenotipo de termosensibilidad de la cepa rho1-596 (Figura 57A). Además, también suprimía parcialmente el fenotipo de sensibilidad a $\mathrm{MgCl}_{2}$ que tiene la cepa rho1-596 (Figura 57B). Esto sugiere que Cam1 podría estar modulando la 


\section{Resultados}

actividad y/o la estabilidad de Rho1 aunque no se sabe si este efecto es dependiente de la calcineurina ya que la cepa rho1-596 ppb1s es letal (Viana et al., 2013).

A

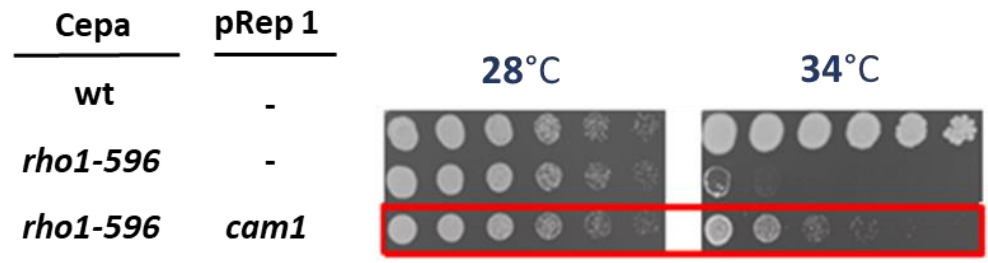

B

\begin{tabular}{|c|c|c|}
\hline Cepa & pRep 1 & \\
\hline wt & - & Q 的 \\
\hline rho1-596 & - & \\
\hline rho1-596 & cam1 & 앙 \\
\hline
\end{tabular}

Figura 57.- La sobreexpresión de Cam1 suprime parcialmente el defecto de crecimiento del mutante rho1-596 a $34^{\circ} \mathrm{C}$ y en $150 \mathrm{mM} \mathrm{MgCl}$. (A y B) Ensayo de crecimiento en gota de la cepa silvestre y rho1596 transformadas con el vector de sobreexpresión pREP1 o pREP1-cam1 ${ }^{+}$(PPG14360, PPG14354 y PPG14359). Las cepas se cultivaron en medio YES a $28^{\circ} \mathrm{C}$ hasta alcanzar densidad óptica 1 , se hicieron diluciones seriadas $1 / 4$ y se incubaron en placas de medio YES a diferentes temperaturas o en presencia de $\mathrm{MgCl}_{2} 150 \mathrm{mM}$ durante 3 días.

Puesto que la calmodulina era capaz de rescatar la termosensibilidad de la cepa rho1596 analizamos si Cam1 interaccionaba con Rho1 modulando de esta forma su actividad o actuando de proteína adaptadora entre Rho1 y sus reguladores. Para ello se realizó un ensayo de pull down en presencia o no de calcio utilizando las proteínas recombinantes GST y GST-Cam1 producidas en bacterias y unidas a bolas de glutatiónsefarosa. Estas bolas se incubaron con extractos de cepas que tenían Rho1 marcada con el epítopo HA en su extremo N-terminal (HA-Rho1) en su propio locus. El resultado nos muestra que Cam1 interacciona con Rho1 y que la interacción se ve aumentada en presencia de calcio (Figura 58A). Realizamos también ensayos de pull down utilizando extractos de cepas que expresaban HA-Rho1 y carecían de Ppb1. Así comprobamos que la interacción entre Cam1 y Rho1 se mantenía en ausencia de la calcineurina (Figura 59B). 


\section{Resultados}

A

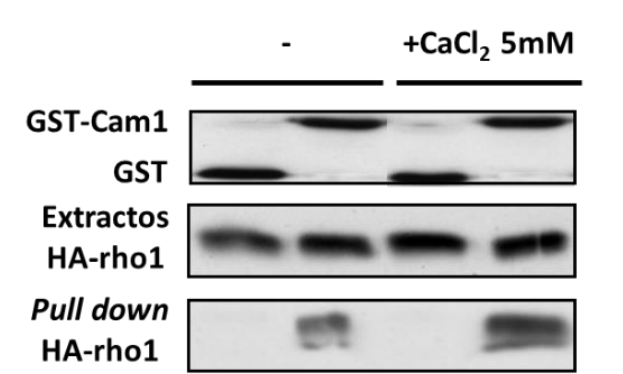

B

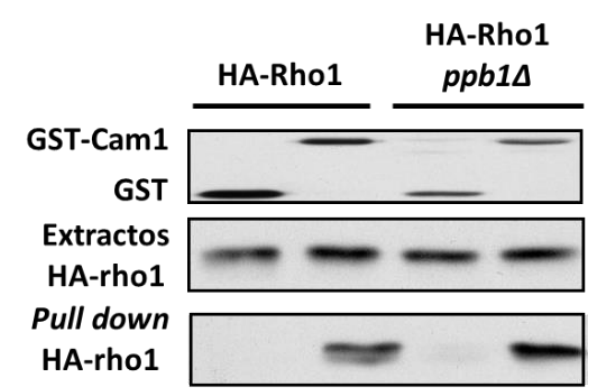

Figura 58.- Cam1 interacciona con Rho1. Esta interacción aumenta en presencia de calcio y es independiente de calcineurina. Ensayo de pull down con extractos de la cepa silvestre que expresa HARho1 en presencia o ausencia de calcio (PPG07847) (A) o con extractos de las cepas silvestre y ppb14 que expresan HA-Rho1 (PPG07847 y PPG12279) (B). Los extractos de las cepas se incubaron con bolas de glutatión-sefarosa que llevan unidas GST y GST-Cam1. Los precipitados y los extractos celulares fueron analizados con anticuerpos anti-GST y anti-HA.

Cam1 interacciona con Rho1 de forma independiente de calcineurina y además su sobreexpresión suprime la termosensibilidad y la sensibilidad a $\mathrm{MgCl}_{2}$ de la cepa rho1596 en la que la actividad de Rho1 se encuentra comprometida. Decidimos por ello estudiar si la sobreexpresión de Cam1 aumentaba la cantidad de Rho1 activa, es decir, unida a GTP en la célula y si esa posible activación por Cam1 era dependiente de calcineurina. El ensayo de cuantificación de Rho1 activa (Rho1-GTP) se realizó con células portadoras de HA-Rho1 y transformadas con el plásmido de sobreexpresión pREP1-cam $1^{+}$o pREP3X vacío, tanto en cepas silvestres como ppb1 1 . Se obtuvieron extractos celulares de ambas cepas y se realizaron ensayos de pull down con bolas de glutatión-sefarosa que llevaban unidos GST o GST-RBD. Este último es el dominio de unión a RhoA (RBD) de la proteína rotequina de mamíferos producido en bacterias unido a GST (Reid et al., 1996). Únicamente la proteína Rho1 que se encuentre activa es capaz de interaccionar con este dominio y precipitará junto a las bolas de glutatiónsefarosa, permitiéndonos detectarla. En la cepa silvestre la sobreexpresión de Cam1 no afectó a la cantidad total de Rho1, pero sí causó un incremento de Rho1 activa. Por otro lado, en la cepa ppb1 tampoco hay variación de los niveles totales de Rho1 respecto a la cepa silvestre y se produjo una disminución de Rho1 activa. Además, en ausencia de calcineurina, la sobreexpresión de calmodulina también aumentó la cantidad de Rho1 activa, aunque sin alcanzar los niveles de la cepa silvestre (Figura 59). Este resultado confirma la hipótesis de que Cam1 regula la actividad de Rho1, pero no exclusivamente mediante la activación de la calcineurina. 


\section{Resultados}

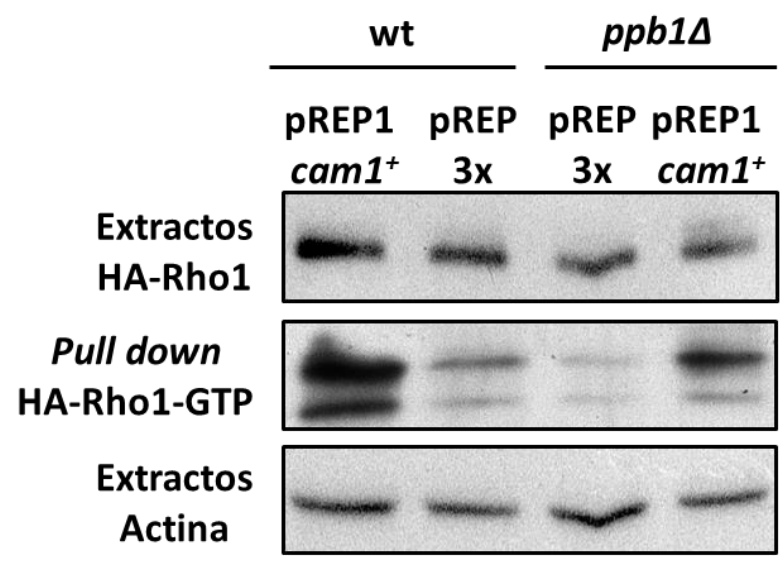

Figura 59.- La sobreexpresión de Cam1 incrementa los niveles de Rho1 activa. Ensayo de pull down con extractos de las cepas silvestre y $p p b 1 \Delta$ que expresan HA-Rho1 transformadas con los vectorespREP3X o pREP1-cam1+ (PPG14174, PPG14172, PPG14176 y PPG14177). Los extractos de las cepas se incubaron con las bolas de glutatión-sefarosa que llevan unidas GST o GST-RBD (dominio de unión a RhoA-GTP). LoS precipitados y los extractos celulares fueron analizados con anticuerpos anti-HA para ver los niveles de Rho1 total y activa. La actina se reveló como control de carga.

\subsection{Identificación de un sitio putativo de unión a calmodulina en la GTPasa Rho1}

En células animales se ha descrito la interacción de la calmodulina con las GTPasas RalA y RalB, pertenecientes a la subfamilia Rac1 de las GTPasas Rho, a través de su extremo C-terminal, siendo esta interacción necesaria para la activación de la GTPasa (Clough et al., 2002). Posteriormente, también en mamíferos, se describió una región entre los residuos 151 y 164 de la GTPasa Rac1 implicada en la interacción con la calmodulina y esencial para su activación (Xu et al., 2012). Para ver si la región de unión a calmodulina identificada en Rac1 se encontraba conservada en Rho1 se realizó un análisis de alineamiento de ambas secuencias y se comprobó que esta región presentaba un alto grado de identidad entre las dos proteínas (Figura 60A). Esto nos indujo a realizar mutagénesis dirigidas para estudiar si la modificación de la zona putativa de unión causaba una pérdida de interacción de Rho1 con Cam1 y en consecuencia una reducción de su actividad. Con el objetivo de estudiar el papel de la calmodulina en la regulación de la GTPasa Rho1 se generaron tres nuevos mutantes de Rho1: rho1-CM1, rho1-CM2 y rho1-CM3, en los que la interacción entre Rho1 y Cam1 debería encontrase disminuida. Para esto se generaron los alelos mutantes que poseían los residuos K156, K163 y E166, conservados entre las GTPasas Rho1 y Rac1, sustituídos por alanina. Para ello se reemplazó de la ORF de $r h o 1^{+}$de una cepa silvestre por las ORFs mutadas en uno de los tres aminoácidos, tal y como se explica en el apartado 5.8.2 de Materiales y Métodos. Así obtuvimos los alelos mutantes rho1-CM1, rho1-CM2 y rho1-CM3 respectivamente (Figura 60B). 


\section{Resultados}

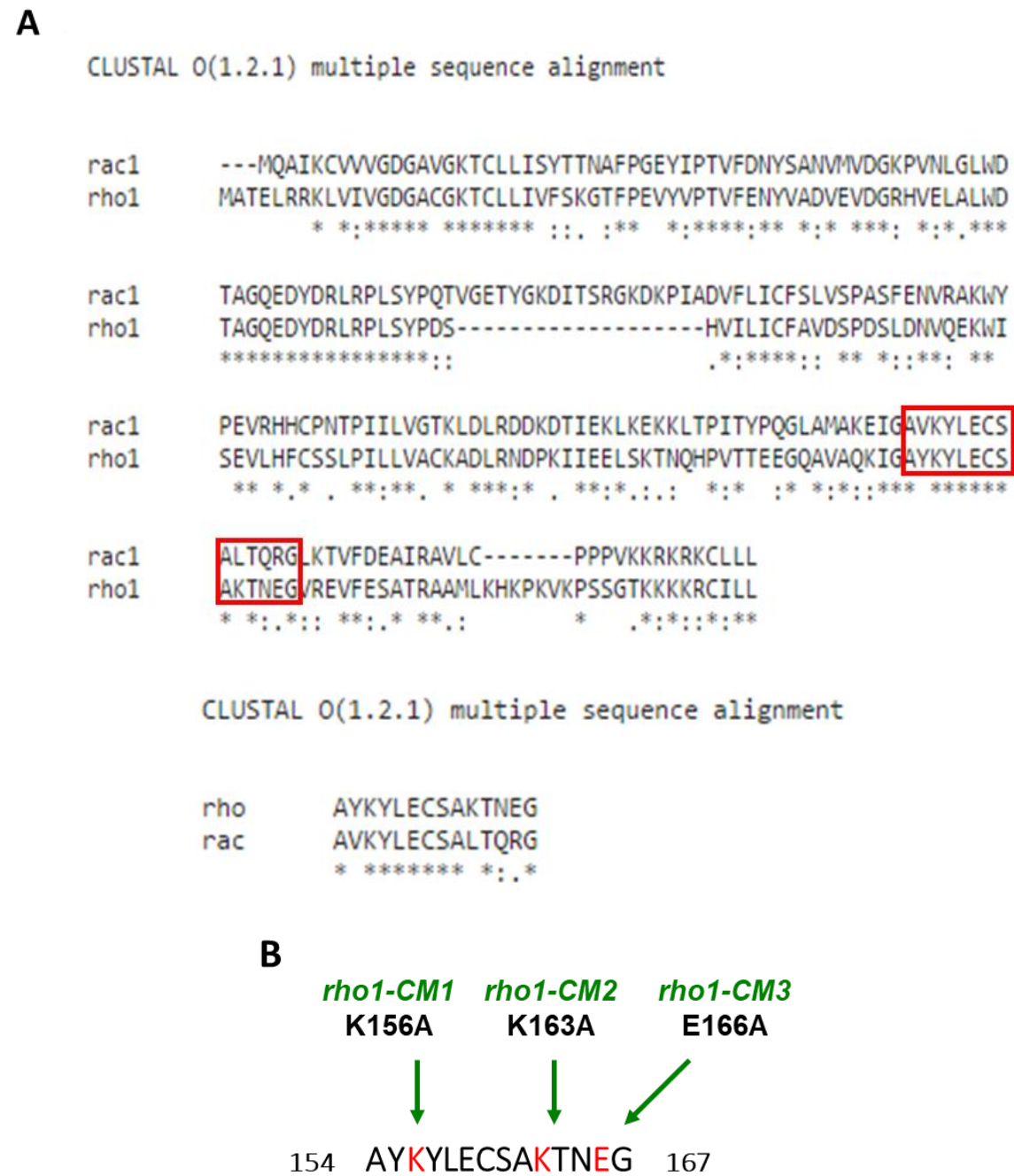

Figura 60.- Sitio putativo de interacción de la GTPasa Rho1 con calmodulina. (A) Alineamiento de las secuencias de las proteínas Rac1 humana y Rho1 de $S$. pombe mediante la utilización de CLUSTAL OMEGA. (B) Aminoácidos del sitio putativo de interacción donde se realizó la mutagénesis dirigida.

\subsection{Los mutantes de unión a calmodulina presentan algunos defectos similares al mutante rho1-596 donde la funcionalidad de Rho1 se encuentra comprometida}

Tras la obtención de las cepas mutantes se procedió a su caracterización para estudiar si poseían defectos similares a los de las cepas mutantes rho1-596 o rho1T20N en los que la funcionalidad de la GTPasa se encuentra comprometida o a los de las células tratadas con el inhibidor W7. El primer paso fue observar estos mutantes mediante microscopía óptica para detectar posibles defectos morfológicos. Las cepas con los alelos mutantes de Rho1 se incubaron en medio YES a $28^{\circ} \mathrm{C}$ y se observó que había algunas células lisadas (15-30\%), al igual que sucede en las células tratadas con el inhibidor W7 y en el mutante rho1-596. No se observó un aumento en el porcentaje de células septando ni aparecían células multiseptadas (Figura 61). 


\section{Resultados}

A

A

wt

rho1-CM1

rho1-CM2

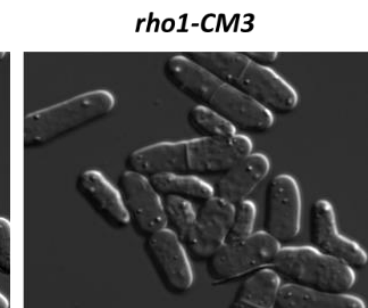

늠
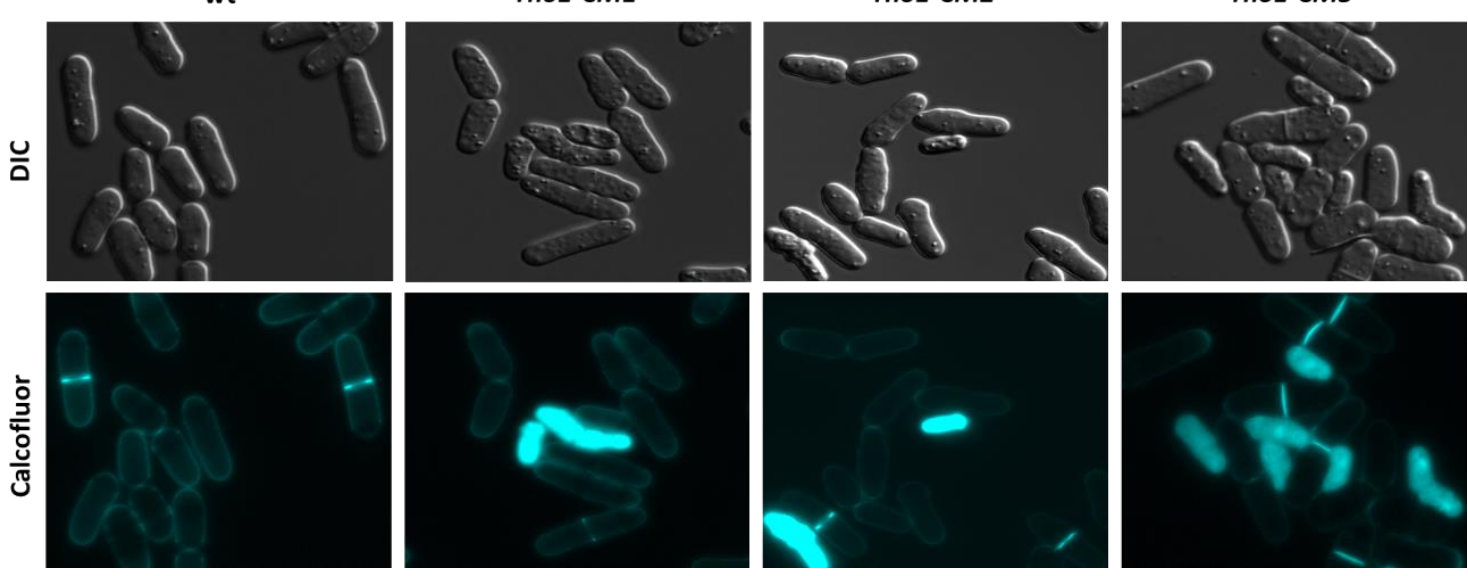

B
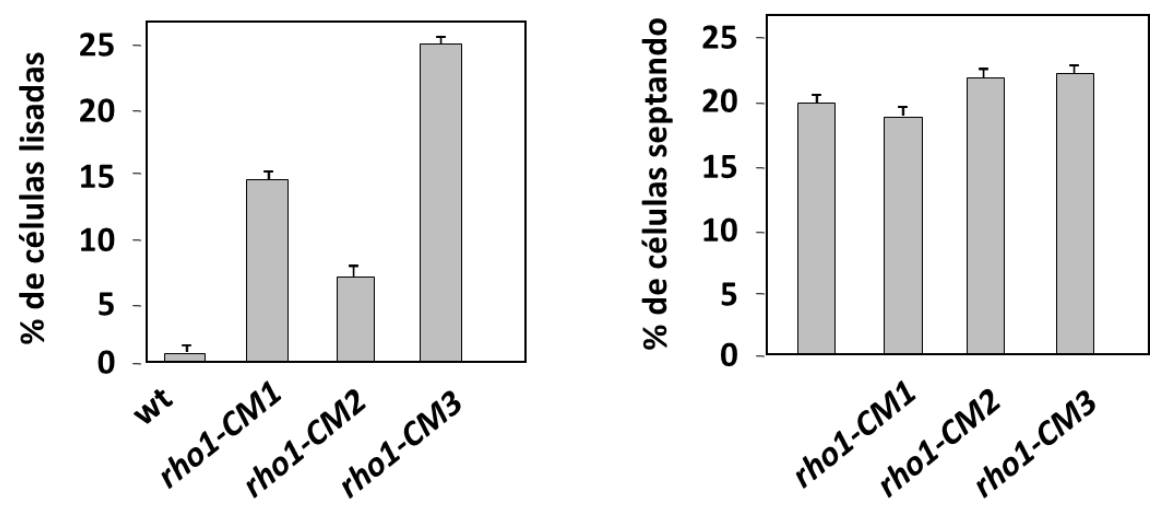

Figura 61.- Los mutantes de Rho1 de unión a calmodulina presentan lisis a 28C. (A) Microscopía óptica y de fluorescencia para estudiar el fenotipo de los mutantes rho1-CM1, rho1-CM2 y rho1-CM3 en medio YES a $28^{\circ} \mathrm{C}$ hasta alcanzar una densidad óptica de 1 (PPG12174, PPG12177 y PPG12180). Se realizó una tinción con calcoflúor para ver la localización del septo y la lisis celular. (B) Porcentaje de células lisadas y de células que poseen septo.

El mutante rho1-596 presenta mayor sensibilidad que la cepa silvestre a distintos compuestos como FK506, $\mathrm{MgCl}_{2}$, caspofungina o calcoflúor (Viana et al., 2013). Para ver si los mutantes de Rho1 de unión a calmodulina eran también más sensibles a estos compuestos, se sembraron diluciones seriadas de estos mutantes en placas de medio YES a las que se añadieron diferentes concentraciones de los correspondientes compuestos. Las tres cepas mutantes del sitio de unión a calmodulina presentaban hipersensibilidad a $\mathrm{FK506}, \mathrm{MgCl} 2$, caspofungina y calcoflúor como el mutante rho1-596 (Tabla 2). 
YES $32^{\circ} \mathrm{C}$

\begin{tabular}{|l|c|c|c|c|}
\hline & FK506 & $\mathrm{MgCl}_{2}$ & Caspofungina & Calcofluor \\
\hline & $\begin{array}{c}0,25 \\
(\mu \mathrm{g} / \mathrm{ml})\end{array}$ & $\begin{array}{c}100 \\
(\mathrm{mM})\end{array}$ & $\begin{array}{c}1 \\
(\mu \mathrm{g} / \mathrm{ml})\end{array}$ & $\begin{array}{c}0,2 \\
(\mathrm{mg} / \mathrm{ml})\end{array}$ \\
\hline rho1-CM1 & - & - & - & - \\
\hline rho1-CM2 & - & - & - & - \\
\hline rho1-CM3 & - & - & - & - \\
\hline wt & + & + & + & + \\
\hline
\end{tabular}

+ Crecimiento hasta la dilución $1 / 16$

++ Crecimiento hasta la dilución 1/64

- No hay crecimiento

Además, el mutante rho1-CM3 presentaba criosensibilidad que ya se observaba a la temperatura de $25^{\circ} \mathrm{C}$ cuando se cultivaba en medio YES, en contraste con el mutante rho1-596 que es sensible a temperaturas superiores a los $32^{\circ} \mathrm{C}$ (Figura 62A). Esta criosensibilidad se suprimía al añadir pequeñas concentraciones de calcio al medio de cultivo (Figura 62B). Esto podría deberse a que la entrada de calcio provoca un aumento de la interacción de la calmodulina con Rho1 y compensaría la pérdida de interacción del mutante. La entrada de calcio aumenta también la actividad de la calcineurina que es necesaria para la supervivencia celular cuando la funcionalidad de Rho1 se encuentra comprometida (Viana et al., 2013).

A

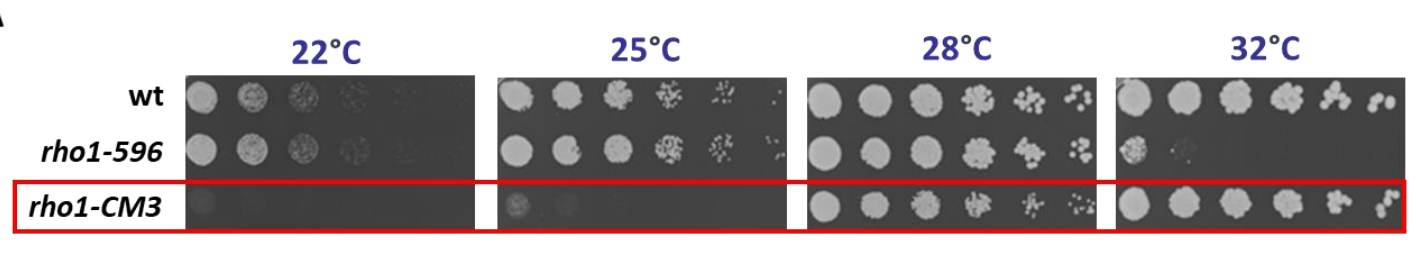

B

YES $\mathrm{YES}+\mathrm{CaCl}_{2} 5 \mathrm{mM} \quad \mathrm{YES}+\mathrm{CaCl}_{2} 10 \mathrm{mM} \quad \mathrm{YES}+\mathrm{CaCl}_{2} 25 \mathrm{mM}$

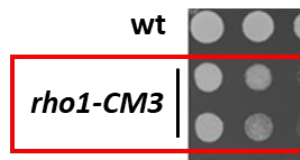

rho1-596

Figura 62.- El mutante rho1-CM3 presenta criosensibilidad que se suprime con bajas concentraciones de $\mathrm{CaCl}_{2}$. (A) Ensayo de crecimiento en gota de la cepa silvestre, rho1-596 y rho1-CM3 (PPG04939, PPG04035 y PPG12180). Las cepas se cultivaron en medio YES a $28^{\circ} \mathrm{C}$ hasta alcanzar densidad óptica 1 , se hicieron diluciones seriadas $1 / 4$ y se incubaron en placas de medio $Y E S$ a diferentes temperaturas durante 2 días. (B) Las mismas cepas se incubaron a $25^{\circ} \mathrm{C}$ en presencia de $\mathrm{CaCl}_{2}$ a bajas concentraciones durante 5 días. 


\section{Resultados}

Como el mutante rho1-CM2 presentaba menos porcentaje de lisis que los otros mutantes, a partir de este punto se procedió a la caracterización únicamente de los mutantes rho1-CM1 y rho1-CM3. La GTPasa Rho1 también está implicada en la regulación del citoesqueleto de actina, así, su sobreexpresión provoca una pérdida de la polaridad de la actina y la aparición de agregados de actina polimerizada. Por el contrario, cuando Rho1 no es funcional la actina se despolimeriza (Arellano et al., 1997). Para comprobar si los mutantes de unión a calmodulina también poseen estos defectos se cultivaron las cepas mutantes rho1-CM1 y rho1-CM3 a $32^{\circ} \mathrm{C}$ y a la temperatura restrictiva de $16^{\circ} \mathrm{C}$ durante 1 hora. Cuando las cepas alcanzaron una densidad óptica adecuada las células se tiñeron con faloidina-Alexa Fluor 488 que se une a las estructuras que forman la actina y permite ver posibles defectos en este citoesqueleto (Figura 63A). Ninguno de los mutantes presentaba defectos en el citoesqueleto de actina a $32^{\circ} \mathrm{C}$ y solo el mutante rho1-CM3 a $16^{\circ} \mathrm{C}$ presentaba la actina ligeramente despolarizada. Por otra parte, para observar el estado del citoesqueleto de microtúbulos se expresó la proteína Atb2, una de las proteínas que conforman el dímero de tubulina, marcada en su extremo $\mathrm{N}$-terminal bajo el control de su promotor (mCherry-Atb2) en las cepas mutantes. Mediante microscopía de fluorescencia no se observó en ninguno de los mutantes de Rho1 alteración de los microtúbulos en cuanto a su número o disposición en la célula incluso a la temperatura restrictiva de $16^{\circ} \mathrm{C}$ (Figura 63B). Sin embargo, cuando se realizaron ensayos de sensibilidad a carbamato de 2-Metil-Benzimidazol ( $\mathrm{MBC}$ ), que impide la polimerización de los microtúbulos (Quinlan et al., 1980) utilizando como control positivo la cepa rgf1 $($ Figura 63C), los mutantes rho1-CM1 y rho1-CM3 mostraron sensibilidad a $\mathrm{MBC}$ respecto a la cepa silvestre en ensayos de crecimiento en placa.

A

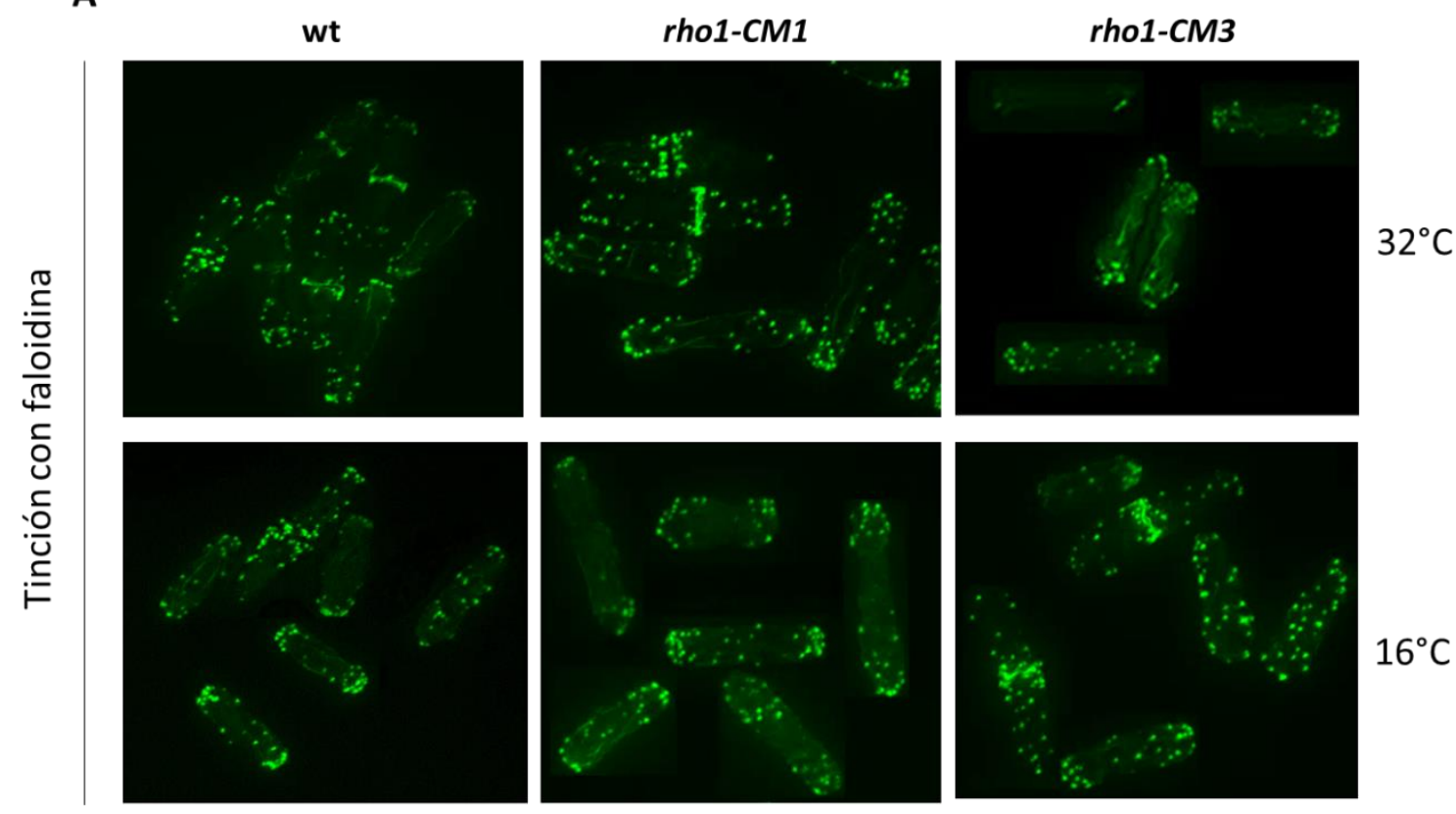




\section{Resultados}

B

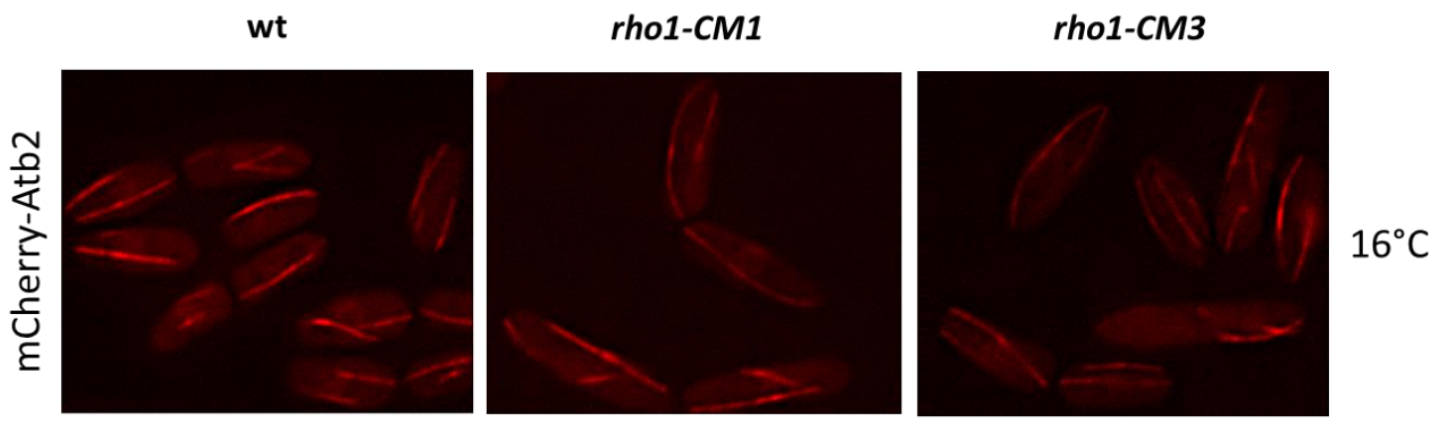

C

YES

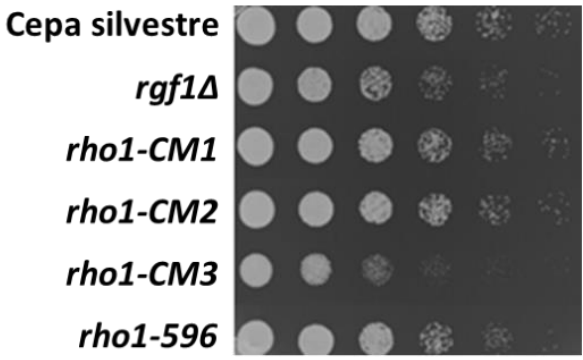

$\mathrm{YES}+\mathrm{MBC} 4 \mu \mathrm{g} / \mathrm{ml}$

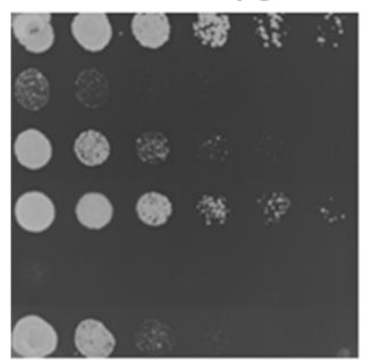

Figura 63.- Los mutantes de Rho1 de unión a calmodulina no presentan defectos aparentes en los citoesqueletos de actina y microtúbulos, aunque son sensibles a MBC. (A) Microscopía de fluorescencia de una cepa silvestre y de las cepas mutantes rho1-CM1 y rho1-CM3 cultivadas a $32^{\circ} \mathrm{C}$ y $16^{\circ} \mathrm{C}$ (PPG04939, PPG12174 y PPG12180). Las células se tiñeron con faloidina-Alexa Fluor 488. (B) Microscopía de fluorescencia de una cepa silvestre y las cepas mutantes rho1-CM1 y rho1-CM3 que poseen la proteína Atb2 de los microtúbulos marcada con la proteína mCherry. Células cultivadas a la temperatura restrictiva de $16^{\circ} \mathrm{C}$ (PPG08038, PPG13827 y PPG13832). (C) Ensayo de crecimiento en gota de la cepa silvestre, rgf1 $\Delta$, los mutantes de Rho1 de unión a calmodulina y el mutante rho1-596 (PPG04939, PPG06036, PPG12174, PPG12177, PPG12180 y PPG04035). Las cepas se cultivaron en medio YES a $28^{\circ} \mathrm{C}$ hasta alcanzar densidad óptica 1 , se hicieron diluciones seriadas $1 / 4$ y se incubaron en placas de medio YES a $28^{\circ} \mathrm{C}$ en presencia de $\mathrm{MBC}$ a una concentración de $4 \mu \mathrm{g} / \mathrm{ml}$. La cepa rgf1 $\Delta$ se utilizó como control positivo al ser sensible a MBC.

Se analizó también el estado del anillo de actomiosina en los mutantes de unión a calmodulina. Para ello se expresó en las cepas mutantes la cadena ligera reguladora de las miosinas Rlc1 unida a la proteína fluorescente roja td-Tomato (Rlc1-tdTomato). No se observó ninguna diferencia con respecto a las células silvestres en la localización de Rlc1 a ninguna de las temperaturas del ensayo (Figura 64). 


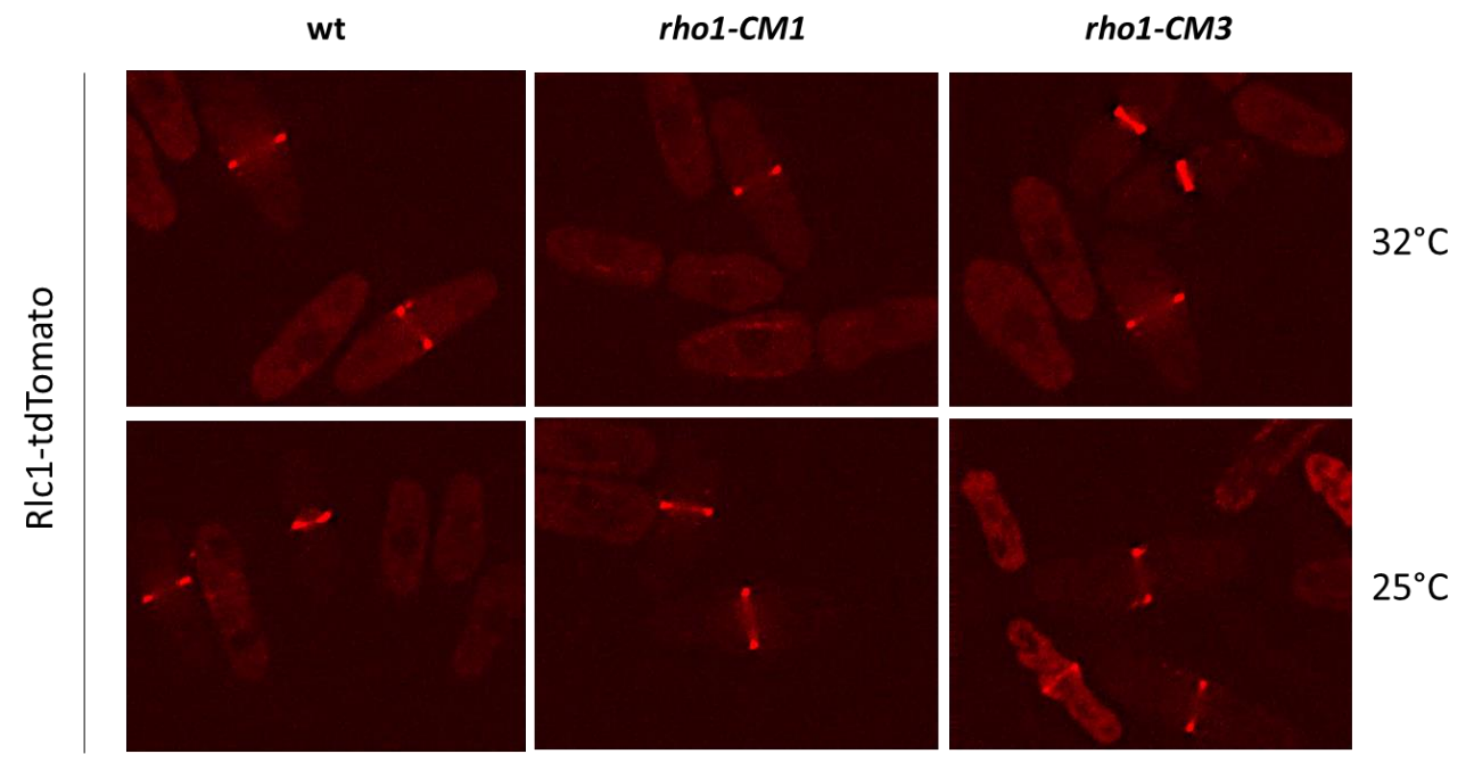

Figura 64.- Los mutantes de unión a calmodulina de Rho1 no presentan defectos aparentes en el CAR. Microscopía de fluorescencia de una cepa silvestre y de las cepas mutantes rho1-CM1 y rho1-CM3 que poseen Rlc1-tdTomato para estudiar el CAR a $32^{\circ} \mathrm{C}$ y $25^{\circ} \mathrm{C}$ (PPG06877, PPG14607 y PPG14610).

En resumen, la caracterización inicial de los mutantes de unión a calmodulina nos muestra que estos mutantes presentan lisis que se observa incluso a la temperatura permisiva de $28^{\circ} \mathrm{C}$ y presentan sensibilidad a los mismos compuestos que el mutante rho1-596. Sin embargo, estos mutantes no muestran defectos aparentes en el citoesqueleto de actina o en los microtúbulos. Por tanto, la actividad de Rho1 podría encontrase comprometida parcialmente o bien la activación de Rho1 por Cam1 se produciría únicamente durante la formación del septo y no afectaría al resto de las funciones de la GTPasa.

\subsection{Los mutantes rho1-CM1 y rho1-CM3 poseen menos cantidad de Rho1 total y mantienen su interacción con Cam1}

Las cepas mutantes rho1-CM1 y rho1-CM3 presentan una lisis en los cultivos similar a la de la cepa mutante rho1-596 y a la de las células tratadas con el inhibidor de la calmodulina W7. Para comprobar si este fenotipo de lisis era debido a la falta de actividad de Rho1 o a la inestabilidad de la proteína, estudiamos primero la cantidad de Rho1 total en estas cepas (Figura 65). Se obtuvieron extractos proteicos de cepas que llevaban estos alelos mutantes marcados con el epítopo HA en su extremo Nterminal (HA-Rho1-CM1/CM3) expresados con su propio promotor e integrados con el plásmido pJK148 en el locus leu1 $1^{+}$y se realizaron ensayos de Western blot. Las cepas mutantes rho1-CM1 y rho1-CM3 presentan una disminución de 2 y 20 veces respectivamente de los niveles de Rho1 total respecto a los de la cepa silvestre. Por 


\section{Resultados}

tanto, parece que las mutaciones realizadas afectan a la estabilidad de Rho1 ya que la cantidad total de esta GTPasa en extractos totales es considerablemente menor.

A

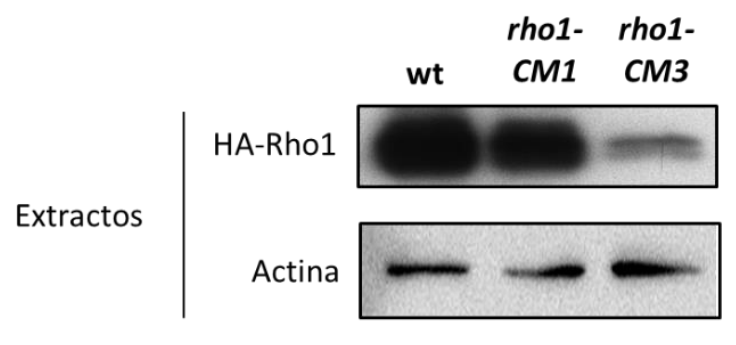

B

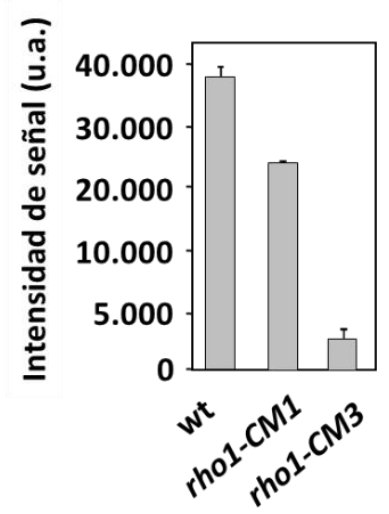

Figura 65.- Las cepas mutantes rho1-CM1 y rho1-CM3 presentan una disminución de la cantidad de Rho1 total. (A) Western blot de las cepas silvestre y los mutantes de Rho1 de unión a calmodulina que poseen fusionado el epítopo HA en su extremo $\mathrm{N}$-terminal, expresados con su propio promotor en el plásmido pJK148 e integrados en el locus leu1 $1^{+}$(PPG06860, PPG14144 y PPG14319). Los extractos celulares fueron analizados utilizando anticuerpos anti-HA y la actina fue utilizada como control de carga. (B) Cuantificación de la intensidad de señal del Western-blot

Para comprobar si, además de la disminución de Rho1 total, las mutaciones realizadas producían una pérdida de interacción de la GTPasa con la calmodulina, se realizaron experimentos de coprecipitación entre ambas proteínas (Figura 66). Se obtuvieron nuevamente extractos proteicos de las cepas silvestre y ppb1 $\Delta$ que expresaban los alelos mutantes de rho1 marcados con el epítopo HA en el locus leu1 $1^{+}$. Estos extractos se incubaron con bolas de glutatión-sefarosa que tenían unida las proteínas recombinantes GST o GST-Cam1 producidas en bacterias. Para compensar la disminución de la cantidad de Rho1 total de estos mutantes se añadió el doble de extracto total de la cepa rho1-CM1 y 20 veces más de la cepa mutante rho1-CM3 respecto a la cepa silvestre. Los resultados obtenidos mostraron que ambos mutantes mantenían la interacción entre la calmodulina y Rho1, por lo que las mutaciones puntuales realizadas no parecen afectar a esta interacción. Es posible que la interacción entre Cam1 y Rho1 sea tan fuerte que la mutación de un aminoácido no influya significativamente o bien que exista otra zona de Rho1 que participe en la unión de Cam1. La interacción se seguía manteniendo también en ausencia de la subunidad catalítica Ppb1. 


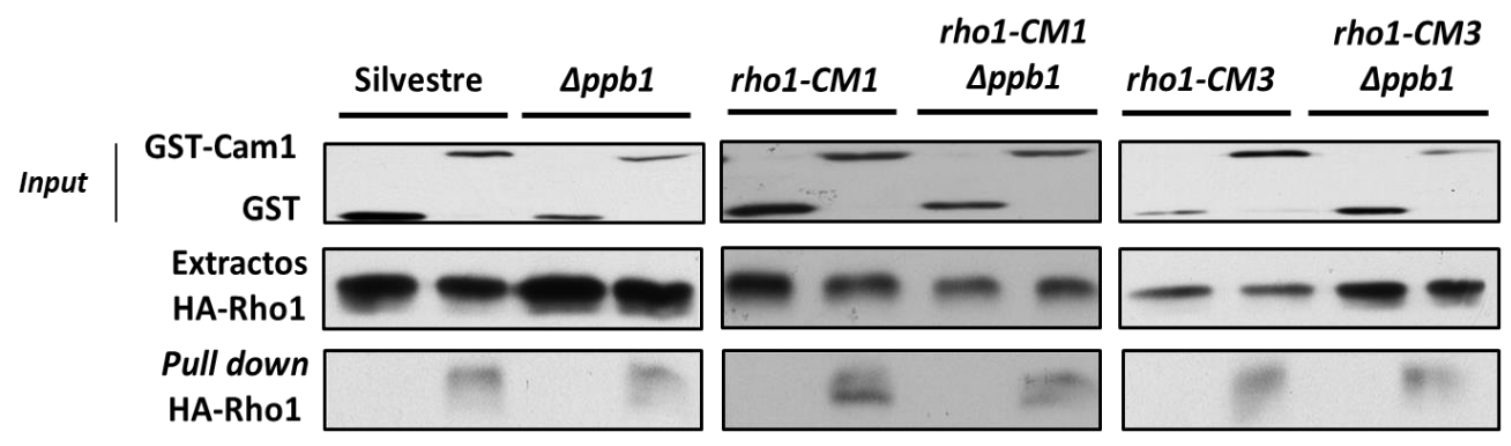

Figura 66.- Los mutantes rho1-CM1 y rho1-CM3 no pierden la interacción con la calmodulina. Ensayo de pull down con extractos de la cepa silvestre, $p p b 1 \Delta$ y los alelos mutantes de Rho1 de unión a calmodulina marcados con el epítopo HA bajo su propio promotor en el vector pJK148 integrado en el locus le $41^{+}$en presencia o ausencia de calcineurina (PPG06860, PPG14613, PPG14144, PPG14616, PPG14319 y PPG14619). Estos extractos se incubaron con bolas de glutatión-sefarosa que llevaban unido GST o GST-Cam1. Los precipitados y los extractos celulares fueron analizados con anticuerpos anti-GST y anti-HA. 
Discusión

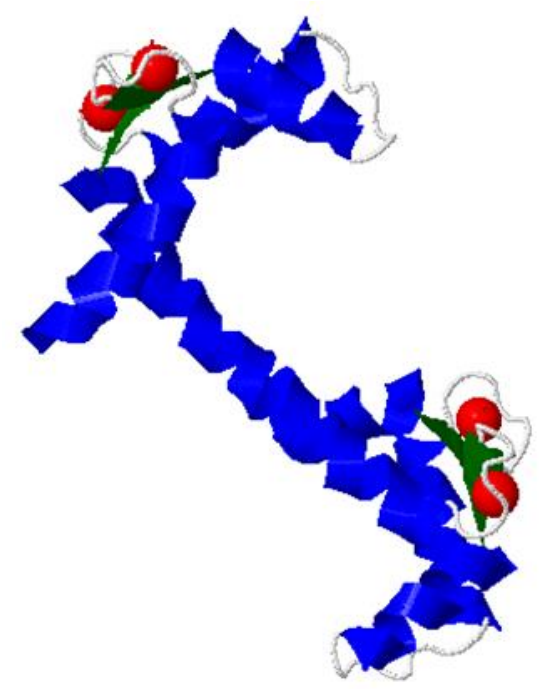





\section{Discusión}

\section{La calcineurina se localiza en el anillo de actomiosina a través de su interacción con los dominios LIM de la paxilina}

La calcineurina es la principal proteína encargada de la transducción de señales mediada por la entrada de calcio extracelular. En mamíferos esta señalización se transmite principalmente por el factor de transcripción NFAT que se localiza en núcleo tras ser desfosforilado por la calcineurina ( $\mathrm{Li}$ et al., 2011). Además, esta fosfatasa también es reclutada por otras proteínas adaptadoras haciendo que participe en la vía de señalización de la insulina (Hinke et al., 2012) o en la función cardiaca (Li et al., 2010). En hongos la calcineurina está implicada en las vías de señalización de respuesta a estrés, integridad celular, morfogénesis, progresión del ciclo celular, virulencia y homeostasis de iones (Fox and Heitman, 2002; Kraus and Heitman, 2003). En S. pombe, la calcineurina tiene un papel relevante en diversos procesos celulares, entre ellos la citocinesis (Sugiura et al., 2002). Inicialmente en este trabajo estudiamos la localización de la calcineurina a lo largo del ciclo celular, observando que esta se encuentra por todo el citoplasma y en el CAR durante citocinesis. La calcineurina colocaliza con la cadena ligera reguladora de las miosinas en el CAR, confirmando que esta forma parte del anillo durante la división celular. Sin embargo, esta fosfatasa no interviene en la formación del CAR, incorporándose a este una vez que ya se ha formado y permanece en él durante su constricción hasta el final de la septación. Estos datos difieren respecto a otros hongos como A. fumigatus donde la calcineurina se halla en la zona de división los polos, pero también se encuentra en los polos y en pequeñas estructuras móviles a lo largo de todo el citoplasma (Juvvadi et al., 2011). Durante la realización del presente trabajo se publicó un estudio sobre la delimitación de diferentes componentes del anillo contráctil en $S$. pombe, realizado mediante microscopía de alta resolución (McDonald et al., 2017). En este estudio se detectó con precisión a la calcineurina en una zona denominada "capa intermedia" del anillo entre la membrana plasmática y los filamentos de actomiosina.

En S. pombe la incorporación en el CAR de la subunidad catalítica de la calcineurina Ppb1 es dependiente de la subunidad reguladora Cnb1, siendo la ubicación de ambas interdependiente. Además, la localización de la calcineurina también se pierde en las cepas tratadas con el inhibidor de la calcineurina FK506. Por tanto, es necesaria la expresión de ambas subunidades completamente funcionales y activas para que la calcineurina esté presente en el anillo contráctil. Estos resultados difieren de lo descrito en otros hongos como $A$. fumigatus, en los que no se necesita la subunidad reguladora para que la subunidad catalítica llegue al CAR (Juvvadi et al., 2011). Por otro lado, en $S$. pombe hemos visto que la subunidad catalítica es capaz de interaccionar con la paxilina en ausencia de la subunidad reguladora. Esto indicaría que la activación de Ppb1 por Cnb1 no provoca un cambio conformacional que permita a la subunidad catalítica el reconocimiento de los sitios de unión en el sustrato (PxIxIT o similares). Por tanto, la desubicación de la calcineurina en el CAR cuando se encuentra inactiva se 


\section{Discusión}

debe a otro mecanismo independiente de la regulación del reconocimiento de estos sitios. La zona de unión a la subunidad reguladora en la subunidad catalítica Ppb1 se encuentra próxima a la zona de unión al inhibidor FK506 y a los sitios LxVP presentes en los sustratos (Juvvadi et al., 2016; Roy and Cyert, 2009). Por tanto, una posible explicación sería que la activación de Ppb1 le provocara un cambio conformacional que permitiera el reconocimiento de los sitios LxVP de la paxilina, orientándola correctamente y facilitando su posicionamiento en el CAR. Es posible también que la subunidad reguladora Cnb1 participe en el reconocimiento in vivo de la paxilina, aunque in vitro no hayamos detectado una unión directa de ambas proteínas.

La deleción del gen codificante de la subunidad catalítica de la calcineurina provoca un aumento del porcentaje de células en septación y células multiseptadas (Fujita et al., 2002; Lu et al., 2002a). Las células carentes de este gen presentan también anillos de actomiosina dobles y aberrantes. Ambos fenotipos son muy similares a los observados en las cepas carentes de paxilina (Pinar et al., 2008; Ge et al 2008; Cortes et al 2015) y en la cepa mutante doble $p x \mid 1 \Delta p p b 1 \Delta$ no se observa un efecto aditivo. Esto sugiere que ambas proteínas están implicadas en la misma vía de señalización. Los datos presentados indican que Ppb1 y Pxl1 interaccionan directamente in vivo y que la calcineurina pierde su localización en el CAR en ausencia de la paxilina o cuando a esta proteína se le eliminan los dominios LIM que le confieren la funcionalidad. No obstante, en ausencia de paxilina todavía se detecta una pequeña cantidad de esta fosfatasa al final de la contracción del CAR.

La calcineurina es capaz de reconocer a sus sustratos a través de los motivos PxIxIT y LxVP presentes en ellos e implicados en la interacción y en la correcta orientación del sustrato respectivamente. Estas secuencias fueron descritas en la levadura de gemación S. cerevisiae analizando distintos sustratos de la calcineurina en este hongo. Son motivos muy degenerados presentando múltiples variantes con mayor o menor afinidad por la calcineurina (Roy and Cyert, 2009). Los posibles sitios de unión a la calcineurina detectados en la región amino y carboxilo de Pxl1 no se ajustan perfectamente a la secuencia consenso PxIxIT. De hecho, solo la proteína PxI1-M4 que posee la mutación del sitio de unión en el tercer dominio LIM, presenta una pérdida de interacción con la calcineurina similar a la que sufre la cepa que expresa el alelo truncado sin el tercer dominio LIM (px/1LLIM3). Los defectos de citocinesis de esta cepa mutante, como el aumento en el porcentaje de células en septación y multiseptadas, son también muy similares a los de la cepa px/1 LLIM3 y menores que los de la cepa que carecía de todos los dominios LIM, lo que sugiere la presencia de otros sitios de interacción de Pxl1 con la calcineurina en estos dominios. Por el contrario, la proteína Pxl1-M3 que posee la mutación en el sitio putativo de unión situado en la mitad N-terminal mantiene una interacción con Ppb1 similar a la de la Pxl1 de la cepa silvestre. Además, esta cepa no presenta una disminución significativa en la localización de la fosfatasa y no tiene defectos en citocinesis. Sin embargo, la 


\section{Discusión}

deleción completa de la región $\mathrm{N}$-terminal de la paxilina sí produce una disminución de la interacción con Ppb1, señalando la presencia de otros sitios de unión a la calcineurina en esta región. Por tanto, es posible que la secuencia identificada presente una baja afinidad por la calcineurina y sea necesaria la mutación de otros sitios con mayor afinidad presentes en la región $\mathrm{N}$-terminal o bien que este no sea un sitio de unión de Ppb1. De esta forma, la calcineurina no es capaz de situarse en el CAR en ausencia de paxilina, observándose defectos en citocinesis tanto en el anillo de actomiosina como en el septo. La cepa pxl1 $\Delta$ que expresa Ppb1-GBP y Rlc1-GFP permite la relocalización artificial de la calcineurina en el CAR, disminuyendo considerablemente los defectos en citocinesis respecto a la cepa $p x / 1 \Delta$ rlc1-GFP. Estos resultados confirman que la función principal de la paxilina es la de unir a la calcineurina al CAR.

Es importante mencionar que en la cepa $p x \mid 1 \Delta$ la calcineurina se localiza al final de la contracción del CAR, aunque con menor intensidad que en la cepa silvestre. Esto sugiere que la calcineurina podría interaccionar con otras proteínas en el CAR al final de la contracción. En las células de mamíferos, la actividad de la calcineurina se requiere durante la etapa de abscisión de la citocinesis y parece estar localizada específicamente en la región del cuerpo medio (Lian et al., 2015). Es interesante constatar que una de las tres subunidades catalíticas humanas de la calcineurina, PPP3CA, interactúa con otras proteínas como LASP1 que tiene dominios LIM y SH3 (Q14847, Uniprot) y es importante para la regulación de la dinámica del citoesqueleto de actina, según la base de datos humana de DEPhOsphorylation (DEPOD, www.depod.org). Cabría, por tanto, pensar en una posible interacción conservada entre la subunidad catalítica de la calcineurina y los dominios LIM de otras proteínas.

En S. pombe existen tres proteínas, además de la paxilina, con dominios LIM: Rga1, Rga3 y Rga4, y todas ellas poseen además dominios RhoGAP. Rga1 y Rga3 poseen un leve porcentaje de similitud con el tercer dominio LIM de la paxilina donde se encuentra el sitio de unión a calcineurina. Sin embargo, en nuestras condiciones de ensayo no se ha detectado ninguna disminución en la intensidad de Ppb1-GFP en el CAR de las cepas carentes de estos GAPs, lo que parece indicar que ninguna de estas proteínas participa en la localización de la calcineurina en el CAR. Pudiera ser que los sitios putativos PxIxIT presentes en Rga1, Rga3 o Rga4 posean una baja afinidad por la calcineurina y que solo interaccionen con ella en ausencia de paxilina, localizando a la fosfatasa al final de la contracción del CAR. Para confirmar esta hipótesis son necesarios más experimentos que analicen la localización de la calcineurina en ausencia de la paxilina y de cada una de estas proteínas GAP. La pérdida total de la localización de la calcineurina en las fases finales de la citocinesis en esas cepas confirmaría que las proteínas GAP mencionadas poseen una función auxiliar que se manifiesta cuando la paxilina está ausente. No hemos analizado tampoco si alguna de estas proteínas GAP es sustrato de la calcineurina, aunque no participe en su localización en el CAR. En S. cerevisiae se ha descrito que la proteína Rga2, que es GAP 


\section{Discusión}

de Cdc42 y posee un dominio LIM, es desfosforilada y activada por la calcineurina que regula así la respuesta a las feromonas limitando su intensidad (Ly and Cyert, 2017; Smith et al., 2002).

En la subunidad catalítica de la calcineurina de $A$. fumigatus se ha implicado a la secuencia FMDVF, muy conservada en los hongos, en la unión de la calcineurina a sus sustratos (Juvvadi et al., 2016). La mutación de este dominio en la levadura de fisión provocó la pérdida de la localización de la calcineurina en el CAR, al igual que ocurría en A. fumigatus. No obstante, en S. pombe dicha secuencia solapa parcialmente con el dominio de unión a la subunidad reguladora Cnb1, por lo que la expresión del alelo mutante del dominio de unión a sustrato de la calcineurina ( $p p b 1-A A)$ resultó codificar una versión poco funcional de la calcineurina que no se encuentra activa y no se une a la subunidad reguladora, por ello no puede localizarse en el CAR.

La función de la paxilina en la señalización de calcineurina durante citocinesis puede no ser exclusiva de la levadura de fisión, y podría estar conservada en otros Ascomycetes como Aspergillus fumigatus. En este hongo, la señalización de calcineurina regula la citocinesis y el crecimiento de las hifas (Steinbach et al., 2006). La localización de la fosfatasa en el septo de la hifa durante todo el proceso de formación de esta estructura es importante para la correcta deposición del nuevo material de pared celular (Juvvadi et al., 2011). Sin embargo, los mecanismos exactos de la unión de calcineurina al septo en este hongo siguen sin estar claros. Experimentos preliminares realizados por nuestro colaborador Mario Pinar ( $\mathrm{ClB}$, Madrid) en Aspergillus nidulans parecen indicar que la paxilina de este hongo es también requerida para la citocinesis. Por tanto, su papel como proteína adaptadora para la unión de la calcineurina podría estar conservado en otros hongos. Por otra parte, la red de interacciones genéticas de la calcineurina en $S$. cerevisiae está enriquecida en genes de polaridad celular y citocinesis, por lo que podría tener funciones aún no identificadas en dichos procesos (Goldman et al., 2014). Sin embargo, en la levadura de gemación no se han descrito defectos en la citocinesis causados por la ausencia de calcineurina. Además, la señalización de la calcineurina determinada mediante las interacciones genéticas a nivel global es diferente en $S$. cerevisiae y $S$. pombe, lo que podría reflejar funciones distintas de esta fosfatasa en ambas levaduras (Koch et al., 2012). En la levadura Cryptococcus neoformans, se ha demostrado que la proteína de unión a fosfolípidos denominada Cts1 controla el posicionamiento del septo y la separación celular en coordinación con la calcineurina (Aboobakar et al., 2011; Fox et al., 2003). Cts1 presenta similitud con Inn1 de S. cerevisiae y con Fic1 de $S$. pombe (Aboobakar et al.,

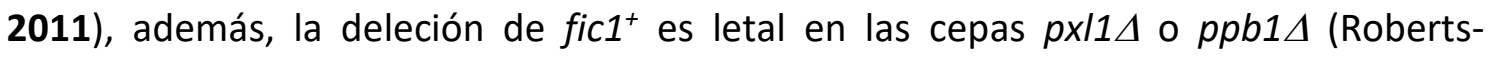
Galbraith et al., 2009). Todos estos datos sugieren que la señalización de paxilina y calcineurina durante la citocinesis está conservada, al menos parcialmente, en otros hongos. 


\section{Discusión}

\section{La calcineurina desfosforila a Cdc15 provocando la llegada de más paxilina al anillo contráctil de actomiosina}

La paxilina es la proteína encargada de la localización de la calcineurina en el CAR y a su vez la paxilina se une al anillo de actomiosina mediante una región de poliprolinas en su región $\mathrm{N}$-terminal que interacciona con el dominio SH3 de la proteína Cdc15 (Ren et al., 2015; Roberts-Galbraith et al., 2009). Estudios recientes han demostrado que la interacción Pxl1-Cdc15 también se produce mediante ciertas regiones de la zona intermedia de esta proteína. La deleción de estas regiones produce la deslocalización de la calcineurina del CAR, al igual que ocurre con la deleción de paxilina (Mangione et al., 2019). Utilizando videomicroscopía de fluorescencia en tiempo real (time lapse) se observó que la paxilina aumenta su concentración en el CAR a lo largo de la citocinesis, aunque, en ausencia de la subunidad catalítica de la calcineurina Ppb1, la paxilina tardaba más tiempo en comenzar a localizarse en el CAR y su intensidad era menor. Esto sugiere que la presencia de calcineurina en el CAR provoca una mayor incorporación de paxilina en esta estructura, pudiendo existir un circuito de retroalimentación o feedback loop positivo entre ambas proteínas, importante para la citocinesis. Este feedback podría explicarse fácilmente si la calcineurina, que se une a la paxilina, la desfosforilara y esto favoreciese su localización en el CAR llevando consigo a más calcineurina. Así, la fosfatasa provocaría su propia localización en el anillo de actomiosina al desfosforilar a la paxilina. A pesar de la observación de diversos estados de fosforilación de la paxilina tras la electroforesis en presencia de phos tag y posterior ensayo de Western blot, no logramos ver un cambio en la movilidad electroforética que pudiera indicar una modificación de su estado de fosforilación en ausencia de Ppb1. Por el contrario, sí se observó un cambio en la movilidad electroforética de Cdc15 en ausencia de la fosfatasa. Cdc15 está descrita como una fosfoproteína cuya desfosforilación en anafase provoca el cambio a su conformación abierta. Este estado le permite la unión a otras proteínas del CAR mientras que su posterior refosforilación produce nuevamente la transición a su conformación cerrada (Roberts-Galbraith et al., 2010). Mediante ensayos de coinmunoprecipitación, se demostró que Cdc15 interacciona con Ppb1 in vivo, además, se ha demostrado que esta es un sustrato de la calcineurina in vitro (MartínGarcía et al., 2018). Asimismo, el análisis de la fosforilación de Cdc15 en cultivos sincrónicos tratados con el inhibidor de la calcineurina FK506 corroboró que Cdc15 se encontraba más fosforilada durante anafase. Este estado hiperfosforilado de Cdc15 provocaría que esta proteína se encuentre en su conformación cerrada durante más tiempo, produciéndose así una menor localización de paxilina y de otras proteínas en el CAR. Así, Cdc15 se convierte en la proteína mediadora de la retroalimentación positiva de la calcineurina y la paxilina.

La falta de actividad de la calcineurina en el CAR altera la fosforilación de Cdc15 de una manera que recuerda la descrita para la ausencia de fosfatasa Clp1, por lo que es 


\section{Discusión}

probable que ambas fosfatasas colaboren en la desfosforilación de Cdc15 durante la citocinesis (Clifford et al., 2008; Wachtler et al., 2006). La conformación cerrada de Cdc15 cuando la calcineurina no llega al CAR se confirmó al demostrar también la disminución en la intensidad de fluorescencia de otros componentes del CAR reclutados a través de su dominio SH3, como Fic1-GFP. De esta forma, el estado hiperfosforilado de Cdc15 puede ser la causa de la formación de anillos de actomiosina aberrantes y que fallan al contraerse en la cepa ppb1 $\Delta$ debido a la falta de reclutamiento de algunos de sus componentes como Pxl1 o Fic1 (Roberts-Galbraith et al., 2010). Si bien, esto no explica todos los defectos causados por la deleción de $p p b 1^{+}$ o $p x / 1^{+}$como, por ejemplo, la aparición de anillos de actomiosina dobles o deslocalizados. La calcineurina permanece en el CAR durante su contracción hasta la formación del septo, sugiriendo que esta fosfatasa puede tener otros sustratos en el CAR además de Cdc15. Algunos de estos sustratos podrían ser las proteínas reclutadas al anillo contráctil por el dominio SH3 de Cdc15. Sin embargo, el estado de fosforilación de Fic1 no parece cambiar en ausencia de la subunidad catalítica de la calcineurina Ppb1, aunque sería necesario realizar experimentos de fosfoproteómica para confirmarlo. Además, otras proteínas reclutadas al CAR a través de Cdc15 como Cyk3 sí podrían ser reguladas por la fosfatasa.

\section{Otros sustratos de la calcineurina en el CAR}

El ensayo de proteómica realizado en el Instituto Curie se hizo para identificar estos nuevos posibles sustratos de la calcineurina, abriendo nuevas líneas de investigación en la señalización de esta fosfatasa durante la citocinesis. Este análisis reveló la posible interacción de la calcineurina con algunos componentes del CAR y del septo como la propia Cdc15, Myo2, Rng2 o las glucán-sintasas. Estos resultados refuerzan la importancia de la señalización de la calcineurina en la citocinesis a través de proteínas diferentes del factor de transcripción Prz1. De manera similar, en Aspergillus la función de la calcineurina en el crecimiento de las hifas y la citocinesis depende solo en parte del factor de transcripción CrzA, homólogo a Prz1, lo que indica que se requieren otras proteínas transmisoras de la señal de la calcineurina para la citocinesis (Cramer et al., 2008; Juvvadi et al., 2017; Soriani et al., 2008).

Los mecanismos moleculares que ocurren durante la contracción del CAR y la septación requieren la activación e inactivación de diversas vías de señalización, probablemente a través de la fosforilación y desfosforilación de diferentes proteínas. Por ello, estudiamos el estado de fosforilación de algunas de las proteínas identificadas en el ensayo de proteómica en presencia y ausencia de calcineurina. Inicialmente se observó la movilidad electroforética de estas proteínas mediante ensayos de Western blot y posteriormente se realizaron ensayos de fosfoproteómica de algunas de las proteínas candidatas a ser desfosforiladas por la fosfatasa. Los resultados presentados 


\section{Discusión}

en esta memoria son preliminares y es necesario realizar ensayos de fosfoproteómica adicionales para confirmarlos. Entre estos resultados merece la pena destacar los datos obtenidos con Rga7 y Pom1 que serán objeto de estudios posteriores en el laboratorio.

Los análisis de fosfoproteómica indicaron que Rga7 se encuentra más fosforilada en la cepa $p p b 1 \Delta$ y esta hiperfosforilación ocurre en dos secuencias próximas a su dominio GAP, ampliando ligeramente el dominio de fosforilación descrito previamente en esta proteína (Kettenbach et al., 2015). La deleción de Rga7 cursa con la aparición de anillos de actomiosina fragmentados junto con la formación de septos aberrantes y presenta letalidad sintética con $p x / 1^{+}$(Martín-García et al., 2014). Rga7 se localiza al comienzo del ciclo celular en los polos, pasando a localizarse posteriormente también en la zona de división (Arasada and Pollard, 2011). La localización de Rga7 no se modifica de forma significativa en ausencia de calcineurina. Para analizar con más precisión cómo influye la fosforilación de Rga7 en su función hemos iniciado estudios con mutantes fosfomiméticos y fosfonulos de Rga7 en las secuencias reveladas mediante el análisis de fosfoproteómica. La caracterización de estos mutantes será necesaria para comprobar si el estado hiperfosforilado de Rga7 produce algún defecto en el CAR o en el proceso de septación.

Rga7 forma un complejo con Rng10, siendo la localización de ambas interdependiente (Liu et al., 2016). En el análisis de fosfoproteómica de Rga7 se determinó que Rng10 también posee una secuencia fosforilable por la calcineurina no descrita previamente. Rng10 se encuentra más fosforilada en ausencia de la fosfatasa y este estado podría provocar también alteraciones en su localización y/o función en la citocinesis y que será necesario estudiar.

La quinasa Pom1 tiene numerosos sustratos que participan en la regulación de la polaridad, la citocinesis y el tamaño celular. Entre los sustratos de Pom1 que regulan la citocinesis se encuentran Cdc15, Rga7, Imp2 y Cyk3 (Kettenbach et al., 2015; Ullal et al., 2015). Se han identificado varios sitios de fosforilación de Cdc15 por Pom1 en su extremo C-terminal (Lee et al., 2018), por lo que esta quinasa podría estar implicada en la refosforilación de Cdc15 al final de la citocinesis, estando inhibida al inicio de esta por acción de la calcineurina. Nuestros resultados indicaron que Pom1 se encuentra más fosforilada en ausencia de Ppb1, observándose además un aumento en la cantidad de esta proteína localizada en el CAR y el septo durante la citocinesis. Se ha descrito que la autofosforilación de la quinasa Pom1 promueve su disociación rápida de la membrana plasmática en los polos y que esto es contrarrestado por la fosfatasa Dis2 unida a Tea4 (Hachet et al., 2011, Gerganova et al 2019). Una posible hipótesis es que la calcineurina estuviese desfosforilando a Pom1 en el anillo. Así, en ausencia de esta fosfatasa Pom1 permanecería más tiempo en el anillo y tanto Pom1 como sus sustratos, como Cdc15 y Rga7, estarían más fosforilados. En este caso, en el feedback loop positivo descrito entre la paxilina y la calcineurina participaría también Pom1. 


\section{Discusión}

Otra posibilidad es que la calcineurina esté activando a la fosfatasa Dis2. Así, la ausencia de calcineurina impediría que Dis2 desfosforile a Pom1 y promueva su localización en los polos. La calcineurina también podría actuar activando a una quinasa capaz de fosforilar y deslocalizar a Pom1 en las fases iniciales de la citocinesis. El ensayo de proteómica realizado en el Instituto Curie reveló la interacción de la calcineurina con la quinasa Kin1 en el CAR. Esta quinasa colabora con Pom1 en la fosforilación de Cdc15 y, a pesar de poseer funciones no redundantes sobre este sustrato, Kin1 podría regular la localización espacial y temporal de Pom1 en el CAR al final de la contracción para que pueda realizar su función (Kettenbach et al., 2015; Lee et al., 2018). Finalmente, es posible que la localización de Pom1 en la zona de división esté regulada de forma diferente a la localización en los polos.

En trabajos previos de nuestro laboratorio se identificó una interacción letal sintética entre $p x / 1 \Delta$ y el alelo termosensible de la glucán-sintasa Bgs1 que forma el septo primario, lo que indicó que Pxl1 y Bgs1 colaboran en un proceso esencial (Cortés et al., 2015). La represión de Bgs1, que en células silvestres provoca la formación de células multiseptadas, en células que además carecen de paxilina provoca una disminución significativa en el número de septos debido a que las otras glucán-sintasas como Bgs4 y Ags1, son incapaces de concentrarse en la zona de división para formar el septo (Cortés et al., 2015). Este fenotipo es similar cuando se apaga Bgs1 en ausencia de la calcineurina, por tanto, la localización de esta fosfatasa en el CAR a través de paxilina coopera junto con Bgs1 para regular la localización de las otras glucán-sintasas (Martín-García et al., 2018). La opción más probable es que la calcineurina desfosforilara a Ags1 y Bgs4 para regular su localización y el análisis inicial de proteómica también identificó a ambas glucán-sintasas como posibles sustratos de la calcineurina. Sin embargo, el análisis fosfoproteómico realizado posteriormente con la proteína Ags1 determinó que las dos secuencias fosforilables en esta proteína se encontraban desfosforiladas durante la citocinesis tanto en la cepa silvestre como en la cepa $p p b 1 \Delta$. Por tanto, parece que Ags1 no es un sustrato de esta fosfatasa, lo que confirma los resultados obtenidos mediante Western blot en los que no se detectaron cambios en la movilidad electroforética de Ags1 en la cepa carente de calcineurina. La calcineurina debe desfosforilar a otro sustrato que regule a Ags1 y/o Bgs4 y que colabore con Bgs1 en la función de localizar a las glucán-sintasas en el CAR. Uno de estos sustratos podría ser el GEF de Rho1, Rgf3, que también se une a Cdc15 (Ren et al 2015). Sin embargo, la movilidad electroforética de Rgf3 tampoco parece cambiar en ausencia de la calcineurina.

El análisis preliminar, realizado mediante Western blot, del estado de fosforilación de otras proteínas del CAR detectadas en el análisis de proteómica, como las cadenas de las miosinas tipo II, Rng2, o la formina Cdc12, no detectó cambios dependientes de calcineurina en ninguna de ellas. Se han descrito varios sitios de fosforilación tanto en la cadena pesada Myo2 como en las cadenas ligeras de las miosinas que regulan la 


\section{Discusión}

actividad motora de Myo2, de hecho, los mutantes fosfomiméticos de Rlc1 presentan retrasos en la contracción del CAR (Sladewski et al., 2009). La deleción de la paxilina, y por tanto la deslocalización de la calcineurina en el CAR, produce la desorganización de las miosinas y en algunos casos la aparición de anillos de actomiosina dobles (Pinar et al., 2008), lo que indica que la calcineurina podría regular a las cadenas de las miosinas. Sin embargo, la interacción de la cadena ligera reguladora de las miosinas, Rlc1, con la paxilina no es dependiente de la presencia de calcineurina. Esto unido a que la deleción de la calcineurina no parece provocar un estado hiperfosforilado en ninguna de las cadenas de las miosinas, parece indicar que esta fosfatasa no es la encargada de iniciar la contracción del CAR mediante la regulación de las miosinas. No obstante, el peso molecular de las cadenas pesadas de las miosinas es muy elevado y un cambio leve en su estado de fosforilación podría no detectarse mediante Western blot. Por tanto, será necesario realizar ensayos de fosfoproteómica para determinar si Myo2, Myp2, Cdc4 o Rlc1 son desfosforiladas por la calcineurina.

Cdc12 es la formina encargada de polimerizar los filamentos de actina que posteriormente Myo2, gracias a su actividad motora, entrecruzaría produciéndose de este modo la contracción del CAR (Stachowiak et al., 2014). Al igual que Cdc15, Cdc12 se encuentra desfosforilada durante la formación y contracción del CAR, mientras que se fosforila durante su etapa de maduración (Bohnert et al., 2013). Sin embargo, el estado de fosforilación de Cdc12 no parece cambiar en ausencia de la calcineurina, lo que indica que esta no sería la fosfatasa encargada de desfosforilar a la formina tras la maduración del anillo de actomiosina para que se produzca la contracción del CAR. Sorprendentemente, $\mathrm{Cdc12}$ presentó un cambio en su movilidad electroforética en la cepa $p x / 1 \Delta$, lo que sugiere que se encuentra más fosforilada y además se produce un leve aumento de localización de Cdc12-GFP en el CAR en esta misma cepa. Esto sugiere que la paxilina posee otras funciones en el anillo de actomiosina independientes de la calcineurina como podría ser la localización de otras fosfatasas como Clp1. Esta fosfatasa es reclutada al CAR por Mid1 (Clifford et al., 2008) y podría mantener su localización en el CAR mediante la paxilina. Cdc12 interacciona con el dominio F-BAR de Cdc15 (Carnahan and Gould, 2003). Esta interacción es necesaria para la localización de Cdc12 en el CAR observándose un retraso en su formación cuando esta interacción se encuentra comprometida en el estado hiperfosforilado del dominio F-BAR de Cdc15 (Roberts-Galbraith et al., 2010). La ausencia de Ppb1 que provoca una hiperfosforilación de Cdc15 podría, por tanto, impedir la localización de Cdc12 en el CAR durante su contracción. Sin embargo, Cdc12 mantiene su localización en el CAR durante la contracción cuando Cdc15 se encuentra hiperfosforilada en ausencia de Ppb1. Esto implicaría que la calcineurina desfosforilaría a Cdc15 en la región media o Cterminal afectando al comportamiento de las proteínas reclutadas a través del dominio SH3 de Cdc15 que disminuyen su localización. 


\section{Discusión}

El inicio de la ruta SIN comienza con la activación de la GTPasa Spg1 que favorece la localización asimétrica de $\mathrm{Cdc7}$, la primera quinasa de la vía de la señalización, mediante su interacción con esta GTPasa (Fankhauser and Simanis, 1994; Mehta and Gould, 2006). Tanto Spg1 como Cdc7 se localizan con mayor intensidad en el SPB en ausencia de calcineurina, lo que indicaría que esta ruta parecería encontrase más activa. Se ha relacionado a la calcineurina junto con otras fosfatasas como PP2A o Clp1 en la inactivación de la ruta SIN (Jiang and Hallberg, 2001; Lahoz et al., 2010; Trautmann et al., 2001) por lo que el resultado obtenido confirmaría que esta fosfatasa podría cooperar en la inhibición de esta ruta. PP2A y Clp1 inhiben la ruta SIN a través de la regulación de la GTPasa Spg1 (Jiang and Hallberg, 2001; Lahoz et al., 2010; Trautmann et al., 2001), sin embargo, en nuestras condiciones de ensayo, ni Spg1 ni Cdc7 parecen cambiar su estado de fosforilación en ausencia de la calcineurina. La vía SIN de señalización provoca la activación de la quinasa Sid2 que se sitúa, además de en el SPB, en el CAR y de esta manera inicia la formación del septo (Hou et al., 2004, 2000; Salimova et al., 2000). Sid2 no muestra cambios detectables en su movilidad electroforética en la cepa $p p b 1 \Delta$. Sin embargo, su localización en el CAR disminuye en ausencia de la fosfatasa, al contrario de lo que ocurre en el SPB donde la intensidad de fluorescencia se mantiene. Esta disminución de la localización en el CAR de Sid2 sugiere que la calcineurina podría ser necesaria para el movimiento de Sid2 del SPB al CAR. De esta forma, la disminución de Sid2 en el CAR debido a la ausencia de la fosfatasa podría ser una de las causas del aumento en el tiempo de septación.

\section{La calmodulina como proteína adaptadora entre la GTPasa Rho1 y otras proteínas como la calcineurina}

La calmodulina se localiza en la membrana de los polos de la célula regulando la endocitosis, en la zona de división regulando a la calcineurina y en el SPB (Moser et al., 1997). Esta proteína mantiene su localización en la zona de división en ausencia de la calcineurina y de la paxilina. Además, el tratamiento con el inhibidor de la calmodulina W7 origina la aparición de un fenotipo de lisis celular que se produce al comienzo de la división. Sin embargo, no se observan defectos en la formación del septo o del anillo contráctil ni la aparición de células multiseptadas como se observa en la cepa $p p b 1 \Delta$. Estos resultados en conjunto indican que la calmodulina posee otras funciones independientes de la fosfatasa calcineurina durante la citocinesis que todavía no se han descrito en la levadura de fisión. La calmodulina interacciona con la GTPasa Rho1 de forma independiente de la calcineurina y esta interacción aumenta en presencia de bajas concentraciones de $\mathrm{CaCl}_{2}$. Además, la sobreexpresión de la calmodulina corrige la termosensibilidad de la cepa rho1-596 a $32^{\circ} \mathrm{C}$ y la sensibilidad al cloruro de magnesio a una concentración de $150 \mathrm{mM}$ que produce un aumento de los niveles de Rho1 activo (Rho1-GTP). Por tanto, la calmodulina interacciona con Rho1 y la activa directamente o actuando como proteína adaptadora de otras proteínas activadoras. Previamente, en 


\section{Discusión}

nuestro grupo de investigación se describió que la calcineurina es esencial cuando la GTPasa Rho1 es poco funcional y, por tanto, podría ser una proteína reguladora de esta GTPasa (Viana et al., 2013). Por este motivo, podría ser que la calmodulina actuara como proteína adaptadora de la calcineurina para que esta regule la actividad de Rho1. Sin embargo, la sobreexpresión de calcineurina era capaz de activar a Rho1 incluso en ausencia de calcineurina. Además, a pesar de que la deleción de la calcineurina producía menor cantidad de Rho1 activa, esta aumentaba al sobreexpresarse la calmodulina, aunque no se recuperaban los niveles de la cepa silvestre. Por otra parte, la calmodulina mantiene su localización en el CAR en ausencia de calcineurina, lo que también indica que también se encuentra unida a otras proteínas. En conclusión, la calmodulina es capaz de activar a la calcineurina y a Rho1 de forma independiente. De esta forma, durante la citocinesis, la pérdida de actividad de las glucán-sintasas activadas por Rho1 podría ser la causa de la lisis producida tras la inhibición de la calmodulina con el compuesto W7.

En mamíferos se han identificado varios residuos del dominio de interacción de las GTPasas de la familia Rho con calmodulina, esenciales para la interacción entre ambas proteínas y por tanto para la activación de la GTPasa (Clough et al., 2002; Xu et al., 2012). Las cepas de $S$. pombe con mutaciones de Rho1 en este sitio de interacción (rho1-CM1, rho1-CM2 y rho1-CM3) presentan células lisadas cuando se cultivan incluso a la temperatura permisiva de $28^{\circ} \mathrm{C}$. En el mutante rho1-CM3 la lisis se suprimió añadiendo pequeñas concentraciones de $\mathrm{CaCl}_{2}$ al medio. Esto se debe, probablemente, a que el calcio es capaz de activar a la calcineurina que es necesaria para la supervivencia celular cuando la función de Rho1 se encuentra comprometida (Viana et al., 2013).

Desafortunadamente, las mutaciones de Rho1 en el sitio de interacción con calmodulina hacen a la proteína muy inestable por lo que, al igual que ocurre en el mutante hipofuncional rho1-596, los mutantes de unión a calmodulina presentan sensibilidad a compuestos como el FK506, el $\mathrm{MgCl}_{2}$, el $\mathrm{MBC}$, la caspofungina o el calcoflúor. Sin embargo, aunque el dominio de interacción entre la GTPasa Rho1 y la calmodulina se encuentra ampliamente descrito en mamíferos, las proteínas mutantes Rho1-CM1, Rho1-CM2 y Rho1-CM3 no mostraron una disminución de la interacción entre ambas proteínas. Esto puede deberse a que la interacción entre ambas proteínas en la levadura de fisión es muy fuerte y la mutación de uno solo de sus aminoácidos no provoque una pérdida de interacción o bien a que existen otras zonas de Rho1 que también participan en la unión. Por tanto, será necesario analizar las cepas mutantes que combinan mutaciones en varios aminoácidos del dominio de unión. La obtención de un mutante de Rho1 que pierda su capacidad de unión a calmodulina, permitiría un estudio detallado del papel de esta proteína en la citocinesis. No obstante, el hecho de que los niveles totales de Rho1 en las cepas rho1-CM sean inferiores a los de la cepa 


\section{Discusión}

silvestre plantea el problema de que dichas mutaciones alteren la estabilidad de Rho1 de forma dependiente o independiente de la calmodulina, lo que dificulta su estudio.

En resumen, en este trabajo hemos descrito cómo la proteína adaptadora Pxl1, que se asocia físicamente al dominio SH3 de Cdc15 por su extremo N-terminal, se une a la subunidad catalítica de la calcineurina y promueve la localización de esta fosfatasa en el CAR. Por otro lado, la actividad de la calcineurina es capaz de aumentar la concentración de Pxl1 durante la citocinesis, lo que indica la existencia de un ciclo de retroalimentación positivo que podría estar mediado por la desfosforilación de la proteína F-BAR Cdc15. Esta proteína al desfosforilarse cambia la conformación y se une a otras proteínas necesarias para la citocinesis. El papel de la calcineurina en la regulación de este proceso podría limitarse a la desfosforilación de $\mathrm{Cdc15}$, pero también podría regular otras proteínas que participan en la citocinesis como Rga7, Pom1, las glucán-sintasas o proteínas relacionadas con su regulación (Rgf3, Rho1, etc..). Además, hemos visto que la calmodulina, proteína necesaria para la activación de la calcineurina, interacciona también con Rho1 y es capaz de activarla. Sin embargo, la relación funcional de estas proteínas aún no se ha estudiado. 


\section{Conclusiones}

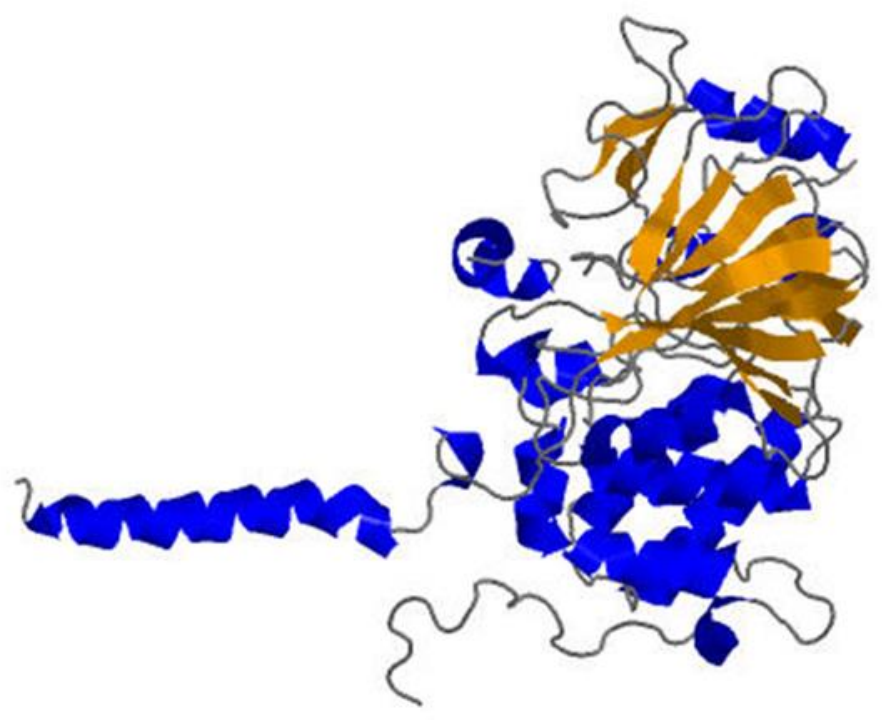





\section{Conclusiones}

\section{CONCLUSIONES}

1. La paxilina y la calcineurina poseen un fenotipo similar durante la citoquinesis.

2. La calcineurina necesita estar activa para localizarse en el CAR.

3. La paxilina se une a la subunidad catalítica de la calcineurina y es necesaria para localizar a esta fosfatasa en el anillo contráctil de actomiosina.

4. La función principal de la paxilina es la localización de la calcineurina en el CAR.

5. Los dominios LIM de paxilina y en particular el dominio C-terminal que posee una secuencia de unión a calcineurina, son necesarios para la localización de la calcineurina en el anillo contráctil de actomiosina.

6. La subunidad catalítica Ppb1 presenta un posible motivo de unión a sustrato que solapa con el dominio de unión a la subunidad reguladora Cnb1.

7. Cdc15 es un sustrato de la calcineurina en el CAR y su desfosforilación por esta fosfatasa es necesaria para la localización de las proteínas reclutadas por el dominio SH3, como Pxl1 o Fic1.

8. La calcineurina afecta al estado de fosforilación de Pom1, Rga7 y Rng10.

9. La calmodulina se localiza en la zona de división de forma independiente de la calcineurina y su ausencia no provoca ningún defecto aparente en el CAR.

10. La calmodulina interacciona in vivo con la GTPasa Rho1 de forma independiente de calcineurina.

11. La sobreexpresión de calmodulina produce la activación de la GTPasa Rho1 de forma independiente de calcineurina. 



\section{Materiales y métodos}

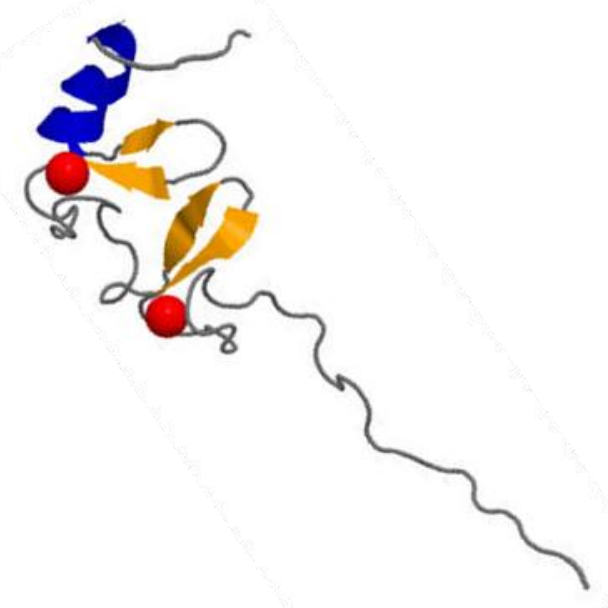



Materiales y métodos

\section{Microorganismos utilizados}

En este trabajo se ha estudiado la división celular utilizando como modelo la levadura de fisión Schizosaccharomyces pombe. En las técnicas de biología molecular se utilizaron también las estirpes $\mathrm{DH} 5 \alpha$ o BL-21 de Eschirichia coli. Todas las cepas utilizadas se recogen en la tabla 3 indicando su genotipo y su origen y se conservaron en glicerol al $25 \%$ a $-80^{\circ} \mathrm{C}$.

Tabla 3. Cepas de S. Pombe utilizadas.

\begin{tabular}{|c|c|c|}
\hline Estirpe & Genotipo & Origen \\
\hline PPG12234 & $\begin{array}{l}\text { h` ppb1-GFP:KanMX6 rlc1-tdTomato:NatMX6 } \\
\text { leu1-32 ura4- } \triangle 18\end{array}$ & Colección laboratorio \\
\hline PPG15444 & $\begin{array}{l}\mathrm{h}^{-} \text {ppb1-GFP:KanMX6 cnb1::KanMX6 rlc1- } \\
\text { tdTomato:NatMX6 leu1-32 ura4- } \Delta 18\end{array}$ & Este trabajo \\
\hline PPG15426 & $\begin{array}{l}\mathrm{h}^{-} \text {cnb1-GFP::KanMX6 rlc1- } \\
\text { tdTomato:NatMX6 leu1-32 ura4- } \Delta 18\end{array}$ & Este trabajo \\
\hline PPG15430 & $\begin{array}{l}\mathrm{h}^{-} \text {cnb1-GFP::KanMX6 ppb1::NatMX6 rlc1- } \\
\text { tdTomato:NatMX6 leu1-32 ura4- } \triangle 18\end{array}$ & Este trabajo \\
\hline PPG11417 & $\mathrm{h}^{-}$ppb1-GFP:KanMX6 leu1-32 ura4- $\triangle 18$ & Colección laboratorio \\
\hline PPG04939 & $\mathrm{h}^{+}$leu1-32 ura4- $\Delta 18$ & Colección laboratorio \\
\hline PPG10122 & $\mathrm{h}^{-}$pxl1::NatMX6 leu1-32 ura4- $\Delta 18$ & Colección laboratorio \\
\hline PPG09766 & $\mathrm{h}^{+}$ppb1::ura4 $4^{+}$leu1-32 ura4- $\Delta 18$ & Colección laboratorio \\
\hline PPG12272 & $\begin{array}{l}\text { h? pxl1::NatMX6 ppb1::ura4+ leu1-32 ura4- } \\
\Delta 18\end{array}$ & Colección laboratorio \\
\hline PPG07036 & $\mathrm{h}^{-}$rlc1-tdTomato:NatMX6 leu1-32 ura4- $\Delta 18$ & Colección laboratorio \\
\hline PPG13238 & $\begin{array}{l}\mathrm{h}^{\text {? ppb1::ura4 }}+\text { rlc1-tdTomato:NatMX6 leu1- } \\
32 \text { ura4- } \Delta 18\end{array}$ & Colección laboratorio \\
\hline PPG05748 & $\begin{array}{l}\mathrm{h} ? \text { pxl1::ura4 }{ }^{+} \text {rlc1-tdTomato:NatMX6 leu1- } \\
32 \text { ura4- } \Delta 18\end{array}$ & Colección laboratorio \\
\hline PPG14044 & $\begin{array}{l}\mathrm{h}^{?} \text { pxl1::KanMX6 ppb1::ura4 } 4^{+} \text {rlc1- } \\
\text { tdTomato:NatMX6 leu1-32 ura4- } \Delta 18\end{array}$ & Este trabajo \\
\hline PPG12236 & $\begin{array}{l}\mathrm{h}^{\text {? ppb1-GFP:KanMX6 pxl1::ura4 }}{ }^{+} \text {mCherry- } \\
\text { pxl1:leu1 }{ }^{+} \text {leu1-32 ura4- } \Delta 18 \text { ade6 }\end{array}$ & Colección laboratorio \\
\hline
\end{tabular}




\begin{tabular}{|c|c|c|}
\hline PPG13471 & $\begin{array}{l}h^{\text {? pxl1::NatMX6 HA-pxl1:leu1 }}+\text { ppb1- } \\
\text { GFP:KanMX6 leu1-32 ura4- } \Delta 18\end{array}$ & Este trabajo \\
\hline PPG11414 & $\mathrm{h}^{-}$ppb1-HA:KanMX6 leu1-32 ura4- $\Delta 18$ & Colección laboratorio \\
\hline PPG14945 & $\begin{array}{l}\mathrm{h}^{?} \text { ppb1-HA:KanMX6 cnb1::NatMX6 leu1-32 } \\
\text { ura4- } \Delta 18\end{array}$ & Este trabajo \\
\hline PPG14674 & h? cnb1-HA:KanMX6 leu1-32 ura4- $\Delta 18$ & Colección laboratorio \\
\hline PPG14946 & $\begin{array}{l}\mathrm{h}^{\text {? }} \text { cnb1-HA:KanMX6 ppb1::NatMX6 leu1-32 } \\
\text { ura4- } \Delta 18\end{array}$ & Este trabajo \\
\hline PPG12264 & $\begin{array}{l}\text { h? ppb1-GFP:KanMX6 pxl1::ura4+ rlc1- } \\
\text { tdTomato:NatMX6 leu1-32 ura4- } \Delta 18\end{array}$ & Colección laboratorio \\
\hline PPG13473 & $\begin{array}{l}\mathrm{h}^{?} \text { pxl1::ura4 } \\
\text { GFP:KanMX6 leu1-32 ura4- } \Delta 18\end{array}$ & Este trabajo \\
\hline PPG14632 & $\begin{array}{l}\mathrm{h}^{?} \text { pxl1::ura4 } \\
\text { GFP:KanMX6 leu1-32 ura4- } \Delta 18\end{array}$ & Este trabajo \\
\hline PPG13807 & $\begin{array}{l}\mathrm{h}^{\text {? }} \text { pxl1::ura4+ } \\
\text { rlc1-tdTomato:NatMX6 leu1-32 ura4- } \Delta 18\end{array}$ & Este trabajo \\
\hline PPG14310 & $\begin{array}{l}\mathrm{h}^{\text {? }} \text { pxl1::ura4 } \\
\text { GFP:KanMX6 rlc1-tdTomato:NatMX6 leu1- } \\
32 \text { ura4- } \Delta 18\end{array}$ & Este trabajo \\
\hline PPG14313 & $\begin{array}{l}\mathrm{h}^{\text {? }} \text { pxl1::ura4 } \\
\text { GFP:KanMX6 rlc1-tdTomato:NatMX6 leu1- } \\
32 \text { ura4- } \Delta 18\end{array}$ & Este trabajo \\
\hline PPG14362 & 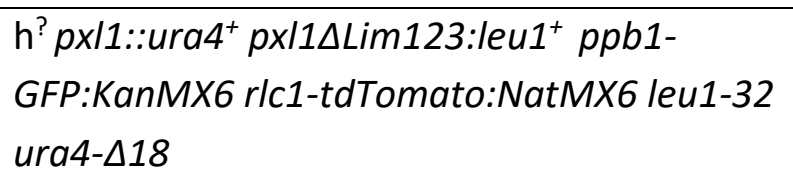 & Este trabajo \\
\hline PPG14366 & $\begin{array}{l}\mathrm{h}^{\text {? }} \text { pxl1::ura4 } \\
\text { GFP:KanMX6 rlc1-tdTomato:NatMX6 leu1-32 } \\
\text { ura4- } \Delta 18\end{array}$ & Este trabajo \\
\hline PPG15528 & $\begin{array}{l}\text { h? Ppb1-GFP:NatMX6 pxl1::ura4+ rlc1-GBP- } \\
\text { mCherry:KanMX6 leu1-32 ura4- } \Delta 18\end{array}$ & Este trabajo \\
\hline PPG15525 & 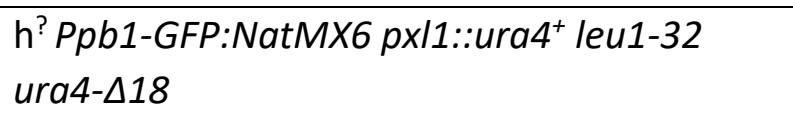 & Este trabajo \\
\hline
\end{tabular}


Materiales y métodos

PPG15526 h?Ppb1-GFP:NatMX6 pxl1::ura4+ rlc1- Este trabajo GBP:KanMX6 leu1-32 ura4- $\triangle 18$

\begin{tabular}{|c|c|c|}
\hline PPG15501 & $\begin{array}{l}\mathrm{h}^{\text {? }} \text { rga1::ura4 } \\
\text { ura4- } \Delta 18\end{array}$ & Este trabajo \\
\hline PPG15540 & $\begin{array}{l}\mathrm{h}^{?} \text { rga3::leu }{ }^{+} \text {ppb1-GFP:KanMX6 leu1-32 } \\
\text { ura4- } \Delta 18\end{array}$ & Este trabajo \\
\hline PPG15570 & $\begin{array}{l}\mathrm{h}^{?} \text { rga4::ura4 }{ }^{+} \text {ppb1-GFP:KanMX6 leu1-32 } \\
\text { ura4- } \Delta 18\end{array}$ & Este trabajo \\
\hline PPG15273 & $\begin{array}{l}\text { h? ppb1::NatMX6 pREP41-EGFP-ppb1:leu1 } \\
\text { leu1-32 ura4- } \triangle 18\end{array}$ & Este trabajo \\
\hline PPG15274 & $\begin{array}{l}\mathrm{h}^{?} \text { ppb1::NatMX6 pREP41-EGFP- } \\
\text { ppb1AA:leu1 }{ }^{+} \text {leu1-32 ura4- } \triangle 18\end{array}$ & Este trabajo \\
\hline PPG15505 & $\begin{array}{l}\mathrm{h}^{\text {? }} \text { ura4-294::pkk2 PCDRE-GFP:ura4 } \\
\text { pREP41:leu1 } \\
+ \text { leu1-32 his2 }\end{array}$ & Este trabajo \\
\hline PPG15506 & $\begin{array}{l}\mathrm{h}^{?} \text { ppb1::NatMX6 ura4-294::pkk2 PCDRE- } \\
\text { GFP:ura4+ pREP41:leu1+ leu1-32 his2 }\end{array}$ & Este trabajo \\
\hline PPG15507 & $\begin{array}{l}\text { h? ppb1::NatMX6 ura4-294::pkk2 PCDRE- } \\
\text { GFP:ura4+ }{ }^{+} \text {pREP41-ppb1:leu1+ leu1-32 his2 }\end{array}$ & Este trabajo \\
\hline PPG15508 & $\begin{array}{l}\mathrm{h}^{?} \text { ppb1::NatMX6 ura4-294::pkk2 PCDRE- } \\
\text { GFP:ura4+ pREP41-ppb1AF:leu1+ leu1-32 his2 }\end{array}$ & Este trabajo \\
\hline PPG15509 & 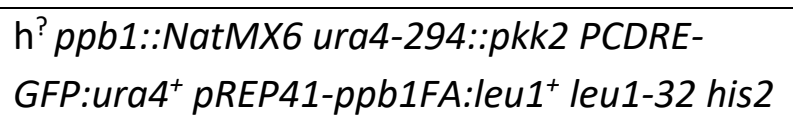 & Este trabajo \\
\hline PPG15510 & $\begin{array}{l}\text { h? ppb1::NatMX6 ura4-294::pkk2 PCDRE- } \\
\text { GFP:ura4+ pREP41-ppb1AA:leu1+ leu1-32 } \\
\text { his2 }\end{array}$ & Este trabajo \\
\hline PPG14879 & $\begin{array}{l}\mathrm{h}^{?} \text { px|1::KanMX6 GFP-px|1:px|1+ mcherry- } \\
\text { atb2:aur leu1-32 ura4- } \Delta 18\end{array}$ & Este trabajo \\
\hline PPG14877 & $\begin{array}{l}\text { h?ppb1::NatMX6 pxl1::KanMX6 GFP- } \\
\text { pxl1:pxl1+ mcherry-atb2:aur leu1-32 ura4- } \\
\Delta 18\end{array}$ & Este trabajo \\
\hline PPG05060 & $\begin{array}{l}\mathrm{h}^{+} p x \mid 1:: K a n M X 6 \text { GFP-px|1:px|1+ leu1-32 } \\
\text { ura4- } \Delta 18\end{array}$ & Colección laboratorio \\
\hline PPG14825 & $\mathrm{h}^{?}$ ppb1::NatMX6 pxl1::KanMX6 GFP- & Este trabajo \\
\hline
\end{tabular}




\begin{tabular}{|c|c|c|}
\hline PPG14861 & $\begin{array}{l}\text { h? cdc25-22 cdc15-HA:KanMX6 leu1-32 ura4- } \\
\Delta 18\end{array}$ & Este trabajo \\
\hline PPG15403 & $\begin{array}{l}\text { h? cdc25-22 ppb1-GFP:KanMX6 leu1-32 ura4- } \\
\Delta 18\end{array}$ & Este trabajo \\
\hline PPG15420 & $\begin{array}{l}\text { h? cdc25-22 cdc15-HA:KanMX6 ppb1- } \\
\text { GFP:NatMX6 leu1-32 ura4- } \triangle 18\end{array}$ & Este trabajo \\
\hline PPG05161 & $\begin{array}{l}\text { h- GFP-cdc15:KanMX6 leu1-32 ura4- } \Delta 18 \\
\text { ade6 }\end{array}$ & T. Pollard \\
\hline PPG14864 & $\begin{array}{l}h^{?} \text { cdc25-22 GFP-cdc15:KanMX6 leu1-32 } \\
\text { ura4- } \Delta 18\end{array}$ & Este trabajo \\
\hline PPG11624 & $\mathrm{h}^{+}$fic1-GFP:KanMX6 leu1-32 ura4- $\Delta 18$ & Colección laboratorio \\
\hline PPG15231 & $\begin{array}{l}\mathrm{h}^{?} \text { ppb1::NatMX6 fic1-GFP:KanMX6 leu1-32 } \\
\text { ura4- } \Delta 18\end{array}$ & Este trabajo \\
\hline PPG14810 & $\begin{array}{l}\mathrm{h}^{?} \text { ppb1::ura4 } \\
\text { Ppb1:leu }{ }^{+} \text {leu1-32 ura4- } \Delta 18\end{array}$ & Colección laboratorio \\
\hline PPG14812 & 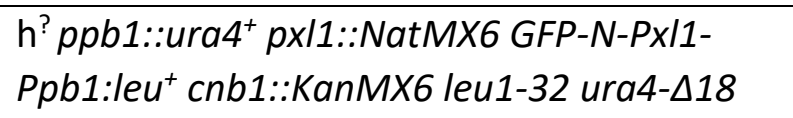 & Colección laboratorio \\
\hline PPG02543 & h? pom1-GFP:KanMX6 leu1-32 ura4- $\triangle 18$ & Colección laboratorio \\
\hline PPG15209 & $\begin{array}{l}\text { h? ppb1::NatMX6 pom1-GFP:KanMX6 leu1- } \\
32 \text { ura4- } \triangle 18\end{array}$ & Este trabajo \\
\hline PPG09936 & h? rga7-GFP:KanMX6 leu1-32 ura4- $\Delta 18$ & Colección laboratorio \\
\hline PPG15251 & $\begin{array}{l}\mathrm{h} ? \text { ppb1::NatMX6 rga7-GFP:KanMX6 leu1-32 } \\
\text { ura4- } \Delta 18\end{array}$ & Este trabajo \\
\hline PPG11363 & $\mathrm{h}^{-}$ags1-GFP:ura4+ leu1-32 ura4- $\Delta 18$ & Colección laboratorio \\
\hline PPG15517 & $\begin{array}{l}\mathrm{h}^{?} \text { ppb1::NatMX6 ags1-GFP:KanMX6 leu1-32 } \\
\text { ura4- } \Delta 18\end{array}$ & Este trabajo \\
\hline PPG06875 & h-GFP-myo2:KanMX6 leu1-32 ura4- $\Delta 18$ & Colección laboratorio \\
\hline PPG15253 & $\begin{array}{l}\mathrm{h} ? \text { ppb1::NatMX6 GFP-myo2:KanMX6 leu1-32 } \\
\text { ura4- } \Delta 18\end{array}$ & Este trabajo \\
\hline
\end{tabular}


Materiales y métodos

PPG15249 $\mathrm{h}$ ? ppb1::NatMX6 myp2-GFP:KanMX6 leu1-32 Este trabajo ura4- $\Delta 18$

\begin{tabular}{|c|c|c|}
\hline PPG04132 & $\mathrm{h}^{-}$cdc4-GFP:ura4+ leu1-32 ura4- $\Delta 18$ & M. Balasubramanian \\
\hline PPG15503 & $\begin{array}{l}\mathrm{h}^{?} \text { ppb1::NatMX6 cdc4-GFP:ura4 }{ }^{+} \text {leu1-32 } \\
\text { ura4- } \Delta 18\end{array}$ & Este trabajo \\
\hline PPG02619 & $\mathrm{h}^{+}$rlc1-GFP:KanMX6 leu1-32 ura4- $\Delta 18 \mathrm{~h}$ & Colección laboratorio \\
\hline PPG15217 & $\begin{array}{l}\mathrm{h} ? \text { ppb1::NatMX6 rlc1-GFP:KanMX6 leu1-32 } \\
\text { ura4- } \Delta 18\end{array}$ & Este trabajo \\
\hline PPG03753 & $\begin{array}{l}\mathrm{h}^{+} \text {YFP-rng2:KanMX6 leu1-32 ura4- } \Delta 18 \text { ade6- } \\
\text { M210 }\end{array}$ & T. Pollard \\
\hline PPG15247 & $\begin{array}{l}\mathrm{h} ? \text { ppb1::NatMX6 YFP-rng2:KanMX6 leu1-32 } \\
\text { ura4- } \triangle 18 \text { ade6-M210 }\end{array}$ & Este trabajo \\
\hline PPG02505 & $\mathrm{h}^{+}$GFP-cdc12:KanMX6 leu1-32 ura4- $\Delta 18$ & B. Feierbach \\
\hline PPG15219 & $\begin{array}{l}\mathrm{h}^{+} \text {ppb1::NatMX6 GFP-cdc12:KanMX6 leu1- } \\
32 \text { ura4- } \Delta 18\end{array}$ & Este trabajo \\
\hline PPG15221 & $\begin{array}{l}\mathrm{h}^{+} \text {pxl1::NatMX6 GFP-cdc12:KanMX6 leu1-32 } \\
\text { ura4- } \Delta 18\end{array}$ & Este trabajo \\
\hline PPG08815 & $\mathrm{h}^{+}$spg1-GFP:KanMX6 leu1-32 ura4- $\Delta 18$ & Colección laboratorio \\
\hline PPG15758 & $\begin{array}{l}\mathrm{h} ? \text { ppb1::NatMX6 spg1-GFP:KanMX6 leu1-32 } \\
\text { ura4- } \Delta 18\end{array}$ & Este trabajo \\
\hline PPG08814 & $\mathrm{h}^{+}$cdc7-GFP:ura4+ leu1-32 ura4- $\Delta 18$ & Colección laboratorio \\
\hline PPG15279 & $\begin{array}{l}\mathrm{h} ? \text { ppb1::NatMX6 cdc7-GFP:ura4 }{ }^{+} \text {leu1-32 } \\
\text { ura4- } \Delta 18\end{array}$ & Este trabajo \\
\hline PPG15754 & $\mathrm{h}^{+}$sid2-GFP:ura4 leu1-32 ura4- $\Delta 18$ & Y. Sánchez \\
\hline PPG15755 & $\begin{array}{l}\mathrm{h}^{+} \text {ppb1::NatMX6 sid2-GFP:ura4 }{ }^{+} \text {leu1-32 } \\
\text { ura4- } \Delta 18\end{array}$ & Este trabajo \\
\hline PPG14653 & $\mathrm{h}^{+}$cam1-GFP:KanMX6 leu1-32 ura4- $\triangle 18$ & D. Mulvihill \\
\hline PPG14913 & $\begin{array}{l}\mathrm{h}^{?} \text { pxl1::NatMX6 cam1-GFP:KanMX6 leu1-32 } \\
\text { ura4- } \Delta 18\end{array}$ & Este trabajo \\
\hline PPG14916 & $\begin{array}{l}\mathrm{h}^{\text {? }} \text { ppb1::NatMX6 cam1-GFP:KanMX6 leu1-32 } \\
\text { ura4- } \Delta 18\end{array}$ & Este trabajo \\
\hline
\end{tabular}


Materiales y métodos

\begin{tabular}{|c|c|c|}
\hline PPG14360 & $\mathrm{h}^{+} p R E P 1$ leu1-32 ura4- $\triangle 18$ & Colección laboratorio \\
\hline PPG14354 & $\begin{array}{l}\mathrm{h}^{+} \text {rho1-596:kanMX6 pREP1 leu1-32 ura4- } \\
\Delta 18\end{array}$ & Colección laboratorio \\
\hline PPG14359 & $\begin{array}{l}\mathrm{h}^{+} \text {rho1-596:kanMX6 pREP1-cam1 leu1-32 } \\
\text { ura4- } \triangle 18\end{array}$ & Este trabajo \\
\hline PPG07847 & h-HA-rho1:kanMX6 leu1-32 ura4- $\Delta 18$ & Colección laboratorio \\
\hline PPG12279 & $\begin{array}{l}\mathrm{h}^{?} \text { ppb1::ura4 } \\
\text { ura4- } \mathrm{H} \text { A-rho1:kanMX6 leu1-32 }\end{array}$ & Colección laboratorio \\
\hline PPG14172 & $\begin{array}{l}\mathrm{h}^{-} H A-r h o 1: k a n M X 6 \text { pREP3X leu1-32 ura4- } \\
\Delta 18\end{array}$ & Este trabajo \\
\hline PPG14174 & $\begin{array}{l}\text { h- HA-rho1:kanMX6 pREP1-cam1 leu1-32 } \\
\text { ura4- } \triangle 18\end{array}$ & Este trabajo \\
\hline PPG14177 & $\begin{array}{l}\mathrm{h}^{\text {? }} \text { ppb1::ura4 }{ }^{+} \text {HA-rho1:kanMX6 pREP3X } \\
\text { leu1-32 ura4- } \triangle 18\end{array}$ & Este trabajo \\
\hline PPG14176 & $\begin{array}{l}\text { h? ppb1::ura4 }{ }^{+} \text {HA-rho1:kanMX6 pREP1- } \\
\text { cam1 leu1-32 ura4- } \triangle 18\end{array}$ & Este trabajo \\
\hline PPG12174 & $\mathrm{h}^{+}$rho1-CM1:kanMX6 leu1-32 ura4- $\Delta 18$ & Este trabajo \\
\hline PPG12177 & $\mathrm{h}^{+}$rho1-CM2:kanMX6 leu1-32 ura4- $\Delta 18$ & Este trabajo \\
\hline PPG12180 & $\mathrm{h}^{+}$rho1-CM3:kanMX6 leu1-32 ura4- $\Delta 18$ & Este trabajo \\
\hline PPG04035 & $\mathrm{h}^{+}$rho1-596:kanMX6 leu1-32 ura4- $\Delta 18$ & Colección laboratorio \\
\hline PPG06036 & $\mathrm{h}^{-}$rgf1::KanMX6 leu1-32 ura4- $\Delta 18$ & Y. Sánchez \\
\hline PPG08038 & $\mathrm{h}^{-} \mathrm{mCherry-atb2:aur} \mathrm{leu1-32}$ ura4- $\Delta 18$ & Colección laboratorio \\
\hline PPG13827 & $\begin{array}{l}\text { h? mCherry-atb2:aur rho1-CM1:kanMX6 } \\
\text { leu1-32 ura4- } \triangle 18\end{array}$ & Este trabajo \\
\hline PPG13832 & $\begin{array}{l}\text { h? mCherry-atb2:aur rho1-CM3:kanMX6 } \\
\text { leu1-32 ura4- } \triangle 18\end{array}$ & Este trabajo \\
\hline PPG06877 & $\mathrm{h}^{-}$rlc1-tomato:natMX6 leu1-32 ura4- $\Delta 18$ & Colección laboratorio \\
\hline PPG14607 & $\begin{array}{l}\text { h? rlc1-tomato:natMX6 rho1-CM1:kanMX6 } \\
\text { leu1-32 ura4- } \triangle 18\end{array}$ & Este trabajo \\
\hline PPG14610 & $\begin{array}{l}\text { h? rlc1-tomato:natMX6 rho1-CM3:kanMX6 } \\
\text { leu1-32 ura4- } \triangle 18\end{array}$ & Este trabajo \\
\hline
\end{tabular}




\begin{tabular}{|c|c|c|}
\hline PPG06860 & h? HA-rho1:leu1+ leu1-32 ura4- $\Delta 18$ & Colección laboratorio \\
\hline PPG14144 & $\begin{array}{l}\mathrm{h}^{+} \text {rho1-CM1:kanMX6 HA-rho1-CM1:leu1 } \\
\text { leu1-32 ura4- } \triangle 18\end{array}$ & Este trabajo \\
\hline PPG14319 & $\begin{array}{l}\mathrm{h}^{+} \text {rho1-CM3:kanMX6 HA-rho1-CM3:leu1 } \\
\text { leu1-32 ura4- } \triangle 18\end{array}$ & Este trabajo \\
\hline PPG14613 & $\begin{array}{l}\mathrm{h}^{?} \text { ppb1::NatMX6 HA-rho1:leu1+ leu1-32 } \\
\text { ura4- } \Delta 18\end{array}$ & Este trabajo \\
\hline PPG14616 & $\begin{array}{l}\mathrm{h}^{+} \text {ppb1::NatMX6 rho1-CM1:kanMX6 HA- } \\
\text { rho1-CM1:leu1+ leu1-32 ura4- } \triangle 18\end{array}$ & Este trabajo \\
\hline PPG14619 & $\begin{array}{l}\mathrm{h}^{+} \text {ppb1::NatMX6 rho1-CM3:kanMX6 HA- } \\
\text { rho1-CM3:leu1 }{ }^{+} \text {leu1-32 ura4- } \triangle 18\end{array}$ & Este trabajo \\
\hline
\end{tabular}

\section{Medios de cultivo}

\subsection{Medios de cultivo para S. pombe}

Los medios de cultivo utilizados para el crecimiento y mantenimiento de $S$. pombe han sido descritos por (Moreno et al., 1991), añadiéndoles agar a una concentración del 2\% en el caso de los medios sólidos. Todos los medios se prepararon con agua destilada (Milli-Rho) y esterilizados mediante autoclave.

- Medio YES (medio rico): Se utilizó rutinariamente para el crecimiento vegetativo de S. pombe. Está compuesto por glucosa al $3 \%$ y extracto de levadura al $0,5 \%$ y suplementado con adenina, histidina, lisina y uracilo a una concentración de $250 \mathrm{mg} / \mathrm{l}$. A este medio se le han añadido distintos antibióticos o compuestos una vez esterilizado partiendo de soluciones stock más concentradas y esterilizadas por filtración para la realización de determinados experimentos:

YES+G y YES+NAT: Estos medios se obtuvieron añadiendo sulfato de geneticina (G-418, Life Technologies) a $100 \mu \mathrm{g} / \mathrm{ml}$ y sulfato de nourseotricina o clonNat (WERNER BioAgents) a $50 \mu \mathrm{g} / \mathrm{ml}$. Se utilizaron para la selección de cepas transformadas con el gen de resistencia a estos antibióticos.

* YES + compuestos o sales: Estos medios se obtuvieron suplementando el medio con diversos compuestos disueltos en agua o DMSO, como caspofungina (MERK), calcoflúor (BAYER), $\mathrm{MgCl}_{2}$ (FISHER CHEMICAL), FK506 (LC Laboratories) o W7 (TOCRIS) a las concentraciones adecuadas. 
- Medio mínimo (EMM, Edimburgh Minimal Media): Se utilizó para la selección de cepas auxótrofas para leucina o uracilo y para el cultivo de cepas transformadas con plásmidos de sobreexpresión que poseen el promotor del gen $n m t^{+}$. Las células se cultivaron en presencia de tiamina $(5 \mu \mathrm{g} / \mathrm{l})$, represor de este promotor (Maundrell, 1990). Posteriormente, las células se lavaron 4 veces con agua estéril y se reinocularon en este medio sin tiamina, provocando la inducción del promotor y por tanto del gen incluido en el plásmido. Este medio está compuesto por glucosa al $2 \%$, ftalato monopotásico al $0,3 \%$, $\mathrm{Na}_{2} \mathrm{HPO}_{4}$ al $0,22 \%$ y $\mathrm{NH}_{4} \mathrm{Cl}$ al $0,5 \%$ al que se le añaden diferentes concentraciones de minerales y vitaminas que han sido esterilizados previamente por filtración:

Solución concentrada de sales (50X): $\mathrm{MgCl}_{2} \cdot 6 \mathrm{H}_{2} \mathrm{O} 0.26 \mathrm{M}, \mathrm{CaCl}_{2} \cdot 2 \mathrm{H}_{2} \mathrm{O} 5$ $\mathrm{mM}, \mathrm{KCl} 0,67 \mathrm{M} \mathrm{y} \mathrm{Na}_{2} \mathrm{SO}_{4} 14 \mathrm{mM}$.

Solución concentrada de minerales (10.000X): $\mathrm{H}_{3} \mathrm{BO}_{3} 81 \mathrm{mM}, \mathrm{MnSO}_{4}$ 23,7 mM, ZnSO $4 \cdot 7 \mathrm{H}_{2} \mathrm{O} 14 \mathrm{mM}, \mathrm{FeCl}_{3} \cdot 6 \mathrm{H} 2 \mathrm{O} 7,4 \mathrm{mM}, \mathrm{MoO}_{4} \cdot 2 \mathrm{H}_{2} \mathrm{O} 2,5 \mathrm{mM}$, $\mathrm{KI} 6 \mathrm{mM}, \mathrm{CuSO}_{4} \cdot 5 \mathrm{H}_{2} \mathrm{O} 1,6 \mathrm{mM}$ y ácido cítrico $47,6 \mathrm{mM}$.

Solución concentrada de vitaminas (1.000X): ácido nicotínico 81,2 mM, inositol 55,5 mM, biotina 40,8 mM y ácido pantoténico 4,2 mM.

Este medio se suplementa con adenina, histidina, leucina o uracilo a una concentración de $225 \mathrm{mg} / \mathrm{l}$ en aquellos casos en los que sea necesario.

- Medio de esporulación (MEA): Se utilizó para inducir la conjugación y la esporulación. Está compuesto por extracto de malta al 3\% suplementado con adenina, histidina, leucina o uracilo a una concentración de $225 \mathrm{mg} / \mathrm{l}$.

\subsection{Medios de cultivo para E. coli}

Los medios de cultivo utilizados para el crecimiento de $E$. coli fueron los siguientes:

- Medio Luria-Bertani (LB): Se utilizó para el crecimiento rutinario de E. coli. Su composición es: Triptona al $1 \%$, extracto de levadura al $0,5 \%$ y $\mathrm{NaCl}$ al $1 \%$. Antes de esterilizar en el autoclave se ajustó el pH a 7,2-7,4.

- Medio 2XYT: Su composición es: Triptona al 1,6 \%, extracto de levadura al $1 \%$ y $\mathrm{NaCl}$ al $1 \%$.

La selección de clones resistentes a ampicilina se realizó suplementando los medios con ampicilina a una concentración final de $100 \mu \mathrm{g} / \mathrm{ml}$. 


\section{Materiales y métodos}

\section{Condiciones y estimación del crecimiento}

\subsection{Condiciones de crecimiento para S. pombe}

Los experimentos se realizaron siempre con cultivos en fase exponencial de cepas de $S$. pombe cuyas características genéticas se habían comprobado anteriormente. Normalmente se realizó un preinóculo en medio líquido que se cultivó varias horas y a partir del cual se preparó el cultivo a analizar. Todos los cultivos se incubaron a la temperatura requerida por el experimento concreto, normalmente, $16^{\circ} \mathrm{C}, 25^{\circ} \mathrm{C}, 28^{\circ} \mathrm{C}$, $32^{\circ} \mathrm{C}$ y $36^{\circ} \mathrm{C}$ o $37^{\circ} \mathrm{C}$. En el caso de los cultivos líquidos, los matraces se mantuvieron con una agitación de entre 200 y 250 rpm y el volumen de cultivo no superó $1 / 4$ del volumen del matraz, para permitir su correcta aireación. En medio líquido el crecimiento se determinó mediante lectura de la absorbancia del cultivo a $600 \mathrm{~nm}$ en un espectrofotómetro (BioRad Smart-Spec 3000). Se emplearon curvas de calibración obtenidas previamente en el laboratorio según las cuales una densidad óptica de 0,8 equivale aproximadamente a $10^{7}$ células $/ \mathrm{ml}$ de $S$. pombe. El mantenimiento de las cepas se realizó por resiembra en placas de medio sólido.

\subsection{Sincronización de los cultivos celulares de $S$. pombe mediante el uso de cepas mutantes termosensibles}

La cepa mutante de S. pombe cdc25-22 es termosensible y presenta un ciclo mitótico normal a la temperatura permisiva $\left(25^{\circ} \mathrm{C}\right)$, mientras que a la temperatura restrictiva $\left(36^{\circ} \mathrm{C}\right)$ las células detienen el ciclo celular en fase G2 (Mitchison and Creanor, 1971b). Esta propiedad se puede aprovechar para conseguir cultivos sincrónicos. Inicialmente, la cepa mutante se cultivó en medio YES a $25^{\circ} \mathrm{C}$ durante toda la noche. A la mañana siguiente, se inoculó en medio YES a una densidad óptica de 0,3 a $600 \mathrm{~nm}$ y se incubó a $36^{\circ} \mathrm{C}$ durante 4 horas para provocar la parada del ciclo celular. Después, para reanudar el ciclo celular, se hizo descender rápidamente la temperatura a $25^{\circ} \mathrm{C}$ sumergiendo el cultivo en un baño de hielo e incubando las células posteriormente a esta temperatura. Así las células entran en mitosis de forma sincrónica y continúan el ciclo celular.

\subsection{Ensayos de crecimiento en gota}

Los estudios de crecimiento de $S$. pombe a diferentes temperaturas o en presencia de distintos compuestos se realizaron en medios sólidos, YES o EMM con o sin tiamina. Partiendo de cultivos líquidos, las células se concentraron hasta una densidad óptica 1 a $600 \mathrm{~nm}$ en el caso de crecimiento en medio YES o 4 en el caso de crecimiento en medio mínimo. A partir de esa suspensión celular concentrada se realizaron diluciones seriadas $1 / 4$ hasta un total de 6 concentraciones decrecientes de células y con un replicador (Sigma) se colocó una gota de cada concentración sobre las placas con el 
medio de cultivo. Las placas fueron incubadas a las distintas temperaturas de 2 a 4 días, dependiendo del medio y de la temperatura.

\subsection{Condiciones de crecimiento para E. coli}

Las células de $E$. coli se cultivaron en medio líquido en incubadores con agitación orbital a una temperatura de $37^{\circ} \mathrm{C}$ o a $25^{\circ} \mathrm{C}$ para inducir la sobreexpresión de proteínas. Para el crecimiento en medios solidos las células se incubaron en estufas a $37^{\circ} \mathrm{C}$.

\section{MÉTOdOS GENÉTICOS}

\subsection{Conjugación}

Para inducir la conjugación entre dos cepas de $S$. pombe se usaron estirpes heterotálicas de tipo sexual opuesto $\left(\mathrm{h}^{+} \circ \mathrm{h}^{-}\right)$incubadas durante $24 \mathrm{~h}$ en placas de medio YES. Se recogió aproximadamente la misma cantidad de células de cada cepa y se mezclaron en un pequeño volumen de agua estéril $(25 \mu \mathrm{l})$. A continuación, se depositó la suspensión de células en una placa de MEA. Los zigotos se originan después de 12-20 horas e inmediatamente sufren meiosis y esporulación, formando ascas con 4 ascosporas al cabo de 1-2 días de incubación a $25^{\circ} \mathrm{C}$.

\subsection{Aislamiento y selección de ascosporas}

Para obtener esporas, se hicieron suspensiones en agua estéril de la mezcla de conjugación incubadas durante 2 días a $25^{\circ} \mathrm{C}$ en placas de MEA y se trataron con 20-50 unidades de glusulasa (PerkinElmer Life Sciences Inc.) durante toda la noche en agitación a temperatura ambiente. Este tratamiento destruye las paredes de las células vegetativas, sin afectar a las ascosporas, que poseen una pared más resistente. Se recogieron las esporas por centrifugación a $3.000 \mathrm{rpm}$ durante 1 minuto y la suspensión de esporas fue lavada 4 veces con agua estéril. Se estimó el número de esporas por mililitro mediante la ayuda de una cámara Thoma y se realizaron diluciones apropiadas para obtener entre 100 y 1.000 esporas por placa. Se incubaron en placas YES durante 4 días a $25^{\circ} \mathrm{C}-28^{\circ} \mathrm{C}$ y mediante réplica en placas de diferentes medios selectivos o a distintas temperaturas se seleccionaron las estirpes con el genotipo deseado. 


\section{PROCEDIMIENTOS GENERALES DE BIOLOGIA MOLECULAR}

\subsection{Vectores utilizados}

\subsubsection{Vectores de $E$. coli}

- $\quad$ BBluescript KS+ (Stratagene): Son plásmidos autorreplicativos de 2,9 kb que llevan el gen de resistencia a ampicilina, el origen de replicación colE1 y un fragmento del operón de lactosa de $E$. coli que codifica el péptido $\alpha$ de la $\beta$ galactosidasa (LacZ'). También llevan el origen de replicación del fago f1 que permite la obtención de ADN monocatenario.

- pGEX (Pharmacia): Contiene el gen que codifica la proteína Glutation-S Transferasa (GST), el gen de resistencia a ampicilina y el promotor T7 junto con el operón de lactosa para inducir la expresión del gen clonado en presencia de isopropil-ß-D-tiogalactopiranósido (IPTG). Se utilizó para la expresión del dominio RBD de unión a RhoA contenido en la proteína rotequina de células animales.

- pJC20 (ATCC): Es un vector de 2,34 kb que contiene 10 sitios únicos para enzimas de restricción. Porta el promotor T7 junto con el operón de lactosa para inducir la expresión del gen clonado en presencia de isopropil- $\beta-D-$ tiogalactopiranósido (IPTG). Permite la selección de clones recombinantes mediante el crecimiento en medio con ampicilina (Clos and Brandau, 1994). Se utilizó para la expresión de paxilina recombinante.

\subsubsection{Vectores de S. pombe}

- pJK148. Es un vector de 5,3 kb que lleva el gen leu1+ de S. pombe como marcador de selección y carece de secuencias ars1, por lo que no se replica de manera autónoma. Se utiliza para la integración de secuencias de ADN en el genoma de S. pombe. Para que la integración tenga lugar es necesario linearizar el plásmido mediante el tratamiento con la enzima de restricción Nrul o Tth111l, que se encuentra en el gen leu1 ${ }^{+}$. El plásmido linearizado se introduce en una cepa leu1-32, de modo que, tras la recombinación, en el genoma de $S$. pombe se reconstituyen 2 copias del gen leu1, una mutada y otra silvestre, recuperándose así la capacidad de crecer en un medio sin leucina (Keeney and Boeke, 1994). Además, este plásmido posee un fragmento de ADN que incluye sitios de reconocimiento para 19 enzimas de restricción y el gen de resistencia a ampicilina.

- $\quad$ RREP. Son varios vectores de expresión en S. pombe reprimibles en presencia de tiamina. Todos ellos poseen en su estructura un origen de replicación de $E$. coli, el gen de resistencia a ampicilina, el origen de replicación $\operatorname{ars} 1^{+}$, un gen 
marcador de complementación de auxotrofías y el promotor y terminador del gen $n \mathrm{mt}^{+}$(no messenger with thiamine) fusionado a un sitio de clonación múltiple. Este promotor permite sobreexpresar los insertos clonados cuando se incuban las células en ausencia de tiamina. Todos los vectores PREPX proceden del vector pREP1 (Maundrell, 1990), de elevada expresión, al que se le incorporó un sitio Xhol en el sitio de clonación múltiple (Forsburg, 1993). Existen diferentes clases de vectores pREPX que se diferencian entre sí por el nivel de expresión. Para poder inducir niveles de expresión intermedios, se modificó el promotor $n m t$ original introduciendo una serie de mutaciones en su secuencia TATA, que disminuyen la fortaleza de éste. Así, los vectores de expresión fuertes utilizados en este trabajo fueron el vector pREP1 y pREP3X mientras que los de expresión intermedia fueron pREP41X y pREP41-EGFP.

\subsection{Obtención del ADN}

La extracción de ADN plasmídico a partir de bacterias se realizó mediante el método de lisis alcalina (Zhou et al., 1990), que consiste en romper las células en presencia de una mezcla de hidróxido sódico $(\mathrm{NaOH})$ y dodecil sulfato sódico (SDS). Finalmente, el producto obtenido tras la lisis de las células se introdujo en columnas de intercambio aniónico comerciales Wizard Plus Minipreps (Promega) siguiendo las indicaciones del fabricante para obtener ADN más puro y en mayor cantidad.

\subsection{Reacción en cadena de la polimerasa (PCR)}

La amplificación de fragmentos de ADN mediante PCR se llevó a cabo en los termocicladores GeneAmp PCR System 2.700 de Applied Biosystems y MyCyclerTM Thermal Cycler de BioRad. Las mezclas de reacción contenían: tampón de reacción suministrado por el proveedor, $\mathrm{MgCl}_{2}$ 1,5 $\mathrm{mM}$, los 4 desoxinucleótidos trifosfato precursores a una concentración final de 0,2 $\mathrm{mM}$ cada uno, 0,40 $\mu \mathrm{M}$ de cada oligonucleótido utilizado como cebador, $0,5 \mathrm{U} / \mu \mathrm{l}$ de polimerasa Taq y una cantidad de ADN molde variable, dependiendo de si se trataba de ADN genómico o plasmídico. Para la comprobación rutinaria de cepas mutantes de $S$. pombe, se realizó PCR utilizando células directamente, sin necesidad de extraer el ADN.

La reacción requiere la desnaturalización del ADN molde, el anillamiento de los cebadores u oligonucleótidos incorporados a la reacción y, finalmente, la extensión de las hebras sintetizadas. En cada momento se requiere que la reacción se encuentre a una temperatura determinada. El número de ciclos, la temperatura de anillamiento y el tiempo de extensión se modificaron dependiendo de las características del 
experimento. La purificación de los productos de PCR se realizó mediante el sistema GFX PCR DNA and Gel Band Purification Kit (GE Healthcare).

Las mutaciones de los sitios de los sitios de interacción en la paxilina y la calmodulina se realizaron por mutagénesis dirigida mediante PCR. Para ello, se usó la enzima Pfu Ultra High Fidelity Polymerase (Agilent Technologies), oligonucleótidos que contenían las mutaciones en los sitios de interacción y como ADN molde la ORF de $p x / 1^{+}$o cam $1^{+}$ clonada en el vector pBluescript KS+. El ADN resultante de la PCR se secuenció para confirmar el reemplazamiento de todos los aminoácidos de ambos sitios por alaninas. Los oligonucleótidos utilizados en este trabajo fueron suministrados por Integrated DNA Technologies (IDT) y sus secuencias y utilidad se describen en la Tabla 4.

Tabla 4. Lista de oligonucleótidos utilizados en este trabajo

\begin{tabular}{|c|c|c|}
\hline Nombre & Secuencia & Utilidad \\
\hline $\begin{array}{l}\text { Pxl1- } \\
\text { dock3 }\end{array}$ & $\begin{array}{l}\text { 5'CTACGATTGGAAAGTTTACTGGATTTTCgcagcAGcAgcAG } \\
\text { cAGcAAGTTGTTTGGATGCGAAGGTTTTTTGTCTG-3' }\end{array}$ & $\begin{array}{l}\text { Construcción casete } \\
\text { pxl1-M3 }\end{array}$ \\
\hline $\begin{array}{l}\text { Pxl1- } \\
\text { dock4 }\end{array}$ & $\begin{array}{l}\text { 5'GCAAGAAATGCCGTAAAgCCgcTgcGGcGgcCgctGTAA } \\
\text { AAGGGTCTGATGGTGAATATCATAG-3' }\end{array}$ & $\begin{array}{l}\text { Construcción casete } \\
\text { pxl1-M4 }\end{array}$ \\
\hline Pax-1 & 5'-CGCGGATCCATATGCATTCACCAATTCCAGATT-3' & $\begin{array}{l}\text { Construcción casete } \\
\text { pxl1-M3 }\end{array}$ \\
\hline Pax-2 & 5'-CGCGGATCCTTAATCCAAATTAAACTTGACTGA-3' & $\begin{array}{l}\text { Construcción casete } \\
\text { pxl1-M4 }\end{array}$ \\
\hline Pax-5 & 5'-GTGTAATTTCTTTCCTGAAGCAC-3' & $\begin{array}{l}\text { Comprobación } \\
\text { casete pxl1-M3/M4 }\end{array}$ \\
\hline Pax-7 & 5'-TTGCGGCTAGATTTATACCCTG-3' & $\begin{array}{l}\text { Comprobación } \\
\text { casete pxl1-M3/M4 }\end{array}$ \\
\hline $\begin{array}{l}\text { Rho1- } \\
\text { K156A-F }\end{array}$ & $\begin{array}{l}\text { 5'-CTCAGAAGATTGGTGCTTACgCATACCTTGAGTGTTCT } \\
\text { GCC-3' }\end{array}$ & $\begin{array}{l}\text { Construcción casete } \\
\text { rho1-CM1 }\end{array}$ \\
\hline $\begin{array}{l}\text { Rho1- } \\
\text { K156A-R }\end{array}$ & $\begin{array}{l}\text { 5'-GGCAGAACACTCAAGGTATgcGTAAGCACCAATCTTC } \\
\text { TGAG-3' }\end{array}$ & $\begin{array}{l}\text { Construcción casete } \\
\text { rho1-CM1 }\end{array}$ \\
\hline $\begin{array}{l}\text { Rho1- } \\
\text { K163A-F }\end{array}$ & 5'-CCTTGAGTGTTCTGCCgcGACGAATGAAGGTGTTGC-3' & $\begin{array}{l}\text { Construcción casete } \\
\text { rho1-CM2 }\end{array}$ \\
\hline $\begin{array}{l}\text { Rho1- } \\
\text { K163A-R }\end{array}$ & 5'-CGAACACCTTCATTCGTCgcGGCAGAACACTCAAGG-3' & $\begin{array}{l}\text { Construcción casete } \\
\text { rho1-CM2 }\end{array}$ \\
\hline
\end{tabular}


Materiales y métodos

\begin{tabular}{|c|c|c|}
\hline $\begin{array}{l}\text { Rho1- } \\
\text { E166A-F }\end{array}$ & 5'-GTTCTGCCAAGACGAATGcAGGTGTTCGTGAGG-3' & $\begin{array}{l}\text { Construcción casete } \\
\text { rho1-CM3 }\end{array}$ \\
\hline $\begin{array}{l}\text { Rho1- } \\
\text { E166A-R }\end{array}$ & 5'-CCTCACGAACACCTgCATTCGTCTTGGCAGAAC-3' & $\begin{array}{l}\text { Construcción casete } \\
\text { rho1-CM3 }\end{array}$ \\
\hline Ppb1.15 & 5'-CTTTCCCGTTCTTCTCTAAGC-3' & $\begin{array}{l}\text { Construcción vector } \\
\text { mutantes de Ppb1 }\end{array}$ \\
\hline Ppb1.16 & 5'-CTACATACTTTGAATGATATACGAATG-3' & $\begin{array}{l}\text { Construcción vector } \\
\text { mutantes de Ppb1 }\end{array}$ \\
\hline Ppb1.3 & 5'-CGGGTTTCCATCTTTGATGAC-3' & $\begin{array}{l}\text { Construcción vector } \\
\text { mutantes de Ppb1 }\end{array}$ \\
\hline Ppb1.8 & 5'-ATATAGGATCCTACAAAGAGCTTTTCTTATCTG-3' & $\begin{array}{l}\text { Construcción vector } \\
\text { mutantes Ppb1 }\end{array}$ \\
\hline Ppb1.9 & 5'-ATATAGGATCCCTTTAGAAGTGTTCCAATGTC-3' & $\begin{array}{l}\text { Construcción casetes } \\
\text { rho1-CM }\end{array}$ \\
\hline Ppb1.12 & 5'-ATATAGAGCTCGTTCGGAGAACAGTCAGCTAG-3' & $\begin{array}{l}\text { Construcción casetes } \\
\text { rho1-CM }\end{array}$ \\
\hline Kan10 & 5'-GATGCGAAGTTAAGTGCGC-3' & $\begin{array}{l}\text { Comprobación } \\
\text { casetes rho1-CM }\end{array}$ \\
\hline $\mathrm{HC} 22$ & 5'-GGTTTTGATCGAGTTTCAATC-3' & $\begin{array}{l}\text { Comprobación } \\
\text { casetes rho1-CM }\end{array}$ \\
\hline HC11 & 5'-CATATGGCCATGGCGACAGAACTTCGC-3' & $\begin{array}{l}\text { Comprobación } \\
\text { casetes rho1-CM }\end{array}$ \\
\hline $\mathrm{HC} 12$ & 5'-GGATCCTTACAACAAGATACAACGCT-3' & $\begin{array}{l}\text { Comprobación } \\
\text { casetes rho1-CM }\end{array}$ \\
\hline $\mathrm{HC} 23$ & 5'-CGCTTTTTGAATTTAGGAATTCATC-3' & $\begin{array}{l}\text { Comprobación } \\
\text { casetes rho1-CM }\end{array}$ \\
\hline Kan5 & 5'-GGCCTCCATGTCGCTGGCCG-3' & $\begin{array}{l}\text { Comprobación } \\
\text { casetes rho1-CM }\end{array}$ \\
\hline
\end{tabular}




\section{Materiales y métodos}

\subsection{Secuenciación del ADN}

La secuenciación de fragmentos de ADN se realizó en el servicio de secuenciación de la Universidad de Salamanca que utiliza un secuenciador automático Abi prism 3100 Genetic analyzer (Applied Biosystems). Este sistema inicia una reacción de PCR mediante la extensión enzimática de una cadena de DNA a partir de un oligonucleótido iniciador, empleando DNA bicatenario como molde. Esta es interrumpida por la incorporación de didesoxinucleotidos marcados con fluorocromos y un láser es capaz de reconocer los distintos colores (longitud de onda de emisión) de los fluorocromos, que corresponden a cada una de las bases del DNA.

\subsection{Manipulación del ADN}

Todos los protocolos utilizados para la manipulación de ADN se recogen en (Ausubel, 1987; Sambrook et al., 1989) y se realizaron teniendo en cuenta las especificaciones de las casas comerciales suministradoras de los materiales y enzimas utilizados.

El análisis de los fragmentos de ADN obtenidos por tratamiento con enzimas de restricción o por amplificación con la PCR se llevó a cabo mediante electroforesis en geles de agarosa (UltraPure, Life Technologies) de distinto porcentaje (0,6-1,5\%), según el tamaño de los fragmentos que se iban a analizar. Los geles de agarosa llevaban el agente intercalante de ADN Midori Green Advance (Nippon Genetics Europe) a una concentración final de $0,04 \mu \mathrm{l} / \mathrm{ml}$, para localizar el ADN mediante iluminación con una fuente de luz ultravioleta. Se utilizó el tampón TAE (Tris-Acetato $40 \mathrm{mM}$, EDTA (ácido etilén diamino tetra-acético) $1 \mathrm{mM}, \mathrm{pH} 8,0$ ) para preparar la agarosa y realizar la electroforesis.

El aislamiento y purificación de los fragmentos de ADN después de su separación en geles de agarosa se llevó a cabo mediante el sistema GFX PCR DNA and Gel Band Purification Kit de GE Healthcare. El grupo fosfato del extremo $5^{\prime}$ del vector se eliminó mediante tratamiento con fosfatasa alcalina (AP 713023, Boehringer) y la ligación se realizó con la enzima ADN ligasa del fago T4 (EL0335, Fermentas).

\subsection{Transformación de $E$. coli}

La transformación de $E$. coli con plásmidos o con mezclas de ligación se realizó mediante choque térmico según el protocolo diseñado por (Kushner, 1978). En algunos casos, la transformación con plásmidos purificados se realizó por un método simplificado conocido como "transformación del minuto" (Golub, 1988). 


\subsection{Transformación de S. pombe}

La transformación de S. pombe se realizó mediante el método del acetato de litiosorbitol (Ito et al., 1983), complementado con las modificaciones descritas (Bähler et al., 1998b).

\subsection{Vectores de integración}

5.8.1 Construcción del módulo de integración de los alelos de $p x / 1^{+}$con mutaciones en el sitio de unión a calcineurina

Para poder integrar la ORF de los alelos mutantes $p x / 1-M 3$ y $p x / 1-M 4$ se construyó un módulo de integración. Este contenía 720 pb de la región promotora de $p x / 1^{+}$, la ORF de $p \times 11^{+}$y $460 \mathrm{pb}$ de la región terminadora de $p x / 1^{+}$y el módulo entero se clonó en el plásmido KS+ (Figura 70).

Primero se obtuvo un fragmento de ADN con las mutaciones de los alelos px/1-M3 y pxl1-M4 generadas mediante PCR de alta fidelidad utilizando como molde el vector pJK148-pxI1 ${ }^{+}$y los oligonucleótidos que poseen la mutación de los sitios de interacción con calcineurina. Posteriormente se realizó una segunda PCR de alta fidelidad utilizando nuevamente como molde el vector pJK148-px $11^{+}$y como cebadores el producto de la PCR anterior que contiene las mutaciones de los sitios de unión y otro oligonucleótido que hibrida con la secuencia de paxilina.

Después se reemplazó la ORF de $p \times 11^{+}$del módulo de integración clonado en el plásmido KS+ por los productos de PCR obtenidos que poseen las mutaciones px/1-M3 y px/1-M4 mediante corte con las enzimas de restricción Ndel-Bamh/ (Figura 67). La nueva ORF del módulo de integración se secuenció para comprobar la mutación de los sitios de interacción y el módulo entero se clonó en el sitio Pstl-Sacl de la secuencia de clonación múltiple del plásmido pJK-148. Finalmente, el plásmido obtenido se linearizó mediante digestión con las enzimas Nrul o Tth111l y se transformó la cepa la cepa $\mathrm{h}^{+}$

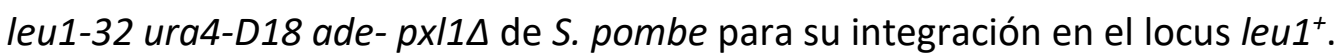

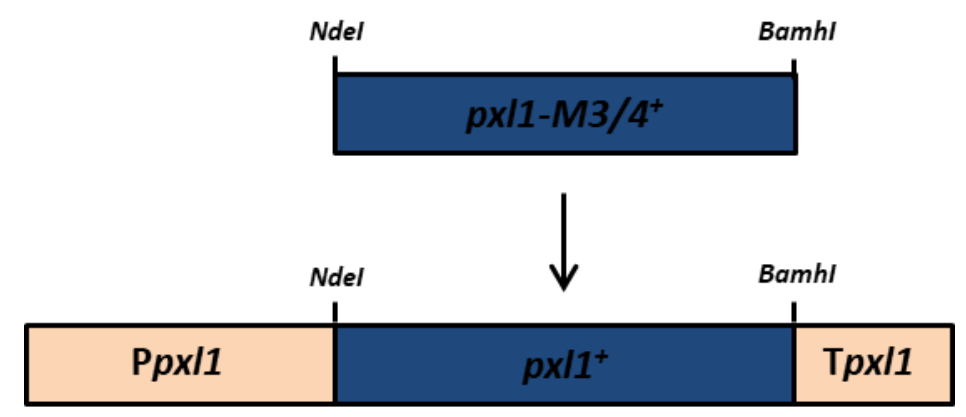

Figura 67. Construcción del módulo de integración de $p x \mid 1^{+}$. 


\subsubsection{Construcción del módulo de integración de los alelos mutantes de rho1 ${ }^{+}$ del sitio de unión a calmodulina}

Para obtener las cepas con los alelos mutantes de rho1': rho1-CM1, rho1-CM2 y rho1CM3 se construyó un módulo de integración. Este módulo contenía 610 pares de bases de la región promotora de $r h o 1^{+}$, la ORF con los alelos mutantes de $r h o 1^{+}$, la secuencia $3^{\prime}$ no codificante del gen $a d h^{+}$como terminador, el módulo de resistencia a geneticina (KanMX6) y 500 pares de bases de la región 3' no codificante de rho1+ (Figura 68A). Para la obtención de las ORFs de los alelos mutantes se realizó una mutagénesis dirigida utilizando el kit QuickChange II Site-directed Mutagenesis Kit (Agilent). A partir del plásmido KS+ que contiene el casete completo con la ORF de $r h o 1^{+}$se realizó una PCR de alta fidelidad empleando oligonucleótidos que poseen la mutación de los sitios de interacción con calmodulina. El producto de la PCR se trató con DpnI para eliminar el plásmido molde y mantener los plásmidos que contienen la ORF de los alelos mutantes de rho1 $1^{+}$. Estos plásmidos se secuenciaron para comprobar las mutaciones de los sitios de interacción. Finalmente, se obtuvo por PCR el módulo completo y se utilizó para transformar una cepa $\mathrm{h}^{+}$leu1-32 ura4-D18 ade-. El módulo se integró en el locus de rho $^{+}$mediante recombinación homóloga y se realizaron distintas PCRs para comprobar la integración y orientación correctas del módulo en el locus de rho $1^{+}$.

El módulo anterior sirvió para la construcción de otro módulo que además poseía el epítopo HA. Este epítopo se clonó en el sitio Ndel entre la región promotora de $\mathrm{rho1}^{+} \mathrm{y}$ la ORF de los alelos mutantes de $\mathrm{rho1}^{+}$(Figura 68B). Posteriormente todo el módulo de integración se clonó en el plásmido integrativo pJK148, en el sitio Xhol-Sacll de su secuencia de clonación múltiple. El vector se linearizó después mediante digestión con las enzimas Nrul o Tth111l y las cepas mutantes rho1-CM1, rho1-CM2 o rho1-CM3 se transformaron con el plásmido linearizado que se integró en el locus leu1 ${ }^{+}$. Finalmente, se comprobó que las cepas que crecían en medio sin leucina tenían integrados los alelos HA-rho1-CM en el locus leu1'.

A

\begin{tabular}{|l|l|l|l|l|}
\hline Prho1 & rho1-CM1/2/3+ & Tadh & KanMX6 & Trho1 \\
\hline
\end{tabular}

B

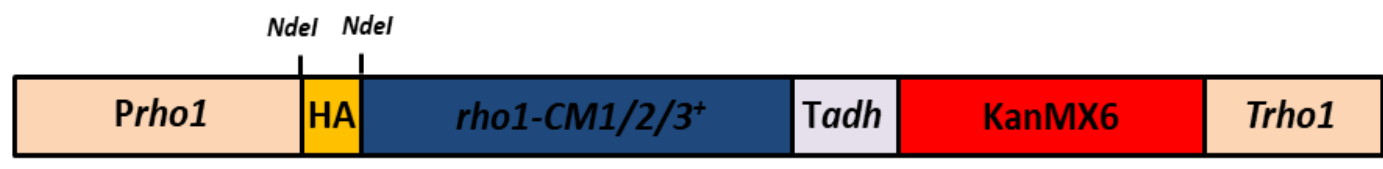

Figura 68. Módulos de integración de los alelos mutantes de rho1 ${ }^{+}$. 


\subsection{Vectores de expresión}

5.9.1 Construcción del vector de sobreexpresión de los alelos mutantes de $p p b 1^{+}$del sitio de unión a sustrato

Para obtener los alelos mutantes $p p b 1-A F, p p b 1-F A$ y $p p b 1-A A$ se encargaron unos fragmentos sintéticos de $698 \mathrm{pb}$ que codificaban parte de la secuencia de $p p b 1^{+}$pero con las mutaciones que cambiaban los aminoácidos F368, F372 o ambos por alanina (Integrated DNA Technologies ITD). El vector KS-ppb1 ${ }^{+}$se cortó en los sitios Bcl1-Xho1 dentro de la ORF de $p p b 1^{+}$y el fragmento eliminado se reemplazó por el fragmento sintético previamente amplificado mediante PCR de alta fidelidad. El nuevo vector KS con la ORF que posee los alelos mutantes de $p p b 1^{+}$se secuenció para comprobar la mutación de los sitios de interacción. Posteriormente las ORFs mutadas se clonaron en el sitio Ndel-BamHI de la secuencia de clonación múltiple del vector pREP41-EGFP y con este plásmido de sobreexpresión se transformó la cepa $\mathrm{h}^{+}$leu1-32 ura4-D18 adeppb1ऽ (Figura 69).

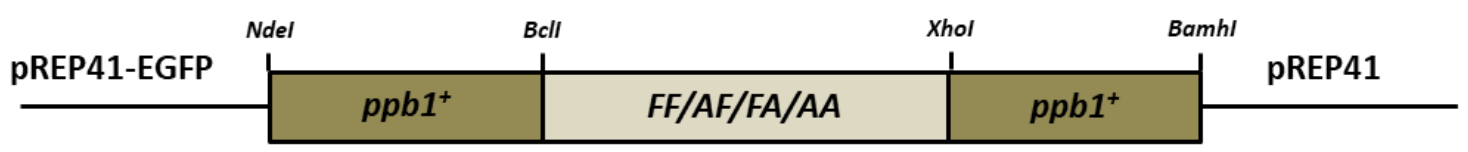

Figura 69. Vector de sobreexpresión de $p p b 1^{+}$y sus alelos mutantes.

5.9.2 Construcción del vector de expresión de $p x / 1^{+}$, sus truncamientos y sus alelos mutantes del sitio de unión a calcineurina.

Para obtener proteínas recombinantes en bacterias, las ORFs de $p x / 1^{+}, p x / 1 \Delta N^{+}$, $p x / 1 \Delta 123^{+}, p x / 1-M 3^{+}$y $p x / 1-M 4^{+}$se clonaron en el sitio $\mathrm{Ndel}-\mathrm{BamHI}$ de la secuencia de clonación múltiple del vector pJC20 a partir de los vectores pJK148 que las contenían. A continuación, se clonó la ORF que codifica la proteína GST por delante de las ORFs, en el sitio Ndel-Ndel para que estuviese en fase y con los vectores obtenidos se transformó la estirpe BL-21 de E. coli (Figura 70).

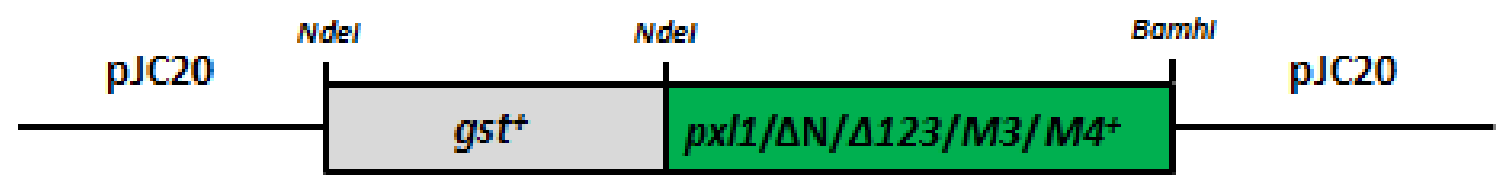

Figura 70. Vector de sobreexpresión de $p x / 1^{+}$, sus truncamientos y sus alelos mutantes. 


\section{Materiales y métodos}

\section{ANÁLISIS DE PROTEÍNAS}

\subsection{Obtención de extractos celulares con TCA}

Los ensayos de Western blot para estudiar el estado de fosforilación de las proteínas se realizaron con extractos celulares de las distintas cepas precipitados con ácido tricloroacético (TCA) al $8 \%$. Se recogieron $10 \mathrm{ml}$ de células en fase exponencial (D.0.600nm = 0,5), se lavaron con $1 \mathrm{ml}$ de TCA al 20\%, se resuspendieron en $100 \mu \mathrm{l}$ de TCA al $20 \%$ y se lisaron con bolitas de vidrio (G8772, Sigma) en una Fast-Prep FP120 (Bio 101 Savant), durante 3 pulsos de 20 segundos a una potencia de $6,5 \mathrm{~m} / \mathrm{s}$. Se añadieron otros $150 \mu \mathrm{l}$ de TCA al $20 \%$ y se centrifugó a $1.600 \mathrm{rpm}$ durante 2 minutos para recoger el lisado y retirar las bolas de vidrio. Se añadieron $300 \mu \mathrm{l}$ de TCA al 5\% y se volvió a centrifugar a $1.600 \mathrm{rpm}$ durante 2 minutos para lavar las bolas. Después se añadieron $700 \mu \mathrm{l}$ de TCA al 5\% al sobrenadante obtenido (concentración final de TCA $8 \%)$ y se realizó una centrifugación a $5.000 \mathrm{rpm}$ durante 10 minutos a $4^{\circ} \mathrm{C}$ para precipitar las proteínas y retirar el TCA. Posteriormente se realizó una segunda centrifugación a $5.000 \mathrm{rpm}$ durante 2 minutos a $4^{\circ} \mathrm{C}$ y se eliminó todo el TCA. Se resuspendió el "pellet" en $70 \mu$ l de tampón de carga 2X (SDS al 4\%, glicerol al 20\%, DTT $100 \mathrm{mM}$ y azul de bromofenol al 0,08\%) y $70 \mu \mathrm{l}$ de Tris-HCl $1 \mathrm{M} \mathrm{pH} \mathrm{8,0.} \mathrm{Se} \mathrm{calentaron}$ las muestras 10 minutos a $95^{\circ} \mathrm{C}$ y, a continuación, se centrifugaron durante 10 minutos a $13.000 \mathrm{rpm}$ para recuperar el sobrenadante que se analizó mediante Western Blot.

\subsection{Obtención de extractos celulares}

Los extractos celulares para los ensayos de coinmunoprecipitación y pull down de las proteínas marcadas con distintos epítopos se realizaron a partir de $1 \times 10^{8}$ células que se resuspendieron en $300 \mu \mathrm{l}$ del tampón de lisis que consta de Tris- $\mathrm{HCl} 20 \mathrm{mM}$ pH8, EDTA $2 \mathrm{mM}, \mathrm{NaCl} 137 \mathrm{mM}$, glicerol al 10\% y NP-40 al 0,5\% con inhibidores de proteasas (aprotinina $2 \mu \mathrm{g} / \mathrm{ml}$, leupeptina $2 \mu \mathrm{g} / \mathrm{ml}$, pestatina $2 \mu \mathrm{g} / \mathrm{ml}$ y PMSF $1 \mathrm{mM}$ ). Las células se lisaron con bolas de vidrio (G8772, Sigma), en una Fast-Prep FP120 (Bio 101 Savant) durante 3 pulsos de 20 segundos a una potencia de $6 \mathrm{~m} / \mathrm{s}$, comprobándose la rotura celular por observación al microscopio de contraste de fases. Los extractos se centrifugaron a $5.000 \mathrm{rpm}$ durante 10 minutos para retirar los restos celulares. Todo el proceso se realizó a $4^{\circ} \mathrm{C}$ para evitar la degradación de las proteínas. La concentración de proteína de los extractos se cuantificó mediante el método colorimétrico descrito por (Bradford, 1976) (Protein Assay Dye Reagent Concentrate, Biorad) y se preparó la muestra en tampón de carga 2X (SDS al $4 \%$, glicerol al $20 \%$, DTT $100 \mathrm{mM}$ y azul de bromofenol al 0,08 \%). 


\section{Materiales y métodos}

\subsection{Ensayos de inmunoprecipitación}

Para los ensayos de coinmunoprecipitación se utilizaron extractos celulares (2-2,5 mg de proteína en un volumen de $500 \mu \mathrm{l}$ ) y se incubaron durante 2 horas con anticuerpos policlonales frente al epítopo HA o la proteína GFP. Después se añadieron $40 \mu \mathrm{l}$ de proteína A-sefarosa (Protein A sepharose CL-4B, GE Healthcare) al $50 \%$ en tampón de lisis y se mantuvo la incubación durante 2-4 horas más a $4^{\circ} \mathrm{C}$. A continuación, los complejos unidos a la matriz de sefarosa se sedimentaron por centrifugación y se lavaron 5 veces con $1 \mathrm{ml}$ de tampón de lisis o tampón de lavado. Los inmunoprecipitados se resuspendieron en $30 \mu \mathrm{l}$ de tampón de carga 2X (SDS al $4 \%$, glicerol al $20 \%$, DTT $100 \mathrm{mM}$ y azul de bromofenol al 0,08 \%) para proceder a la electroforesis en geles de poliacrilamida. Los anticuerpos utilizados para la inmunoprecipitación fueron:

- Anticuerpos policlonales de conejo frente al epítopo HA (Abcam), 2 $\mu \mathrm{g}$.

- Anticuerpos policlonales de conejo frente al epítopo GFP (Invitrogen), 2 нg.

\subsection{Ensayos de pull down}

Para analizar la interacción entre algunas proteínas se realizaron ensayos de pull down utilizando extractos celulares a los que se añadió la correspondiente proteína recombinante producida en bacterias. La interacción de la proteína de interés con la proteína recombinante permite que precipite con ella y se pueda observar en ensayos de Western blot.

\subsubsection{Producción de proteínas recombinantes (GST-Px|1/Cam1)}

La sobrexpresión y purificación de las diferentes proteínas recombinantes se realizó en la estirpe BL-21 de E. coli transformada con el plásmido pJC20 conteniendo la ORF que codificara la proteína que se quiere producir. Las bacterias transformadas se incubaron a $28^{\circ} \mathrm{C}$ en $500 \mathrm{ml}$ de medio LB con el antibiótico ampicilina $(100 \mu \mathrm{g} / \mathrm{ml})$ hasta que alcanzaron una D.0.600nm de 0,6-0,8. En este momento se añadió IPTG a una concentración final de 0,5 mM para inducir la expresión de las proteínas codificadas en la ORF del plásmido pJC20 y se incubaron 3 horas más a $28^{\circ} \mathrm{C}$ para evitar la formación de cuerpos de inclusión. Se recogieron las células por centrifugación a $5.000 \mathrm{rpm}$ durante 5 minutos y se resuspendieron en $20 \mathrm{ml}$ de tampón PBS (tampón fosfato salino: $\mathrm{Na}_{2} \mathrm{HPO}_{4} 10 \mathrm{mM}, \mathrm{KH}_{2} \mathrm{HPO}_{4} 2 \mathrm{mM}, \mathrm{NaCl} 137 \mathrm{mM}$ y $\mathrm{KCl}$ 2,7 mM) frío al que se añadieron inhibidores de proteasas (pestatina $2 \mu \mathrm{g} / \mathrm{ml}$, leupeptina $2 \mu \mathrm{g} / \mathrm{ml}$, aprotinina $2 \mu \mathrm{g} / \mathrm{ml}$ y PMSF $1 \mathrm{mM}$ ) y lisozima ( $2 \mathrm{mg} / \mathrm{ml}$ ). Tras 30 minutos de incubación en hielo, las células se sonicaron 5 veces a una potencia de $15 \mu \mathrm{m}$ de amplitud de onda durante 1 


\section{Materiales y métodos}

minuto. Se añadió Tritón TX-100 a una concentración final del 1\% y se centrifugaron las células lisadas a $10.000 \mathrm{rpm}$ durante 1 hora a $4^{\circ} \mathrm{C}$ para precipitar los restos celulares.

A continuación, se añadieron al sobrenadante $600 \mu \mathrm{l}$ de bolas de glutatión sefarosa (glutatión-sepharose 4B, GE Healthcare) al 50\% previamente equilibradas con PBS y se incubaron durante 2 horas a $4^{\circ} \mathrm{C}$. Las bolas de lutatión-sefarosa con las proteínas recombinantes unidas se lavaron 3 veces con $40 \mathrm{ml}$ de PBS con inhibidores de proteasas y se recogieron por centrifugación a $3.000 \mathrm{rpm}$. Por último, se resuspendieron al $50 \%$ en solución de lisis $\mathrm{B}$ o en tampón de unión (Tris- $\mathrm{HCl} 50 \mathrm{mM} \mathrm{pH}$ 7,6, $\mathrm{NaCl} 20 \mathrm{mM}$, glicerol al 10\%, $\mathrm{MgCl}_{2} 2 \mathrm{mM}$, DTT 0,1 mM y NP-40 al 0,5\%) nuevamente con inhibidores de proteasas a la misma concentración que la descrita anteriormente. La cantidad de proteína purificada se cuantificó mediante electroforesis en gel de poliacrilamida al $10 \%$ teñido con azul de Coomassie, comparándola con diferentes concentraciones conocidas de seroalbúmina bovina. Finalmente, la proteína recombinante se ajustó a una concentración de $0,5 \mu \mathrm{g} / \mu \mathrm{l}$ para añadirla los extractos celulares.

\subsubsection{Ensayo de unión}

Se prepararon de extractos celulares $(2.5 \mathrm{mg}$ de proteína total en un volumen de 500 $\mu l)$ de cepas que expresaban Ppb1-HA o HA-Rho1 marcadas con el epítopo HA, como se describió en el apartado 6.2 de Materiales y Métodos, pero utilizando tampón de lisis B o tampón de unión. Se añadieron $15 \mu \mathrm{g}$ de la proteína recombinante correspondiente asociada a bolas de lutatión sefarosa (glutatión-sepharose 4B, GE Healthcare) a los extractos totales y se incubaron durante 2 horas a $4^{\circ} \mathrm{C}$. Tras la incubación se realizaron 3 lavados con $1 \mathrm{ml}$ de tampón de lisis B. Después se centrifugó a $5.000 \mathrm{rpm}$ durante 5 minutos y los precipitados se resuspendieron en $30 \mu \mathrm{l}$ de tampón de carga 2X (SDS al 4\%, glicerol al $20 \%$, DTT 100 mM y azul de bromofenol al $0,08 \%)$.

\subsection{Análisis de la actividad de Rho1 (GTP-Rho1)}

La cantidad de Rho1 activa se determinó mediante el ensayo de precipitación con bolas de sefarosa unidas a la proteína recombinante GST-RBD que contiene el dominio de unión a RhoA (RBD, Rho Binding Domain) de la proteína rotequina fusionado a la proteína GST (Reid et al., 1996b). Este dominio sólo se une de forma específica a Rho1 cuando está activa, es decir, unida a GTP. 


\subsubsection{Producción de GST-RBD recombinante}

Para realizar este ensayo se sobrexpresó y purificó la proteína recombinante GST-RBD en una cepa $\mathrm{DH} 5 \alpha$ de $E$. coli transformada con el plásmido pGEX-RBD. Las bacterias transformadas con dicho plásmido se incubaron a $28^{\circ} \mathrm{C}$ en $400 \mathrm{ml}$ de medio LB con el antibiótico ampicilina (100 $\mathrm{\mu g} / \mathrm{ml})$ hasta que alcanzaron una D.0.600 $\mathrm{nm}$ de 0,6-0,8. La inducción y purificación de la proteína recombinante se realizó en las mismas condiciones descritas en el apartado 6.4.1 de Materiales y Métodos. La cantidad de proteína GST-RBD purificada se cuantificó mediante electroforesis en gel de poliacrilamida al $12 \%$ teñido con azul de Coomassie, comparándola con diferentes concentraciones conocidas de seroalbúmina bovina. Finalmente, la proteína recombinante se ajustó a una concentración de $0,3 \mu \mathrm{g} / \mu \mathrm{l}$ para añadirla a los extractos celulares.

\subsubsection{Ensayo de unión}

Se obtuvieron extractos celulares de las cepas silvestre y $p p b 1 \Delta$ que expresaban HARho1 como se describió en el apartado 6.2 de Materiales y Métodos, pero utilizando tampón de lisis B. Se añadieron $10 \mu \mathrm{g}$ de GST-RBD unida a bolas de glutation sefarosa a los extractos totales y se incubaron durante 2 horas a $4^{\circ} \mathrm{C}$. Tras la incubación se lavaron 3 veces con $1 \mathrm{ml}$ de tampón de lisis B. Se centrifugó las bolas a $5.000 \mathrm{rpm}$ durante 5 minutos y los precipitados se resuspendieron en $30 \mu \mathrm{l}$ de tampón de carga $2 X$ (SDS al 4\%, glicerol al $20 \%$, DTT $100 \mathrm{mM}$ y azul de bromofenol al 0,08 \%).

\subsection{Electroforesis y electrotransferencia de proteínas}

Los extractos celulares totales o los precipitados se desnaturalizaron durante 5 minutos a $95^{\circ} \mathrm{C}$ y las muestras provenientes de coinmunoprecipitación o pull down se centrifugaron además a $5.000 \mathrm{rpm}$ durante 1 minuto para separar las bolas del sobrenadante. Las proteínas desnaturalizadas se cargaron en geles de poliacrilamida de diferente porcentaje (6-12\%) y se separaron según su tamaño molecular mediante electroforesis en condiciones desnaturalizantes (SDS-PAGE) a una intensidad de $30 \mathrm{~mA}$ por gel, como describe (Laemmli, 1970). El tampón de carrera utilizado fue Tris/Glicina $(24,8 \mathrm{mM} / 192 \mathrm{mM})$ y SDS al $0,1 \% \mathrm{pH} 8,3$. Las proteínas se transfirieron a membranas de PVDF (Immobilon-P, Millipore) mediante el sistema Mini Protean III de BioRad, usando como tampón Tris/Glicina $(24,8 \mathrm{mM} / 192 \mathrm{mM})$ y metanol al $10 \% \mathrm{pH} \mathrm{8,3,}$ durante 90 minutos a $100 \mathrm{~V}$. 


\section{Materiales y métodos}

\subsection{Inmunodetección de proteínas}

Tras la electrotransferencia, las membranas se bloquearon en TBST (Tris- $\mathrm{HCl} 20 \mathrm{mM} \mathrm{pH}$ 7,6, $\mathrm{NaCl} 137 \mathrm{mM}$ y Tween 20 al 0,1\% de SIGMA) con leche desnatada al 5\%, durante toda la noche a $4^{\circ} \mathrm{C}$ o 45 minutos a temperatura ambiente. Posteriormente se incubaron con el anticuerpo primario a la dilución apropiada en TBST con leche desnatada al $5 \%$, durante 1 hora a temperatura ambiente o durante toda la noche a $4^{\circ} \mathrm{C}$. Se lavaron 3 veces durante 10 minutos con abundante TBST y se incubaron después durante 60 minutos a temperatura ambiente con un anticuerpo secundario anti-IgG unido a peroxidasa (HRP, horseradish peroxidase) diluido en TBST con leche desnatada al 5\%. Las membranas se volvieron a lavar 3 veces con TBST y se añadió el sustrato de la peroxidasa (WesternBright ${ }^{\mathrm{TM}}$ Sirius, HRP substrate Advansta, Ecogen) para la detección de su actividad por quimioluminiscencia. Las proteínas reconocidas por los anticuerpos se detectaron utilizando películas Medical X-Ray Film Blue 100 NIF (AGFA). Los anticuerpos utilizados fueron:

- Anticuerpo monoclonal de rata frente al epítopo HA, HA high affinity, a una dilución de 1:10.000.

- Anticuerpo monoclonal de ratón frente a la proteína GFP, JL-8 (BD Biosciences), a una dilución 1:3.000.

- Anticuerpo monoclonal de ratón frente a la proteína actina, C4 (ICN Biomedicals), a una dilución 1:10.000.

- Anticuerpo monoclonal de cabra anti-IgG de ratón unido a HRP (BioRad) a una dilución 1:10.000-1:15.000.

- Anticuerpo monoclonal de cabra anti-IgG de conejo unido a HRP (BioRad) a una dilución 1:10.000.

- Anticuerpo monoclonal de cabra anti-IgG de rata unido a HRP (Santa Cruz Biotechnology) a una dilución 1:15.000.

- Anticuerpo policlonal anti-GST unido a HRP (GE Healthcare) a una dilución 1:5.000. 


\subsection{Ensayos de proteómica}

Para los ensayos de proteómica realizados en el Instituto Curie se obtuvieron extractos celulares ( $5 \mathrm{mg}$ de proteína total) de una cepa silvestre y otra cnb1 $\Delta$ que expresaban una proteína quimérica formada por el dominio $\mathrm{N}$-terminal de la paxilina (aminoácidos 1-257) fusionado con la subunidad catalítica de la calcineurina (N-pxl1-ppb1). Esta proteína quimérica estaba marcada con la proteína fluorescente verde (GFP) en su extremo $\mathrm{N}$-terminal y expresada bajo el control del promotor y el terminador de la paxilina. A partir de estos extractos se purificó la proteína quimérica en ambas cepas mediante la utilización de bolas magnéticas (UMACS ${ }^{\mathrm{TM}}$ GFP Isolation Kit, MACS Miltenyi Biotec) que se unen al epítopo GFP de la proteína quimérica y la retienen en la columna (uColumns, MACS Miltenyi Biotec) mediante un imán. Junto a la proteína quimérica quedan retenidas todas las proteínas que se asocian a ella. Finalmente, las proteínas retenidas se eluyeron y se enviaron al servicio de proteómica del Instituto Curie de París para su análisis mediante cromatografía líquida y espectrometría de masas (LC-MS/MS).

\subsection{Ensayo de fosfoproteómica}

Para los ensayos de fosfoproteómica se obtuvieron $8 \mathrm{mg}$ de extractos celulares totales de las cepas silvestre y ppb1 $1 \Delta$ que expresaban Rga7 y Ags1 marcadas con GFP. A partir de estos se purificó la proteína de interés mediante la utilización de bolas magnéticas (UMACS $^{\text {TM }}$ GFP Isolation Kit, MACS Miltenyi Biotec) que se unen al epítopo GFP de estas proteínas y la retienen en la columna (uColumns, MACS Miltenyi Biotec) mediante un imán. La proteína de interés se eluyó de la columna y su concentración se cuantificó mediante electroforesis en gel de poliacrilamida al $8 \%$ teñido con azul de Coomassie, comparándola con diferentes concentraciones conocidas de seroalbúmina bovina.

La obtención de los péptidos de Rga7 y Ags1 para su análisis se realizó mediante filter aided sample preparation, que permite la eliminación de los detergentes contaminantes, la digestión de las proteínas y la purificación de los péptidos obtenidos (Wiśniewski, 2018). Para ello se utilizó el kit Expedeon FASPTM Protein Digestion Kit (Thermo Fisher Scientific). Las muestras se trataron con urea $8 \mathrm{M}$ y se filtraron mediante centrifugación para eliminar los detergentes presentes en la muestra quedando las proteínas retenidas en el filtro comercial. Las proteínas, alquiladas por el tratamiento con urea, se digirieron en el mismo filtro con una combinación de enzimas (tripsina y endoproteinasa Lys-C). Los péptidos obtenidos tras la lisis se eluyeron del filtro utilizando acetonitrilo al $80 \%$ mediante centrifugación (Figura 71). Para la eliminación de posibles sales contaminantes, los péptidos se purificaron mediante cromatografía de exclusión por tamaño utilizando una columna Zeba ${ }^{T M}$ Spin Desalting Columms (Thermo Fisher Scientific). 


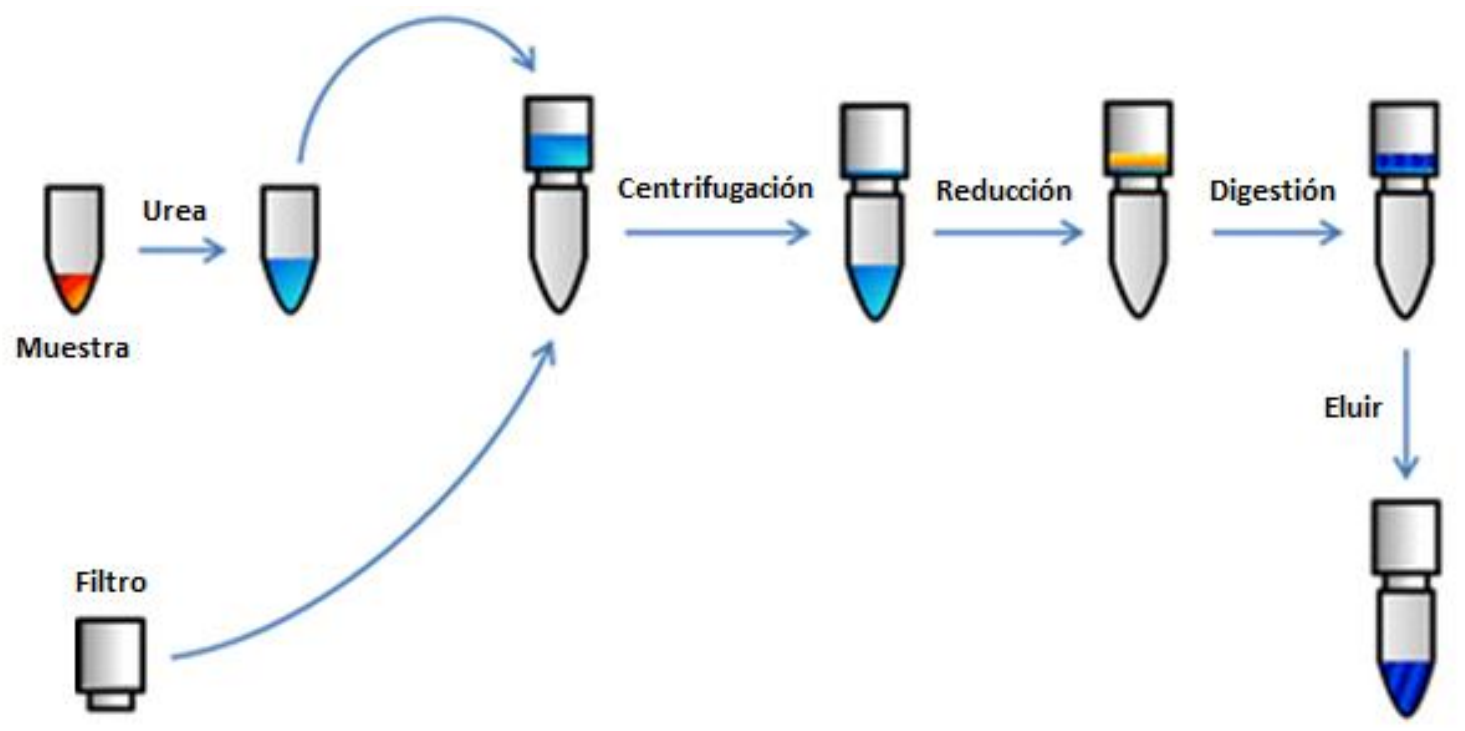

Figura 71.- Filter aided sample preparation (FASP). Esta técnica permite la eliminación de detergentes, digestión y purificación de la muestra. Adaptado de Erde et al., 2014.

Tras la digestión se cuantificó la mezcla de péptidos mediante el ensayo colorimétrico cuantitativo de Pierce (PIERCE et al., 1953) Thermo Scientific ${ }^{T M}$ Pierce $^{T M}$ Quantitative Colorimetric Peptide Assay (Thermo Scientific). A continuación, se añadió a cada muestra el marcador isobárico de masas tandem mass tag (TMT) del kit Thermo Scientific ${ }^{T M} T M T^{T M}$ Isobaric Mass Tagging Kits and Reagents (Thermo Scientific). Finalmente, los péptidos de las muestras se mezclaron y se analizaron mediante espectrometría de masas (LC-MS/MS). Los péptidos se separaron según su tamaño por cromatografía líquida y se detectaron las modificaciones postraduccionales presentes en ellos por su relación carga/masa.

\section{TÉCNICAS DE MICROSCOPÍA Y TINCIONES}

Para llevar a cabo estas técnicas se tomaron muestras de cultivos en medio líquido crecidos en fase logarítmica empleándose diversos microscopios:

- Leica DM RXA y Nikon Eclipse TE-2000U: poseen un sistema de iluminación halógena con filtros para microscopía de contraste interdiferencial (DIC) y contraste de fases y objetivos de inmersión en aceite. Estos equipos están equipados con una cámara fotográfica digital Leica DFC350FX y una cámara Orca-ER acoplada al microscopio respectivamente. Ambos microscopios son controlados mediante el software MetaMorph ${ }^{\circledR}$ (MDS Analytical Technologies).

- Personal Deltavision Microscope (Applied Precision): equipado con un microscopio invertido Olympus IX-70 controlado mediante el software softWoRx Resolve3D, y una cámara CooISNAP HQ2 (PHOTOMETRICS). 
- Spinning Disk: consta de un microscopio invertido Olympus IX-81, controlado mediante el software MetamorphR (MDS Analytical Technologies), una cámara Evolve y un módulo confocal de Spinning Disk CSU-X1 de Yokogawa.

Las imágenes se procesaron posteriormente con los programas Image-J (http://rsb.info.nih.gov/ij/) y Adobe Photoshop CS4 (Adobe System, Inc).

\subsection{Microscopía de fluorescencia}

Para observar la localización de proteínas marcadas con proteínas fluorescentes, se utilizaron los filtros que dejan pasar la luz ultravioleta de una determinada longitud de onda, según los espectros de excitación-emisión propios de las proteínas fluorescentes utilizadas. Como referencia se tomaron imágenes de contraste interdiferencial (Nomarsky) o de contraste de fases.

\subsubsection{Fluorescencia directa con GFP o RFP}

La proteína verde fluorescente (GFP) es un polipéptido de 238 aminoácidos procedente de la medusa Aequorea victoria, que posee la capacidad de emitir luz verde cuando se excita con luz ultravioleta de longitud de onda de $488 \mathrm{~nm}$. Esta propiedad hace que esta proteína sea utilizada para la detección de la expresión y localización subcelular de proteínas in vivo. Para ello, hay que fusionar la secuencia de ADN que codifica esta proteína en fase con la del gen de la proteína objeto de estudio. Existen variantes de la proteína verde fluorescente utilizadas en los experimentos como la EGFP (Enhanced Green Fluorescent Protein), más brillante que la original, que emite luz de $507 \mathrm{~nm}$ de longitud de onda cuando es excitada con luz de $488 \mathrm{~nm}$ o la proteína amarilla fluorescente o YFP (Yellow Fluorescent Protein) que emite luz de 527 $\mathrm{nm}$ de longitud de onda cuando es excitada con luz de $514 \mathrm{~nm}$.

Por otro lado, la proteína roja fluorescente (DsRFP), aislada del coral, emite luz de 586 $\mathrm{nm}$ de longitud de onda cuando es excitada con luz de $556 \mathrm{~nm}$ de la que se han realizado diferentes modificaciones. Una de ellas es la proteína mCherry que emite luz de $610 \mathrm{~nm}$ de longitud de onda cuando es excitada con luz de $587 \mathrm{~nm}$ y es más brillante y estable (Shaner et al., 2005) o la proteína TdTomato que emite luz de 581 $\mathrm{nm}$ cuando es excitada con luz de $554 \mathrm{~nm}$. Ambas proteínas fueron utilizadas en este trabajo.

Pueden fusionarse varias repeticiones de una misma proteína en tándem para aumentar la intensidad de la luz de emisión. Además, el marcaje de distintas proteínas dentro de la célula con diferentes proteínas fluorescentes nos permitió realizar estudios de colocalización. 


\subsubsection{Tinción con calcoflúor}

En S. pombe el calcoflúor es un fluorocromo que se une fundamentalmente al $\beta-(1,3)$ glucano lineal del septo y de los polos en crecimiento (Cortés et al., 2007). El calcoflúor emite fluorescencia azul cuando se excita al recibir luz de $372 \mathrm{~nm}$ de longitud de onda. El calcoflúor (Blankophor BBH, Bayer Corporation) se preparó en agua a una concentración de $1 \mathrm{mg} / \mathrm{ml}$ añadiéndose gotas de $\mathrm{KOH} 10 \mathrm{~N}$ para facilitar su disolución. Finalmente se esterilizó por filtración y se guardó a $4^{\circ} \mathrm{C}$ protegido de la luz. La tinción de calcoflúor se realizó directamente sobre la muestra antes de su observación, añadiendo el calcoflúor a una dilución 1/6 (v/v).

\subsubsection{Tinción de actina}

Para esta tinción se utiliza la faloidina, una toxina extraída del hongo Amanita phalloides, que se une con alta afinidad a la actina $F$ (actina polimerizada). La faloidina está conjugada al compuesto fluorescente Alexa-fluor 448 que emite luz de $520 \mathrm{~nm}$ cuando es excitada con luz de $493 \mathrm{~nm}$. La tinción se realizó a partir del protocolo inicial descrito por Marks and Hyams, 1985, siguiendo las indicaciones y modificaciones realizadas por $\mathrm{F}$. Chang. De un cultivo en fase exponencial de crecimiento se tomaron 5 $\mathrm{ml}$ de células que se fijaron añadiendo $1 \mathrm{ml}$ ( $1 / 5$ del volumen del cultivo) de formaldehído al 16\% (EM-grade MeOH Free, Polysciences) y $500 \mu \mathrm{l}$ (1/10 del volumen del cultivo) de tampón PEM (PIPES 100 mM, EGTA 1 mM, Mg2SO4 1 mM, pH 6,9). Las células se incubaron en agitación durante 1 hora y posteriormente se lavaron 3 veces con tampón PEM. Se recogieron y se permeabilizaron resuspendiéndolas en PEM con Tritón T-X100 al 1\% durante 30 segundos para permitir la posterior entrada de la faloidina fluorescente. Finalmente, las células se lavaron tres veces con PEM, se centrifugaron, se eliminó el sobrenadante y el "pellet" se resuspendió en el líquido restante. Se tomó $1 \mu \mathrm{l}$ de células permeabilizadas y se mezcló con $8 \mu \mathrm{l}$ de Alexa-fluor 448-faloidina (Molecular Probes), resuspendida en PEM. Las muestras se incubaron en oscuridad durante 1 hora en un agitador orbital a temperatura ambiente y se examinaron con el microscopio de fluorescencia. Estas muestras pueden guardarse durante 1 o 2 días a $4^{\circ} \mathrm{C}$ antes de observarse al microscopio. 


\section{Materiales y métodos}

\subsection{Video-microscopía a tiempo real}

Esta técnica consiste en la observación de células durante un periodo de tiempo, lo que permite ver su progreso a lo largo del ciclo celular. Se utilizaron cámaras multipocillo $\mu$-Slide (Ibidi) con $0,3 \mathrm{ml}$ de cultivos líquidos creciendo en fase logarítmica en uno de los 8 pocillos, previamente recubierto con $10 \mu \mathrm{l}$ de lectina (Sigma-Aldrich) a $1 \mathrm{mg} / \mathrm{ml}$ (Cortés et al., 2012). Los experimentos de video-microscopía se realizaron a $25^{\circ} \mathrm{C}$ o $28^{\circ} \mathrm{C}$ gracias a una cámara termostatizada acoplada a los microscopios Personal Deltavision Microscope (Applied Precision) y Spinning Disk. Se capturaron imágenes en un único plano, en el punto medio de enfoque, a distintos intervalos de tiempo.

\section{ANÁLISIS BIOINFORMÁTICO DE LOS DATOS}

Para el análisis informático de las secuencias de ADN y de proteínas, mapas de restricción y para realizar alineamientos de secuencias se utilizó el programa DNAStar y Clustal Omega.

El análisis informático de los ensayos de fosfoproteómica se realizó utilizando el software Proteome Discover 2.1.

Las secuencias de genes y proteínas y sus dominios se obtuvieron de la base de datos de S. pombe Pombase (https://www.pombase.org/).

Las búsquedas bibliográficas se realizaron a través de la base de datos de NCBI (https://www.ncbi.nlm.nih.gov/pubmed/). 


\section{Bibliografía}

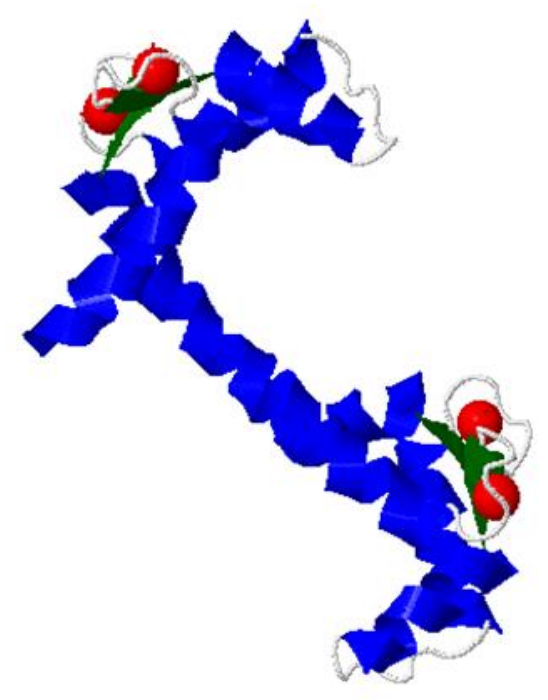





\section{Bibliografía}

Aboobakar, E.F., Wang, X., Heitman, J., and Kozubowski, L. (2011). The C2 domain protein Cts1 functions in the calcineurin signaling circuit during high-temperature stress responses in Cryptococcus neoformans. Eukaryot. Cell 10, 1714-1723.

Alcaide-Gavilán, M., Lahoz, A., Daga, R.R., and Jimenez, J. (2014). Feedback Regulation of SIN by Etd1 and Rho1 in Fission Yeast. Genetics 196, 455-470.

Almonacid, M., Moseley, J.B., Janvore, J., Mayeux, A., Fraisier, V., Nurse, P., and Paoletti, A. (2009). Spatial Control of Cytokinesis by Cdr2 Kinase and Mid1/Anillin Nuclear Export. Curr. Biol. 19, 961-966.

Alonso-Nuñez, M.L., An, H., Martín-Cuadrado, A.B., Mehta, S., Petit, C., Sipiczki, M., del Rey, F., Gould, K.L., and Vázquez de Aldana, C.R. (2005). Ace2p Controls the Expression of Genes Required for Cell Separation in Schizosaccharomyces pombe. Mol. Biol. Cell 16, 2003-2017.

Alvarez-Tabares, I., Grallert, A., Ortiz, J.-M., and Hagan, I.M. (2007). Schizosaccharomyces pombe protein phosphatase 1 in mitosis, endocytosis and a partnership with Wsh3/Tea4 to control polarised growth. J. Cell Sci. 120, 3589-3601.

An, H., Morrell, J.L., Jennings, J.L., Link, A.J., and Gould, K.L. (2004). Requirements of fission yeast septins for complex formation, localization, and function. Mol. Biol. Cell $15,5551-5564$.

Arai, R., and Mabuchi, I. (2002). F-actin ring formation and the role of F-actin cables in the fission yeast Schizosaccharomyces pombe. J. Cell Sci. 115, 887-898.

Arasada, R., and Pollard, T.D. (2011). Distinct Roles for F-BAR Proteins Cdc15p and Bzz1p in Actin Polymerization at Sites of Endocytosis in Fission Yeast. Curr. Biol. 21, 1450-1459.

Arasada, R., and Pollard, T.D. (2014). Contractile Ring Stability in S. pombe Depends on F-BAR Protein Cdc15p and Bgs1p Transport from the Golgi Complex. Cell Rep. 8, 1533-1544.

Arasada, R., and Pollard, T.D. (2015). A role for F-BAR protein Rga7p during cytokinesis in S. pombe. J. Cell Sci. 128, 2259-2268.

Arellano, M., Durán, A., and Pérez, P. (1996). Rho 1 GTPase activates the (1-3)beta-Dglucan synthase and is involved in Schizosaccharomyces pombe morphogenesis. EMBO J. 15, 4584-4591.

Arellano, M., Duran, A., and Perez, P. (1997). Localisation of the Schizosaccharomyces pombe rho1p GTPase and its involvement in the organisation of the actin cytoskeleton. J. Cell Sci. 110 ( Pt 20), 2547-2555.

Arellano, M., Coll, P.M., and P rez, P. (1999). RHO GTPases in the control of cell morphology, cell polarity, and actin localization in fission yeast. Microsc. Res. Tech. 47, 51-60. 


\section{Bibliografía}

Arellano, M., Valdivieso, M.H., Calonge, T.M., Coll, P.M., Duran, A., and Perez, P. (1999). Schizosaccharomyces pombe protein kinase $C$ homologues, pck1p and pck2p, are targets of rho1p and rho2p and differentially regulate cell integrity. J. Cell Sci. 112 ( Pt 20), 3569-3578.

Atilgan, E., Magidson, V., Khodjakov, A., and Chang, F. (2015). Morphogenesis of the Fission Yeast Cell through Cell Wall Expansion. Curr. Biol. 25, 2150-2157.

Attanapola, S.L., Alexander, C.J., and Mulvihill, D.P. (2009). Ste20-kinase-dependent TEDS-site phosphorylation modulates the dynamic localisation and endocytic function of the fission yeast class I myosin, Myo1. J. Cell Sci. 122, 3856-3861.

Ausubel, F.M. (1987). Current protocols in molecular biology. (Greene Pub. Associates).

Bader, T., Bodendorfer, B., Schröppel, K., and Morschhäuser, J. (2003). Calcineurin is essential for virulence in Candida albicans. Infect. Immun. 71, 5344-5354.

Bähler, J., and Pringle, J.R. (1998). Pom1p, a fission yeast protein kinase that provides positional information for both polarized growth and cytokinesis. Genes Dev. 12, 13561370.

Bähler, J., Steever, A.B., Wheatley, S., Wang, Y. I, Pringle, J.R., Gould, K.L., and McCollum, D. (1998). Role of polo kinase and Mid1p in determining the site of cell division in fission yeast. J. Cell Biol. 143, 1603-1616.

Bähler, J., Wu, J.Q., Longtine, M.S., Shah, N.G., McKenzie, A., Steever, A.B., Wach, A., Philippsen, P., and Pringle, J.R. (1998). Heterologous modules for efficient and versatile PCR-based gene targeting in Schizosaccharomyces pombe. Yeast 14, 943-951.

Baker, J.P., and Titus, M.A. (1998). Myosins: matching functions with motors. Curr. Opin. Cell Biol. 10, 80-86.

Balasubramanian, M.K., Helfman, D.M., and Hemmingsen, S.M. (1992). A new tropomyosin essential for cytokinesis in the fission yeast S. pombe. Nature 360, 84-87.

Bathe, M., and Chang, F. (2010). Cytokinesis and the contractile ring in fission yeast: towards a systems-level understanding. Trends Microbiol. 18, 38-45.

Bendezú, F.O., Vincenzetti, V., Vavylonis, D., Wyss, R., Vogel, H., and Martin, S.G. (2015). Spontaneous Cdc42 polarization independent of GDI-mediated extraction and actin-based trafficking. PLoS Biol. 13, e1002097.

Berg, J.S., Powell, B.C., and Cheney, R.E. (2001). A Millennial Myosin Census. Mol. Biol. Cell 12, 780-794.

Berlin, A., Paoletti, A., and Chang, F. (2003). Mid2p stabilizes septin rings during cytokinesis in fission yeast. J. Cell Biol. 160, 1083-1092.

Berro, J., Sirotkin, V., and Pollard, T.D. (2010). Mathematical modeling of endocytic actin patch kinetics in fission yeast: disassembly requires release of actin filament fragments. Mol. Biol. Cell 21, 2905-2915. 


\section{Bibliografía}

Bezanilla, M., and Pollard, T.D. (2000). Myosin-II Tails Confer Unique Functions in Schizosaccharomyces pombe : Characterization of a Novel Myosin-II Tail. Mol. Biol. Cell 11, 79-91.

Bezanilla, M., Forsburg, S.L., and Pollard, T.D. (1997). Identification of a second myosin-II in Schizosaccharomyces pombe: Myp2p is conditionally required for cytokinesis. Mol. Biol. Cell 8, 2693-2705.

Bohnert, K.A., and Gould, K.L. (2012). Cytokinesis-based constraints on polarized cell growth in fission yeast. PLoS Genet. 8, e1003004.

Bohnert, K.A., Grzegorzewska, A.P., Willet, A.H., Vander Kooi, C.W., Kovar, D.R., and Gould, K.L. (2013). SIN-dependent phosphoinhibition of formin multimerization controls fission yeast cytokinesis. Genes Dev. 27, 2164-2177.

Bonilla, M., Nastase, K.K., and Cunningham, K.W. (2002). Essential role of calcineurin in response to endoplasmic reticulum stress. EMBO J. 21, 2343-2353.

Bos, J.L., Rehmann, H., and Wittinghofer, A. (2007). GEFs and GAPs: Critical Elements in the Control of Small G Proteins. Cell 129, 865-877.

Bradford, M. (1976). A Rapid and Sensitive Method for the Quantitation of Microgram Quantities of Protein Utilizing the Principle of Protein-Dye Binding. Anal. Biochem. 72, 248-254.

Brown, M.C., and Turner, C.E. (2004). Paxillin: Adapting to Change. Physiol. Rev. 84, 1315-1339.

Bush, D.A., Horisberger, M., Horman, I., and Wursch, P. (1974). The Wall Structure of Schizosaccharomyces pombe. J. Gen. Microbiol. 81, 199-206.

Bustelo, X.R., Sauzeau, V., and Berenjeno, I.M. (2007). GTP-binding proteins of the Rho/Rac family: regulation, effectors and functions in vivo. BioEssays 29, 356-370.

Calonge, T.M., Nakano, K., Arellano, M., Arai, R., Katayama, S., Toda, T., Mabuchi, I., and Perez, P. (2000). Schizosaccharomyces pombe Rho2p GTPase Regulates Cell Wall $\alpha$-Glucan Biosynthesis through the Protein Kinase Pck2p. Mol. Biol. Cell 11, 4393-4401.

Calonge, T.M., Arellano, M., Coll, P.M., and Perez, P. (2003). Rga5p is a specific Rho1p GTPase-activating protein that regulates cell integrity in Schizosaccharomyces pombe. Mol. Microbiol. 47, 507-518.

Carnahan, R.H., and Gould, K.L. (2003). The PCH family protein, Cdc15p, recruits two F-actin nucleation pathways to coordinate cytokinetic actin ring formation in Schizosaccharomyces pombe. J. Cell Biol. 162, 851-862.

Carragher, N.O., and Frame, M.C. (2004). Focal adhesion and actin dynamics: a place where kinases and proteases meet to promote invasion. Trends Cell Biol. 14, 241-249.

Carroll, C.W., Altman, R., Schieltz, D., Yates, J.R., Kellogg, D., and Kellogg, D. (1998). The septins are required for the mitosis-specific activation of the Gin4 kinase. J. Cell Biol. 143, 709-717. 


\section{Bibliografía}

Celton-Morizur, S., Racine, V., Sibarita, J.-B., and Paoletti, A. (2006). Pom1 kinase links division plane position to cell polarity by regulating Mid1p cortical distribution. J. Cell Sci. 119, 4710-4718.

Cerone, L., Novák, B., and Neufeld, Z. (2012). Mathematical Model for Growth Regulation of Fission Yeast Schizosaccharomyces pombe. PLoS One 7, e49675.

Chang, F., Woollard, A., and Nurse, P. (1996). Isolation and characterization of fission yeast mutants defective in the assembly and placement of the contractile actin ring. J. Cell Sci. 109 ( Pt 1), 131-142.

Chang, F., Drubin, D., and Nurse, P. (1997). cdc12p, a protein required for cytokinesis in fission yeast, is a component of the cell division ring and interacts with profilin. $J$. Cell Biol. 137, 169-182.

Chatfield-Reed, K., Vachon, L., Kwon, E.-J.G., and Chua, G. (2016). Conserved and Diverged Functions of the Calcineurin-Activated Prz1 Transcription Factor in Fission Yeast. Genetics 202, 1365-1375.

Chen, C.-T., Feoktistova, A., Chen, J.-S., Shim, Y.-S., Clifford, D.M., Gould, K.L., and McCollum, D. (2008). The SIN Kinase Sid2 Regulates Cytoplasmic Retention of the S. pombe Cdc14-like Phosphatase Clp1. Curr. Biol. 18, 1594-1599.

Chen, J.-S., Broadus, M.R., McLean, J.R., Feoktistova, A., Ren, L., and Gould, K.L. (2013). Comprehensive proteomics analysis reveals new substrates and regulators of the fission yeast clp1/cdc14 phosphatase. Mol. Cell. Proteomics 12, 1074-1086.

Chen, J.-S., Beckley, J.R., Ren, L., Feoktistova, A., Jensen, M.A., Rhind, N., and Gould, K.L. (2016). Discovery of genes involved in mitosis, cell division, cell wall integrity and chromosome segregation through construction of Schizosaccharomyces pombe deletion strains. Yeast 33, 507-517.

Chen, Y.-H., Wang, G.-Y., Hao, H.-C., Chao, C.-J., Wang, Y., and Jin, Q.-W. (2017). Facile manipulation of protein localization in fission yeast through binding of GFPbinding protein to GFP. J. Cell Sci. 130, 1003-1015.

Cherfils, J., and Zeghouf, M. (2013). Regulation of small GTPases by GEFs, GAPs, and GDIs. Physiol. Rev. 93, 269-309.

Chhabra, E.S., and Higgs, H.N. (2007). The many faces of actin: matching assembly factors with cellular structures. Nat. Cell Biol. 9, 1110-1121.

Chiou, J.-G., Balasubramanian, M.K., and Lew, D.J. (2017). Cell Polarity in Yeast. Annu. Rev. Cell Dev. Biol. 33, 77-101.

Chyan, C.-L., Irene, D., and Lin, S.-M. (2017). The Recognition of Calmodulin to the Target Sequence of Calcineurin-A Novel Binding Mode. Molecules 22, 1584.

Cisneros-Barroso, E., Yance-Chávez, T., Kito, A., Sugiura, R., Gómez-Hierro, A., Giménez-Zaragoza, D., and Aligue, R. (2014). Negative feedback regulation of calcineurin-dependent Prz1 transcription factor by the CaMKK-CaMK1 axis in fission yeast. Nucleic Acids Res. 42, 9573-9587. 


\section{Bibliografía}

Clayton, J.E., Sammons, M.R., Stark, B.C., Hodges, A.R., and Lord, M. (2010). Differential regulation of unconventional fission yeast myosins via the actin track. Curr. Biol. 20, 1423-1431.

Clifford, D.M., Wolfe, B.A., Roberts-Galbraith, R.H., McDonald, W.H., Yates, J.R., and Gould, K.L. (2008a). The Clp1/Cdc14 phosphatase contributes to the robustness of cytokinesis by association with anillin-related Mid1. J. Cell Biol. 181, 79-88.

Clos, J., and Brandau, S. (1994). pJC20 and pJC40--two high-copy-number vectors for T7 RNA polymerase-dependent expression of recombinant genes in Escherichia coli. Protein Expr. Purif. 5, 133-137.

Clough, R.R., Sidhu, R.S., and Bhullar, R.P. (2002). Calmodulin Binds RalA and RalB and Is Required for the Thrombin-induced Activation of Ral in Human Platelets. J. Biol. Chem. 277, 28972-28980.

Coffman, V.C., Nile, A.H., Lee, I.-J., Liu, H., and Wu, J.-Q. (2009). Roles of Formin Nodes and Myosin Motor Activity in Mid1p-dependent Contractile-Ring Assembly during Fission Yeast Cytokinesis. Mol. Biol. Cell 20, 5195-5210.

Cohen, P. (1989). The Structure and Regulation of Protein Phosphatases. Annu. Rev. Biochem. 58, 453-508.

Coll, P.M., Trillo, Y., Ametzazurra, A., and Perez, P. (2003). Gef1p, a new guanine nucleotide exchange factor for $\mathrm{Cdc} 42 p$, regulates polarity in Schizosaccharomyces pombe. Mol. Biol. Cell 14, 313-323.

Cortés, J.C.G., Ishiguro, J., Durán, A., and Ribas, J.C. (2002). Localization of the $(1,3)$ beta-D-glucan synthase catalytic subunit homologue Bgs1p/Cps1p from fission yeast suggests that it is involved in septation, polarized growth, mating, spore wall formation and spore germination. J. Cell Sci. 115, 4081-4096.

Cortés, J.C.G., Katoh-Fukui, R., Moto, K., Ribas, J.C., and Ishiguro, J. (2004). Schizosaccharomyces pombe Pmr1p is essential for cell wall integrity and is required for polarized cell growth and cytokinesis. Eukaryot. Cell 3, 1124-1135.

Cortés, J.C.G., Carnero, E., Ishiguro, J., Sánchez, Y., Durán, A., and Ribas, J.C. (2005). The novel fission yeast $(1,3) \beta$-D-glucan synthase catalytic subunit Bgs $4 p$ is essential during both cytokinesis and polarized growth. J. Cell Sci. 118, 157-174.

Cortés, J.C.G., Konomi, M., Martins, I.M., Muñoz, J., Moreno, M.B., Osumi, M., Durán, A., and Ribas, J.C. (2007). The $(1,3) \beta$-d-glucan synthase subunit Bgs1p is responsible for the fission yeast primary septum formation. Mol. Microbiol. 65, 201217.

Cortés, J.C.G., Sato, M., Muñoz, J., Moreno, M.B., Clemente-Ramos, J.A., Ramos, M., Okada, H., Osumi, M., Durán, A., and Ribas, J.C. (2012). Fission yeast Ags1 confers the essential septum strength needed for safe gradual cell abscission. J. Cell Biol. 198, 637656. 


\section{Bibliografía}

Cortés, J.C.G., Pujol, N., Sato, M., Pinar, M., Ramos, M., Moreno, B., Osumi, M., Ribas, J.C., and Pérez, P. (2015). Cooperation between Paxillin-like Protein PxI1 and Glucan Synthase Bgs1 Is Essential for Actomyosin Ring Stability and Septum Formation in Fission Yeast. PLoS Genet. 11, e1005358.

Cortés, J.C.G., Ramos, M., Osumi, M., Pérez, P., and Ribas, J.C. (2016). Fission yeast septation. Commun. Integr. Biol. 9, e1189045.

Craig, R., and Norbury, C. (1998). The novel murine calmodulin-binding protein Sha1 disrupts mitotic spindle and replication checkpoint functions in fission yeast. J. Cell Sci. 111 ( Pt 24), 3609-3619.

Cramer, R.A., Perfect, B.Z., Pinchai, N., Park, S., Perlin, D.S., Asfaw, Y.G., Heitman, J., Perfect, J.R., and Steinbach, W.J. (2008). Calcineurin target CrzA regulates conidial germination, hyphal growth, and pathogenesis of Aspergillus fumigatus. Eukaryot. Cell 7, 1085-1097.

Cruz Quintana, S.M., Álvarez Suárez, J.M., and Díaz, P. (2014). The cell wall of Schizosaccharomyces pombe as a model of study in the search for ney antifungal targets.

Cunningham, K.W., and Fink, G.R. (1994). Calcineurin-dependent growth control in Saccharomyces cerevisiae mutants lacking PMC1, a homolog of plasma membrane Ca2+ ATPases. J. Cell Biol. 124, 351-363.

Cyert, M.S. (2001). Genetic analysis of calmodulin and its targets in Saccharomyces cerevisiae. Annu. Rev. Genet. 35, 647-672.

Cyert, M.S., and Thorner, J. (1992). Regulatory subunit (CNB1 gene product) of yeast $\mathrm{Ca} 2+/$ calmodulin-dependent phosphoprotein phosphatases is required for adaptation to pheromone. Mol. Cell. Biol. 12, 3460-3469.

Cyert, M.S., Kunisawa, R., Kaim, D., and Thorner, J. (1991). Yeast has homologs (CNA1 and CNA2 gene products) of mammalian calcineurin, a calmodulin-regulated phosphoprotein phosphatase. Proc. Natl. Acad. Sci. U. S. A. 88, 7376-7380.

D'souza, V.M., Naqvi, N.I., Wang, H., and Balasubramanian, M.K. (2001a). Interactions of Cdc4p, a myosin light chain, with IQ-domain containing proteins in Schizosaccharomyces pombe. Cell Struct. Funct. 26, 555-565.

Daga, R.R., Lahoz, A., Muñoz, M.J., Moreno, S., and Jimenez, J. (2005). Etd1p is a novel protein that links the SIN cascade with cytokinesis. EMBO J. 24, 2436-2446.

Daga, R.R., Yonetani, A., and Chang, F. (2006). Asymmetric Microtubule Pushing Forces in Nuclear Centering. Curr. Biol. 16, 1544-1550.

Davidson, R., Laporte, D., and Wu, J.-Q. (2015). Regulation of Rho-GEF Rgf3 by the arrestin Art1 in fission yeast cytokinesis. Mol. Biol. Cell 26, 453-466.

Davis, T.N., Urdea, M.S., Masiarz, F.R., and Thorner, J. (1986). Isolation of the yeast calmodulin gene: calmodulin is an essential protein. Cell 47, 423-431. 


\section{Bibliografía}

Dekker, N., Speijer, D., Grün, C.H., van den Berg, M., de Haan, A., and Hochstenbach, F. (2004). Role of the $\alpha$-Glucanase Agn1p in Fission-Yeast Cell Separation. Mol. Biol. Cell 15, 3903-3914.

Dekker, N., de Haan, A., and Hochstenbach, F. (2006). Transcription regulation of the $\alpha$-glucanase gene agn 1 by cell separation transcription factor Ace $2 p$ in fission yeast. FEBS Lett. 580, 3099-3106.

Demeter, J., and Sazer, S. (1998). imp2, a new component of the actin ring in the fission yeast Schizosaccharomyces pombe. J. Cell Biol. 143, 415-427.

Deng, L., Sugiura, R., Takeuchi, M., Suzuki, M., Ebina, H., Takami, T., Koike, A., Iba, S., and Kuno, T. (2006). Real-time monitoring of calcineurin activity in living cells: evidence for two distinct Ca2+-dependent pathways in fission yeast. Mol. Biol. Cell 17, 4790-4800.

DerMardirossian, C., and Bokoch, G.M. (2005). GDIs: central regulatory molecules in Rho GTPase activation. Trends Cell Biol. 15, 356-363.

Devrekanli, A., Foltman, M., Roncero, C., Sanchez-Diaz, A., and Labib, K. (2012). Inn1 and Cyk3 regulate chitin synthase during cytokinesis in budding yeasts. J. Cell Sci. 125, 5453-5466.

Dischinger, S., Krapp, A., Xie, L., Paulson, J.R., and Simanis, V. (2008). Chemical genetic analysis of the regulatory role of $\mathrm{Cdc} 2 \mathrm{p}$ in the $\mathrm{S}$. pombe septation initiation network. J. Cell Sci. 121, 843-853.

Dixon, M.J., Gray, A., Schenning, M., Agacan, M., Tempel, W., Tong, Y., Nedyalkova, L., Park, H.-W., Leslie, N.R., van Aalten, D.M.F., et al. (2012). IQGAP Proteins Reveal an Atypical Phosphoinositide (aPI) Binding Domain with a Pseudo C2 Domain Fold. J. Biol. Chem. 287, 22483-22496.

Drgonová, J., Drgon, T., Tanaka, K., Kollár, R., Chen, G.C., Ford, R.A., Chan, C.S., Takai, Y., and Cabib, E. (1996). Rho1p, a yeast protein at the interface between cell polarization and morphogenesis. Science 272, 277-279.

Drummond, D.R., and Cross, R.A. (2000). Dynamics of interphase microtubules in Schizosaccharomyces pombe. Curr. Biol. 10, 766-775.

Durán, A., and Pérez, P. (2004). Cell Wall Synthesis. In The Molecular Biology of Schizosaccharomyces Pombe, (Berlin, Heidelberg: Springer Berlin Heidelberg), pp. 269279.

Egel, R., and Egel-Mitani, M. (1974). Premeiotic DNA synthesis in fission yeast. Exp. Cell Res. 88, 127-134.

Eng, K., Naqvi, N.I., Wong, K.C., and Balasubramanian, M.K. (1998). Rng2p, a protein required for cytokinesis in fission yeast, is a component of the actomyosin ring and the spindle pole body. Curr. Biol. 8, 611-621.

Epp, J.A., and Chant, J. (1997). An IQGAP-related protein controls actin-ring formation and cytokinesis in yeast. Curr. Biol. 7, 921-929. 


\section{Bibliografía}

Erde, J., Loo, R.R.O., and Loo, J.A. (2014). Enhanced FASP (eFASP) to increase proteome coverage and sample recovery for quantitative proteomic experiments. $J$. Proteome Res. 13, 1885-1895.

Escobar-Cabrera, E., Venkatesan, M., Desautels, M., Hemmingsen, S.M., and McIntosh, L.P. (2005). Dissecting the Domain Structure of Cdc4p, a Myosin Essential Light Chain Involved in Schizosaccharomyces pombe Cytokinesis ${ }^{\dagger}$. Biochemistry 44, 12136-12148.

Espinoza-Sanchez, S., Metskas, L.A., Chou, S.Z., Rhoades, E., and Pollard, T.D. (2018). Conformational changes in Arp2/3 complex induced by ATP, WASp-VCA, and actin filaments. Proc. Natl. Acad. Sci. 115, E8642-E8651.

Estravís, M., Rincón, S.A., Santos, B., and Pérez, P. (2011). Cdc42 regulates multiple membrane traffic events in fission yeast. Traffic 12, 1744-1758.

Estravís, M., Rincón, S.A., Portales, E., Pérez, P., and Santos, B. (2017). Cdc42 activation state affects its localization and protein levels in fission yeast. Microbiology 163, 1156-1166.

Fan, J.-Q., Deng, X.-L., Feng, B.-W., Wang, J.-F., Yu, Y., and Lv, H. (2013). [Cnb1 involved in cytokinesis in Schizosaccharomyces pombe]. Yi Chuan $=$ Hered. 35, 10301039.

Fankhauser, C., and Simanis, V. (1994). The cdc7 protein kinase is a dosage dependent regulator of septum formation in fission yeast. EMBO J. 13, 3011-3019.

Fankhauser, C., Reymond, A., Cerutti, L., Utzig, S., Hofmann, K., and Simanis, V. (1995). The S. pombe cdc15 gene is a key element in the reorganization of F-actin at mitosis. Cell 82, 435-444.

Fantes, P.A., and Hoffman, C.S. (2016). A Brief History of Schizosaccharomyces pombe Research: A Perspective Over the Past 70 Years. Genetics 203, 621-629.

Faty, M., Fink, M., and Barral, Y. (2002). Septins: a ring to part mother and daughter. Curr. Genet. 41, 123-131.

Feierbach, B., and Chang, F. (2001). Roles of the fission yeast formin for $3 p$ in cell polarity, actin cable formation and symmetric cell division. Curr. Biol. 11, 1656-1665.

Feoktistova, A., Morrell-Falvey, J., Chen, J.-S., Singh, N.S., Balasubramanian, M.K., and Gould, K.L. (2012). The fission yeast septation initiation network (SIN) kinase, Sid2, is required for SIN asymmetry and regulates the SIN scaffold, Cdc11. Mol. Biol. Cell 23, 1636-1645.

Flory, M.R., Morphew, M., Joseph, J.D., Means, A.R., and Davis, T.N. (2002). Pcp1p, an Spc110p-related calmodulin target at the centrosome of the fission yeast Schizosaccharomyces pombe. Cell Growth Differ. 13, 47-58.

Forsburg, S.L. (1993). Comparison of Schizosaccharomyces pombe expression systems. Nucleic Acids Res. 21, 2955-2956.

Fox, D.S., and Heitman, J. (2002). Good fungi gone bad: The corruption of calcineurin. BioEssays 24, 894-903. 


\section{Bibliografía}

Fox, D.S., Cox, G.M., and Heitman, J. (2003). Phospholipid-binding protein Cts1 controls septation and functions coordinately with calcineurin in Cryptococcus neoformans. Eukaryot. Cell 2, 1025-1035.

Fujita, M., Sugiura, R., Lu, Y., Xu, L., Xia, Y., Shuntoh, H., and Kuno, T. (2002). Genetic interaction between calcineurin and type 2 myosin and their involvement in the regulation of cytokinesis and chloride ion homeostasis in fission yeast. Genetics 161, 971-981.

G. Cortés, J.C., Ramos, M., Konomi, M., Barragán, I., Moreno, M.B., Alcaide-Gavilán, M., Moreno, S., Osumi, M., Pérez, P., and Ribas, J.C. (2018). Specific detection of fission yeast primary septum reveals septum and cleavage furrow ingression during early anaphase independent of mitosis completion. PLOS Genet. 14, e1007388.

Gachet, Y., and Hyams, J.S. (2005). Endocytosis in fission yeast is spatially associated with the actin cytoskeleton during polarised cell growth and cytokinesis. J. Cell Sci. 118, 4231-4242.

Gachet, Y., Mulvihill, D., and S. Hyams, J. (2004). The Fission Yeast Actomyosin Cytoskeleton. 225-242.

Gallagher, S.C., Gao, Z.H., Li, S., Dyer, R.B., Trewhella, J., and Klee, C.B. (2001). There is communication between all four $\mathrm{Ca}(2+)$-bindings sites of calcineurin $\mathrm{B}$. Biochemistry 40, 12094-12102.

Gallo Castro, D., and Martin, S.G. (2018). Differential GAP requirement for Cdc42-GTP polarization during proliferation and sexual reproduction. J. Cell Biol. 217, 4215-4229.

Gao, X.-D., Caviston, J.P., Tcheperegine, S.E., and Bi, E. (2004). Pxl1p, a Paxillin-like Protein in Saccharomyces cerevisiae, May Coordinate Cdc42p and Rho1p Functions during Polarized Growth. Mol. Biol. Cell 15, 3977-3985.

García-Cortés, J.C., and McCollum, D. (2009). Proper timing of cytokinesis is regulated by Schizosaccharomyces pombe Etd1. J. Cell Biol. 186, 739-753.

Garcia, I., Tajadura, V., Martin, V., Toda, T., and Sanchez, Y. (2006). Synthesis of alpha-glucans in fission yeast spores is carried out by three alpha-glucan synthase paralogues, Mok12p, Mok13p and Mok14p. Mol. Microbiol. 59, 836-853.

García, I., Jiménez, D., Martín, V., Durán, A., and Sánchez, Y. (2005). The a-glucanase Agn1p is required for cell separation in Schizosaccharomyces pombe. Biol. Cell 97, 569-576.

García, P., Tajadura, V., García, I., and Sánchez, Y. (2006). Rgf1p is a specific Rho1-GEF that coordinates cell polarization with cell wall biogenesis in fission yeast. Mol. Biol. Cell 17, 1620-1631.

García, P., García, I., Marcos, F., de Garibay, G.R., and Sánchez, Y. (2009). Fission yeast rgf $2 p$ is a rho1p guanine nucleotide exchange factor required for spore wall maturation and for the maintenance of cell integrity in the absence of rgf1p. Genetics $181,1321-1334$. 


\section{Bibliografía}

García Cortés, J.C., Ramos, M., Osumi, M., Pérez, P., and Ribas, J.C. (2016). The Cell Biology of Fission Yeast Septation. Microbiol. Mol. Biol. Rev. 80, 779-791.

Garrett-Engele, P., Moilanen, B., and Cyert, M.S. (1995). Calcineurin, the $\mathrm{Ca} 2+/$ calmodulin-dependent protein phosphatase, is essential in yeast mutants with cell integrity defects and in mutants that lack a functional vacuolar $\mathrm{H}(+)$-ATPase. Mol. Cell. Biol. 15, 4103-4114.

Geli, M.I., Wesp, A., and Riezman, H. (1998). Distinct functions of calmodulin are required for the uptake step of receptor-mediated endocytosis in yeast: the type I myosin Myo5p is one of the calmodulin targets. EMBO J. 17, 635-647.

Gerien, K.S., and Wu, J.-Q. (2018). Molecular mechanisms of contractile-ring constriction and membrane trafficking in cytokinesis. Biophys. Rev. 10, 1649-1666.

Glotzer, M. (2004). Cleavage furrow positioning. J. Cell Biol. 164, 347-351.

Le Goff, X., Woollard, A., and Simanis, V. (1999). Analysis of the cps1 gene provides evidence for a septation checkpoint in Schizosaccharomyces pombe. Mol. Gen. Genet. $262,163-172$.

Le Goff, X., Motegi, F., Salimova, E., Mabuchi, I., and Simanis, V. (2000). The S. pombe rlc1 gene encodes a putative myosin regulatory light chain that binds the type II myosins myo3p and myo2p. J. Cell Sci. 113 Pt 23, 4157-4163.

Goldman, A., Roy, J., Bodenmiller, B., Wanka, S., Landry, C.R., Aebersold, R., and Cyert, M.S. (2014). The calcineurin signaling network evolves via conserved kinasephosphatase modules that transcend substrate identity. Mol. Cell 55, 422-435.

Golub, E.I. (1988). "one minute" transformation of competent E.coli by plasmid DNA. Nucleic Acids Res. 16, 1641.

Grötsch, H., Giblin, J.P., Idrissi, F.-Z., Fernández-Golbano, I.-M., Collette, J.R., Newpher, T.M., Robles, V., Lemmon, S.K., and Geli, M.-I. (2010). Calmodulin dissociation regulates Myo5 recruitment and function at endocytic sites. EMBO J. 29, 2899-2914.

Grun, C.H., Hochstenbach, F., Humbel, B.M., Verkleij, A.J., Sietsma, J.H., Klis, F.M., Kamerling, J.P., and Vliegenthart, J.F.G. (2004). The structure of cell wall -glucan from fission yeast. Glycobiology 15, 245-257.

Guertin, D.A., and McCollum, D. (2001). Interaction between the Noncatalytic Region of Sid1p Kinase and Cdc14p Is Required for Full Catalytic Activity and Localization of Sid1p. J. Biol. Chem. 276, 28185-28189.

Guertin, D.A., Chang, L., Irshad, F., Gould, K.L., and McCollum, D. (2000). The role of the Sid1p kinase and Cdc14p in regulating the onset of cytokinesis in fission yeast. EMBO J. 19, 1803-1815.

Guertin, D.A., Venkatram, S., Gould, K.L., and McCollum, D. (2002). Dma1 prevents mitotic exit and cytokinesis by inhibiting the septation initiation network (SIN). Dev. Cell 3, 779-790. 


\section{Bibliografía}

Hachet, O., and Simanis, V. (2008). Mid1p/anillin and the septation initiation network orchestrate contractile ring assembly for cytokinesis. Genes Dev. 22, 3205-3216.

Hachet, O., Berthelot-Grosjean, M., Kokkoris, K., Vincenzetti, V., Moosbrugger, J., and Martin, S.G. (2011). A Phosphorylation Cycle Shapes Gradients of the DYRK Family Kinase Pom1 at the Plasma Membrane. Cell 145, 1116-1128.

Hagan, I.M. (1998). The fission yeast microtubule cytoskeleton. J. Cell Sci. 111 ( Pt 12), 1603-1612.

Hagan, I., and Yanagida, M. (1997). Evidence for cell cycle-specific, spindle pole bodymediated, nuclear positioning in the fission yeast Schizosaccharomyces pombe. J. Cell Sci. 110 ( Pt 16), 1851-1866.

Hagan, I.M., and Hyams, J.S. (1996). Forces acting on the fission yeast anaphase spindle. Cell Motil. Cytoskeleton 34, 69-75.

Hamasaki-Katagiri, N., and Ames, J.B. (2010). Neuronal Calcium Sensor-1 (Ncs1p) Is Up-regulated by Calcineurin to Promote $\mathrm{Ca}^{2+}$ Tolerance in Fission Yeast. J. Biol. Chem. 285, 4405-4414.

Hartwell, L.H. (1971). Genetic control of the cell division cycle in yeast. IV. Genes controlling bud emergence and cytokinesis. Exp. Cell Res. 69, 265-276.

Hashimoto, Y., Perrino, B.A., and Soderling, T.R. (1990). Identification of an autoinhibitory domain in calcineurin. J. Biol. Chem. 265, 1924-1927.

Heckman, D.S., Geiser, D.M., Eidell, B.R., Stauffer, R.L., Kardos, N.L., and Hedges, S.B. (2001). Molecular Evidence for the Early Colonization of Land by Fungi and Plants. Science (80-. ). 293, 1129-1133.

Heidarinejad, M., Nakamura, H., and Inoue, T. (2018). Stimulation-induced changes in diffusion and structure of calmodulin and calmodulin-dependent protein kinase II proteins in neurons. Neurosci. Res. 136, 13-32.

Heitman, J., Koller, A., Cardenas, M.E., and Hall, M.N. (1993). Identification of Immunosuppressive Drug Targets in Yeast. Methods 5, 176-187.

Heitz, M.J., Petersen, J., Valovin, S., and Hagan, I.M. (2001). MTOC formation during mitotic exit in fission yeast. J. Cell Sci. 114, 4521-4532.

Higa, M., Kita, A., Hagihara, K., Kitai, Y., Doi, A., Nagasoko, R., Satoh, R., and Sugiura, R. (2015). Spatial control of calcineurin in response to heat shock in fission yeast. Genes to Cells 20, 95-107.

Hinke, S.A., Navedo, M.F., Ulman, A., Whiting, J.L., Nygren, P.J., Tian, G., JimenezCaliani, A.J., Langeberg, L.K., Cirulli, V., Tengholm, A., et al. (2012). Anchored phosphatases modulate glucose homeostasis. EMBO J. 31, 3991-4004.

Hirayama, S., Sugiura, R., Lu, Y., Maeda, T., Kawagishi, K., Yokoyama, M., Tohda, H., Giga-Hama, Y., Shuntoh, H., and Kuno, T. (2003). Zinc Finger Protein Prz1 Regulates Ca ${ }^{2+}$ but $\mathrm{Not} \mathrm{Cl}^{-}$Homeostasis in Fission Yeast. J. Biol. Chem. 278, 18078-18084. 


\section{Bibliografía}

Hochstenbach, F., Klis, F.M., van den Ende, H., van Donselaar, E., Peters, P.J., and Klausner, R.D. (1998). Identification of a putative alpha-glucan synthase essential for cell wall construction and morphogenesis in fission yeast. Proc. Natl. Acad. Sci. U. S. A. 95, 9161-9166.

Hodge, R.G., and Ridley, A.J. (2016). Regulating Rho GTPases and their regulators. Nat. Rev. Mol. Cell Biol. 17, 496-510.

Hou, M.-C., Guertin, D.A., and McCollum, D. (2004). Initiation of cytokinesis is controlled through multiple modes of regulation of the Sid2p-Mob1p kinase complex. Mol. Cell. Biol. 24, 3262-3276.

Hou, M.C., Salek, J., and McCollum, D. (2000). Mob1p interacts with the Sid2p kinase and is required for cytokinesis in fission yeast. Curr. Biol. 10, 619-622.

Humbel, B.M., Konomi, M., Takagi, T., Kamasawa, N., Ishijima, S.A., and Osumi, M. (2001). In situ localization of ?-glucans in the cell wall ofSchizosaccharomyces pombe. Yeast 18, 433-444.

Hunziker, W. (1994). The calmodulin antagonist W-7 affects transcytosis, lysosomal transport, and recycling but not endocytosis. J. Biol. Chem. 269, 29003-29009.

Ishida, H., Rainaldi, M., and Vogel, H.J. (2009). Structural Studies of Soybean Calmodulin Isoform 4 Bound to the Calmodulin-binding Domain of Tobacco Mitogenactivated Protein Kinase Phosphatase-1 Provide Insights into a Sequential Target Binding Mode. J. Biol. Chem. 284, 28292-28305.

Itadani, A., Nakamura, T., Hirata, A., and Shimoda, C. (2010). Schizosaccharomyces pombe Calmodulin, Cam1, Plays a Crucial Role in Sporulation by Recruiting and Stabilizing the Spindle Pole Body Components Responsible for Assembly of the Forespore Membrane. Eukaryot. Cell 9, 1925-1935.

Ito, H., Fukuda, Y., Murata, K., and Kimura, A. (1983). Transformation of intact yeast cells treated with alkali cations. J. Bacteriol. 153, 163-168.

Jaumouillé, V., Krishnan, D., and Alexander, R.T. (2011). The calmodulin antagonist W-7 inhibits the epithethial $\mathrm{Na}^{+} / \mathrm{H}^{+}$exchanger via modulating membrane surface potential. Channels 5, 308-313.

Jiang, W., and Hallberg, R.L. (2001). Correct regulation of the septation initiation network in Schizosaccharomyces pombe requires the activities of par1 and par2. Genetics 158, 1413-1429.

Jin, Q.-W., Zhou, M., Bimbo, A., Balasubramanian, M.K., and McCollum, D. (2005). A Role for the Septation Initiation Network in Septum Assembly Revealed by Genetic Analysis of sid2-250 Suppressors. Genetics 172, 2101-2112.

Johnson, A.E., and Gould, K.L. (2011). Dma1 ubiquitinates the SIN scaffold, Sid4, to impede the mitotic localization of Plo1 kinase. EMBO J. 30, 341-354.

Johnson, A.E., McCollum, D., and Gould, K.L. (2012). Polar opposites: Fine-tuning cytokinesis through SIN asymmetry. Cytoskeleton 69, 686-699. 


\section{Bibliografía}

Johnson, A.E., Chen, J.-S., and Gould, K.L. (2013). CK1 Is Required for a Mitotic Checkpoint that Delays Cytokinesis. Curr. Biol. 23, 1920-1926.

Juvvadi, P., and Steinbach, W. (2015). Calcineurin Orchestrates Hyphal Growth, Septation, Drug Resistance and Pathogenesis of Aspergillus fumigatus: Where Do We Go from Here? Pathogens 4, 883-893.

Juvvadi, P.R., Fortwendel, J.R., Rogg, L.E., Burns, K.A., Randell, S.H., and Steinbach, W.J. (2011). Localization and activity of the calcineurin catalytic and regulatory subunit complex at the septum is essential for hyphal elongation and proper septation in Aspergillus fumigatus. Mol. Microbiol. 82, 1235-1259.

Juvvadi, P.R., Gehrke, C., Fortwendel, J.R., Lamoth, F., Soderblom, E.J., Cook, E.C., Hast, M.A., Asfaw, Y.G., Moseley, M.A., Creamer, T.P., et al. (2013). Phosphorylation of Calcineurin at a Novel Serine-Proline Rich Region Orchestrates Hyphal Growth and Virulence in Aspergillus fumigatus. PLoS Pathog. 9, e1003564.

Juvvadi, P.R., Lamoth, F., and Steinbach, W.J. (2014). Calcineurin-Mediated Regulation of Hyphal Growth, Septation, and Virulence in Aspergillus fumigatus. Mycopathologia 178, 341-348.

Juvvadi, P.R., Pemble, C.W., Ma, Y., and Steinbach, W.J. (2016). Novel motif in calcineurin catalytic subunit is required for septal localization of calcineurin in Aspergillus fumigatus. FEBS Lett. 590, 501-508.

Juvvadi, P.R., Lee, S.C., Heitman, J., and Steinbach, W.J. (2017). Calcineurin in fungal virulence and drug resistance: Prospects for harnessing targeted inhibition of calcineurin for an antifungal therapeutic approach. Virulence 8, 186-197.

Kakalis, L.T., Kennedy, M., Sikkink, R., Rusnak, F., and Armitage, I.M. (1995). Characterization of the calcium-binding sites of calcineurin B. FEBS Lett. 362, 55-58.

Kamasaki, T., Osumi, M., and Mabuchi, I. (2007). Three-dimensional arrangement of F-actin in the contractile ring of fission yeast. J. Cell Biol. 178, 765-771.

Kang, M.S., and Cabib, E. (1986). Regulation of fungal cell wall growth: a guanine nucleotide-binding, proteinaceous component required for activity of (1----3)-beta-Dglucan synthase. Proc. Natl. Acad. Sci. U. S. A. 83, 5808-5812.

Katayama, S., Hirata, D., Arellano, M., Pérez, P., and Toda, T. (1999). Fission yeast alpha-glucan synthase Mok1 requires the actin cytoskeleton to localize the sites of growth and plays an essential role in cell morphogenesis downstream of protein kinase C function. J. Cell Biol. 144, 1173-1186.

Keeney, J.B., and Boeke, J.D. (1994). Efficient targeted integration at leu1-32 and ura4294 in Schizosaccharomyces pombe. Genetics 136, 849-856.

Kelly, M., Burke, J., Smith, M., Klar, A., and Beach, D. (1988). Four mating-type genes control sexual differentiation in the fission yeast. EMBO J. 7, 1537-1547. 


\section{Bibliografía}

Kettenbach, A.N., Deng, L., Wu, Y., Baldissard, S., Adamo, M.E., Gerber, S.A., and Moseley, J.B. (2015). Quantitative Phosphoproteomics Reveals Pathways for Coordination of Cell Growth and Division by the Conserved Fission Yeast Kinase Pom1. Mol. Cell. Proteomics 14, 1275-1287.

Kim, H., Yang, P., Catanuto, P., Verde, F., Lai, H., Du, H., Chang, F., and Marcus, S. (2003). The kelch repeat protein, Tea1, is a potential substrate target of the p21activated kinase, Shk1, in the fission yeast, Schizosaccharomyces pombe. J. Biol. Chem. $278,30074-30082$.

Kincaid, R.L., Nightingale, M.S., and Martin, B.M. (1988). Characterization of a CDNA clone encoding the calmodulin-binding domain of mouse brain calcineurin. Proc. Natl. Acad. Sci. U. S. A. 85, 8983-8987.

Kita, A., Higa, M., Doi, A., Satoh, R., and Sugiura, R. (2015). Imp2, the PSTPIP homolog in fission yeast, affects sensitivity to the immunosuppressant FK506 and membrane trafficking in fission yeast. Biochem. Biophys. Res. Commun. 457, 273-279.

Kitayama, C., Sugimoto, A., and Yamamoto, M. (1997). Type II myosin heavy chain encoded by the myo2 gene composes the contractile ring during cytokinesis in Schizosaccharomyces pombe. J. Cell Biol. 137, 1309-1319.

Klar, A., Ishikawa, K., and Moore, S. (2014). A Unique DNA Recombination Mechanism of the Mating/Cell-type Switching of Fission Yeasts: a Review. In Microbiology Stectrum, (American Society of Microbiology), pp. 515-528.

Klee, C.B., and Krinks, M.H. (1978). Purification of cyclic 3',5'-nucleotide phosphodiesterase inhibitory protein by affinity chromatography on activator protein coupled to sepharose. Biochemistry 17, 120-126.

Klee, C.B., Crouch, T.H., and Krinks, M.H. (1979). Calcineurin: a calcium- and calmodulin-binding protein of the nervous system. Proc. Natl. Acad. Sci. U. S. A. 76, 6270-6273.

Koch, E.N., Costanzo, M., Bellay, J., Deshpande, R., Chatfield-Reed, K., Chua, G., D'Urso, G., Andrews, B.J., Boone, C., and Myers, C.L. (2012). Conserved rules govern genetic interaction degree across species. Genome Biol. 13.

Konomi, M., Fujimoto, K., Toda, T., and Osumi, M. (2003). Characterization and behaviour of ?-glucan synthase inSchizosaccharomyces pombe as revealed by electron microscopy. Yeast 20, 427-438.

Kopecká, M., Fleet, G.H., and Phaff, H.J. (1995). Ultrastructure of the Cell Wall of Schizosaccharomyces pombe Following Treatment with Various Glucanases. J. Struct. Biol. 114, 140-152.

Korinek, W.S., Bi, E., Epp, J.A., Wang, L., Ho, J., and Chant, J. (2000). Cyk3, a novel SH3-domain protein, affects cytokinesis in yeast. Curr. Biol. 10, 947-950.

Kovar, D.R., Kuhn, J.R., Tichy, A.L., and Pollard, T.D. (2003). The fission yeast cytokinesis formin $\mathrm{Cdc} 12 \mathrm{p}$ is a barbed end actin filament capping protein gated by profilin. J. Cell Biol. 161, 875-887. 


\section{Bibliografía}

Kovar, D.R., Sirotkin, V., and Lord, M. (2011). Three's company: the fission yeast actin cytoskeleton. Trends Cell Biol. 21, 177-187.

Koyano, T., Konishi, M., Martin, S.G., Ohya, Y., Hirata, D., Toda, T., and Kume, K. (2015). Casein kinase $1 \gamma$ ensures monopolar growth polarity under incomplete DNA replication downstream of Cds1 and calcineurin in fission yeast. Mol. Cell. Biol. 35, 1533-1542.

Krapp, A., Cano, E., and Simanis, V. (2003). Mitotic hyperphosphorylation of the fission yeast SIN scaffold protein cdc11p is regulated by the protein kinase cdc7p. Curr. Biol. 13, 168-172.

Krapp, A., Collin, P., Cano del Rosario, E., and Simanis, V. (2008). Homoeostasis between the GTPase Spg1p and its GAP in the regulation of cytokinesis in S. pombe. J. Cell Sci. 121, 601-608.

Kraus, P.R., and Heitman, J. (2003). Coping with stress: calmodulin and calcineurin in model and pathogenic fungi. Biochem. Biophys. Res. Commun. 311, 1151-1157.

Kübler, E., Schimmöller, F., and Riezman, H. (1994). Calcium-independent calmodulin requirement for endocytosis in yeast. EMBO J. 13, 5539-5546.

Kume, K., Koyano, T., Kanai, M., Toda, T., and Hirata, D. (2011). Calcineurin ensures a link between the DNA replication checkpoint and microtubule-dependent polarized growth. Nat. Cell Biol. 13, 234-242.

Kuno, T., Takeda, T., Hirai, M., Ito, A., Mukai, H., and Tanaka, C. (1989). Evidence for a second isoform of the catalytic subunit of calmodulin-dependent protein phosphatase (calcineurin A). Biochem. Biophys. Res. Commun. 165, 1352-1358.

Kushner, S.R. (1978). An improved method for transformation of Escherichia coli with ColElderived plasmids. Elsevier.

Laemmli, U.K. (1970). Cleavage of structural proteins during the assembly of the head of bacteriophage T4. Nature 227, 680-685.

Lagorce, A., Hauser, N.C., Labourdette, D., Rodriguez, C., Martin-Yken, H., Arroyo, J., Hoheisel, J.D., and François, J. (2003). Genome-wide Analysis of the Response to Cell Wall Mutations in the Yeast Saccharomyces cerevisiae. J. Biol. Chem. 278, 2034520357.

Lahoz, A., Alcaide-Gavilan, M., Daga, R.R., and Jimenez, J. (2010). Antagonistic Roles of PP2A-Pab1 and Etd1 in the Control of Cytokinesis in Fission Yeast. Genetics 186, 1261-1270.

Lam, H.Y. (1984). Tamoxifen is a calmodulin antagonist in the activation of cAMP phosphodiesterase. Biochem. Biophys. Res. Commun. 118, 27-32.

Lang, P., Gesbert, F., Delespine-Carmagnat, M., Stancou, R., Pouchelet, M., and Bertoglio, J. (1996). Protein kinase A phosphorylation of RhoA mediates the morphological and functional effects of cyclic AMP in cytotoxic lymphocytes. EMBO J. 15, 510-519. 


\section{Bibliografía}

Laporte, D., Coffman, V.C., Lee, I.-J., and Wu, J.-Q. (2011). Assembly and architecture of precursor nodes during fission yeast cytokinesis. J. Cell Biol. 192, 1005-1021.

Lee, I.-J., Coffman, V.C., and Wu, J.-Q. (2012). Contractile-ring assembly in fission yeast cytokinesis: Recent advances and new perspectives. Cytoskeleton (Hoboken). 69, 751-763.

Lee, M.E., Rusin, S.F., Jenkins, N., Kettenbach, A.N., and Moseley, J.B. (2018). Mechanisms Connecting the Conserved Protein Kinases Ssp1, Kin1, and Pom1 in Fission Yeast Cell Polarity and Division. Curr. Biol. 28, 84-92.e4.

Lee, W.L., Bezanilla, M., and Pollard, T.D. (2000). Fission yeast myosin-I, Myo1p, stimulates actin assembly by Arp $2 / 3$ complex and shares functions with WASp. J. Cell Biol. 151, 789-800.

Lei, B., Zhou, N., Guo, Y., Zhao, W., Tan, Y.-W., Yu, Y., and Lu, H. (2014). Septin ring assembly is regulated by Spt20, a structural subunit of the SAGA complex. J. Cell Sci. 127, 4024-4036.

Leupold, U. (1949). Die Vererbung von Homothallie und Heterothallie bei Schizosaccharomyces Pombe. Luno.

Li, H., Zhang, L., Rao, A., Harrison, S.C., and Hogan, P.G. (2007). Structure of Calcineurin in Complex with PVIVIT Peptide: Portrait of a Low-affinity Signalling Interaction. J. Mol. Biol. 369, 1296-1306.

Li, H., Rao, A., and Hogan, P.G. (2011). Interaction of calcineurin with substrates and targeting proteins. Trends Cell Biol. 21, 91-103.

Li, J., Negro, A., Lopez, J., Bauman, A.L., Henson, E., Dodge-Kafka, K., and Kapiloff, M.S. (2010). The mAKAP $\beta$ scaffold regulates cardiac myocyte hypertrophy via recruitment of activated calcineurin. J. Mol. Cell. Cardiol. 48, 387-394.

Lian, A.T.Y., Hains, P.G., Sarcevic, B., Robinson, P.J., and Chircop, M. (2015). IQGAP1 is associated with nuclear envelope reformation and completion of abscission. Cell Cycle 14, 2058-2074.

Lippincott, J., and Li, R. (2000a). Involvement of PCH family proteins in cytokinesis and actin distribution. Microsc. Res. Tech. 49, 168-172.

Liu, J., Wang, H., McCollum, D., and Balasubramanian, M.K. (1999). Drc1p/Cps1p, a 1,3-beta-glucan synthase subunit, is essential for division septum assembly in Schizosaccharomyces pombe. Genetics 153, 1193-1203.

Liu, J., Wang, H., and Balasubramanian, M.K. (2000). A checkpoint that monitors cytokinesis in Schizosaccharomyces pombe. J. Cell Sci. 113 ( Pt 7), 1223-1230.

Liu, J., Tang, X., Wang, H., Oliferenko, S., and Balasubramanian, M.K. (2002). The localization of the integral membrane protein Cps1p to the cell division site is dependent on the actomyosin ring and the septation-inducing network in Schizosaccharomyces pombe. Mol. Biol. Cell 13, 989-1000. 


\section{Bibliografía}

Liu, Y., Ishii, S., Tokai, M., Tsutsumi, H., Ohki, O., Akada, R., Tanaka, K., Tsuchiya, E., Fukui, S., and Miyakawa, T. (1991). The Saccharomyces cerevisiae genes (CMP1 and CMP2) encoding calmodulin-binding proteins homologous to the catalytic subunit of mammalian protein phosphatase 2B. Mol. Gen. Genet. 227, 52-59.

Liu, Y., Lee, I.-J., Sun, M., Lower, C.A., Runge, K.W., Ma, J., and Wu, J.-Q. (2016). Roles of the novel coiled-coil protein Rng10 in septum formation during fission yeast cytokinesis. Mol. Biol. Cell 27, 2528-2541.

Liu, Y., McDonald, N.A., Naegele, S.M., Gould, K.L., and Wu, J.Q. (2019). The F-BAR Domain of Rga7 Relies on a Cooperative Mechanism of Membrane Binding with a Partner Protein during Fission Yeast Cytokinesis. Cell Rep. 26, 2540-2548.e4.

Loo, T.-H., and Balasubramanian, M. (2008). Schizosaccharomyces pombe Pak-related protein, Pak1p/Orb2p, phosphorylates myosin regulatory light chain to inhibit cytokinesis. J. Cell Biol. 183, 785-793.

Lu, J., and Pollard, T.D. (2001). Profilin Binding to Poly- I-Proline and Actin Monomers along with Ability to Catalyze Actin Nucleotide Exchange Is Required for Viability of Fission Yeast. Mol. Biol. Cell 12, 1161-1175.

Lu, Y., Sugiura, R., Yada, T., Cheng, H., Sio, S.O., Shuntoh, H., and Kuno, T. (2002). Calcineurin is implicated in the regulation of the septation initiation network in fission yeast. Genes Cells 7, 1009-1019.

Ly, N., and Cyert, M.S. (2017). Calcineurin, the Ca2+-dependent phosphatase, regulates Rga2, a Cdc42 GTPase-activating protein, to modulate pheromone signaling. Mol. Biol. Cell 28, 576-586.

Ma, Y., Kuno, T., Kita, A., Asayama, Y., and Sugiura, R. (2006). Rho2 is a target of the farnesyltransferase Cpp1 and acts upstream of Pmk1 mitogen-activated protein kinase signaling in fission yeast. Mol. Biol. Cell 17, 5028-5037.

Ma, Y., Sugiura, R., Koike, A., Ebina, H., Sio, S.O., and Kuno, T. (2011). Transient Receptor Potential (TRP) and Cch1-Yam8 Channels Play Key Roles in the Regulation of Cytoplasmic Ca2+ in Fission Yeast. PLoS One 6, e22421.

Macara, I.G., Baldarelli, R., Field, C.M., Glotzer, M., Hayashi, Y., Hsu, S.-C., Kennedy, M.B., Kinoshita, M., Longtine, M., Low, C., et al. (2002). Mammalian Septins Nomenclature. Mol. Biol. Cell 13, 4111-4113.

Mackin, N.A., Sousou, T.J., and Erdman, S.E. (2004). The PXL1 Gene of Saccharomyces cerevisiae Encodes a Paxillin-like Protein Functioning in Polarized Cell Growth. Mol. Biol. Cell 15, 1904-1917.

Madaule, P., and Axel, R. (1985). A novel ras-related gene family. Cell 41, 31-40.

Madrid, M., Jiménez, R., Sánchez-Mir, L., Soto, T., Franco, A., Vicente-Soler, J., Gacto, M., Pérez, P., and Cansado, J. (2015). Multiple layers of regulation influence cell integrity control by the PKC ortholog Pck2 in fission yeast. J. Cell Sci. 128, 266-280. 


\section{Bibliografía}

Madrid, M., Vázquez-Marín, B., Soto, T., Franco, A., Gómez-Gil, E., Vicente-Soler, J., Gacto, M., Pérez, P., and Cansado, J. (2017). Differential functional regulation of protein kinase C (PKC) orthologs in fission yeast. J. Biol. Chem. 292, 11374-11387.

Maeda, T., Sugiura, R., Kita, A., Saito, M., Deng, L., He, Y., Yabin, L., Fujita, Y., Takegawa, K., Shuntoh, H., et al. (2004). Pmr1, a P-type ATPase, and Pdt1, an Nramp homologue, cooperatively regulate cell morphogenesis in fission yeast: the importance of Mn2+ homeostasis. Genes Cells 9, 71-82.

Maki, T., Ogura, N., Haber, J.E., Iwasaki, H., and Thon, G. (2018). New insights into donor directionality of mating-type switching in Schizosaccharomyces pombe. PLoS Genet. 14, e1007424.

Makushok, T., Alves, P., Huisman, S.M., Kijowski, A.R., and Brunner, D. (2016). SterolRich Membrane Domains Define Fission Yeast Cell Polarity. Cell 165, 1182-1196.

Mangione, M.C., Snider, C.E., and Gould, K.L. (2019). The intrinsically disordered region of the cytokinetic F-BAR protein Cdc15 provides a unique essential function in maintenance of cytokinetic ring integrity. Mol. Biol. Cell mbcE19060314.

Manjón, E., Edreira, T., Muñoz, S., and Sánchez, Y. (2017). Rgf1p (Rho1p GEF) is required for double-strand break repair in fission yeast. Nucleic Acids Res. 45, 52695284.

Manners, D.J., and Meyer, M.T. (1977). The molecular structures of some glucans from the cell walls of Schizosaccharomyces pombe. Carbohydr. Res. 57, 189-203.

Marks, J., and Hyams, J. (1985). Localization of F-actin through the cell division cycle of Schizosaccharomyces pombe.

Marks, J., Hagan, I.M., and Hyams, J.S. (1986). Growth polarity and cytokinesis in fission yeast: the role of the cytoskeleton. J. Cell Sci. Suppl. 5, 229-241.

Marston, A.L., Chen, T., Yang, M.C., Belhumeur, P., and Chant, J. (2001). A localized GTPase exchange factor, Bud5, determines the orientation of division axes in yeast. Curr. Biol. 11, 803-807.

Martín-Cuadrado, A.B., Dueñas, E., Sipiczki, M., Vázquez de Aldana, C.R., and del Rey, F. (2003). The endo-beta-1,3-glucanase eng1p is required for dissolution of the primary septum during cell separation in Schizosaccharomyces pombe. J. Cell Sci. 116, 16891698.

Martín-Cuadrado, A.B., Morrell, J.L., Konomi, M., An, H., Petit, C., Osumi, M., Balasubramanian, M., Gould, K.L., del Rey, F., and de Aldana, C.R.V. (2005). Role of Septins and the Exocyst Complex in the Function of Hydrolytic Enzymes Responsible for Fission Yeast Cell Separation. Mol. Biol. Cell 16, 4867-4881.

Martín-García, R., Durán, A., and Valdivieso, M.-H. (2003). In Schizosaccharomyces pombe chs $2 p$ has no chitin synthase activity but is related to septum formation. FEBS Lett. 549, 176-180. 


\section{Bibliografía}

Martín-García, R., Coll, P.M., and Pérez, P. (2014). F-BAR domain protein Rga7 collaborates with Cdc15 and Imp2 to ensure proper cytokinesis in fission yeast. J. Cell Sci. 127, 4146-4158.

Martín-García, R., Arribas, V., Coll, P.M., Pinar, M., Viana, R.A., Rincón, S.A., CorreaBordes, J., Ribas, J.C., and Pérez, P. (2018). Paxillin-Mediated Recruitment of Calcineurin to the Contractile Ring Is Required for the Correct Progression of Cytokinesis in Fission Yeast. Cell Rep. 25, 772-783.e4.

Martin, S.G. (2009). Microtubule-dependent cell morphogenesis in the fission yeast. Trends Cell Biol. 19, 447-454.

Martin, S.G., and Berthelot-Grosjean, M. (2009). Polar gradients of the DYRK-family kinase Pom1 couple cell length with the cell cycle. Nature 459, 852-856.

Martin, S.G., and Chang, F. (2005). New end take off: regulating cell polarity during the fission yeast cell cycle. Cell Cycle 4, 1046-1049.

Martin, S.G., and Chang, F. (2006). Dynamics of the Formin For3p in Actin Cable Assembly. Curr. Biol. 16, 1161-1170.

Martin, S.G., Rincón, S.A., Basu, R., Pérez, P., and Chang, F. (2007). Regulation of the Formin for3p by cdc42p and bud6p. Mol. Biol. Cell 18, 4155-4167.

Martín, V., García, B., Carnero, E., Durán, A., and Sánchez, Y. (2003). Bgs3p, a putative 1,3-beta-glucan synthase subunit, is required for cell wall assembly in Schizosaccharomyces pombe. Eukaryot. Cell 2, 159-169.

Martins, I.M., Cortés, J.C.G., Muñoz, J., Moreno, M.B., Ramos, M., Clemente-Ramos, J.A., Durán, A., and Ribas, J.C. (2011). Differential activities of three families of specific beta $(1,3)$ glucan synthase inhibitors in wild-type and resistant strains of fission yeast. $J$. Biol. Chem. 286, 3484-3496.

Mata, J., and Nurse, P. (1997). tea1 and the microtubular cytoskeleton are important for generating global spatial order within the fission yeast cell. Cell 89, 939-949.

Matheos, D.P., Kingsbury, T.J., Ahsan, U.S., and Cunningham, K.W. (1997). Tcn1p/Crz1p, a calcineurin-dependent transcription factor that differentially regulates gene expression in Saccharomyces cerevisiae. Genes Dev. 11, 3445-3458.

Maundrell, K. (1990). nmt1 of fission yeast. A highly transcribed gene completely repressed by thiamine. J. Biol. Chem. 265, 10857-10864.

May, K.M., Watts, F.Z., Jones, N., and Hyams, J.S. (1997). Type II myosin involved in cytokinesis in the fission yeast, Schizosaccharomyces pombe. Cell Motil. Cytoskeleton 38, 385-396.

Mazur, P., Morin, N., Baginsky, W., el-Sherbeini, M., Clemas, J.A., Nielsen, J.B., and Foor, F. (1995). Differential expression and function of two homologous subunits of yeast 1,3-beta-D-glucan synthase. Mol. Cell. Biol. 15, 5671-5681.

McCollum, D., Balasubramanian, M.K., Pelcher, L.E., Hemmingsen, S.M., and Gould, K.L. (1995). Schizosaccharomyces pombe cdc4+ gene encodes a novel EF-hand protein essential for cytokinesis. J. Cell Biol. 130, 651-660. 


\section{Bibliografía}

McCollum, D., Feoktistova, A., Morphew, M., Balasubramanian, M., and Gould, K.L. (1996). The Schizosaccharomyces pombe actin-related protein, Arp3, is a component of the cortical actin cytoskeleton and interacts with profilin. EMBO J. 15, 6438-6446.

McCollum, D., Feoktistova, A., and Gould, K.L. (1999). Phosphorylation of the myosinII light chain does not regulate the timing of cytokinesis in fission yeast. J. Biol. Chem. 274, 17691-17695.

McDonald, N.A., Vander Kooi, C.W., Ohi, M.D., and Gould, K.L. (2015). Oligomerization but Not Membrane Bending Underlies the Function of Certain F-BAR Proteins in Cell Motility and Cytokinesis. Dev. Cell 35, 725-736.

McDonald, N.A., Lind, A.L., Smith, S.E., Li, R., and Gould, K.L. (2017). Nanoscale architecture of the Schizosaccharomyces pombe contractile ring. Elife 6.

de Medina-Redondo, M., Arnáiz-Pita, Y., Clavaud, C., Fontaine, T., del Rey, F., Latgé, J.P., and Vázquez de Aldana, C.R. (2010). $\beta(1,3)$-Glucanosyl-Transferase Activity Is Essential for Cell Wall Integrity and Viability of Schizosaccharomyces pombe. PLoS One 5, e14046.

de Médina, P., Favre, G., and Poirot, M. (2004). Multiple targeting by the antitumor drug tamoxifen: a structure-activity study. Curr. Med. Chem. Anticancer. Agents 4, 491-508.

Mehta, S., and Gould, K.L. (2006). Identification of Functional Domains within the Septation Initiation Network Kinase, Cdc7. J. Biol. Chem. 281, 9935-9941.

Mehta, S., Aye-Han, N.-N., Ganesan, A., Oldach, L., Gorshkov, K., and Zhang, J. (2014). Calmodulin-controlled spatial decoding of oscillatory Ca2+ signals by calcineurin. Elife 3, e03765.

Mendoza, I., Rubio, F., Rodriguez-Navarro, A., and Pardo, J.M. (1994). The protein phosphatase calcineurin is essential for $\mathrm{NaCl}$ tolerance of Saccharomyces cerevisiae. J. Biol. Chem. 269, 8792-8796.

Mendoza, I., Quintero, F.J., Bressan, R.A., Hasegawa, P.M., and Pardo, J.M. (1996). Activated calcineurin confers high tolerance to ion stress and alters the budding pattern and cell morphology of yeast cells. J. Biol. Chem. 271, 23061-23067.

Michelot, A., Berro, J., Guérin, C., Boujemaa-Paterski, R., Staiger, C.J., Martiel, J.-L., and Blanchoin, L. (2007). Actin-Filament Stochastic Dynamics Mediated by ADF/Cofilin. Curr. Biol. 17, 825-833.

Miller, P.J., and Johnson, D.I. (1994). Cdc42p GTPase is involved in controlling polarized cell growth in Schizosaccharomyces pombe. Mol. Cell. Biol. 14, 1075-1083.

Minc, N., Bratman, S. V., Basu, R., and Chang, F. (2009). Establishing New Sites of Polarization by Microtubules. Curr. Biol. 19, 83-94.

Minet, M., Nurse, P., Thuriaux, P., and Mitchison, J.M. (1979). Uncontrolled septation in a cell division cycle mutant of the fission yeast Schizosaccharomyces pombe. $J$. Bacteriol. 137, 440-446. 


\section{Bibliografía}

Mishra, M., Karagiannis, J., Trautmann, S., Wang, H., McCollum, D., and Balasubramanian, M.K. (2004). The Clp1p/Flp1p phosphatase ensures completion of cytokinesis in response to minor perturbation of the cell division machinery in Schizosaccharomyces pombe. J. Cell Sci. 117, 3897-3910.

Mishra, M., Huang, J., and Balasubramanian, M.K. (2014). The yeast actin cytoskeleton. FEMS Microbiol. Rev. 38, 213-227.

Mitchison, J.M., and Creanor, J. (1971). Induction synchrony in the fission yeast. Schizosaccharomyces pombe. Exp. Cell Res. 67, 368-374.

Mitchison, J.M., and Nurse, P. (1985). Growth in cell length in the fission yeast Schizosaccharomyces pombe. J. Cell Sci. 75.

Moon, S.Y., and Zheng, Y. (2003). Rho GTPase-activating proteins in cell regulation. Trends Cell Biol. 13, 13-22.

Mooseker, M.S., and Cheney, R.E. (1995). Unconventional Myosins. Annu. Rev. Cell Dev. Biol. 11, 633-675.

Moreno, S., Klar, A., and Nurse, P. (1991). Molecular genetic analysis of fission yeast Schizosaccharomyces pombe. Methods Enzymol. 194, 795-823.

Morrell-Falvey, J.L., Ren, L., Feoktistova, A., Haese, G. Den, and Gould, K.L. (2005). Cell wall remodeling at the fission yeast cell division site requires the Rho-GEF Rgf3p. J. Cell Sci. 118, 5563-5573.

Morrell, J.L., Morphew, M., and Gould, K.L. (1999). A Mutant of Arp2p Causes Partial Disassembly of the Arp2/3 Complex and Loss of Cortical Actin Function in Fission Yeast. Mol. Biol. Cell 10, 4201-4215.

Moseley, J.B., Mayeux, A., Paoletti, A., and Nurse, P. (2009). A spatial gradient coordinates cell size and mitotic entry in fission yeast. Nature 459, 857-860.

Moser, M.J., Lee, S.Y., Klevit, R.E., and Davis, T.N. (1995). Ca2+ binding to calmodulin and its role in Schizosaccharomyces pombe as revealed by mutagenesis and NMR spectroscopy. J. Biol. Chem. 270, 20643-20652.

Moser, M.J., Flory, M.R., and Davis, T.N. (1997). Calmodulin localizes to the spindle pole body of Schizosaccharomyces pombe and performs an essential function in chromosome segregation. J. Cell Sci. 110 ( Pt 15), 1805-1812.

Motegi, F., Nakano, K., Kitayama, C., Yamamoto, M., and Mabuchi, I. (1997). Identification of Myo3, a second type-II myosin heavy chain in the fission yeast Schizosaccharomyces pombe. FEBS Lett. 420, 161-166.

Motegi, F., Nakano, K., and Mabuchi, I. (2000). Molecular mechanism of myosin-II assembly at the division site in Schizosaccharomyces pombe. J. Cell Sci. 113 ( Pt 10), 1813-1825.

Motegi, F., Arai, R., and Mabuchi, I. (2001). Identification of Two Type V Myosins in Fission Yeast, One of Which Functions in Polarized Cell Growth and Moves Rapidly in the Cell. Mol. Biol. Cell 12, 1367-1380. 


\section{Bibliografía}

Mulvihill, D.P., Win, T.Z., Pack, T.P., and Hyams, J.S. (2000). Cytokinesis in fission yeast: A myosinpas de deux. Microsc. Res. Tech. 49, 152-160.

Mulvihill, D.P., Edwards, S.R., and Hyams, J.S. (2006). A critical role for the type V myosin, Myo52, in septum deposition and cell fission during cytokinesis inSchizosaccharomyces pombe. Cell Motil. Cytoskeleton 63, 149-161.

Muñoz, S., Manjón, E., and Sánchez, Y. (2014). The Putative Exchange Factor Gef3p Interacts with Rho3p GTPase and the Septin Ring during Cytokinesis in Fission Yeast. J. Biol. Chem. 289, 21995-22007.

Muñoz, S., Manjón, E., García, P., Sunnerhagen, P., and Sánchez, Y. (2014). The checkpoint-dependent nuclear accumulation of Rho1p exchange factor Rgf1p is important for tolerance to chronic replication stress. Mol. Biol. Cell 25, 1137-1150.

Mutoh, T., Nakano, K., and Mabuchi, I. (2005). Rho1-GEFs Rgf1 and Rgf2 are involved in formation of cell wall and septum, while Rgf3 is involved in cytokinesis in fission yeast. Genes Cells 10, 1189-1202.

Myers, M.D., Ryazantsev, S., Hicke, L., and Payne, G.S. (2016). Calmodulin Promotes N-BAR Domain-Mediated Membrane Constriction and Endocytosis. Dev. Cell 37, 162173.

Nakamura, T., Liu, Y., Hirata, D., Namba, H., Harada, S., Hirokawa, T., and Miyakawa, T. (1993). Protein phosphatase type 2B (calcineurin)-mediated, FK506-sensitive regulation of intracellular ions in yeast is an important determinant for adaptation to high salt stress conditions. EMBO J. 12, 4063-4071.

Nakano, K., and Mabuchi, I. (1995). Isolation and sequencing of two cDNA clones encoding Rho proteins from the fission yeast Schizosaccharomyces pombe. Gene 155, 119-122.

Nakano, K., Mutoh, T., and Mabuchi, I. (2001). Characterization of GTPase-activating proteins for the function of the Rho-family small GTPases in the fission yeast Schizosaccharomyces pombe. Genes Cells 6, 1031-1042.

Naqvi, N.I., Wong, K.C.Y., Tang, X., and Balasubramanian, M.K. (2000). Type II myosin regulatory light chain relieves auto-inhibition of myosin-heavy-chain function. Nat. Cell Biol. 2, 855-858.

Nygren, P.J., and Scott, J.D. (2016). Regulation of the phosphatase PP2B by proteinprotein interactions. Biochem. Soc. Trans. 44, 1313-1319.

Odom, A., Muir, S., Lim, E., Toffaletti, D.L., Perfect, J., and Heitman, J. (1997). Calcineurin is required for virulence of Cryptococcus neoformans. EMBO J. 16, 25762589.

Ohkura, H., Hagan, I.M., and Glover, D.M. (1995). The conserved Schizosaccharomyces pombe kinase plo1, required to form a bipolar spindle, the actin ring, and septum, can drive septum formation in G1 and G2 cells. Genes Dev. 9, 10591073. 


\section{Bibliografía}

Okada, H., Wloka, C., Wu, J.Q., and Bi, E. (2019). Distinct Roles of Myosin-II Isoforms in Cytokinesis under Normal and Stressed Conditions. Food Sci. Hum. Wellness 14, 6987.

Olofsson, B. (1999). Rho guanine dissociation inhibitors: pivotal molecules in cellular signalling. Cell. Signal. 11, 545-554.

Onishi, M., Koga, T., Hirata, A., Nakamura, T., Asakawa, H., Shimoda, C., Bahler, J., Wu, J.-Q., Takegawa, K., Tachikawa, H., et al. (2010). Role of Septins in the Orientation of Forespore Membrane Extension during Sporulation in Fission Yeast. Mol. Cell. Biol. 30, 2057-2074.

Osumi, M. (2012). Visualization of yeast cells by electron microscopy. Microscopy 61, 343-365.

Padmanabhan, A., Bakka, K., Sevugan, M., Naqvi, N.I., D'souza, V., Tang, X., Mishra, M., and Balasubramanian, M.K. (2011). IQGAP-Related Rng2p Organizes Cortical Nodes and Ensures Position of Cell Division in Fission Yeast. Curr. Biol. 21, 467-472.

Padte, N.N., Martin, S.G., Howard, M., and Chang, F. (2006). The Cell-End Factor Pom1p Inhibits Mid1p in Specification of the Cell Division Plane in Fission Yeast. Curr. Biol. 16, 2480-2487.

Palani, S., Chew, T.G., Ramanujam, S., Kamnev, A., Harne, S., Chapa-y-Lazo, B., Hogg, R., Sevugan, M., Mishra, M., Gayathri, P., et al. (2017). Motor Activity Dependent and Independent Functions of Myosin II Contribute to Actomyosin Ring Assembly and Contraction in Schizosaccharomyces pombe. Curr. Biol. 27, 751-757.

Paoletti, A., and Chang, F. (2000). Analysis of mid1p, a protein required for placement of the cell division site, reveals a link between the nucleus and the cell surface in fission yeast. Mol. Biol. Cell 11, 2757-2773.

Paul, A., Pollard, T., Pollard, T.D., and Pollard, T. (2008). The Role of the FH1 Domain and Profilin in Formin-Mediated Actin-Filament Elongation and Nucleation. Curr. Biol. 18, 9-19.

Pelham, R.J., and Chang, F. (2001). Role of actin polymerization and actin cables in actin-patch movement in Schizosaccharomyces pombe. Nat. Cell Biol. 3, 235-244.

Pelham, R.J., and Chang, F. (2002). Actin dynamics in the contractile ring during cytokinesis in fission yeast. Nature 419, 82-86.

Perez, P., and Rincón, S.A. (2010). Rho GTPases: regulation of cell polarity and growth in yeasts. Biochem. J. 426, 243-253.

Pérez, P., Portales, E., and Santos, B. (2015). Rho4 interaction with exocyst and septins regulates cell separation in fission yeast. Microbiol. (United Kingdom) 161, 948-959.

Pérez, P., Cortés, J.C.G., Martín-García, R., and Ribas, J.C. (2016). Overview of fission yeast septation. Cell. Microbiol. 18, 1201-1207.

PIERCE, W.A., STEELE, R.H., and WHITE, A.G. (1953). A colorimetric method for hyaluronic acid estimation. Proc. Soc. Exp. Biol. Med. 83, 373-375. 


\section{Bibliografía}

Pinar, M., Coll, P.M., Rincón, S.A., and Pérez, P. (2008). Schizosaccharomyces pombe Pxl1 is a paxillin homologue that modulates Rho1 activity and participates in cytokinesis. Mol. Biol. Cell 19, 1727-1738.

Plochocka-Zulinska, D., Rasmussen, G., and Rasmussen, C. (1995). Regulation of calcineurin gene expression in Schizosaccharomyces pombe. Dependence on the ste11 transcription factor. J. Biol. Chem. 270, 24794-24799.

Pollard, T.D. (2008). Progress towards understanding the mechanism of cytokinesis in fission yeast. Biochem. Soc. Trans. 36, 425-430.

Pollard, T.D., and Wu, J.-Q. (2010). Understanding cytokinesis: lessons from fission yeast. Nat. Rev. Mol. Cell Biol. 11, 149-155.

Pollard, L.W., Onishi, M., Pringle, J.R., and Lord, M. (2012). Fission yeast Cyk3p is a transglutaminase-like protein that participates in cytokinesis and cell morphogenesis. Mol. Biol. Cell 23, 2433-2444.

Pollard, L.W., Bookwalter, C.S., Tang, Q., Krementsova, E.B., Trybus, K.M., and Lowey, S. (2017). Fission yeast myosin Myo2 is down-regulated in actin affinity by light chain phosphorylation. Proc. Natl. Acad. Sci. 114, E7236-E7244.

Polverino, A., Frost, J., Yang, P., Hutchison, M., Neiman, A.M., Cobb, M.H., and Marcus, S. (1995). Activation of mitogen-activated protein kinase cascades by p21activated protein kinases in cell-free extracts of Xenopus oocytes. J. Biol. Chem. 270, 26067-26070.

Lo Presti, L., Chang, F., and Martin, S.G. (2012). Myosin Vs organize actin cables in fission yeast. Mol. Biol. Cell 23, 4579-4591.

Proctor, S.A., Minc, N., Boudaoud, A., and Chang, F. (2012). Contributions of Turgor Pressure, the Contractile Ring, and Septum Assembly to Forces in Cytokinesis in Fission Yeast. Curr. Biol. 22, 1601-1608.

Quinlan, R.A., Pogson, C.I., and Gull, K. (1980). The influence of the microtubule inhibitor, methyl benzimidazol-2-yl-carbamate (MBC) on nuclear division and the cell cycle in Saccharomyces cerevisiae. J. Cell Sci. 46, 341-352.

Rachfall, N., Johnson, A.E., Mehta, S., Chen, J.-S., and Gould, K.L. (2014). Cdk1 promotes cytokinesis in fission yeast through activation of the septation initiation network. Mol. Biol. Cell 25, 2250-2259.

Rasmussen, C.D. (2000). Cloning of a calmodulin kinase I homologue from Schizosaccharomyces pombe. J. Biol. Chem. 275, 685-690.

Reedy, J.L., Filler, S.G., and Heitman, J. (2010). Elucidating the Candida albicans calcineurin signaling cascade controlling stress response and virulence. Fungal Genet. Biol. 47, 107-116.

Reid, T., Furuyashiki, T., Ishizaki, T., Watanabe, G., Watanabe, N., Fujisawa, K., Morii, N., Madaule, P., and Narumiya, S. (1996). Rhotekin, a new putative target for Rho bearing homology to a serine/threonine kinase, PKN, and rhophilin in the rho-binding domain. J. Biol. Chem. 271, 13556-13560. 


\section{Bibliografía}

Ren, L., Willet, A.H., Roberts-Galbraith, R.H., McDonald, N.A., Feoktistova, A., Chen, J.-S., Huang, H., Guillen, R., Boone, C., Sidhu, S.S., et al. (2015). The Cdc15 and Imp2 $\mathrm{SH} 3$ domains cooperatively scaffold a network of proteins that redundantly ensure efficient cell division in fission yeast. Mol. Biol. Cell 26, 256-269.

Ren, Y., Wang, Z.-X., and Wei, Q. (2009). Mechanism of activation of Saccharomyces cerevisiae calcineurin by Mn2+. Biol. Chem. 390, 1155-1162.

Revilla-Guarinos, M.T., Martín-García, R., Villar-Tajadura, M.A., Estravís, M., Coll, P.M., and Pérez, P. (2016). Rga6 is a fission yeast Rho GAP involved in Cdc42 regulation of polarized growth. Mol. Biol. Cell 27, 1524-1535.

Rincon, S.A., Bhatia, P., Bicho, C., Guzman-Vendrell, M., Fraisier, V., Borek, W.E., Alves, F. de L., Dingli, F., Loew, D., Rappsilber, J., et al. (2014). Pom1 regulates the assembly of Cdr2-Mid1 cortical nodes for robust spatial control of cytokinesis. J. Cell Biol. 206, 61-77.

Rincon, S.A., Estravis, M., Dingli, F., Loew, D., Tran, P.T., and Paoletti, A. (2017). SINDependent Dissociation of the SAD Kinase Cdr2 from the Cell Cortex Resets the Division Plane. Curr. Biol. 27, 534-542.

Roberts-Galbraith, R.H., and Gould, K.L. (2010). Setting the F-BAR: Functions and regulation of the F-BAR protein family. Cell Cycle 9, 4091-4097.

Roberts-Galbraith, R.H., Chen, J.-S., Wang, J., and Gould, K.L. (2009). The SH3 domains of two PCH family members cooperate in assembly of the Schizosaccharomyces pombe contractile ring. J. Cell Biol. 184, 113-127.

Roberts-Galbraith, R.H., Ohi, M.D., Ballif, B.A., Chen, J.-S., McLeod, I., McDonald, W.H., Gygi, S.P., Yates, J.R., Gould, K.L., and Gould, K.L. (2010). Dephosphorylation of F-BAR protein Cdc15 modulates its conformation and stimulates its scaffolding activity at the cell division site. Mol. Cell 39, 86-99.

Rossman, K.L., Der, C.J., and Sondek, J. (2005). GEF means go: turning on RHO GTPases with guanine nucleotide-exchange factors. Nat. Rev. Mol. Cell Biol. 6, 167180.

Roy, J., and Cyert, M.S. (2009). Cracking the Phosphatase Code: Docking Interactions Determine Substrate Specificity. Sci. Signal. 2, re9-re9.

Roy, J., and Cyert, M.S. (2019). Identifying New Substrates and Functions for an Old Enzyme: Calcineurin. Cold Spring Harb. Perspect. Biol.

Rusnak, F., and Mertz, P. (2000). Calcineurin: Form and Function. Physiol. Rev. 80, 1483-1521.

Rustici, G., Mata, J., Kivinen, K., Lió, P., Penkett, C.J., Burns, G., Hayles, J., Brazma, A., Nurse, P., and Bähler, J. (2004). Periodic gene expression program of the fission yeast cell cycle. Nat. Genet. 36, 809-817.

Salimova, E., Sohrmann, M., Fournier, N., and Simanis, V. (2000). The S. pombe orthologue of the $\mathrm{S}$. cerevisiae mob1 gene is essential and functions in signalling the onset of septum formation. J. Cell Sci. 113 ( Pt 10), 1695-1704. 


\section{Bibliografía}

Sambrook, J., Fritsch, E.F., and Maniatis, T. (1989). Molecular cloning : a laboratory manual (Cold Spring Harbor Laboratory).

Sanchez-Mir, L., Franco, A., Martin-Garcia, R., Madrid, M., Vicente-Soler, J., Soto, T., Gacto, M., Perez, P., and Cansado, J. (2014). Rho2 Palmitoylation Is Required for Plasma Membrane Localization and Proper Signaling to the Fission Yeast Cell Integrity Mitogen-Activated Protein Kinase Pathway. Mol. Cell. Biol. 34, 2745-2759.

Sanderson, J.L., Gorski, J.A., Gibson, E.S., Lam, P., Freund, R.K., Chick, W.S., and Dell'Acqua, M.L. (2012). AKAP150-Anchored Calcineurin Regulates Synaptic Plasticity by Limiting Synaptic Incorporation of Ca2+-Permeable AMPA Receptors. J. Neurosci. 32, 15036-15052.

Santana, L.F., Chase, E.G., Votaw, V.S., Nelson, M.T., and Greven, R. (2002). Functional coupling of calcineurin and protein kinase $A$ in mouse ventricular myocytes. J. Physiol. 544, 57-69.

Santos, B., Martín-Cuadrado, A.B., Vázquez de Aldana, C.R., del Rey, F., and Pérez, P. (2005). Rho4 GTPase is involved in secretion of glucanases during fission yeast cytokinesis. Eukaryot. Cell 4, 1639-1645.

Santos, B., Pérez, P., and Portales, E. (2015). Rho4 interaction with exocyst and septins regulates cell separation in fission yeast. Microbiology 161, 948-959.

Schmidt, S., Sohrmann, M., Hofmann, K., Woollard, A., and Simanis, V. (1997). The Spg1p GTPase is an essential, dosage-dependent inducer of septum formation in Schizosaccharomyces pombe. Genes Dev. 11, 1519-1534.

Serrano, R., Bernal, D., Simón, E., and Ariño, J. (2004). Copper and Iron Are the Limiting Factors for Growth of the Yeast Saccharomyces cerevisiae in an Alkaline Environment. J. Biol. Chem. 279, 19698-19704.

Sethi, K., Palani, S., Cortés, J.C.G., Sato, M., Sevugan, M., Ramos, M., Vijaykumar, S., Osumi, M., Naqvi, N.I., Ribas, J.C., et al. (2016). A New Membrane Protein Sbg1 Links the Contractile Ring Apparatus and Septum Synthesis Machinery in Fission Yeast. PLOS Genet. 12, e1006383.

Shaner, N.C., Steinbach, P.A., and Tsien, R.Y. (2005). A guide to choosing fluorescent proteins. Nat. Methods 2, 905-909.

Simanis, V. (2015). Pombe's thirteen - control of fission yeast cell division by the septation initiation network. J. Cell Sci. 128, 1465-1474.

Singh, N.S., Shao, N., Mclean, J.R., Sevugan, M., Ren, L., Chew, T.G., Bimbo, A., Sharma, R., Tang, X., Gould, K.L., et al. (2011). SIN-Inhibitory Phosphatase Complex Promotes Cdc11p Dephosphorylation and Propagates SIN Asymmetry in Fission Yeast. Curr. Biol. 21, 1968-1978.

Sio, S.O., Suehiro, T., Sugiura, R., Takeuchi, M., Mukai, H., and Kuno, T. (2005). The Role of the Regulatory Subunit of Fission Yeast Calcineurin for in Vivo Activity and Its Relevance to FK506 Sensitivity. J. Biol. Chem. 280, 12231-12238. 


\section{Bibliografía}

Sipiczki, M. (2007). Splitting of the fission yeast septum. FEMS Yeast Res. 7, 761-770.

Sipiczki, M., and Bozsik, A. (2000). The use of morphomutants to investigate septum formation and cell separation in Schizosaccharomyces pombe. Arch. Microbiol. 174, 386-392.

Sirotkin, V., Beltzner, C.C., Marchand, J.-B., and Pollard, T.D. (2005). Interactions of WASp, myosin-I, and verprolin with Arp2/3 complex during actin patch assembly in fission yeast. J. Cell Biol. 170, 637-648.

Sirotkin, V., Berro, J., Macmillan, K., Zhao, L., and Pollard, T.D. (2010). Quantitative analysis of the mechanism of endocytic actin patch assembly and disassembly in fission yeast. Mol. Biol. Cell 21, 2894-2904.

Skau, C.T., Neidt, E.M., and Kovar, D.R. (2009). Role of Tropomyosin in Forminmediated Contractile Ring Assembly in Fission Yeast. Mol. Biol. Cell 20, 2160-2173.

Sladewski, T.E., Previs, M.J., and Lord, M. (2009). Regulation of Fission Yeast Myosin-II Function and Contractile Ring Dynamics by Regulatory Light-Chain and Heavy-Chain Phosphorylation. Mol. Biol. Cell 20, 3941-3952.

Smith, G.R., Givan, S.A., Cullen, P., and Sprague, G.F. (2002). GTPase-activating proteins for Cdc42. Eukaryot. Cell 1, 469-480.

Snaith, H.A., and Sawin, K.E. (2003). Fission yeast mod5p regulates polarized growth through anchoring of tea1p at cell tips. Nature 423, 647-651.

Snaith, H.A., and Sawin, K.E. (2005). Tea for three: control of fission yeast polarity. Nat. Cell Biol. 7, 450-451.

Sohrmann, M., Schmidt, S., Hagan, I., and Simanis, V. (1998). Asymmetric segregation on spindle poles of the Schizosaccharomyces pombe septum-inducing protein kinase Cdc7p. Genes Dev. 12, 84-94.

Soriani, F.M., Malavazi, I., da Silva Ferreira, M.E., Savoldi, M., Von Zeska Kress, M.R., de Souza Goldman, M.H., Loss, O., Bignell, E., and Goldman, G.H. (2008). Functional characterization of the Aspergillus fumigatus CRZ1 homologue, CrzA. Mol. Microbiol. $67,1274-1291$.

Soto, T., Villar-Tajadura, M.A., Madrid, M., Vicente, J., Gacto, M., Pérez, P., and Cansado, J. (2010). Rga4 modulates the activity of the fission yeast cell integrity MAPK pathway by acting as a Rho2 GTPase-activating protein. J. Biol. Chem. 285, 1151611525.

Stachowiak, M.R., Laplante, C., Chin, H.F., Guirao, B., Karatekin, E., Pollard, T.D., and O'Shaughnessy, B. (2014). Mechanism of cytokinetic contractile ring constriction in fission yeast. Dev. Cell 29, 547-561.

Stathopoulos, A.M., and Cyert, M.S. (1997). Calcineurin acts through the CRZ1/TCN1encoded transcription factor to regulate gene expression in yeast. Genes Dev. 11, 3432-3444. 


\section{Bibliografía}

Steinbach, W.J., Cramer, R.A., Perfect, B.Z., Asfaw, Y.G., Sauer, T.C., Najvar, L.K., Kirkpatrick, W.R., Patterson, T.F., Benjamin, D.K., Heitman, J., et al. (2006). Calcineurin controls growth, morphology, and pathogenicity in Aspergillus fumigatus. Eukaryot. Cell 5, 1091-1103.

Stemmer, P.M., and Klee, C.B. (1994). Dual calcium ion regulation of calcineurin by calmodulin and calcineurin B. Biochemistry 33, 6859-6866.

Stirling, D.A., Welch, K.A., and Stark, M.J. (1994). Interaction with calmodulin is required for the function of Spc110p, an essential component of the yeast spindle pole body. EMBO J. 13, 4329-4342.

Stuart A. Macneill, P.N. (1997). The Molecular and Cellular Biology of the Yeast <em>Saccharomyces</em>: Cell Cycle and Cell Biology (1997, Volume 21C) (Cold Spring Harbor Laboratory Press,).

Subramanian, D., Huang, J., Sevugan, M., Robinson, R.C., Balasubramanian, M.K., and Tang, X. (2013). Insight into Actin Organization and Function in Cytokinesis from Analysis of Fission Yeast Mutants. Genetics 194, 435-446.

Sugiura, R., Toda, T., Shuntoh, H., Yanagida, M., and Kuno, T. (1998). pmp1+, a suppressor of calcineurin deficiency, encodes a novel MAP kinase phosphatase in fission yeast. $E M B O \mathrm{~J} .17,140-148$.

Sugiura, R., Sio, S.O., Shuntoh, H., and Kuno, T. (2001). Molecular genetic analysis of the calcineurin signaling pathways. Cell. Mol. Life Sci. 58, 278-288.

Sugiura, R., Sio, S.O., Shuntoh, H., and Kuno, T. (2002). Calcineurin phosphatase in signal transduction: lessons from fission yeast. Genes Cells 7, 619-627.

Tajadura, V., García, B., García, I., García, P., and Sánchez, Y. (2004). Schizosaccharomyces pombe Rgf3p is a specific Rho1 GEF that regulates cell wall glucan biosynthesis through the GTPase Rho1p. J. Cell Sci. 117, 6163-6174.

Takaine, M., Numata, O., and Nakano, K. (2009). Fission yeast IQGAP arranges actin filaments into the cytokinetic contractile ring. EMBO J. 28, 3117-3131.

Takeda, T., and Chang, F. (2005). Role of Fission Yeast Myosin I in Organization of Sterol-Rich Membrane Domains. Curr. Biol. 15, 1331-1336.

Takeda, T., and Yamamoto, M. (1987). Analysis and in vivo disruption of the gene coding for calmodulin in Schizosaccharomyces pombe. Proc. Natl. Acad. Sci. U. S. A. 84, 3580-3584.

Takeda, T., Imai, Y., and Yamamoto, M. (1989). Substitution at position 116 of Schizosaccharomyces pombe calmodulin decreases its stability under nitrogen starvation and results in a sporulation-deficient phenotype. Proc. Natl. Acad. Sci. U. S. A. 86, 9737-9741.

Takeda, T., Kawate, T., and Chang, F. (2004). Organization of a sterol-rich membrane domain by cdc15p during cytokinesis in fission yeast. Nat. Cell Biol. 6, 1142-1144. 


\section{Bibliografía}

Tanaka, K., Petersen, J., Maclver, F., Mulvihill, D.P., Glover, D.M., and Hagan, I.M. (2001). The role of Plo1 kinase in mitotic commitment and septation in Schizosaccharomyces pombe. EMBO J. 20, 1259-1270.

Tang, Q., Billington, N., Krementsova, E.B., Bookwalter, C.S., Lord, M., and Trybus, K.M. (2016). A single-headed fission yeast myosin $V$ transports actin in a tropomyosindependent manner. J. Cell Biol. 214, 167-179.

Tanida, I., Hasegawa, A., lida, H., Ohya, Y., and Anraku, Y. (1995). Cooperation of calcineurin and vacuolar $\mathrm{H}(+)$-ATPase in intracellular $\mathrm{Ca} 2+$ homeostasis of yeast cells. J. Biol. Chem. 270, 10113-10119.

Tasto, J.J., Morrell, J.L., and Gould, K.L. (2003). An anillin homologue, Mid2p, acts during fission yeast cytokinesis to organize the septin ring and promote cell separation. J. Cell Biol. 160, 1093-1103.

Tatebe, H., Nakano, K., Maximo, R., and Shiozaki, K. (2008). Pom1 DYRK Regulates Localization of the Rga4 GAP to Ensure Bipolar Activation of Cdc42 in Fission Yeast. Curr. Biol. 18, 322-330.

Tay, Y.D., Leda, M., Goryachev, A.B., and Sawin, K.E. (2018). Local and global Cdc42 guanine nucleotide exchange factors for fission yeast cell polarity are coordinated by microtubules and the Tea1-Tea4-Pom1 axis. J. Cell Sci. 131, jcs216580.

Tebbs, I.R., and Pollard, T.D. (2013). Separate roles of IQGAP Rng2p in forming and constricting the Schizosaccharomyces pombe cytokinetic contractile ring. Mol. Biol. Cell 24, 1904-1917.

Thiyagarajan, S., Munteanu, E.L., Arasada, R., Pollard, T.D., and O'Shaughnessy, B. (2015). The fission yeast cytokinetic contractile ring regulates septum shape and closure. J. Cell Sci. 128, 3672-3681.

Toya, M., Motegi, F., Nakano, K., Mabuchi, I., and Yamamoto, M. (2001). Identification and functional analysis of the gene for type I myosin in fission yeast. Genes Cells 6, 187-199.

Tran, P.T., Marsh, L., Doye, V., Inoué, S., and Chang, F. (2001). A mechanism for nuclear positioning in fission yeast based on microtubule pushing. J. Cell Biol. 153, 397-411.

Trautmann, S., Wolfe, B.A., Jorgensen, P., Tyers, M., Gould, K.L., and McCollum, D. (2001). Fission yeast Clp1p phosphatase regulates $G 2 / M$ transition and coordination of cytokinesis with cell cycle progression. Curr. Biol. 11, 931-940.

Turner, C.E. (2000). Paxillin and focal adhesion signalling. Nat. Cell Biol. 2, E231-E236.

Ullal, P., McDonald, N.A., Chen, J.-S., Lo Presti, L., Roberts-Galbraith, R.H., Gould, K.L., and Martin, S.G. (2015). The DYRK-family kinase Pom1 phosphorylates the F-BAR protein Cdc15 to prevent division at cell poles. J. Cell Biol. 211, 653-668.

Vavylonis, D., Wu, J.-Q., Hao, S., O’Shaughnessy, B., and Pollard, T.D. (2008). Assembly Mechanism of the Contractile Ring for Cytokinesis by Fission Yeast. Science (80-. ). 319, 97-100. 


\section{Bibliografía}

Viana, R.A., Pinar, M., Soto, T., Coll, P.M., Cansado, J., and Pérez, P. (2013). Negative functional interaction between cell integrity MAPK pathway and Rho1 GTPase in fission yeast. Genetics 195, 421-432.

Villalobo, A., Ishida, H., Vogel, H.J., and Berchtold, M.W. (2018). Calmodulin as a protein linker and a regulator of adaptor/scaffold proteins. Biochim. Biophys. Acta Mol. Cell Res. 1865, 507-521.

Villar-Tajadura, M.A., Coll, P.M., Madrid, M., Cansado, J., Santos, B., and Pérez, P. (2008). Rga2 is a Rho2 GAP that regulates morphogenesis and cell integrity in $S$. pombe. Mol. Microbiol. 70, 867-881.

Vos, A., Dekker, N., Distel, B., Leunissen, J.A.M., and Hochstenbach, F. (2007). Role of the Synthase Domain of Ags $1 p$ in Cell Wall $\alpha$-Glucan Biosynthesis in Fission Yeast. J. Biol. Chem. 282, 18969-18979.

Wachtler, V., Huang, Y., Karagiannis, J., and Balasubramanian, M.K. (2006). Cell cycledependent roles for the $\mathrm{FCH}$-domain protein $\mathrm{Cdc} 15 \mathrm{p}$ in formation of the actomyosin ring in Schizosaccharomyces pombe. Mol. Biol. Cell 17, 3254-3266.

Wang, J.H., and Desai, R. (1977). Modulator binding protein. Bovine brain protein exhibiting the Ca2+-dependent association with the protein modulator of cyclic nucleotide phosphodiesterase. J. Biol. Chem. 252, 4175-4184.

Wang, K., Wloka, C., and Bi, E. (2019). Non-muscle Myosin-II Is Required for the Generation of a Constriction Site for Subsequent Abscission. IScience 13, 69-81.

Wang, N., Wang, M., Zhu, Y.-H., Grosel, T.W., Sun, D., Kudryashov, D.S., and Wu, J.-Q. (2015). The Rho-GEF Gef3 interacts with the septin complex and activates the GTPase Rho4 during fission yeast cytokinesis. Mol. Biol. Cell 26, 238-255.

Watanabe, Y., Perrino, B.A., Chang, B.H., and Soderling, T.R. (1995). Identification in the calcineurin $A$ subunit of the domain that binds the regulatory $B$ subunit. J. Biol. Chem. 270, 456-460.

Willet, A.H., McDonald, N.A., Bohnert, K.A., Baird, M.A., Allen, J.R., Davidson, M.W., and Gould, K.L. (2015). The F-BAR Cdc15 promotes contractile ring formation through the direct recruitment of the formin Cdc12. J. Cell Biol. 208, 391-399.

Willet, A.H., McDonald, N.A., and Gould, K.L. (2015). Regulation of contractile ring formation and septation in Schizosaccharomyces pombe. Curr. Opin. Microbiol. 28, 4652.

Willet, A.H., Bohnert, K.A., and Gould, K.L. (2018). Cdk1-dependent phosphoinhibition of a formin-F-BAR interaction opposes cytokinetic contractile ring formation. Mol. Biol. Cell 29, 713-721.

Win, T.Z., Gachet, Y., Mulvihill, D.P., May, K.M., and Hyams, J.S. (2001). Two type V myosins with non-overlapping functions in the fission yeast Schizosaccharomyces pombe: Myo52 is concerned with growth polarity and cytokinesis, Myo51 is a component of the cytokinetic actin ring. J. Cell Sci. 114, 69-79. 


\section{Bibliografía}

Wiśniewski, J.R. (2018). Filter-Aided Sample Preparation for Proteome Analysis. Methods Mol. Biol. 1841, 3-10.

Wood, V., Gwilliam, R., Rajandream, M.-A., Lyne, M., Lyne, R., Stewart, A., Sgouros, J., Peat, N., Hayles, J., Baker, S., et al. (2002). The genome sequence of Schizosaccharomyces pombe. Nature 415, 871-880.

Wu, J.-Q., and Pollard, T.D. (2005). Counting Cytokinesis Proteins Globally and Locally in Fission Yeast. Science (80-. ). 310, 310-314.

Wu, J.-Q., Kuhn, J.R., Kovar, D.R., and Pollard, T.D. (2003). Spatial and temporal pathway for assembly and constriction of the contractile ring in fission yeast cytokinesis. Dev. Cell 5, 723-734.

Wu, J.-Q., Sirotkin, V., Kovar, D.R., Lord, M., Beltzner, C.C., Kuhn, J.R., and Pollard, T.D. (2006). Assembly of the cytokinetic contractile ring from a broad band of nodes in fission yeast. J. Cell Biol. 174, 391-402.

Xu, B., Chelikani, P., and Bhullar, R.P. (2012). Characterization and Functional Analysis of the Calmodulin-Binding Domain of Rac1 GTPase. PLoS One 7, e42975.

Yanagida, M. (2002). The model unicellular eukaryote, Schizosaccharomyces pombe. Genome Biol. 3, COMMENT2003.

Yang, S.A., and Klee, C.B. (2000). Low affinity Ca2+-binding sites of calcineurin B mediate conformational changes in calcineurin A. Biochemistry 39, 16147-16154.

Yang, P., Qyang, Y., Bartholomeusz, G., Zhou, X., and Marcus, S. (2003). The novel Rho GTPase-activating protein family protein, Rga8, provides a potential link between Cdc42/p21-activated kinase and Rho signaling pathways in the fission yeast, Schizosaccharomyces pombe. J. Biol. Chem. 278, 48821-48830.

Yonetani, A., Lustig, R.J., Moseley, J.B., Takeda, T., Goode, B.L., and Chang, F. (2008). Regulation and targeting of the fission yeast formin cdc12p in cytokinesis. Mol. Biol. Cell 19, 2208-2219.

Yoshida, T., Toda, T., and Yanagida, M. (1994a). A calcineurin-like gene ppb1+ in fission yeast: mutant defects in cytokinesis, cell polarity, mating and spindle pole body positioning. J. Cell Sci. 107 ( Pt 7), 1725-1735.

Zambon, P., Palani, S., Kamnev, A., and Balasubramanian, M.K. (2017). Myo2p is the major motor involved in actomyosin ring contraction in fission yeast. Curr. Biol. 27, R99-R100.

Zhao, C., Jung, U.S., Garrett-Engele, P., Roe, T., Cyert, M.S., and Levin, D.E. (1998). Temperature-induced expression of yeast FKS2 is under the dual control of protein kinase $\mathrm{C}$ and calcineurin. Mol. Cell. Biol. 18, 1013-1022.

Zheng, S., Dong, F., Rasul, F., Yao, X., Jin, Q., Zheng, F., and Fu, C. (2018). Septins regulate the equatorial dynamics of the separation initiation network kinase Sid2p and glucan synthases to ensure proper cytokinesis. FEBS J. 285, 2468-2480. 


\section{Bibliografía}

Zhou, C., Yang, Y., and Jong, A.Y. (1990). Mini-prep in ten minutes. Biotechniques 8, 172-173.

Zhou, Z., Munteanu, E.L., He, J., Ursell, T., Bathe, M., Huang, K.C., and Chang, F. (2015). The contractile ring coordinates curvature-dependent septum assembly during fission yeast cytokinesis. Mol. Biol. Cell 26, 78-90.

Zilahi, E., Salimova, E., Simanis, V., and Sipiczki, M. (2000). The S. pombe sep1 gene encodes a nuclear protein that is required for periodic expression of the cdc15 gene. FEBS Lett. 481, 105-108. 
